\title{
Becoming Futurists
}

Citation for published version (APA):

Cramer, T. L. (2020). Becoming Futurists: Reluctant professionals searching for common ground.

[Doctoral Thesis, Maastricht University]. Maastricht University. https://doi.org/10.26481/dis.20200520tc

Document status and date:

Published: 01/01/2020

DOI:

$10.26481 /$ dis.20200520tc

Document Version:

Publisher's PDF, also known as Version of record

\section{Please check the document version of this publication:}

- A submitted manuscript is the version of the article upon submission and before peer-review. There can be important differences between the submitted version and the official published version of record.

People interested in the research are advised to contact the author for the final version of the publication, or visit the DOI to the publisher's website.

- The final author version and the galley proof are versions of the publication after peer review.

- The final published version features the final layout of the paper including the volume, issue and page numbers.

Link to publication

\footnotetext{
General rights rights.

- You may freely distribute the URL identifying the publication in the public portal. please follow below link for the End User Agreement:

www.umlib.nl/taverne-license

Take down policy

If you believe that this document breaches copyright please contact us at:

repository@maastrichtuniversity.nl

providing details and we will investigate your claim.
}

Copyright and moral rights for the publications made accessible in the public portal are retained by the authors and/or other copyright owners and it is a condition of accessing publications that users recognise and abide by the legal requirements associated with these

- Users may download and print one copy of any publication from the public portal for the purpose of private study or research.

- You may not further distribute the material or use it for any profit-making activity or commercial gain

If the publication is distributed under the terms of Article $25 \mathrm{fa}$ of the Dutch Copyright Act, indicated by the "Taverne" license above, 


\section{Becoming Futurists. Reluctant professionals searching for common ground.}

\section{- Tessa Cramer}

\section{Acknowledgements}

\section{Chapter}

Futurists in search of a profession

1.1

1.2

1.3

1.4

1.5

\section{Chapter}

Research approach

2.1

2.2

2.3

2.4

2.5

2.6

2.7

2.8

Adopting a constructivist perspective A qualitative research design Following a struggle Observing futurists Interviewing futurists Group discussions with futurists Coding strategy The making of a profession

Chapter

3 Futurists and the struggle for professionalization

3.1

3.2

3.3

3.4

3.5

3.6

3.7

3.8

Introduction

Urgency of professionalization Attempts to grow as a profession

Demarcation issues

Struggle for common ground

The professionalization quest The traits perspective on professions Conclusions: beyond traits

\section{Chapter}

Identity I the art of being a futurist

4.1

4.2

4.3

4.4

4.5

4.6

4.7
Introduction
Traditions of becoming a profession
Claiming jurisdictions
Skills of a futurist
Image-making of futurists
The paradox of (not) fitting in

Conclusions: the making of a futurist
Chapter

5

Reputations | a heartland-free profession

15.1

5.2

Introduction Redefining the heartland ambition: the making of a reputation

5.3

Scholarly world

5.4

Commercial world

Artistic world

5.5

5.6

5.7 Conclusions: a heartland-free profession

Chapter

Service | a knowledge-producing profession

6.1

Introduction

6.2

6.3

6.4

6.5

6.6

Futurists' products

Serviceability for sensemaking The knowledge-based profession assumption A reservoir of knowledge Conclusions: a knowledge-producing profession

Chapter 7

Futurists and their promise of professionalization

7.1

Introduction

7.2 Reluctance and the making of futurists

7.3 Professionalization themes: identity, reputations and service

An alternative pathway towards professionalization

\section{6}

5

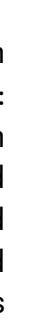




\section{Becoming Futurists.}

Reluctant professionals

searching for common

ground.

Copyright $\odot$ 2020, Tessa Cramer

All rights reserved. No part of this publication may be reproduced, distributed, or transmitted in any form or by any electronic or mechanical means, without the prior written permission of the author, except in the case of brief quotations embodied in critical reviews.

Design: Alt8

Lay-out: Canon Creative Hub

Printed in the Netherlands.

ISBN 9789081843775

The publication was financially supported by

Fontys Academy for Creative Industries,

Maastricht University and WTMC graduate school. 


\section{Becoming Futurists.}

Reluctant professionals searching for common

ground.

\section{DISSERTATION}

to obtain the degree of Doctor at the Maastricht

University, on the authority of the Rector Magnificus,

Prof. dr. Rianne M. Letschert in accordance with the

decision of the Board of Deans, to be defended in

public on Friday, 15 May 2020 at 12:00 a.m.

by Tessa Lianne Cramer

\section{Supervisors}

Prof. dr. ir. Marjolein van Asselt

Prof. dr. ir. Harro van Lente

\section{Assessment Committee}

Prof. dr. Rein de Wilde (chair)

Prof. dr. Maarten Hajer (Utrecht University)

Prof. dr. Mirko Noordegraaf (Utrecht University)

Dr. Alexandra Supper

This study has been made possible with the support of Fontys Academy for Creative Industries. 
Writing a $\mathrm{PhD}$ thesis is a solitary practice, yet I didn't write alone. Becoming Futurists was made possible by a life-giving ecosystem of friends, family, colleagues and students. In these few pages, I am finally able to thank everyone who has contributed to my growth.

First and foremost, I am deeply grateful for my academic guide Marjolein van Asselt. I see in Marjolein a bright scholar who is not afraid to speak her mind and dares to break with conventions. To me, Marjolein is a true example, especially in how science can and should be connected to the world. By leading me the way, Marjolein helped me to rise and spread my wings. My sincere gratitude goes out to supervisor Harro van Lente, from the moment I got acquainted with Harro's academic work, I was captured by his sense of language. Harro helped me to structure my thoughts, making dozens of impressive overviews based on our lengthy academic conversations an guided me in the wonderful and particular world of Science and Technology Studies. Harro's trust, his comforting smile and his ways with words helped me to pass the much-anticipated finish line.

I am very grateful for the support of my colleagues at Fontys Academy for Creative Industries. They have given me time to slow down and write, celebrated with me, and always had my back. Firs and foremost, I thank Anja Sparidaans, a true pioneer who recognized and nourished my drive to grow. I am grateful to Ilse van der Pas for her strong leadership. Thank you, amazing colleagues of the International Lifestyle Studies team, in particular my direct colleagues Vera Verberne, Monica Veeger Christianne Heselmans, Iris van der Zanden, Danielle Naafs, Linda Hofman, Pepijn Rijnbout, Fabienne van Engelen, Pierke Hulshof, Peer van Sprang, Vera van het Hof and John Matthijs. Together we have taught a younger generation how to grow, learn and ask questions about the future. I thank the 'trend team' in particular. Every day I am grateful we found each other as a community, ready to uplift each other, share, help and celebrate our individual and collective successes. Thank you Carlijn Naber, Bodil Jurg, Rudy van Belkom, Saar van der Spek, Tessa Petrusa, Quentijn Wulffers, Ingeborg Bruinewoud, Maud Donga, Maud van der Wiel, Tina Stieger, Bas van Raay, Bas Delmee, Zepha de Roo, Thomas Spronk, Kirsten Eerland, Evelien Dielemans, Mark Schipper, Hortense Koster \& Els Dragt. My students returned the favor by teaching me many life lessons, in particular Anne Pereira, Maud Brock, Eef van Doormaal, Kirsten van Hoof \& Tessa van der Hart. And last but not least, I wish to thank the team of 'bedrijfsbureau' and in particular Franca Sinay, Caroline Klijsen-Jansen, Marije Bos, Ineke Siegenthaler and Miriam Verdonk for their hard work behind the scenes. Someone else who was crucial to make things happen: Rubine van Twillert, thank you for always finding time for me in Marjolein's schedule.

I could not have written this $\mathrm{PhD}$ thesis without the generous futurists that welcomed me into their worlds. This access allowed me to narrate the new pathway that futurists were carving out in the midst of their professional becoming. I am deeply grateful for all interviewees, group discussants and futurists that so generously took time to talk to me. In particular, I thank trailblazer Hilde Roothart for bringing so many futurists together in group discussions and leading us the way. I thank Maaike de Vries for generously hosting me at RIVM, and, Patrick van der Duin and Vincent Marchau for kindly opening the doors at NTV for me.
In 2013, I co-founded the Dutch Future Society together with futurists that felt the necessity, or even urgency, to professionalize their practice. This experience enriched my academic work as I became part of an exciting movement of futurists that articulated the importance of starting the conversation abou their common ground. My gratitude goes out to chair Freija van Duijne, it was a pleasure to see her grow in her role and become a leader in the community. Thank you fellow boardmembers Jan Nekkers, Silke de Wilde, Susan van 't Klooster, Peter van der Wel, Patrick van der Duin, Kim Beerden, Lieke Lamb, Stephan Verveen en Tim Beelen - I loved building a community with you from scratch. A new generation took over and I am grateful to see we created a legacy together.

Over the years, several futurists taught me how to think like a futurist. First and foremost, I am indebted to Carl Rohde, my very first mentor, who taugh me the value of leading the way for younger generations. I was grateful to learn from talented academic Susan van 't Klooster, especially during our mindboggling experience of presenting at Harvard University. It was encouraging to see Erica Bol set up the Dutch chapter of Teach the Future. I was inspired by Sietske Veenman's energy to bring academic depth to societal conversations on sustainability. I appreciated Maurice van Rooijen's ability to critically separate the wheat from the chaff, helping me to see that my work should push the boundaries of what we think we know. With a smile I think of Farid Tabarki, who took me under his wing when I was only 18 years old and continues to inspire me with his eloquent presence. I thank Jan Nekkers for cheering me on from the sidelines from day one, and putting me on stages before I dared to articulate that now is my time. 
I thank Djenny Brugmans and Nanon Soeters for their incredible intuition and helping me to become aware my own role in the community: the guide. Thank you, Karsten van der Donk for asking questions that matter. On this pathway, I was also in fluenced by articles, books and designs of futurists Eleonora Masini, Sohail Inayatullah, Mei-Mei Song, Stuart Candy and Cynthia Selin.

I was lucky to be part of a very wise and wonderful $\mathrm{PhD}$ community. Especially via graduate school weekends of WTMC, I got to meet many inspiring fellow academics. In particular gentle Sarah, incredibly smart Claudia, graceful Simone, bright Jorijn, sharp Jorrit, cool Caspar and amazing Marith. Thank you WTMC teachers Bernike Pasveer and Govert Valkenburg fo holding the space for us to learn and grow.

From the onset, I wished to publish a $\mathrm{PhD}$ thesis that would not only be an interesting read but would also stand out on the bookshelf. I didn't need more than 3 words to explain my wish to designer Nouchka Huijg. She and her Alt8 team exceeded my expectations by creating this exquisite, one of a kind, inside-out design. Moreover, I am grateful to artist Thomas Trum for creating art in such a likeminded spirit that I needed to wrap it as the jacket around my science.

Thank you to my dear friends Hidde, Anne-Fleur, Diederick, Willemijn and Annabel, who brought joy, music and dance moves - relentlessly celebrating with me every single time I told them I made yet another deadline. Thank you to renaissance man Rudy and diamond Bodil. Thank you, Jonathan, I am evermore grateful that the Amazon brought you into my life. Thank you Merel for your lasting presence, you are a sister to me. Thank you dear Willemijn, fo sharing your incredible heart and mind, you show me how to live by example. Thank you to angel Eveline. Thank you dots Tessa \& Ingeborg, I can't wait for the day we all live in the same country again. I am proud to be friends with inevitable style icons Martijn \& Alain as well as formidable Roel, Victoria and Erik.

Thank you to the comforting smile of Maarten, Saar's calm, fellow ENTJ Joe's brain, Anne's creativity and Robert's eye for beauty.

I am grateful that I got the chance work with you, dear paranymph Carlijn, because within a splitsecond we were able to move mountains together. I think of our connection every time I read Cleo Wade's poem: there is no mountain that cannot be climbed and there are more pathways to the top than we could ever imagine. I am grateful for the contagious smile of paranymph Jorijn, we could talk about life and science for hours, but I equally appreciate the moments we were writing side by side - slowly becoming wise together.

And, of course, I am grateful for the lasting support of my big postmodern family. Thank you, Marijke, Amar, Hans, Ingrid \& Stijn for your presence and endless support. I am thankful to Janny for her abundance of love, encouraging me with newspaper articles, spiritual books and inquiry into my academic and personal progress. I am also deeply grateful for the in-depth and sincere questions of Guus, his patience and silence were healing to me. Dear Carl, thank you for being my first role model at age 16 . That day we became family, and to me you always will be. Thank you, Charlotte, for taking the time to patiently show me that love can be felt and expressed on layers that reach beyond words. I am grateful for my brother Daniel, who inspires me to dance, be kind and celebrate life every day, what I love about him most is his incredible awareness of what matters in life. I deeply appreciate the loving presence of my father, a generous teacher on every topic imaginable and with a keen sense of the good things in life - I see it as my task to eventually be able to mirror his wisdom. To conclude, there are not enough words to thank my mother, the grace of her heart makes her a rainbow in anyone's cloud. My mother showed me how to be a woman, a scholar, a leader and how I one day will be a mother too.

And to my love Ben. If I give myself to saying thanks to you, the day shall meet the night and I wouldn't even notice it. Our love is ever-growing and in flux - reflective of the seasons. Our love is strong and sunny, stormy at times, we experienced our winters and yet we always find our way into a new spring. 
There is nothing

left to worry about,

the sun and her

flowers are here. 

Futurists in search of a profession
Introduction

\section{A brief history of futurists}

Studying futurists

Studying professions
Structure of the thesis
1.1

Introduction

Professions are everywhere. When people are introduced in the media, their profession is assumed to detail their identity. Education systems and education policies are designed to channel children to the 'right' profession. And the daily life of nearly anyone is centered around commitment to a particular profession. Professions have become the cornerstones of modern societies and topic of sociological imagination. Professionals are offering their services to society with the commitment to, for example, build houses, write stories, design clothes or cure diseases (Schön, 1983; Noordegraaf, 2007).

Professions change. And the demand for their services changes too. Existing professions make efforts to adapt to the pace of societal, technological and economic changes. At the same time, new professions come into existence to offer additional service that are claimed to be of societal value. Despite the changes, there seems to be a prevailing notion of what a profession is and should be. Belonging to a profession is a prestigious affair; established professions traditionally have earned credit by contributing valuable services to society. ${ }^{1}$ Likewise, when new professions evolve and come into existence, they seek such prestige too. Yet, they also seem hesitant to follow the trodden paths. There is a friction between old images of professionalization and the new realms in which professionals need to operate. "What it means to work as a professional, to regulate professional fields in flexible capitalist economies, transnational spaces, and digital realities has become especially unclear and contested" (Noordegraaf, 2016: 789). In these tensions, contestation and struggles, pertinent questions arise about what professions are, what professionalization entails and
1 A handful of research projects have been carried out with the aim to identify which professions have societal prestige. In one particular example (Cörvers et al., 2017), respondents were asked to rate professions according to how they thought people in general think about professions and prestige. The professions soccer players. Remarkably, the researchers argue that the list of prestigious professions has hardly altered in the past 50 years, in spite of many new professions that have emerged in the meantime. The research demonstrates the static societal conception of prestigious professions.

2 Wiener (1961) was the first to separate a black box from a white box (Jordan and Lynch, 1992). Since then, the notion of a black box has been understood as scientific facts or artefacts of which the internal systems are implicit because they are regarded

what a good professional is. These are the central questions of this thesis.

Addressing such questions is not straightforward. My starting point is to closely follow and examine the making of a profession. What a profession is and what professionalization could mean can best be studied during the construction of a profession, and not when profession is fully established. In this I follow the philosopher Bruno Latour (1999) who stresses that the more successful something becomes (in his case an artefact or a knowledge claim) the more obscure its construction becomes. When something is finished and smoothly operating, the work and struggles that have made it possible are no longer visible. In other words, the better oiled the 'machinery', the smaller the opportunity to open and examine it and in the end, it turns out to be a 'black box'. ${ }^{2}$ Likewise, to examine professionalization, it is helpful if a struggle is still apparent, otherwise it is difficult to open the black box of professionalization. A profession that is in the midst of its making and its struggles, allows for investigating pertinent questions about professions, professionals and professionalization.

In this thesis, I will follow and examine the struggles in the making of the profession of futurists and I am interested in what 'professionalization' means in these struggles. The offerings and demand for futurists is an exemplary industry in which questions regarding professionalization are fully alive and visible. Futurists publicly stress their problems with professionalization and these struggles narrate stories of identity, reputations and services. These themes became the strategic research site of my study. Before examining the futurists' struggles, I will first introduce the community of futurists and their industry. word "blackboxing" as a verb, as an active entity. As such, Latour
and Woolgar emphasized that work is required to let research results become actual facts.

3 Note that the term 'futurist' itself is part of the struggles I development with the label of 'membrane technology'. At first, the label was an umbrella term for various research directions that were proclaimed to be promising, but over time the label became breeding ground for actual activities. Van Lente and Rip observed that "the heterogeneous actors (..) create (as they themselves often phrase it) a membrane world" (1998: 234). This membrane world consisted of heterogeneous actors with shared interest in $a$, at the time, new technology. The promise of membran lechnology became a structure of belonging that outsiders recognized too

There are many definitions of a futurist (e.g., Toffler, 1972; Bell, 2003; Gidley, 2017). Renowned futurist Alvin Toffler stated in 1972 that the word futurist had grown from being virtually unknown to having a particular meaning. ${ }^{3}$ Today, the word futurist is used extensively in academic journals like Futures and Journa of Futures Studies. In general, the term 'futurist' includes anyone who systematically assesses the future and sells this assessment in a more or less packaged form to inform decision-making. Clearly, this is a broad definition which includes many practitioners in firms, governmental agencies and knowledge institutes. Given my interest in what becomes apparent in the struggles of professionalization, I will specifically follow the moves of the futurists that are actively contributing to the debate on professionalization by spending their time e.g. attending conferences, setting up organizations and participating in the dialogue. When I refer to futurists in this $\mathrm{PhD}$ thesis, I am referring to the futurists who actively participate in the professionalization debate.

Futurists might refer to their own occupation by a different term. On the website of the Association of Professional Futurists (derived on 16 Augustus 2017), members use several titles: professional futurists, strategic foresight professionals, change strategists, technological futurists, foresight practitioners, and innovation managers. Yet, most stick to the word futurist, indicating that it is a familiar title in an international context. For example, during my $\mathrm{PhD}$ research, people whom I define as futurists never corrected me in referring to them as such.

People have always wanted to understand the future (Helmer, 1983, Bell, 2003, van Asselt et al., 2003). Of ten, telling the future has been delegated to specific 
4 A term de Wilde (2000: 9) used to refer to the group of futurists specializing in the influence of technology on the future of society and culture.

5 Futurists most influential books listed by Son (2015) in Futures: The Image of the Future (Polak, 1961), Profiles of the Future (Clarke, 1962), the Technological Society (Ellul, 1964), Inventing

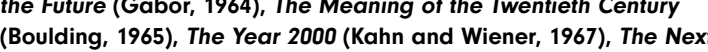
500 Years (Beckwith, 1967), The Most Probable World (Chase, 1968), Population Bomb (Paul, 1968), Mankind 2000 (Jungk \& Galtung, 1969), The Future of the Future (1969) (McHale, 1969), and Future Shock (Toffler, 1970).

groupings, too. In the distant past, for instance, the future was regarded as the domain of fortune tellers, the most famous example being the ancient Greek oracle of Delphi. Today, futurists see themselves as practitioners who aim to anticipate possible future (Toffler, 1972; Bell, 2003; Gidley, 2017). Yet, they also emphatically do not want to be associated with fortune tellers or oracles. Specifically, Bell claims that futurists aim to "demystify the future" (2003: 5). They aim to do this by making "their methods explicit, to be systematic and rational, to base their results on the empirical observation of reality" (Bell, 2003: 5).

Today, futurists are part of an industry that has grown extensively over the years, the so-called 'future industry. ${ }^{4}$ A number of futurist organizations and think tanks have been set up, books by futurists have been published and conferences on futures themes are organized. The sum of those activities gradually extend ed the visibility of what futurists do, beyond their pee group. Examples of such wider visibility include the scenarios of the Club of Rome on the impact of human activity on the environment in 1972 and widespread books by futurists, ${ }^{5}$ such as the Future Shock by Alvin Toffler (1970). More recent examples include The Singularity is Near by Ray Kurzweil (2005) and The Second Machine Age by Brynjolfsson and McAfee (2014). According to the newspaper The Guardian, the future has become 'big business' (Cassidy, 2017). In this article, Trevor Hardy, CEO of the Future Laboratory illustrates this change with an overview; five years ago, he drew up a list of his competitors in the UK, which consisted of just a few other agencies. Since then, the list has rapidly grown and counts over a hundred other agencies. Hardy estimates that the future industry, "comprising traditional trend forecasting companies, futures consulting businesses, and future-facing insight and intelligence" (Cassidy, 2017: 2), is currently worth around $\$ 100 \mathrm{bn}$ globally. Whether this estimation is anywhere near the real number is impossible to verify, but it does articulate the existence of a future industry.

In parallel to the growth of their industry, futurists have become increasingly intrigued by the question: "are we a profession?". In the 1980s, this has led to a lively debate among futurists at conferences and in the literature, and the debate has not been silenced since then. While futurists generally recognize that a 'futures field' (Markley, 1983: 47) has emerged in the sixties and has gradually improved its theory and methods thereafter (Hideg, 2002: 283), they do not agree on what unites the field or how to professionalize it. Some futurists link the development and identity of their profession to methods used in science. For example, Ziaudin Sardar wonders in his article 'The Namesake' whether the futures field could actually become a field of "proper scientific enquiry" (2010: 178 ), such as mathematics or physics. The terminology Sardar uses suggests that the professionalization of futurists should resemble scientific disciplines. Other futurists, like Bell (2005), emphasize the potential contribution to the well-being of humankind. Bell calls this 'action science', in which futurists have a responsibility not to lead people astray in their choices concerning the future.

In the last 20 years, the debate among futurists on professionalization has intensified (Bell, 2003, Inayatullah, 2008, Stevenson, 2008, Slaughter, 2008, Kuosa, 2011). Together with the rise of the number of futurists and their specialties, the concern about preserving standards increased. In response to this, futurists have initiated gatherings and projects to discuss professionalization. For example, a collective named LaFutura was set up in 2009 to bring together European futurists. Their goal is to exchange knowledge and discuss the possibility of creating a community. Moreover, the Association of Professiona Futurists published several white papers and reports that try to enhance and enrich this debate. For example, members collaborated and published titles like the Future of Futures (2012), the Foresight Competency Model (2016) and the Future of Foresight (2017). Additionally, at international conferences, futurists often devoted a (small) section of the overall program to the future of their professionalization

Futurists have pushed to become a profession by organizing events, writing articles and books, and discussing their views on the matter. Despite these committed efforts, futurists continue to struggle to advance their professionalization, as if they are reluctant. When I started to approach futurists about my plans to research their practice, the responses were primarily positive, as it was seen as supporting the collective ambition to become a true profession. A clarifying example was the reaction of Peter Bishop, a prominent American professor, when I described my intentions. He told me that most futurists focus on differences and that this is not helping the profession move forward. He argued that futurists still need to find their common ground and that my study would help in this quest. 
How many futurists are active today? This is a challenging question. Simply using Google to estimate the number of futurists only results in a list of approximately $\mathbf{5 0}$ notable futurists on Wikipedia, including Alvin Toffler, Fred Polak and Lidewij Edelkoort. This list is not exhaustive but at least gives an impression of widely esteemed futurists.

Another way to estimate the worldwide number of futurists is by looking at the number of members who are affiliated with international networks of futurists. Currently, there are a few larger associations and organizations that represent futurists. For instance, on an international level, the World Futures Studies Federation (WFSF) is a household name for many futurists. Sardar (2010) once referred in one of his publications to a lively discussion among futurists held via the WFSF mailing list about the professionalization of futurists. After subscribing to this list, I encountered a lively debate about futurists and their practice, many updates on new work and recommendations for relevant books. Another large organization is the World Future Society. Conferences organized by World Future Society (WFS) represent futurists from various backgrounds. This organization traditionally served American futurists that work at governmental organizations and larger companies with interest in the future. Recently, the organization has taken a more commercial path and attracts businesses that want to create a future-proof strategy.
Another, more exclusive, organization is the Association of Professional Futurists (APF). The futurists who want to be part of the APF are carefully screened. Selection criteria include the number of clients, prior futures education, publications and speaking engagements. An organization founded more recently is LaFutura, initially set up in 2011 to bring together futurists to discuss their work. Several LaFutura conferences were organized with the aim to eventually set up a formal organization. This resulted in the LaFutura Global Trend Network. When that organization was set up the role of LaFutura in taking the lead in professionalization discussions changed. The previous struggle of these futurists was 'solved' the moment the organization became official. LaFutura currently has the aim to connect business-oriented futurists in their network to experts in other industries.

Of these associations and organizations, the World Future Society is by far the largest, with an estimation of 25,000 members. These members have affinity with futures, but are often not futurists that refer to themselves as such. The World Futures Studies Federation, on the other hand, has more than $\mathbf{4 0 0}$ active members. Aspiring members need to apply to be able to join; all involved futurists carry out the work professionally. The same goes

for members of the US-based Association of Professional Futurists, which also has a similar number of members, around 400 . There is some overlap between the members of the organizations. 'LaFutura' is the newest organization and is estimated with around 200 members that mainly consist of European commercially oriented futurists and some larger companies that are interested in the work of futurists.

These numbers only indicate how many futurists are active to advance professionalization. The futures industry is much larger than the plus or minus 600 futurists active in the aforementioned networks. For instance, there are hundreds of freelance futurists who are not part any of the organizations but do carry out the same work. There are consultants who harvest creative insights to help design oriented companies move forward. And government officials who carry out research at governmental organizations like planning agency's, using methodologies like scenario planning as a way to influence policy. There are futureoriented scholars who edit journals like Futures and the Journal of Futures Studies. Moreover, there are keynote speakers who focus on specific topics like 'the future of artificial intelligence' or 'the future of cities'. And, business strategists who benefit from futures methodology to convey their vision. However, the associations and organizations are relevant platforms in understanding futurists and their profession. 
7 In this paragraph, several seminal moments in the history of the futurist' profession are narrated. However, writing a historical account is not an innocent affair. Typically, professionals craf histories to serve the needs of the present. Moreover, the absence or recognition that a common history exists, is a likely part of the struggle of practitioners becoming a profession. An illustrative example is Abir-Am (1985) who has shown how molecular biology, cratted a history 1930 s, to help their legitimation. 8 Among others, the Netherlands Institute for Social Research (SCP), Netherlands Environmental Assessment Agency (PBL), National Institute for Public Health and the Environment (RIVM) and the Netherlands Scientific Council for Government Policy (WRR) (van Asselt et al., 2010b).

9 Technology Assessment has been developed by many

This $\mathrm{PhD}$ thesis aims to deepen our understanding of how current professions-in-the-making professionalize today. This has led me to explore the following research question:

How to understand the making of the futurist profession?

To prepare the ground for my study, I first give a brief historical context of futurists. Next, I describe the theoretical perspectives to underpin the question mentioned above. This leads to a further elaboration of the research questions, to be addressed in the subsequent chapters of this thesis. I conclude the chapter by describing the structure of this thesis.

A brief history of futurists

Traditionally, futurists were regarded as prophets. The future has long been a domain of predictors, who connected the divine and the humans. They used intuitive and spiritual methods to predict what was to come (van Beerden, 2013). Futurists today are often confronted with the persistent caricature of them as modern-day prophets. But since the early 1900s, futurists have advanced their methods and theory. ${ }^{7}$ H.G. Wells' essay Discovery of the Future (1902) is generally regarded as the starting point of a modern, more rational approach to the future (Bell, 2003). Wells was originally a science-fiction author and started to see value of researching the future in a much broader sense. In his writings, Wells expressed his wish for university faculties and departments specializing in futures. In the years that followed, only a handful of futurists were actively developing pioneering techniques and meth odologies to explore and better understand the future. For example, in the beginning of the 1930s, Ogburn reported to the US government on social trends during the New Deal period (Georghiou et al., 2008: 26).
The aftermath of the Second World War gave the demand for futurists a boost. They were expected to provide new perspectives after long years of war and uncertainty. The future was regarded as an object of planning and design, with an ideal of rationally shaping society bearing in mind the premise that history should never repeat itself. For example, in the US, the RAND Corporation, a military research center, was asked in the 1950s to foresee which technological innovations might be crucial in the near future. The idea was that the future should be controlled and altered if anything might point in an unfavorable direction.

In other Western countries, similar initiatives were launched. The Netherlands grew a rich tradition of forward-looking planning agencies and advisory councils. Right after World War II, in September 1945, Nobel prize laureate and economist Tinbergen set up a planning agency in the Netherlands. The Bureau for Economic Policy Analysis (CPB) gives unsolicited advice to the government about long-term issues that reached beyond the daily political realm. ${ }^{8}$

The post-war reconstruction went hand-in-hand with rapid industrial development in Western countries. Successive technological innovations quickly changed economies, regional developments and domestic life. The disadvantage of this situation was a new uncertainty about the effects of new technologies on jobs, competition and social structures. As a consequence, some futurists, amid other likeminded scholars, mainly directed their attention to a specific domain: so-called technology assessment. ${ }^{9}$ Technology assessment is a way to explore the implications of new and emerging technologies (Georghiou et al., 2008). For example, in the US, Kahn started to explore the future with scenario planning by publishing doomsday scenarios in have advanced the evaluation of new technologies in Constructive
Technology Assessment (Rip et al., 1995; Schot and Rip, 1997).

On Thermonuclear War (1960) and sketching possible futures in The World 2000 (1967). He made a name for himself by researching and writing accessible books how technological change influenced US policy. From the sixties onwards, high profile American social scientists bundled their intellectual power to write about the broad theme of post-industrial society.

Georghiou et al. (2008), in their review of future oriented research, recognize an upsurge of futurists in Europe in the sixties. Around the same time, technology assessment became a major research theme in Europe as well. This interest in new topics prompted futurists to move away from the military arena towards technological and societal questions. During this period, the activities of futurists were predominantly situated in governmental spheres. Coinciding was the publication of Limits to Growth by the Club of Rome (1972). According to futurist Bell (2003), this is one of the most impactful studies on the future that has been published to date. Limits to Growth presented a normative outlook on how worldwide industrial growth caused the rapid exhaustion of available resources. The report spoke to a huge audience, the report was translated in 37 languages and sold over 12 million copies worldwide.

The visibility of Limits to Growth was beyond any oth er futures work had obtained so far. But this did not immediately translate into more funding or university positions. On the contrary, on the website of the Acceleration Studies Foundation, futurists refer to the following decade, the eighties, as the 'futures winter' On the same website the editing futurists bring forward the absence of theoretical and methodological grounding, inadequate networking of the practicing futurists, scarce promotion of the value of futures studies and a cultural backlash to "simplistic models of 
the positivist predictive futurists of the 1950s-1960s" as reasons for this arguably 'dark time' (cited from the website of the Acceleration Studies Foundation). ${ }^{10}$

In the early nineties a newfound audience did gave rise to a new 'fame'-futurists also started working in the business sector, with commercial parties. Companies started to articulate their wish to anticipate to economic change, in which they deemed scenario planning as a helpful tool to look forward. One of the early adopters was the French oil executive and head of the business environment division of Shell, Pierre Wack. He had already started to experiment with scenario planning in the 1960s. The goal of these endeavors was to learn how to deal with future uncertainties. Years later, Shell was one of the few oil companies that had already explored the possibility of an oil crisis. When the oil crisis happened in 1973, Shell arguably was better equipped to respond strategically, although others would explain the story as a well-narrated myth (van Duijne and de Wilde, 2016). The scenario approach affirms the power of understanding uncertainties instead of merely focusing on certainties (Schoemaker and Day, 2009).

In the course of the 1990s, futurists started to speak to a broader audience. Futurists offered an analysis of the future for smaller companies and interested individuals by coining understandable terms to illustrate 'the Zeitgeist'. In the early nineties, for instance, Popcorn (1992) came up with the term 'cocooning', which is, in her words, the stay-at-home syndrome. This word had impact because it was used by many as it articulated a new prevailing need of people preferring to retreat at home instead of going out. Son (2015) argued that from the 1990s onwards, futurists' practices fragmented. In the 1990s and especially in the early 2000s, futurists started working in different countries, in different areas of expertise, with different types of experts, and with different job titles too.

1.3

Studying futurists This $\mathrm{PhD}$ thesis builds on the work of scholars who analyze the work of futurists and the role of experts at large. There is a modest body of knowledge about the practice of futurists written by futurists themselves. They created handbooks on how to perform the work and on the broader topic of the value of futurists. Italian futurist Masini (1993) published Why Futures Studies. In her introduction, Masini stated that this book is for young people who will be working in the future and is also directed to those who are interested to better understand their own influence on the future. Moreover, Bell has written three seminal volumes on the foundations of futures studies (2003). These books are known among futurists, and are referenced as a source of inspiration. In his first volume, Bell introduces the reader to what he calls the futurists' body of thought, to emphasize the unity of futurists and their services to society. More contemporary work includes Gidley (2017), who published A Very Short Introduction on the Future. In this introduction, she addresses the history of the future, basic assumptions of futurists and identifies futurists who have contributed to the profession.

Various handbooks have been published by futurists. These handbooks do just not describe theory and content but rather offer a framework for action for how futurists can research the future. Examples include Hines and Bishop's (2012) Teaching about the Future, a handbook that consists of the summary of their curriculum for the post-graduate course at the University of Houston. In addition, Raymond (2010), director of consultancy firm the Future Laboratory, published a book titled The Trend Forecaster's Handbook; his aim may not necessarily have been to write an educational handbook, but because of the clear depiction of ways to research trends, it became a seminal book for several applied universities. In addition, along with colleagues, Dragt (2017) summarized the curriculum of applied university Fontys Academy for Creative Industries in the Netherlands, which resulted in the handbook How to Research Trends.

Scholars have also reflected on practices of futurists. For example, science and technology studies (STS) scholars follow an interdisciplinary approach in reflecting critically on practices of making and performing scientific work, including the work of futurists. STS in general considers the interaction between society on the one hand and scientific research and technological innovation on the other; it is adjacent to the sociology of knowledge, a research field focusing on how scientific ideas came about and have impact on society. STS research addresses the role of the future in our society. For example, van Lente $(1993,2012)$ has studied how science and technology unfold in a 'sea of expectations' and de Wilde (2000) studied the futurists' industry. Moreover, related studies examine how future insights influence policy making (e.g., Staal and van Vught, 1987; 1988; Dammers, 2000; de Laat, 2000).

Moreover, STS scholars have studied the production of knowledge by futurists. For instance, Brown et al (2000) have characterized the change of focus of the analytical gaze from looking into the future to looking at the future. This implies that the STS scholars moved the focus from the content of futures work (e.g. scenario or trend analysis) to emphasizing the process of how to research futures. With several common 
11 According to MacDonald (1995: 11), a sociology of professions scholar who reflects on the history of the discipline, the traits perspective (which he prefers to call the functionalis perspective) did cast a "long shadow" over handbooks on professions. He mentions how American Sociological Association (ASA) president, Kingsly Davis (1959: 757-73) once wrote: "we
are all functionalists now". Although MacDonald values the are all functionalists now". Although MacDonald values the interactionist perspective, he remarks that the
perspective has been, and still is, dominant. publications, van Asselt and van 't Klooster built on Brown's legacy as a backdrop to grasp today's foresight in action. Van Asselt et al. (2010a: 2) argued that "reflection on foresight in action is both lacking and needed". Their Foresight in Action, (2010a), was based on an intensive five-year study of how experts asses the future. In doing so, the authors used ethnographic techniques to unravel the processes of how scenarios are created. Moreover, they emphasized the urgency of reflection on futurist practices, following the footsteps of van der Staal and van Vught (1987), Brown et al. (2000), Dammers (2000), WRR (2000), Bell (2003) and Adam and Groves (2007).

Both futurists and scholars have primarily focused on how to understand the actual knowledge futurists produce when creating alternative futures. This is not surprising, considering that futurist advance a different, unusual topic and bring novel knowledge claims. Futurists have made overviews of the possible ways to research (alternative) futures. For example, Gidley (2017) offers an overarching typology of critical, cultural, participatory and integral futures, each drawing from different philosophical backgrounds, and using suitable methods. While futurists make efforts to translate their perspective to others, they do not often evaluate the overall impact they have as a community. Futurists have reflected on the impact of individua research projects, for example in special issues of journals like Futures (e.g. McHale, 1976; Kuosa, 2011), but evaluating their profession is not a common exercise. Reflection on the connection of futurists and their professionalization is still relatively uncharted territory.

\section{4}

Studying professions

This $\mathrm{PhD}$ thesis aims to deepen our understanding of how futurists professionalize and to unravel their underlying assumptions of what a profession should be. The above-mentioned literature will be useful to study futurists' views on professionalization and to study their practice and delivered services.

Professions in general have been examined by scholars in the field of the sociology of professions. The sociology of professions is a research area that has been explored by sociologists, economists and historians (Tamir \& Wilson, 2005). Seminal books on professions have been authored by, among others, Larson (The Rise of Professionalism, 1977), Abbott (Systems of Professions, 1988) and Freidson (Professionalism the Third Logic, 2001). While many definitions of the word profession have been coined, the definition of Abbott (1988: 8) seems a useful starting point: "professions are exclusive occupational groups applying somewhat abstract knowledge to particular cases." Abbott's description of a profession is deliberately broad. Abbott explains that it is "unnecessary and dangerous" to pinpoint one definition of a profession; "one needs only a definition strong enough to support one's theoretical machinery" (1988: 318). Schön (1983: 4) proposed a more specific characterization: "a profession offers the definition and solution of our problems." Here, the 'our' refers to society. This perspective is noteworthy because it articulates that a profession is not just bringing a solution for problems, but can also contribute to formulating the actual problem. What this sociology of professions definition stresses is that professions have societal responsibility, for example to solve problems, or contribute to society in some way (Schön, 1983).

Sociology of professions scholars have been working on the topic of professionalization for more than a century. Initially, the main goal was to understand what a profession is. Social scientists like
Flexner (1915), Carr-Saunders and Wilson (1934) and Millerson (1964) tried to understand the role of a profession in society by delineating 'traits' and 'characteristics' that a profession needs to have. According to Brante (2011), numerous lists of traits have been produced since the 1930s. The 'traits' defining a particular profession typically involve theoretical knowledge, education, examinations, licensing, specific associations, organizations, various types of control, collegiality, ethics, work for the common good, autonomy, discretion and sometimes class position (see also Chapter 3 ).

Both Flexner (1915) and Millerson (1964) tried to understand what makes a profession a profession. They searched for a 'structure' of how professions professionalize. Classic examples of such traditiona studies are law and medicine (Abbott, 1988). These two professions were seen as representative of how professions ought to develop and as examples of professions that have found consensus. These two remained the archetype for professionalization ever since. Several scholars (Flexner, 1915; Carr-Saunders and Wilson, 1934; Millerson, 1964) highlighted the most relevant traits, but over time, only a few professions reached consensus on the traits that should be met. In the 1960s scholars within the sociology of professions started to question if a traits-based stance could be too one-sided to define professionalization. They concluded that for practitioners, finding a full consensus on basic elements like education, common ethics and clear licensing is a challenging activity and maybe not needed to function a profession.

Critics argued that the traits perspective was 'elitist' (Becker, 1962; Hughes, 1960). ${ }^{11}$ For example, social workers, flight attendants and auto mechanics wer 
not included as a profession because, at the time, they did not meet the requirements of a 'real' profession. In addition, sociology of professions scholars realized that the traits perspective could not fully explain how professions came into existence. This triggered the sociology of professions to focus on the making of professions. For example, Wilensky (1964) distinguished phases through which every profession evolves. $\mathrm{He}$ showed that "all occupations are placed on a continuum of professionalization, some progressing, others remaining static and yet others moving backward" (cited from Freeman, 1997: 65). The central concept of Wilensky's work is the movement of an occupation along a spectrum of degrees of professionalization which gives opportunity to think in steps instead of an archetype. Wilensky describes the first phase as when professionals "start doing full time the thing that needs doing" (1964: 142-143). Often, they were educated in other disciplines but start working on this novel topic or skill. Secondly, according to Wilensky "the question of training" (1964: 142-143) starts to rise: early professionals start educating their peers and students. After that the soul searching on whether the occupation is a profession starts usually within organizations. As one of the last phases Wilensky describes how licensing and certification can be used as "weapons" (1964: 142143) to achieve professional authority and to finalize this phase with a common push for professional status. Wilensky's perspective transcended the view of professionalization as fulfilling a mere list of traits. Rather, he emphasized the dynamics of becoming a profession. Several scholars followed Wilensky's lead in the 1960s, emphasizing the process of becoming a profession.

Correspondingly, sociology of professions scholars who initiated the traits perspective soon started to move beyond it. By the 1970s, the perspective on professions rapidly changed as scholars articulated its shortcomings. Informed by critique on the traits perspective, the focus of the professionalism studies moved from form (structure) to functions (process). Scholars like Larson (1977), Abbott (1988), MacDonald (1995) and Evetts (2003), started to research how a group of experts develops into a profession. This perspective allowed for more dynamics as it rejected the notion of solidly basing professions on characteristics or traits.

The types of professions central in research also changed. Abbott (1988) stated, for example, that it was important and more interesting to conduct research in the fields of market-driven professions, like accountancy, instead of the classic examples of medicine and law. In the new body of literature, there was a strong emphasis on how professions reach a certain 'heartland', that is, the endpoint of professionalization. This heartland could be reached by obtaining jurisdictions on three different levels, or 'arenas': the workplace arena, in the public opinion arena, and the final (and most difficult to obtain) legal arena (see also Chapter 5).

Meanwhile, the context in which professionals operate has changed as well. Many point out the rise of the knowledge economy, demanding flexible professionals not only giving information but also offering services in broader sense making (Drucker, 1993, Abramowitz \& David, 1996, OECD, 2000). According to these studies, the context of knowledge economy has notably changed the role of professions. A sharp characterization of the changing context of professionalization is Liquid Modernity by eminent sociologist Zygmunt Bauman (2000), who has argued that we find ourselves in a time in which old systems are no longer sustained, but that new modes of life have not yet been designed, let alone set in operation. Bauman finds solace in the notion of 'liquidization' of forms an settings, a development he called 'liquid modernity'. In Liquid Modernity, Bauman argues that work has lost its centrality in society; it is not just an ethical service to society anymore, rather it is an activity anticipated to be rewarding for practitioners. The value of professions has shifted from the necessity to contribute, to the necessity to fulfill the lives of the practitioners.

Currently, the theoretical conversation in the sociology of professions has advanced in different directions. Generally, a common analytical framework, similar to those provided by the earlier perspectives, is absent (Saks, 2012). Although scholars adopt new perspectives (with new methods like discourse analysis) and topics (among others, culture and ideology in work contexts), their thoughts do not align automatically. They do not seem to agree on which methods to use and which perspective could be most valuable. As a result, there is more than one strong discourse to which they relate. For example, Saks (2012) pleas for a Neo-Weberian perspective, focusing on the socio-political process of power and macro level market interests. Evetts (2011) states there are two competing discourses in professionalization today: organizational and occupational. The organizational perspective, in contrast to the occupational perspective, includes the logics of the organization and its market: "managerialism and commercialism" (Evetts, 2011: 407). The shift from occupational to organizational professionalization is recognized in notions of "partnership, collegiality, discretion and trust to increasing levels of managerialism, bureaucracy, standardization, assessment and performance review" (Evetts, 2011: 407)'. Although, in spite of this diversity, the interpretative perspective is dominant among academics. 
Recently, scholars outside of the sociology of professions also observe changes in how professions are currently constructed. For example, Noordegraaf (2011), professor in law, economics and governance, seeks a more dynamic understandings of professions. He suggested that "we need new notions and images of professionalism" (Noordegraaf, 2016: 801) and in a more recent article argued that there are "all the more reasons to reframe understandings of professional work" (Noordegraaf, 2016: 789). In his work, Noor degraaf also refers to the work of sociology of professions scholars like Evetts (2003), Kirkpatrick and Muzio (2011) and Suddaby and Greenwood (2001) but blends their theory with organizational and public administration studies (Waring and Currie, 2009). All aforementioned studies stress the changing character of professions and their organizational contexts; they all share a curiosity to study how exactly professions are changing.

On the basis of the theoretical perspectives described above, the central concern of this study, how to understand the making of the futurist profession, can be broken down into three research questions. As start, I examine how futurists identify with the existing notions of a profession. Futurists ask themselves: "are we a profession?". While they may have different approaches to answer the question, they seem to share the urgency to discuss this topic. At the outset, I expect it to be worthwhile to examine how futurists currently imagine their professionalization in relation to existing notions of a profession. Hence: How do futurists identify with existing notions of a profession?

This question offers the opportunity to study how futurists identify with the conceptualization of the model of professionalization that sociology of profes- sions scholars have developed over the years. In a second step, I direct my focus 'under the hood', examining the machinery of futurists' professionalization by studying the actions futurists take to professionalize. These actions are significant as I expect they provide another entrance point into how futurists experience their process of aiming to become a profession. The more recent interdisciplinary perspective on professions has inspired me to use multiple perspectives (sociology of professions as well as science and technology studies) to answer the following question: Which actions do futurists take to professionalize?

And finally, after examining the particular actions futurists have taken, I question which notions of professionalization become apparent. To structure the analysis, I first direct my attention to how futurists are building reputations and second, to the knowledge claims they produce about the future. As such, I examine the pathway futurists take to become professional by asking: Which notions of professionalization become apparent in futurists' efforts to professionalize?

This third and last question focuses on how futurists pave their pathway in their professionalization and how the concomitant notions of professionalization differ from earlier notions.

This thesis consists of seven chapters. This first chapter introduces the problem definition, the theory and my approach. Chapter 2 details my methodological approach. The questions I raised above are answered in the four subsequent empirical chapters. The first and second question are respectively addressed in Chapters 3 and 4, respectively, while Chapters 5 and 6 are devoted to the third question. To conclude,
Chapter 7 offers reflection and discussion on the findings presented in this thesis.

With this $\mathrm{PhD}$ thesis I aim to trace how futurists struggle with professionalization, and the study was, as it should, a struggle in itself, unfolding with contingent opportunities as they arose. Conversation were held behind the scenes, observations were made amongst many different groups of futurists and interviews were conducted in informal, private settings. To do justice to the subtlety of this process, I elaborate in Chapter 2 how I chose and defined a qualitative research design, based on existing theoretica perspectives on becoming a profession. As such, this $\mathrm{PhD}$ thesis is based on theoretically informed empirical accounts, which consist of observations, interviews and group discussions. I observed futurists in formal settings like conferences or meetings that often contained a topic regarding professionalization. In total, I attended more than 50 conferences that served as meeting places for futurists from all over the world. At those conferences I observed the attending futurists and interviewed a representative group of 33 international futurists. The visibility of my research project at conferences and meetings provoked direct and indirect responses of futurists. Henceforth, the third aspect of my empirical account was initiated by futurists: they asked me to organize group discussions. On two separate occasions, Dutch futurists asked for guidance in their discussions on professionalization. In Chapter 2, I give a detailed account of my methodological choices to address the various source materials.

Over the years, futurists have discussed their professionalization in books, journals, newspapers, and a conferences. In Chapter 3, I examine which topic 
futurists frequently discuss in relation to professionalization. Based on this, I characterize how futurists discuss their professionalization in relation to the existing notions of what a profession should be. My aim is to answer the question: how do futurists identify with the existing notion of a profession? To answer this question, I systematically compare the topics futurists discuss and confront these with the existing theoretical perspectives on professions within the sociology of professions. In this chapter, I examin how futurists struggle to professionalize and conclude that futurists tend to relate to a classic notion of professionalization: the traits model. Futurists are aware of, but not discouraged by, the lack of common education and their inability to organize thei community and their diversity. There are contrasting ways in which futurists interpret this, as a failure or as a chance. Futurists on both ends have trouble understanding the respective pessimism or optimism of the other futurists. The resulting struggle reveals both futurists' eagerness to professionalize and, at the same time, their reluctance to do so.

Chapter 4 continues to examine why futurists are reluctant to professionalize. I direct my attention to how futurists search for further professionalization in face of this reluctance. In this analysis, I benefit from two seminal thinkers in the sociology of professions: Abbott (1988) and Larson (1977). They offer useful concepts, such as 'jurisdiction' (Abbott) and the 'professional project' (Larson). At the end of the chapter Ianswer the following research question: which actions do futurists take to professionalize? Abbott's conceptualization of jurisdiction proves especially useful to grasp the art of being a futurist by examining actions involved practitioners take. As described in Paragraph 1.4 Abbott points to three arenas in which practitioners take actions to professionalize: the workplace, public opinion and the legal arena. In their practice, futurists explicitly discuss the key skills that shape their identity. This is a type of conversation that can be ascribed to Abbott's conceptualization of a workplace jurisdiction. Futurists are also aware of the dominant societal images of them as prophets, which can be qualified as Abbott's public opinion. However, futurists find communality in their reluctance to claim any type of legal jurisdiction as defined by Abbott.

In Chapter 5, I continue with examining how futurists take actions to professionalize. The former chapters indicate that futurists are reluctant to adhere to the classical notions of becoming a profession. Hence, the question which notions of professionalization become apparent in futurists' efforts to professionalize? In this chapter, I study the assumption that every profession aims for a heartland-to become an advanced profession by standardizing practices and knowledge. The concept of a heartland suggests that each profession strives for a particular endpoint in the process of professionalization by claiming the workplace, public opinion as well as legal jurisdiction (see Paragraph 1.4). Futurists lack the ambition to formulate a legal agreement, which would imply that they are not even considering reaching the heartland. Against this background, I further examine how futurists build reputations as a 'heartland-free' profession. This leads towards an alternative route of crossing the boundaries of academic, commercial as well as artistic worlds. In Chapter 6, I move the focus to futurists' knowledge production in relation to their professionalization. The sociology of professions follows a model of a knowledge-based profession, i.e. knowledge as a resource in professionalization. In this chapter, I examine how futurists adopt alternative ways of valuing knowledge in a profession. Based on the products of futurists, for example, reports, workshops and keynotes, I outline the way in which futurists attribute value to knowledge in their services. The key mode is that futurists produce, preferably serviceable knowledge as input for assessing the future to inform decision-making. By challenging the assumption that knowledge should be regarded as a resource to become a professional, futurists make room for a broader idea of the role of knowledge in professionalization.

To conclude, in Chapter 7, I return to the efforts of scholars in the sociology of professions to point out an alternative pathway of becoming a profession. Based on my findings I am in the position to examine whether these scholars theoretically went far enough in their characterization. I conclude that new typologies are necessary to fully comprehend the professionalization of futurists. In this chapter, I therefore propose to regard futurists as an example of a 'Type 2 profession. This 'Type 2' profession exists alongside the classic 'Type 1' professionalization that has become familiar but not all-encompassing. In this fina chapter, I discuss the significance of this alternative pathway for the many, 21st century professions that currently do not fit in the dominant, classic notions of a profession. 


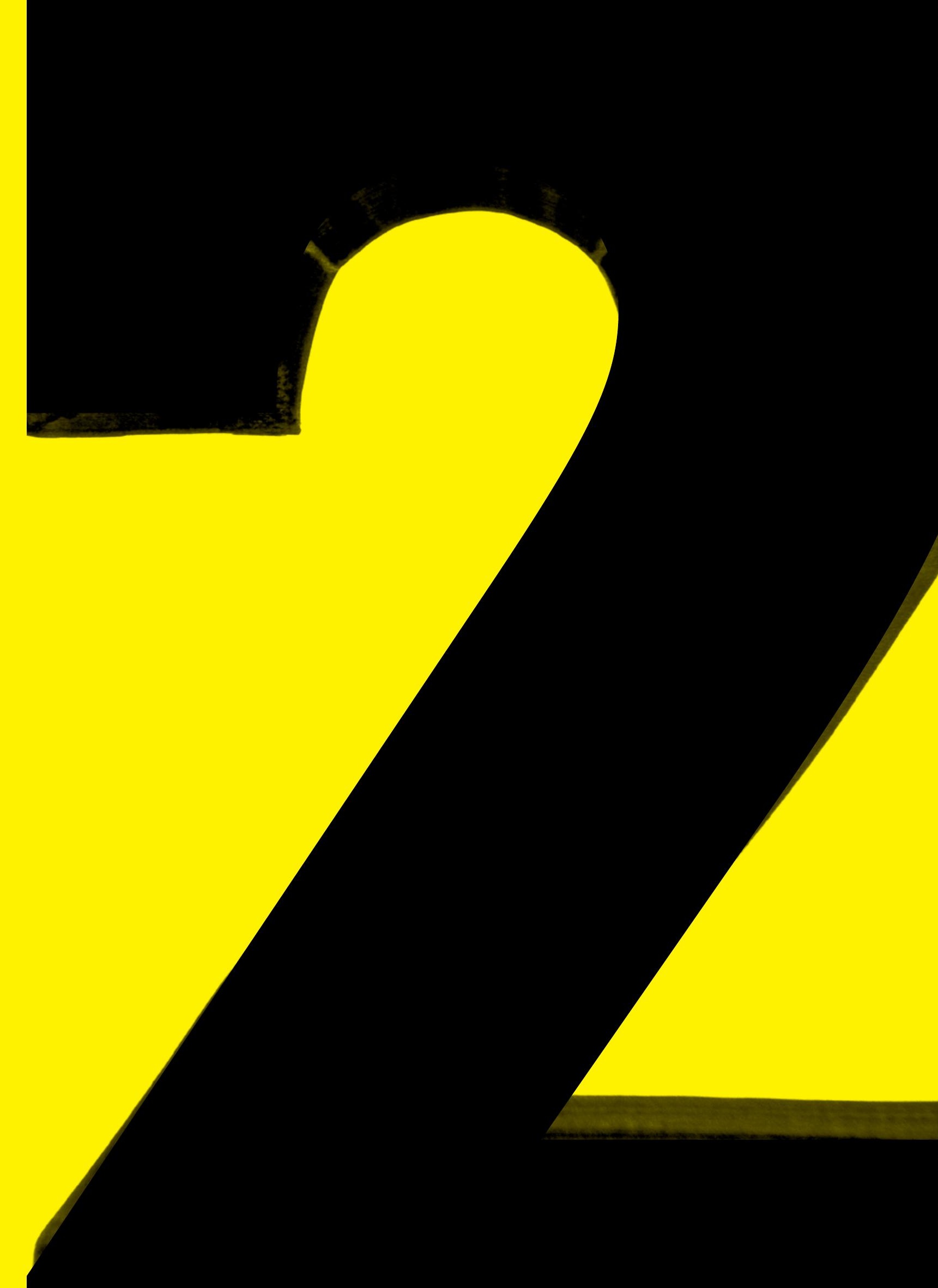




\section{Research approach}

Adopting a constructivist perspective

A qualitative research design

Following a struggle

Observing futurists

Interviewing futurists

Group discussions with futurists

Coding strategy
12 Examples include The Manufacture of Knowledge (KnorrCetina, 1981), Opening Pandora's Box (Gilbert and Mulkay, 1984), Art and Artifact in Laboratory Science (Lynch, 1985).
2.1 Adopting a constructivist perspective To study the process of professionalization selected futurists as example. As noted in Chapter 1, futurists have been and still are publicly struggling to professionalize both in terms of what becoming a profession means and in terms of getting there. Professionals are recurrently negotiating and renegotiating their position as they are continuously exposed to new insights, ideas and views.

Several authors have made a plea to reflect upon the practices of futurists from a constructivist perspective (for example: van der Staal and van Vught, 1987; Ester et al., 1997; Brown et al., 2000; Dammers, 2000; WRR, 2000; van der Meulen, 2002; Bell, 2003; Adam and Groves, 2007; van Asselt et al., 2010ab). This perspective is useful, as Ogilvy (1992) argued, because futurists stay away in their practice from positivistic efforts; they are not seeking to identify general laws. Futurists' work is not based on "firm foundations of accepted science" (cited from De Laat, 2000: 25). Futurists have been described to combine their creativity and imagination of not-yet existing scenario's with sound scientific knowledge (van Asselt et al., 2010b) In this thesis my aim is to describe, interpret and explain the professionalization of futurists, by examining their collective effort to establish what is a 'good" futurist and the individual efforts of getting there.

Fuller and Loogma (2009: 73) observed that futurists themselves are not necessarily aware of the constructivist nature of their practice: "A search for the term 'social constructivist' in existing futures literature, yields little result, whether via online databases or in the indexes of key texts." Additionally, in literature reviews I have also hardly encountered references of futurists that elaborate on their constructivist per- spective. With the exception of the publications of van Asselt et al. (2010ab), explicitly reflecting on the conceptual practice of futurists as they create, imagine, and construct images of the future. I did notice how other futurists did implicitly lean on this perspective, an observation shared by Fuller and Loogma (2009: 73): "constructionism, at least in its weak form, seems to be implicit in much of the epistemological assumptions underlying futures studies".

Constructivist scholars start from the assumption that there is no definite, fixed, 'truth' to be found in the examined phenomena. Rather, constructivists argue: "there is no unique 'real world' that preexists and is independent of human mental activity and human symbolic language" (Bruner, 1986: 95). They describe how "we invent concepts, models, and schemes to make sense of experience and, further, we continually test and modify these constructions in the light of new experience" (Schwandt, 1998: 237). Constructivists regard reality as the creation of the human minds. And in their perspective, reality is endlessly invented and re-invented.

One of the areas of interest of constructivists is science in the making. And specifically, how knowledge is produced. At the end of the seventies, science and technology scholars started to use ethnographic methods to study knowledge production in laboratories. For example, in their seminal book, Laboratory Life, authors Latour and Woolgar (1979) treated knowledge production of scientists in laboratories as a constructing activity. They questioned how scientists in laboratories made sense of a sea of complex data, and how they constructed facts, bearing in mind there were so many opportunities to alternative interpretations. As such, Latour and Woolgar demon- strated how scientists go about to actively construct facts. The study inspired many other scholars to raise similar questions on knowledge production. ${ }^{12}$

Max Weber argued that motivation and ideas were the forces behind change, instead of social structures and systems, which was the dominant stance amongst sociologists at the time. Weber argued that "ideas, values and beliefs had the power to bring about transformations" (cited in Giddens, 2009: 20). The actions that were taken, based on those ideas, values and beliefs, formed a complex entangled web of actions. Sociologists, guided by Weber's viewpoint, regarded it their duty to disentangle the web by establishing behavioral patterns and ascribe meaning to them. Constructivism is by no means a united perspective, rather "it is developing in parallel fashion in a number of disciplines" (Flick, 2014: 76). For example, sociology of professions scholars would not explicitly call their work constructivist, but have been inspired by the kindred scholarly perspective of symbolic interactionism.

Today, symbolic interactionism is a general label for scholars (mostly sociologists) that examine the "social interactions amongst individuals, rather than starting from society or its constituent social structures" (Giddens, 2009: 85). Blumer defined symbolic interactionism as a common set of symbols and understanding possessed by people in a group. Instead of emphasizing the importance of social structures (like functionalist would), interactionists focus on "micro-level interaction and the way in which meanings are constructed and transmitted" (Giddens, 2009: 85).

By directing the attention to the interactional leve instead of social structures, interactionist scholars 
opposed the then dominant scholarly perspective of functionalism. The functionalists had the goal to grasp how society functions as a whole. In doing so, they used the analogy of societal norms, institutions, traditions and customs as organs, each functioning to keep the 'body' (society) in motion. Famous functionalist scholars are August Comte and Talcott Parsons. The symbolic interactionists presented alternative views on how to understand the social world (MacDonald, 1995). For example, Ervin Goffman's dramaturgical metaphors (like front- and backstage) gained a lot of traction. With these metaphors, Goffman found ways to describe how individuals present "their selves" in social interaction (Giddens, 2009: 85).

Social constructivism leans on a similar interpretive philosophy as symbolic interactionism, but with an emphasis on the construction of knowledge and practices, rather than symbols in interactions. The constructivist perspective on science emphasizes how people and groups together construct reality. Interactionists and constructivists both counter "the "straightjacket" approach of functionalists who stress (..) that most interaction is fixed in advance" (Wallace \& Wolf, 2006: 199). Both interpretative perspectives concentrate on actions and interactions of people organizing their social worlds. Both perspectives agree that the interactions in that social world are in flux and ever-changing, not static and fixed like functionalists made it seem. Moreover, both interpretative perspectives are inclined to use qualitative research methods. Given the potential of constructivism and interactionism to unravel intricate social processe and ideas, I adopted an interpretive perspective to carry out qualitative research. Typically, qualitative research has the aim to "describe, interpret and explain social reality through the medium of language (as opposed to quantitative research, which aims to do so through the medium of mathematics)" (Beuving and de Vries, 2015: 19).

The research questions in this thesis have a constructivist character and ask for a design that is appropriate to address the complexity of professionalization (Flick, 2014). It is my aim to do justice to, and represent the rich, but ambiguous, social process of futurists' professionalization. Another reason why a qualitative perspective is suitable, is that it accommodates reflexivity. As I will detail below, my methods to gather relevant empirical data consisted of carrying out observations, doing interviews and organizing group discussions. Whereas, while doing the research, my presence (sometimes) influenced the topics of conversations and the actions that futurists took (for example, by asking me to organize group discussions). My reflections on actions, my impressions and my questions became "data in their own right" (Flick, 2014: 17). I further elaborate on this role and the data it yielded in Section 2.2 .

In order to address my research questions, ethnographic methods were used to study practitioners in action, also referred to as 'participant observation'. Daily doings and social interaction where examined by observing at meetings, the coffee machine, in elevators and corridors. Originally, ethnography was carried out by anthropologists to grasp 'exotic' cultures but their methods also proved to be valuable in other settings such as science or other institutions. Wodak (1996: 10) described how participant observation was carried out; "by observing an institution from the inside, by participating in meetings and other rituals or by following the insiders through their everyday life at work". These scholars have ques- tioned what is taken for granted, and thus reveal tacit knowledge and routine interactions. In this chapter I further describe my methodological choices in formed by the constructivist stance while elaborating on the qualitative research involving observations, interviews and group discussions.

\section{2}

A qualitative research design The design of this study is based on a qualitative approach for two reasons. The first being that a qualitative research design is dedicated to meaning making (Crouch \& McKenzie, 2006). In this thesis the qualitative approach is especially useful to trace how futurists make meaning of becoming a profession. Secondly, futurists are not organized in a specific manner. Their professionalization happens in indistinct and often de-institutionalized, settings. Qualitative methods enable me to grasp the subtilty of the professionalization of futurists in these settings.

In the research design, three basic aspects of qualitative research need to be considered; triangulation, reliability and validity. I summarize my elaboration of each of these aspects below.

\section{Triangulation of data and methods}

The term triangulation refers to the combination of different methodological and theoretical perspectives in researching a phenomenon. According to Lincoln and Guba (1985), triangulation is one of the main strategies to achieve credible results. I used this strategy to strengthen the quality of this qualitative research and to conduct it in an appropriate way (Flick, 2014). Denzin (1970) was the first to develop this notion. He examined, amongst others, data triangulation, which entails using several sources of data, for example, from different people or at different points 
in time. This prevents the analysis from being a snapshot of one situation. Denzin also studied methodological triangulation, which means combining different methods to reach an optimal result. In addition, I will use the notion of triangulation, to change perspectives, to interchange and connect qualitative research methods and to create a rich narrative.

\section{Reliability}

The issue of reliability questions whether simila results will be found when the research is repeated (Beuving and de Vries, 2015). Flick (2011: 483) argued that reliability ensues from a carefully documented research process. The procedures should be explicit to improve comparability. Reliability has been considered in designing the research for this thesis. The research process has been documented in a structural way that enables other researchers to access the empirical material. Possibly, researchers will find the interviews and group discussions helpful for further analyses. The data on participant observation may be less useful, since it consists of a large selection of personal notes. In the empirical chapters, the moments of interpretation are clearly delineated.

\section{Validity}

According to Flick (2011), the concern for validity boils down to the question whether the researchers se what they think they see. Kirk and Miller (1986, 29-30) distinguish three types of common errors regarding validity: a wrong interpretation of relationships (for example, there are none), the rejection of correct relationships, and a wrong question from the beginning. The formulation of these errors has been altered over the years, for example, by Mishler (1990), who was predominantly interested in the process of validity itself (instead of just recognizing the possible errors as mentioned above). Mishler argued that it is especially relevant to evaluate the trustworthiness of reported observations, interpretations, and generalizations.

\section{Methodological choices}

In this thesis, I aimed for triangulation of several qualitative methods, with the intention to grasp the subtleties of the professionalization of futurists. Moreover, in my methodological choices I have been mindful to reassure the reliability of the gathered information and to safeguard the validity my interpretations of the empirical material. The three research principles were guiding in the set-up of the research design. Instead of listing all methodological choices at once, I decided to designate those choices to the particular explanation of the observations, interviews and group discussions. All with the aim to provide answers to the following questions:

1. How do futurists identify with the existing notions of a profession?

2. Which actions do futurists take to professionalize?

3. Which notions of professionalization become

apparent in futurists efforts to professionalize?

Each question demanded empirical inquiry, but should also be theoretically evaluated through reviewing literature on futurists and professions. As such, during the course of this project, I conducted several literature reviews (including, but not limited, to bodies of knowledge in sociology of professions, reputation structures and science and technology studies). Some of these reviews are introduced in Chapter 1. In the empirical chapters, supplementary aspects of these reviews are given that helped addressing the research questions.
I was no stranger to futurists before I embarked on the study. I had some practical experience as a futuristin-training before I embarked on a job as teacher at Fontys Applied University, in which my job was to teach students how to become a futurist. I needed to fully comprehend the tools and methods futurists use to explain to my students how they could conduct insightful and robust research as futurists. This role and this affinity have impacted my role as a scholar.

I was not the only scholar experiencing this duality of being a practitioner versus a scholar. Van Asselt et al. (2010a) described similar tensions. Correspondingly, van Asselt et al. (2010a) were futurists before embarking on an ethnographic study. In this study, the authors questioned how they could deal with tacit or taken-for-granted methodological issues while actively practicing as a futurist. In performing ethnographic work, it is considered helpful if the researcher does not have too much connection with the subject beforehand. This helps the researcher uncover the latent understandings and agreements that the subjects will not articulate directly. Therefore, Asselt et al. (2010a) concluded that they had to refrain from being futurists to adopt a role of a scholar. They had to be insiders stepping out.

I did not 'step out' to the extent as van Asselt et al. (2010a) decided to do, but I did refrain from any type of activity that could be regarded as work done by a futurist-like providing keynotes or creating commercial reports. During the course of my research, did not withdraw from my duties as a teacher, given that teaching is regarded by futurists as a somewhat more 'neutral' activity than giving presentations. The response of futurists to my research role was welcoming; my roles as teacher and scholar were not 
regarded as direct competition. Next to my teaching responsibilities, I became co-founder and board member of the Dutch Future Society, an initiative to advance the professionalization of futurists. The aim of the newfound organization was so close to the topic of my thesis, that it was worth to endure any possible struggle of roles. During the fieldwork (during board meetings and at (in)formal conferences), I in troduced myself to futurists as a 'scholar researching futurists'.

My existing ties with (particularly) Dutch futurists granted me extensive access to the community. My endeavor was not easy for futurists to understand, but at the same time, the topics I addressed generated activity. I was lucky to witness an increasing movement of futurists wanting to discuss professionalization. Several initiatives gradually started to blossom between 2012 and 2017. Dutch examples of this in cluded Teach the Future and the Dutch Future Society. Some of the leaders of these movements were my direct colleagues and as such, provided me with direct access. I got to be part of this movement, and sometimes I was, without realizing it yet, acting as a catalyst for discussions on professionalization by reporting my preliminary results. It made futurists wonder and, on some occasions, it left them frustrated. At the very least, it raised their awareness and as a consequence, created a willingness to discuss their professionalization.

In practice, it proved challenging at times to keep the necessary distance as a researcher. Especially in in stances when futurists approached me for help to talk about their professionalization. For the futurists, this led to a growing consciousness in the making of their profession. But for me, taking on the scholarly role proved to be challenging at times. It became increasingly demanding to separate the futurist from the scholar. At times, it seemed as if two separate authors were working on the same thesis. But the benefit was worth the struggle, it was productive.

The struggle between my two roles as futurist and scholar is similar as those in action research (Dick, 2004). Futurists actively responded to the questions I posed and the reflections I offered, either on the spot or sometimes later by inviting me to be part of their networks or groups. At one instance, during the round of questions right after my presentation, a futurist publicly challenged one of my observations. During a presentation of my preliminary results, I told the audience that futurists had difficulty answering a specific question: who are founding fathers and mothers of the futurist profession? And I shared three examples of initial answers:

An established futurist: "You got me..."

A newcomer: - silence

A futurist familiar with the community: "Ehm..."

I also shared that when futurists got over their initial hesitation, they were doubtful about the precise moment futurists started to do this type of work. For example, an academically oriented futurist clarifies:

This is a difficult question because thinking about the future belongs to the human being in general; so, the question is when did it become a profession? I find it difficult to pinpoint a specific moment, area, locus.

After I had finished my presentation, a well-known futurist was struck by my claim that futurists were unsure about their historical roots. The futurists replied in front of a room full of peers that I had probably interviewed the wrong futurists. What followed was an intense conversation, which took me aback. Was I asking the right questions, if this futurist could not acknowledge my preliminary outcomes? The nex day this particular futurist gave a presentation herself, which I attended. During that presentation the futurist actually referred to our discussion and that it had made her think about a new initiative: an online library for futurists. So that, if another scholar was to ask this question again, futurists could answer it So, while the duality of my roles interfered with the unfolding of events, it also was helpful in articulating what futurists unconsciously considered important in their professionalization: to know their history.

Another challenging fight between my roles as scholar and futurist, transpired in my role as co-founder of the Dutch Future Society from 2013 onwards. This initiative aimed to be the home of futurists. In the years thereafter, we organized several events and set up a community website. Over time, more futurists found the organization and started to take part in the meetings. During my time as a board member, was constantly interchanging my role as a participating board-member (referred to as a futurist) and as a scholar. In early 2017, after years on the board, I decided to step down to fully commit to my scholarly role.

The struggle between roles became particularly apparent when I started to write separate chapters. It required my full attention to separate my insider's knowledge from the reflective stance I had to take to contribute on an academic level. As such, I had to always remain aware of my tacit knowledge that could potentially, or rather inadvertently, influence the research. 
Nonetheless, this struggle was worthwhile, because it also generated a huge benefit: access to futurists' practices. My presence in the community was recognized. Futurists regarded me as an ally and trusted my intentions. As an example: from an early poin onwards, I wanted to share my preliminary finding with futurists. I went to their conferences and on many occasions was given a slot to present, and I eagerly accepted those opportunities. I shared insights from my first series of interviews, asked the attendee questions and explored what happened to them while hearing my reflections. This was an intimidating task at times, because my presentations resonated and could influence the direction of my research. Taken together, by continuously engaging with futurists, it was not only possible to contribute to the academic understanding of professionalization, but also to (in)directly advance the conversation of futurists on their professionalization.

Following a struggle

In this $\mathrm{PhD}$ thesis I regard the struggle of professionalization as a social phenomenon (Giddens, 2009). I commenced the fieldwork by attending conferences where futurists gathered to discuss professionalization (see Paragraph 2.4). Here, I noticed an active forefront of practitioners that deeply cared about this topic. At first, it was hard to demarcate these active futurists as a specific group. I learned that not just academics, or solely commercial oriented futurists, or merely governmental employees participated in the conversation. At each conference I encountered a different mix of futurists. I witnessed academics sharing their research. I saw commercially oriented futurist presenting their imaginative stories. I observed creatives searching how they could use futures methods in their design practice. I noticed how employees of planning agency's found inspiration for their reports. And I saw soloist employees of bigger companies find a sense of community. There was no conference I attended that just included one of the respective communities; the struggle of professionalization was not bound to one specific grouping.

Yet, as I attended more conferences I started to discern a few futurists that were doing more than others. Those futurists not only chaired organizations and organized conferences, they were active inciters of conversations with vocal contributions and eagerness to give meaning to their collective work. I decided to first interview them, as they could introduce me to the topic of professionalization and help me find my way (see Paragraph 2.5). As a rule, the interviewees preferred to speak anonymously as their professionalization was not (yet) a topic they wanted to publicly take a stance in. They experienced a public position on professionalization as a struggle in its own right.

After attending several conferences and interviewing dozens of futurists, a leader in the professionalization discussion asked me to organize a group discussion together. She was fascinated by my questions and observations and suggested to facilitate in-depth conversations in her office. This was a methodological 'present' as I was in the midst of exploring how best to proceed studying social processes of professionalization. The conversation resulted in a series of group discussions and this inspired other Dutch futurists to approach me with the same question and to explore the issue with their communities.

The selection of futurists I interviewed was thus based on their visibility in the community and their contribution to the discussions around professional- ization. Of course, there are also futurists who do no feel the urgency to spend their time on professionalization discussions. I learned that not every professional working with the future wished to actively discuss professionalization to the same degree. Some futurists participated in conferences but did not wish to be part of interviews or group discussions. For example, during the fieldwork, I met several futurists that worked at Dutch planning agencies, like Netherlands Environmental Assessment Agency (PBL), the National Institute for Public Health and the Environment (RIVM), and the Netherlands Institute for Social Research (SCP). Especially RIVM was noticeable active on future studies at the time, as they published a large-scale study on the future of public health every four years. In 2016, RIVM even dubbed 2016 the 'year of the future', hosting several future-minded events for colleagues, policy makers and futurists. ${ }^{13}$ Initially, encouraged by the interest of several futurists to host group discussions, I aimed to also organize a session for futurists at Dutch planning agencies. I started to work on this idea with an interested contact person via the National Institute for Public Health and the Environment (RIVM) as they were vocally present that year. However, this proved to be more difficult than we anticipated. For the futurists at planning agencies there was, at the time, no similar urgency to get together and discuss professionalization like other futurists had expressed. The group discussions were cancelled.

In the next three paragraphs I detail the fieldwork carried out to study how futurists struggle to professionalize. The fieldwork is described in chronologica order, starting with observations, leading to interviews with vocal futurists and concluding with group discussions. 
Earlier studies on knowledge production of futurists were carried out in predominantly institutional settings (van 't Klooster, 2008; van Asselt et al. 2010b; Kunseler, 2017). However, in this case, it was not possible to simply 'follow the futurist' (inspired by Latour and Woolgar's Laboratory studies). Observing the professionalization discussions by futurists needed a different approach since they were not embedded in specific organizations or organized in a particular way. Hence, I decided to observe futurist during the 'formal' moments in which they gathered as a community: during their conferences.

In this thesis I choose to observe at so-called "ethnographic moments" (van Asselt et al., 2010a: 16), which consisted of a series of moments of observation, spread over a specific course of time, between 2012 and 2017. I attended any conference that had connection with the professionalization of futurists. The advantage of these moments, instead of a fixed and hence shorter period of full-time observation, was that I could be open to unexpected conferences that may or may not be relevant over a longer period of time, between 2012 and 2017. It helped me to grasp the diversity of the community of futurists. I attended lectures, academic and commercial conferences and (in)formal meetups. In each of these settings, the futurists were specifically intending to discuss professionalization.

I quickly decided that conferences would be the starting point of the observations. From the outset, a divide between commercial and academic oriented conferences was observable. The logical next step was to start at conferences that represented these two settings. The first conference that came to the attention was the bi-annual World Futures Studies Federation (from now on: WFSF), gathering in Bucharest in the spring of 2013. WFSF has an active email list that updates futurists from around the world. The conversations in the mailing had a scholarly approach with a focus on methods and exchange of knowledge. When WFSF announced this conference, the organizers set up a call to submit abstracts and after confirmation, the authors where requested to write papers to present at the conference. Professionalization was among the themes, and therefore my abstract was eligible to be selected.

Around the same time, European futurists announced in early 2013 that they were organizing LaFutura in Amsterdam. Earlier editions were held in Berlin (2010), New York (2011) and Helsinki (2012).

The participants flew in from all over Europe and even from Singapore and the US. The theme of the event was 'NOW NEW NEXT: Building the future industry'. The organizers stated that a good overview of the broadness and the depth of this new industry is lacking and asked: which methods are being used? How can futurists work together to be of value for prospective clients? These questions caught my attention. They illustrated how futurists were actively discussing their professionalization.

These two conferences were a fruitful start and since then I followed the attending futurists, which events they were attending next and trying to find out where I had to be (if time and resources permitted). I visited as many relevant conferences as possible to observe the community of futurists. Between 2012 and 2017, I attended 50 (in)formal conferences. The full list is added to Appendix A.

At many events, I was asked to present some findings of my research. On some occasions, I returned year after year to give presentations at succeeding conferences. The futurists I encountered were eager to hear about my research. It was often the first time they were confronted with a scholarly reflection on their practice and more specifically, their professionalization efforts.

I initially visited the conferences to observe futurists and interact with them on the reflections that I offered. A precondition for attending the conferences was that professionalization had to be a theme during the events. During the conferences I made notes of the discussions, paraphrasing anything that stood out in relation to the professionalization of futurists. For example, I noted the topics that were on the agenda the words futurists used, the hierarchy futurists implicitly acknowledged. In addition to the notes, I also took photographs that have been used as illustrations in each of the chapters; the collection of images can be found inside the book jacket.

The observations were useful to get acquainted with various futurists and get an impression of the professionalization themes and topics that they wanted to contemplate. The observations were also helpful in identifying the futurists that were vocal in the conversations on professionalization.

\section{5}

Interviewing futurists

The interviews were held because the futurists only allocated limited time to discuss professionalization during their conferences. It required more thorough conversations to understand exactly how futurists were professionalizing and at conferences it was not always possible to fully articulate the tensions, struggles and doubts that futurists experience. For those reasons, I decided to start a series of interviews with international futurists. 
The three research questions ask for an international orientation as I observed that futurists at conferences were not restricted by geographical borders. As such, the interviews were held with futurists from around the world. These futurists were founding fathers, icons and prize-winners, as well as newcomers. My aim with these conversations was to gain a richer understanding of the actions taken by futurists to professionalize. The ideas, values, physical realities and mechanisms that futurists recognize could give me insight into the reality as experienced by the futurist (Klostermann, 2003).

The scope of this interview series had to be international from the outset, as futurists operate in an in ternational context. For example, the email list from the World Futures Studies Federation contains hundreds of active members from the US, Europe, Russia, Africa, Asia, Australia and the Middle East.

As I shortly described in the previous paragraph, the futurists to be interviewed were not a random sample. Becker states (1963: 46) that "it would not be possible to draw a random sample, since no one knows the nature of the universe from which it would have to be drawn." The entire population of futurists has not been identified to date. Therefore, the sample of futurists is not intended to be representative of the full population of futurists. Although representation of a whole population was not my aim, the question remained who I should interview to gather the information in a reliable and valid manner.

As soon as I started to get familiar with the community of futurists, I started the selection of possible interviewees. During the ethnographic moments, I was attentive of the research principle of reliability.
Research procedures should be explicit to improve comparability. I questioned: who was I going to select? And why? The selection of futurists initially focused on finding 'leaders' (not necessarily in hierarchical terms but in active participation in the professionalization discussion) within the community. I quickly identified the futurists that were vocal about professionalization issues, and decided I would be most helpful to start the interview series with them. This is referred to as "purposive sampling" (Flick, 2014: 175). For this first selection, I was primarily interested in futurists that were vocal in professionalization issues, had international focus and a willingness to discuss professionalization with me. The aim of this first sample of interviewees was also to identify which futurists should be next on my list. I concluded each interview with the question who else would be eligible to talk about professionalization. This is referred to as "snowball sampling" (Flick, 2014: 234). Two separate locations were eligible as a starting point: LaFutura in Amsterdam in 2013 and the WFSF conference in Bucharest in 2013.

The first group of interviewees proposed futurists they thought were relevant to include. Based on these recommendations, I created a list with possible interviewees. It was not possible to speak to all of the proposed futurists. As selection criteria, I considered the diversity of the respondents in terms of gender, geographical location and their respective roles in the professionalization debate. The distinction of roles was made in the context of the professionalization discussion. At the conferences, it was easy to detect the futurists with an established role, they were outspoken and listened to. However, when entering a group, one should not just listen to the leaders but also to the rest of the community. I demarcated three roles of futurists, 'established', 'familiar with community' and 'newcomers'. I referred to the futurists that were at the center of the debate as 'established'. For example, because other futurists acknowledged the arguments of these futurists. There were many futurists that took on the mid-level 'familiar with community' role, they were familiar with the discussion and contributed from time to time. The 'newcomers' were futurists that offered new perspectives and different ideas, often because of age (fresh out of college) or experience (coming from other disciplines or worlds). See Appendix B for the detailed list of the interviewed futurists.

Each of the interviews was conducted in confidentiality because the topic of professionalization was regarded by most respondents as delicate. The in terviewed futurists hesitated about publicly speaking out about professionalization as this could affect their reputation. In addition, many interviewees agreed to have a conversation as an opportunity to fully explore and express their thoughts without having to watch their words. The agreed confidentiality gave me the opportunity to probe their thoughts on the matter. The quotations in the empirical chapters are anonymized, but I do provide as much context as possible. With these conditions, all interviewees allowed me to include their name in a general overview.

Before selecting the first interviewees, I conducted two trial interviews with two Dutch futurists. The trial interviews helped me estimate how the futurists could respond to the questions. It also helped me to estimate how much time it would take to ask the questions. As a preparation, I conducted the trial interviews to discover anything unexpected. 
Based on these two interviews, I slightly altered the questions in the interview guide (see Appendix C).

After seven interviews, including the trial interviews,

I reflected with my supervisor on my interview style and to decide if any alterations where necessary.

At first, I did not send the topic list to the futurists beforehand. But during those interviews, I noticed that this made some of the respondents uncomfortable and insecure. The respondents said that the questions were rather different than they had expected and that they did not know how to answer to the questions. Therefore, in the next rounds, I sent the topic list beforehand to each of the respondents. Some futurists did not look at it, while others, thoroughly prepared their answers. In some cases, some interviewees prepared so much, that it was hard to improvise with them or get them to switch topics.

Over the course of 3 years, I conducted 33 interviews. The selection of those futurists was based on my selection criteria and their availability. This process was repeated until I collected sufficient data. I conducted the interviews in several phases of the research project between 2013 and 2016. I did not determine in advance how many futurists should be interviewed. Instead, I decided that had to depend on how much 'new' information I would hear. After around 25 in terviews, I started to see patterns in the answers. After

33 interviews, I decided that I had gathered enough data. An overview of the interviewed futurists:

\section{Gender}

17 Males | 16 Females

\section{The roles of futurists}

11 established futurists

13 futurists familiar with the community

9 newcomer futurists

\section{Geographical location}

5 FROM THE UNITED STATES

New York

Texas

California

16 FROM EUROPE

Netherlands

Germany

Finland

Austria

Denmark

Romania

Spain

Sweden

France

6 FROM ASIA

Singapore

Taiwan

6 FROM AUSTRALIA \& NEW ZEALAND

Australia

New Zealand 


\section{Content of interviews}

The topic list with questions for the futurists was open but informed. The full interview guide is added to Appendix C. I formulated the questions inspired by the literature review of the sociology of professions. In so doing, I defined four main themes (history, a futurist, the community and context of knowledge) and accompanying questions that had to be part of the conversation. This scholarly informed approach enabled me to examine how futurists relate to classic notions of professionalization. The interviews were semi-structured, and I not only prepared for a question and answer conversation, but also made sure to hold the space for unexpected themes, to enable myself to look further than the obvious. I asked the questions when the moment was appropriate; for example, often futurists started to discuss differences with others after the first question on how futurists introduced themselves to others. I often took this moment to further explore their thoughts on this topic. As the series of interviews started to evolve, allowed myself to experiment with the sequence.

The first question of the topic list produced yielded more insight than expected on beforehand, I asked, what does your business card say? The futurists immediately knew what to say. This question created space for futurists to talk about their professiona identity. Futurists mentioned many different job titles like professor, researcher or strategist. Unintentionally, it also evoked other useful insights on why futurists do what they do and how they situate themselves compared to other futurists. This question also opened up conversations on differences among futurists, or types of futurists and their roles. Next, I highlight three short samples of the varying answers that were given to me by futurists.
Each of the futurists below brought up the common job title 'futurist' and how they relate to it.

An established futurist: "I wave that flag, but putting this on a business card is awkward." A newcomer futurist: "I am named like that by others, but I do not call myself a futurist."

An established futurist: "I am not good enough to call myself a futurist."

In Chapter 4, I elaborate more on the insights derived from what the futurists told me. The style of interviewing, including audio recording and transcriptions, rendered a sizeable set of data. Before the interview, I asked the futurists if I was allowed to make audio recordings to be able to make transcripts afterwards. In every case, this was allowed.

After around 10 interviews, and a thorough evaluation of the initial results with my supervisors, I had mastered a looser interview style, which provided me with more valuable insights. This became especially visible in one of the most difficult interviews I conducted. A futurist had the tendency to dominate the conversation by questioning everything I asked. Initially, I was a bit confused and discouraged by this response, but then I started noticing how valuable this conversation was. By neutralizing my own role to the minimum, I could take the time to immerse in the perspective of this futurist.

by Dutch futurists to take their discussion of professionalization to a new level. Inspired by my presentations with preliminary results of my $\mathrm{PhD}$ research at $\mathrm{La}$ Futura and the Dutch Future Society, Hilde Roothart (the chair of the Trendnetwork) asked whether I wanted to facilitate discussion at her futurist network. Together we decided to initiate group-level discussions. Subsequently, encouraged by futurists that had participated in the first group discussions, Vincent Marchau (chair Netwerk Toekomst Verkenningen) invited me to host another group discussion at his futurist network.

This unexpected but welcome extra layer of my data collection led me to research the value of group discussions. These group discussions could potentially add depth to the observations at conferences and the interviews. Blumer (1969:41) described the value as follows:

"A small number of individuals, brought together as a discussion or resource group, is more valuable (..) than any representative sample. Such a group, (..), will do more to lift the veils covering the sphere of life than any other device that I know of.

In the research design of group discussions, an important element is group dynamics. According to Flick (2014: 244), group discussions correspond to the way in which opinions are produced, expressed, and exchanged in everyday life. This third methodological perspective to grasp professionalization of futurists was a true present; it helped me deepen the topics and themes that I had not been able to address in the interviews or observations. This was optima triangulation. The three research methods produced different results but corresponded and enabled me to deepen my understanding.

The goals of the group discussions were to share knowledge and practical experiences and to discuss professionalization. The questions I asked in the group 
sessions were the same as the questions I asked the individual futurists. I expected that sticking with the same topic guide would provide me with richer insight into how futurists describe their professionalization.

At conferences I had been quite visible because I often presented my preliminary results. In the group discussions, I gradually changed my approach. In this setting I needed to direct the participants' focus on their own peers instead of me, the scholar. In agreement with the futurists with whom I organized the session, we asked selected participants to present their own work. After the short presentations (usually we aimed for three futurists to share their work), the participants sat together in an informal setting to discuss questions on why they are active in the futures industry, what they produce, and how they characterize their work.

In the interviews, I asked futurists to elaborate on thei professional dynamics, but I noticed that this was not easy for them to articulate. Interviews can only partly, or even hardly, unveil social norms that exist among futurists. Pollock (1955) argued that isolation from context should be prevented. To that end, group discussions proved to be an interesting addition to the series of interviews. For example, in asking the question about the community and who the people are around them, I started to notice that futurists often did not refer to others as futurists but rather as experts in a functional area (for example, as a technology expert or graphic designer). The group discussions helped to study on the nuances of these types of distinctions.

\section{Locations of group discussions}

The locations were chosen by the involved futurists. At the trend network event, it was the Amsterdambased office of Hilde Roothart, the founder of the network. The office had an artistic feel to it and had already served as a meeting place for futurists. The group discussion of NTV was conducted at their office location in the center of The Hague. This was also the location where all of the previous gatherings of this organization occurred.

\section{Participants}

The number of participants differed between the groups. At the four trend network gatherings, 10-12 people showed up each time. Hilde Roothart invited her network via an email and paid careful attention to the RSVPs and the actual attendance. At every meeting, she told the group which futurists had cancelled last minute, which gave the participants an extra incentive to show up next time. The group discussion at NTV was different; the group was large, with around 25 futurists attending. We divided them into five groups after the first part was over. The participants in the group discussions were already quite familiar with one another (with the exception of the student assistants that I brought to help make notes). These NTV futurists only gathered occasionally, but they had strong professional ties and communicated often.

The role of the moderator was connected to the setting. Commonly, at each group discussion there was a non-directive style. At the Trendnetwork sessions, the moderation tasks were performed by Hilde Roothart. She guided the participants through the program but also gave space to let the group dynamics evolve. The larger group of NTV did not allow for this flexibility and the moderation had to be more formal. I was asked to do the moderation of the larger group, while the organizers assisted me with the smaller groups.

\section{Preparation of group discussions}

In advance, the organizer and I discussed which themes could be relevant. After that, I decided which questions from my interview guide would best fit that particular theme. As a result, I created an observation list. This was a list of questions I would ask during the group discussion. Next, I shared the questions with the organizing futurist. The organizer had the final say on the questions. At some occasions, the organizer asked me to withdraw one of the questions that I proposed. For example, at one group discussion I wanted to ask the same question as at the previous discussion because I thought it was not discussed thoroughly enough. The organizer asked me to remove it because otherwise the participants would notice the duplicity with the previous event, and, in the organizer's words, "might get bored". Also, beforehand the organizer decided which words I should and should not use. For example, at once instance, the word 'trend' had to be removed from an invitation to attend a group discussion because the participants would probably not identify with this word. Instead, I was told, it would be better if I used the word 'future' as the community preferred a more scientific perspective.

To record the group discussions, I brought a student assistant. To be sure that I could use the notes afterwards, I asked a motivated student to take detailed notes of the conversations with the observation list as guide. I also took as many notes as possible. At the start of each group discussion, I introduced myself and the student to the group. We deliberately took seats at opposing sides of the space. We also arranged that if the group would split up, we would both sit at different groups to take notes.

To organize the data in advance, I drew up an observation list with key topics. The student and I both 
had this hardcopy list with us. We observed how the participants responded to the lectures and what type of topics they wanted to discuss. We took general notes of the interactions and were specifically focused on any references to the topics on the observation lists. During the lectures and interactive sessions, did not bring up new topics, but did ask clarifying questions. After the session, I wrote a short overview of the lectures and the interactive discussions. These overviews were not anonymous, because it would otherwise be too inaccessible for the participants. Next to the value for scientific purposes, these transcriptions of the conversations also proved valuable to the participants. In particular, the discussion benefitted from the documentation, as it allowed futurists to follow up on previous conversations. The transcriptions unintentionally gave the participants tools to keep talking with each other about professionalization.

\section{Before the session}

Before starting the group discussion, I told the participants that I was going to observe the session and audio record the conversations. I asked if anyone objected to being recorded; nobody did. Moreover, told the participants that I would only use the materials for the data collection of my $\mathrm{PhD}$ thesis and that the results would be treated anonymously.

\section{During the session}

Every session was divided into two parts: first, the presentations of futurists; second, discussions in groups. Each presentation took about 20 minutes. The organizer preferably selected the presenting members. For example, at NTV, the organizer proposed a few names (representatives of universities and consultants) and I was asked to arrange their participation. At the Trend- network, all members of the community were asked to apply to be part of one of the four sessions. They had the opportunity to choose the theme they felt most affiliated with. Each of the sessions had a general theme, which was decided upon with the organizers. For example, at NTV, the theme was the 'future of the future professional'. At the Trendnetwork, the sessions were centered around questions like 'why are you active in the futures industry?'. Or 'how do you work?'. After every lecture, we allocated time for questions and discussions. We gave a small break before we started with the interactive conversation. In Appendix D background information on the group discussions can be found. For example, which main questions were raised and who were the presenting futurists.

After the presentations, we asked the participants to sit in groups of 5 to 10 . To guide the participants, we prepared several questions, which were based on the combination of the general themes and the interview guide with questions asked to international futurists. At every session, the questions had been specifically prepared for the audience.

Coding strategy

To support a reliable and valid analysis from the data collected by a triangulated approach, it was important to structure the derived data with a solid coding strategy. The analysis was based on a thematic coding strategy. Braun and Clarke (2006: 79) describe this strategy as:

"a method for identifying, analysing and reporting patterns (themes) within data. It minimally organizes and describes your data set in (rich) detail. However, frequently it goes further than this, and interprets various aspects of the research topic."
The limitations are that this approach does not provide enough body for 'over-complex' aims, like developing a theory. Flick (2014) states that this type of coding strategy is straightforward and, in a sense, basic. ${ }^{14}$

I conducted the analysis using ATLAS.ti. After transcribing the interviews, group discussions and observations, I gathered the texts in one analysis unit. In total, I analyzed 696 quotations, created 15 codes and drafted 17 memos. I coded all the transcripts based on the interview guide. In the overview below, I show the specific themes with the accompanying codes.

To be able to identify whether there had been any blind spots, and to trust the "factual accuracy" (Maxwell, 1992: 285) of my coding, I asked another student assistant to simultaneously code 5 interviews with the coding scheme. Subsequently, we evaluated the coding and anything else that stood out. The evaluation did not lead to any significant changes in the coding process. It did help me to oversee the coding process and how I could streamline the codes. For example, after reflecting on the conversation with the assistant, I got rid of a few unnecessary codes. A few other codes were part of the analysis, but were not included in the final version of the coding scheme. An example is the search for a code on how futurist relate to their community. The initial code [community] could not cover all the quotations. I realized this during one the group discussions when a participant described that she was surrounded by several circles of professionals. Each of the circles represented a with different relation to the futurist, for example their clients, or co-workers from other disciplines (like designers, marketers) and futurists articulated circle of people they do not necessarily work with, but find inspirational. 


\section{Coding scheme}

\section{Main clusters}

\section{Profession (traits)}

$\rightarrow$ based on traditional assumptions

of what a profession is.

- [ways of organizing]

- [job title]

- [qualifications]

- [license to operate]

Professionalization (process)

$\rightarrow$ based on the activity to set boundaries of the profession. Doing it in real life.

- [types of futurists]

- [bad practices]

- [good practices]

- [professional identity]

- [circles of colleagues / peers / clients / experts]

\section{Knowledge}

$\rightarrow$ based on the account on what

knowledge means to the futurists.

- [transferring knowledge]

- [knowledge basis]

- [autonomy]

\section{Explanation of codes}

Each of the clusters contains four or five codes that relate to the content relevant for the analysis.

\section{Cluster profession}

- The code [ways of organizing] refers to any quotations on how futurists communicate and get together, both from a historical and present perspective.

- The code [job title] refers to the specific way the respondents refer to their job and the name(s) that suit their practice. During the interview, this question evoked conversations on several topics on identity.

- The code [qualifications] refers to any mentioning of the traits a futurist needs in practice.

- The code [license to operate] contains references to the explanation of the instance practitioners can call themselves futurists. In addition, it includes references to the broader group of futurists and their credibility.

\section{Cluster professionalization}

- The first code of the second cluster [types of futurists] refers to 'others' in the field, explaining their ways of working. This code also includes references to differences among futurists.

- The codes [bad practices] and [good practices] are regarded as interlinked. They respectively contain the references to bad practices and the ways in which futurists refer to how work should be done, for example, what is good work? During the analysis of the data, it became clear that this category is very close to the [qualifications] code. The difference between the codes is that [good practice] is the active verb (i.e., at any moment futurists are doing it and talking about it). The code [qualifications] is more static in that it depicts what futurists expect in another futurist. If the futurist is doing something and believes this is the right way of doing it, it is a [good practice] code. If the futurist describes that a futurist should be intuitive, it is a [qualifications] code.

- The code [professional identity] contains the instances when a respondent talked about elements that affect futurists' professional identity. What does the respondent think about what make the professional, which activities futurists undertake to professionalize (boundary work) and in which contexts (and with whom) do they do this?

- The last code [circles] was added after group discussions. In the topic list for the interviews and group discussions, futurists often mentioned the people around them (not specifically futurists). In one group discussion, futurists referred to others as 'circles' of professionals, each with different significance for their work. Hence, this code was added to do justice to the people around futurists.

\section{Cluster knowledg}

The first code of the third and last cluster [transferring knowledge] was also added as a question to the topic list: How do you transfer your knowledge to others? This code refers to all the mentions of how knowledge is brought to a specific/relevant audience.

- The second code in this cluster [knowledge basis] consists of the references to common knowledge, tacit knowledge and professional knowledge of futurists' practices. Which knowledge is needed to do the work?

- The third code [autonomy] refers to instances when futurists mention the originality of their practice and the originality of their knowledge. 
My interpretative perspective led me to interview, observe, and let futurists discuss how they professionbse. In this thesis I did not ain to construct an alstruct an allencompassing narrative of how futurists professionalize. What I do offer is an account of what I have observed during futurist conferences, what I have been told by futurists individually and in group discussions and how I saw them interacting. In the next chapters, I have made an effort to give a comprehensive report of my findings and hope to inspire discussion what this could say about professionalization in general.

The chapters are the result of a long puzzle. A story never unfolds in a linear way, I had to use my interpretive perspective, my methodological research design and all analytical tools available to make sense of the large collection of data I had gathered over the years. Early on in this research, I observed futurists diversity in every professionalization aspect thinkable. This initially caused doubt, I was not even sure if it was going to be possible to characterize the professionalization of futurists. But over the course of the years, patterns started to become visible, and it was possible to deepen the layers, to do justice to the professionalization of futurists and to be able to draw more generic lessons that may be relevant for other professions that are in a similar situation.

In the following empirical chapters I question how, futurists identify with existing notions of a profession (Chapter 3), I examine the actions that futurist take to professionalize (Chapter 4), and study which notions of professionalization become apparent in futurists efforts to professionalize (Chapter 5 and 6). 


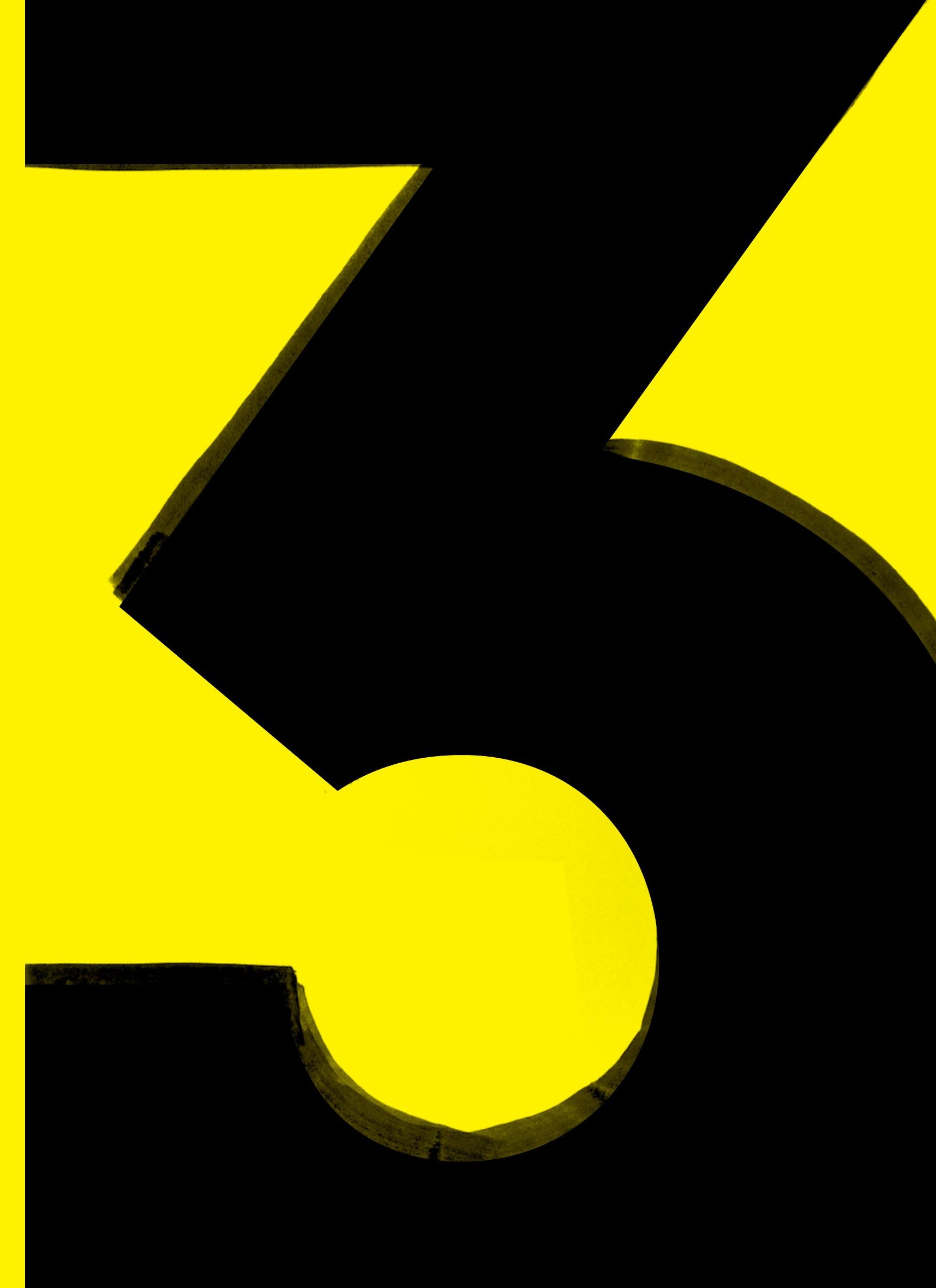




\section{Futurists and the struggle for professionalization}

Introduction

Urgency of professionalization Attempts to grow as a profession

Demarcation issues

Struggle for common ground

The professionalization quest

The traits perspective on professions

Conclusions: beyond traits
15 Futurist Hines writes on his personal website (posted on 12 July 2013): "It has been great to see a surge of interest in the topic of professionalizing foresight. To be clear, it is still in what we might call the exploratory phase. But the issue is being raised and discussed in a variety of forums, papers, and grou
(retrieved on 3 October 2017 from www.andyhinesight.com).
3.1

Introduction

How should a futurist behave? What is a proper futurist? What are the norms in producing knowledge about the future? These questions are frequently raised by futurists when they discuss their professionalization. They foster these questions in written accounts, at conferences they organize, and during discussions amongst themselves.

In this chapter I explore their questions, their answers, but also in particular, their difficulties while answering these questions. Let us, for the sake of the argument, start with Andy Hines, a vocal futurist in discussing professionalization. On his website, Hine (2013) points out that there is a surge of interest and that the issue of professionalization is raised on severa platforms. ${ }^{15}$ Hines adds that the discussion is in an exploratory phase. Marien (2002) argued to raise awareness among futurists about the importance of selfreflection. He claims that "in a complex society of aging individuals and shifting work roles, where the notion of the 'self is up for grabs, it makes increasing sense to recruit non-futurists to become secondary futurists, and to offer attractive opportunities where they could become primary futurists" (cited from Marien, 2002: 279). Marien points out that whilst a growing number of practitioners are entering the field, futurists plea for more clarity about demarcating their field.

Regarding basic premises, futurists seem to agree. For example, most futurists share the premise that futurists guide others to help understand that there is not one "single, predictable, fixed future" (Gidley, 2017: 2). Instead, futurists anticipate a multitude of possible futures and provide tools to imagine and create possible, plausible or preferred futures. As such, they broaden the expectations of the future for anyone who is open to it. In spite of this the common understanding about their service to society, the question of how futurists ought to professionalize elicits lively debates. To be able to unravel these conversations, I question: how do futurists identify with the existing notions of a profession?

My analysis is based on futurists' discussions in journals and on my observations during conferences I attended. I analyzed the topics futurists frequently addressed in their debates. I clustered these topics into main themes: 1. educational training, 2. the possibility of creating quality standards, 3 . diversity of practitioners and 4 . how futurists should organize their community. For each theme, I examined what futurists stated and how they reflected upon the professionalization issues they identify. Next, I reflect upon the way in which futurists discuss their professionalization from the theoretical perspective of the sociology of professions. This theory provides an analytical framework that is helpful in contextualizing the professionalization discussions among futurists. Finally, I draw conclusions on how the struggle of futurists to professionalize can be understood, and what this means in view of the central question raised in this thesis.

From the moment I set foot in the future industry in the Netherlands after graduating in 2009, I noticed how futurists felt the urgency to advance their profession. For example, futurists complained to me about the limited resources available to build an educational curriculum to research trends and the future. But I also observed how they took action by setting up the Trendrede (literal translation: trend address), a yearly Dutch conference to present the main trends in society. The collective of trend researchers that joined forces decided to give something to society: their knowledge. Around the same time, another group of Dutch futurists expressed the need for a new organization to channel the diversity of voices in a more organized manner. This latter initiative resulted in the Dutch Future Society; whose aim was to create a home for all futurists. The organization flourished and still exists today.

Engaging in dialogue with the client, mapping out the process and evaluating afterwards. Developing a joint vocabulary. That should also be an international goal. More cooperation within the future industry. That is why we organize this kind of sessions. Think about roles that futurists take on. Futurists are good at certain things and futurists have to think about doing the right things and what is missing. In this way, futurists can separate the wheat from the chaff. Futurists stay alert with regard to the products that are made and the service that is delivered. That enables futurists to, for example, develop quality guidelines.

This is a stylized transcript I wrote of a conversation during a group discussion between futurists (which took place on September 10, 2015). This conversation took place at the end of the session (after 2 hours of talking), and was an answer to the question how futurists find ways to connect their products with the demand of clients. The transcript tellingly illustrates how futurists formulated their hope in advancing the profession.

Over time, I became aware that professionalization was also an issue elsewhere. Also, in Germany,

Belgium, Finland, the US and Taiwan, futurists sparked conversations about the future of the profession. They did this online, in mailing lists of international 


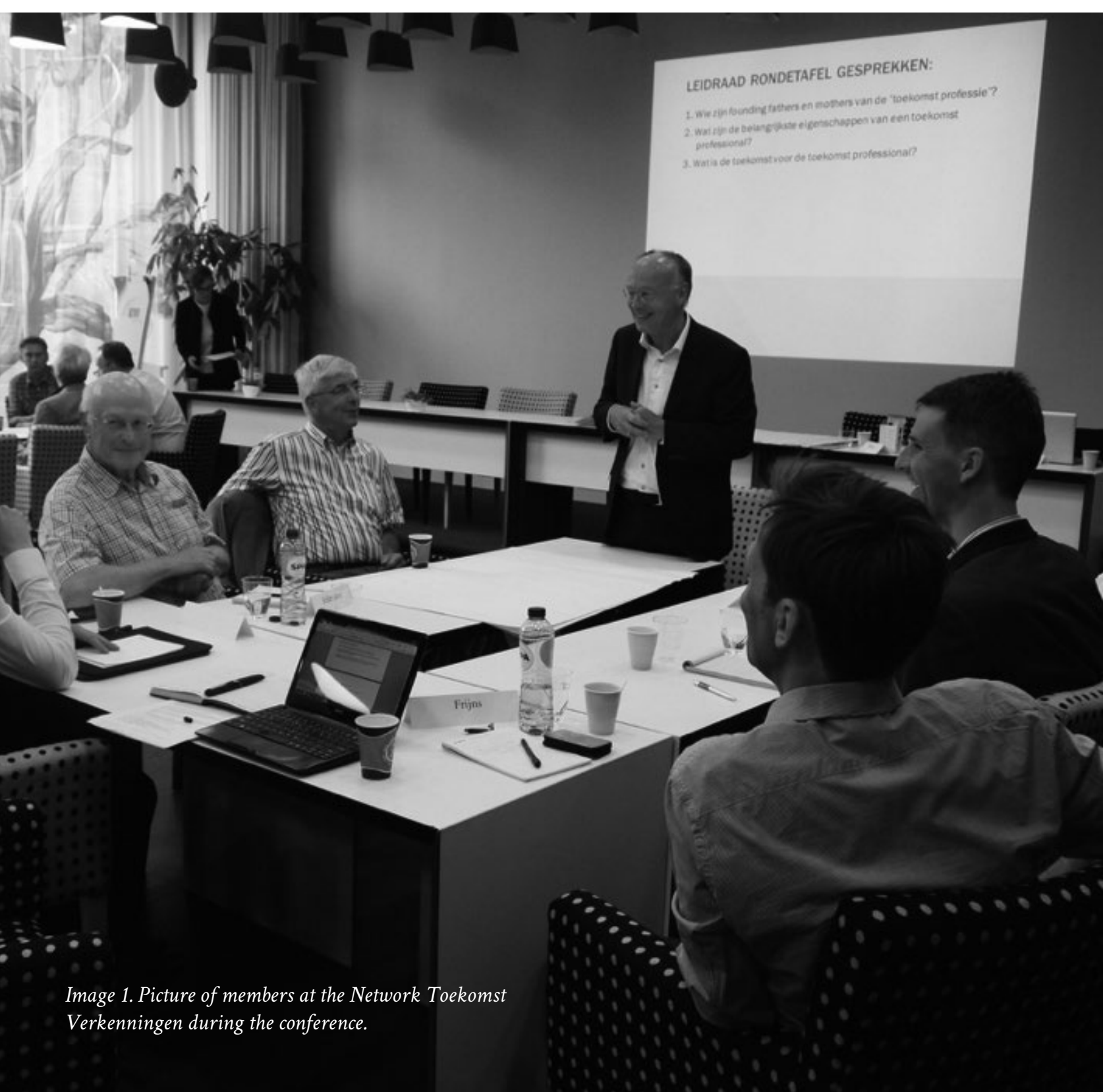

organizations, and offline by allocating timeslots at conferences. On several occasions during my research, futurists connected with other futurists to talk about their profession. To give an impression of the character of those occasions, I selected three examples. These contain an image and a short excerpt of my fieldnotes. These examples illustrate the ways in which futurists set up their conversations about their profession and how they articulated the urgency to professionalize.

1. Netwerk Toekomst Verkenningen (NTV) during the 'future of the future professional' conference on 26 June 2015 in The Hague. This Dutch network of futurists has been set up in 1968 to encourage interaction between futurists.

"Within the profession, an effort should be made to stimulate self-organization. But we also need to learn how to grow our networks of peers and learn how to value them."

"In addition to working with uncertainties, it is also important to focus on creating more support in society to acknowledge change. Especially, because today it [futures thinking] is interwoven in society. Change will also become a focal point of the profession."

(stylized quotes that were part of the conversation of the sub-group reflecting in the picture)

My impression of this conference was that the attending futurists wished to find more structural connection with other futurists. They expressed their concerns emphasizing the solitary character of their practice and the failure to value mutual learning opportunities.
2. Session by Association of Professional Futurists (APF) during the World Future Society conference on 23 July 2016 in Washington DC. This international network of futurists was founded in 2002. The conference was organized to introduce potential new members and to recognize futurists with prizes like 'the Most Significant Futures Work'.

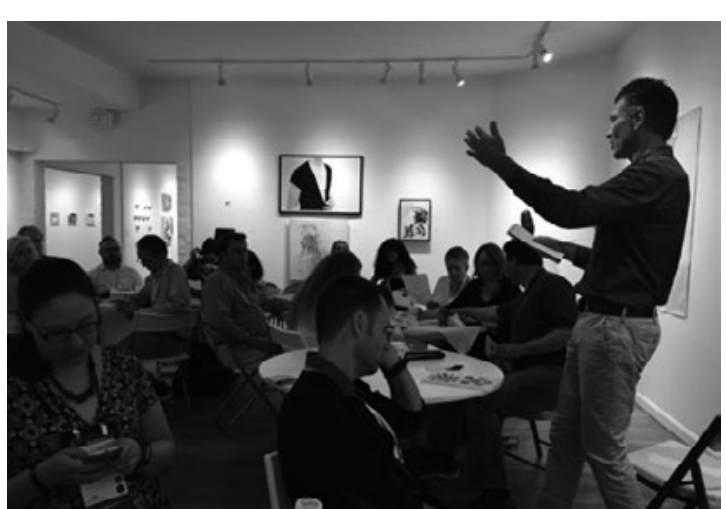

Image 2. Picture of presentation by Andy Hines during the conference.

"We try to tell our story," Andy Hines passionately shares with the present futurists, "especially because it is not an official occupation yet." A futurist asks: "is it possible to add futurist to our passports?' The futurists giggle. "What are standards for us, futurists?" The attending members explain they tried to answer this question with a taskforce, set up by members from the Association of Professional Futurists. "The goal is to explain our profession to the public."

(stylized conversation based on fieldnotes 23 July 2016) 


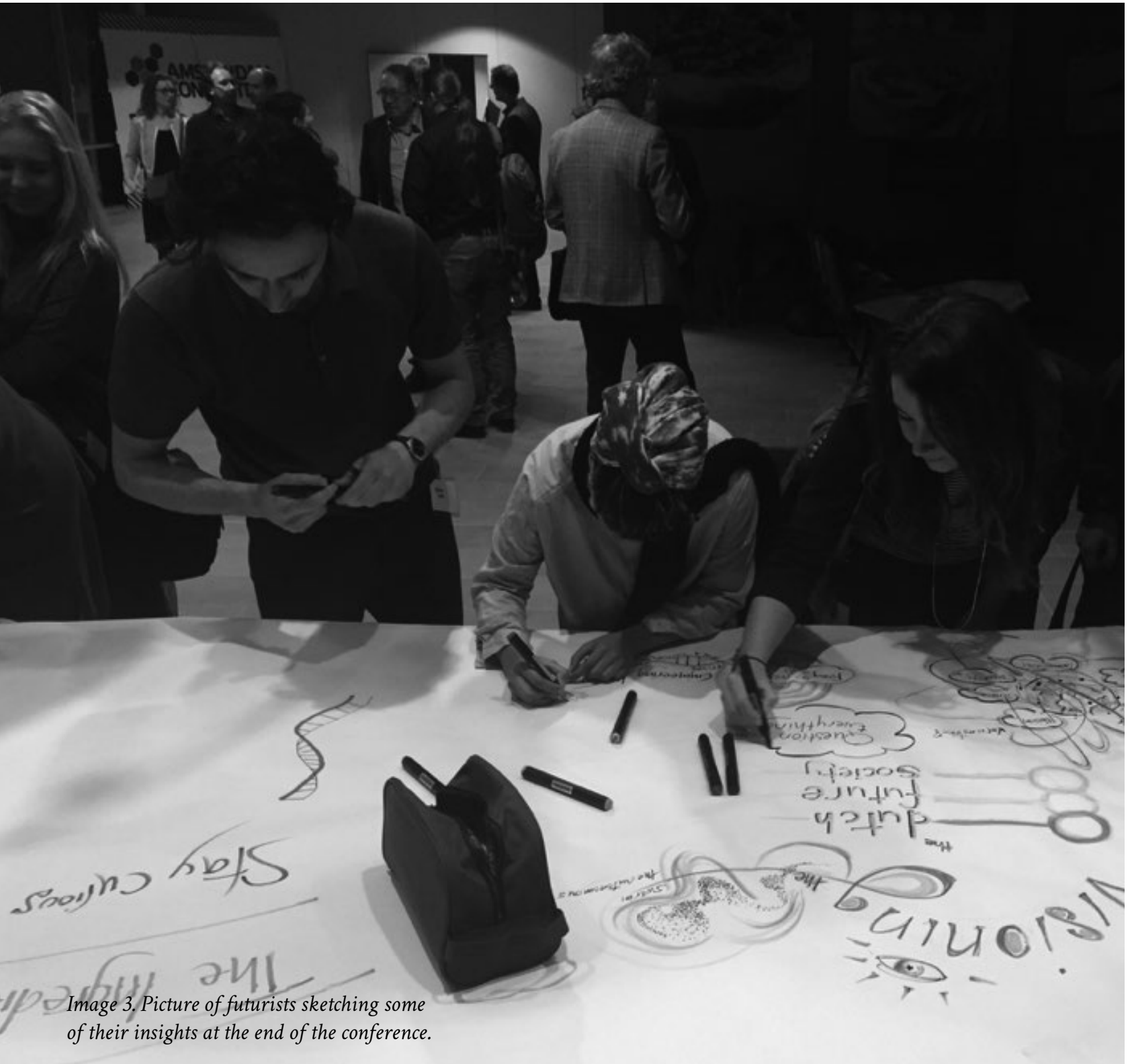

This conference attracted a likeminded group of international futurists, they express the urgency to professionalize to be able to communicate to broader audiences. The present futurists express they are sure that they will become an official occupation. The passport reference also demonstrated how much the attending futurists felt connected to the purpose of their work.

3. Dutch Future Society, An Interesting Day on 25 November 2016 in Amsterdam. This Dutch network, of which I was a founding board member until 2017, was set-up to unite futurists from Dutch speaking countries. This annual conference had the goal to exchange knowledge among futurists.

At the beginning of this conference, the organization allowed me to make a request to the audience. I asked the attendees to pick a moment during the day to express their wish for the future of the profession on a large piece of paper. In addition, a visual typist (delivering a drawing instead of a text) kept track of the conversations of that day.

The assignment illustrated that futurists were able to articulate and envision the future of their profession. Image 4 depicts what futurists wrote down. They emphasized, among others, curiosity, interconnectedness and synergy but also raised questions how to move beyond current competition and start working together.

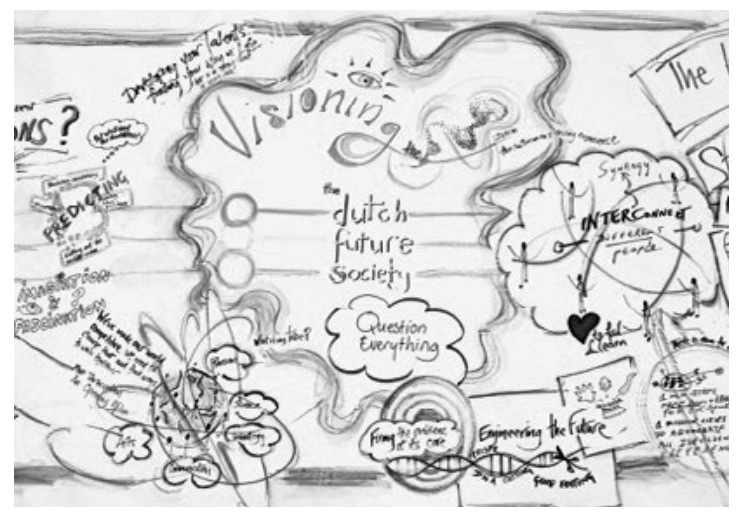

Image 4. Image derived from photos shared after An Interesting Day, November 25, 2016.

The three examples demonstrate that futurists have made efforts to organize conversations on professionalization. The conversations were very different in many ways, for example, the attending futurists, how the conversations were set up and the geographical locations, but what stood out was a shared urgency to discuss professionalization of futurists. These conferences have not been the only site where futurists have (physically or virtually) gathered to discuss their profession. For example, many of the conversations were written discussions in journals and via mailing lists. In the next paragraphs, the topics that futurists brought up during these conversations have been examined. 
3.3 Attempts to grow as a profession There have been numerous attempts to grow and develop the futurists' practice as a discipline, complete with a theoretical structure, specific terminology and clear boundaries (Sardar, 2008). Two futurists were vocal from the onset. Sohail Inayatullah argues that 'field of knowledge' is too strong a term; rather, futures thinking is a discourse, a way of seeing the world (2008: 924). Ziauddin Sardar also recognizes this and states that "equally numerous and strenuous effort have been made to keep the field open" (2008: 893). According to Inayatullah and Sardar, those different perspectives lead to a rich blend of theory, methodology, analysis and practice. Sardar concludes that practices have become much "wider, broader, deeper and varied" (2008: 893) than the early futurists would have thought possible. Yet, both scholars claim that futurists have not managed to organize the profession as a whole because there was no professional unanimity.

Associations like the World Future Society, the World Futures Studies Federation, the Association of Professional Futurists and LaFutura are a way to gain an overview of how futurists organize their community. But there are also other, informal, ways in which futurists connect. For example, in the Netherlands, the Trendrede is the first effort of futurists, in this country generally referred to as trendwatch ers, to work together as a group. The first Trendrede was held in 2010 at the Seats to Meet office at Utrecht Central station, tucked away in a room in the back. Gradually, over the years, the effort was recognized, resulting in an increasing attendance at the subsequent annual conferences. The Trendrede was presented as a gift to Dutch society and was used by a growing number of people as a reference when describing societal trends.
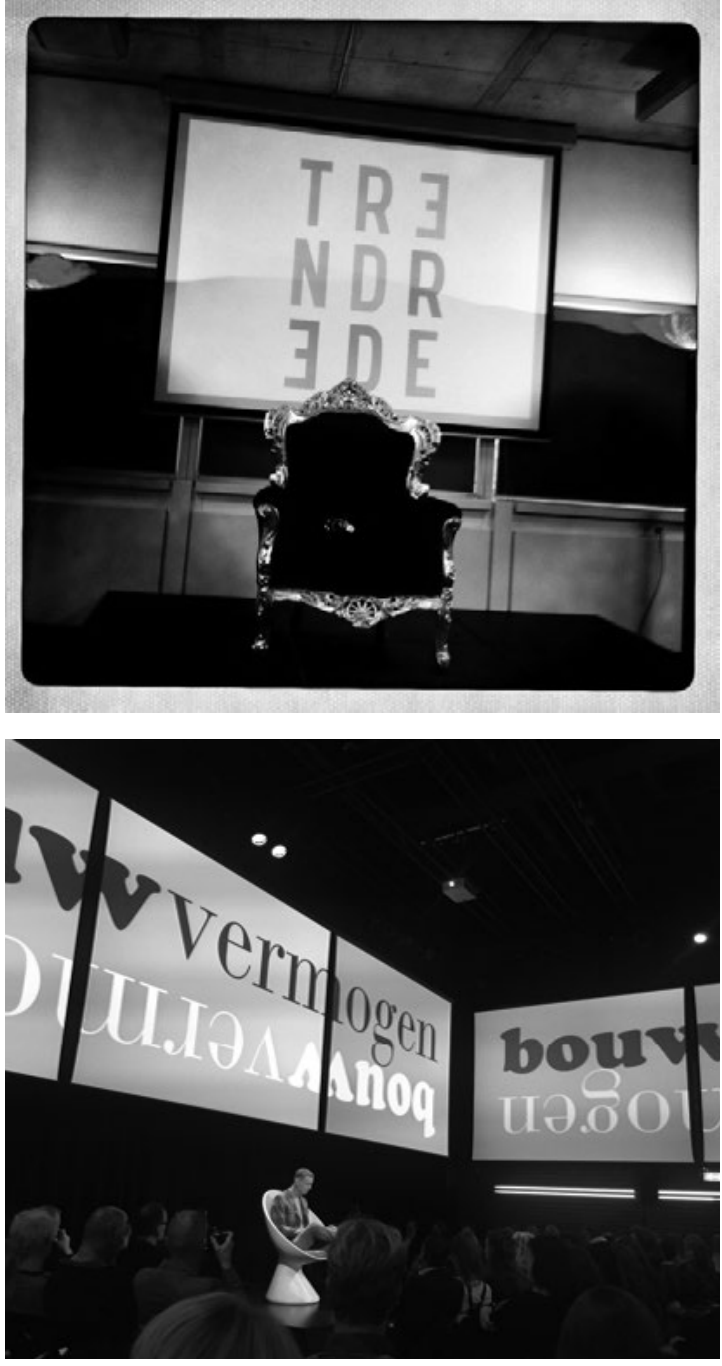

A professionalization issue that futurists discuss during conferences organized by for example APF or LaFutura is education. Many futurists consider lack of common educational training a professionalization problem. For instance, Marien argued in 1987 that there was a lack of common background among futurists. This caused him doubt whether the field could progress. In contrast, Bell argued years later that the lack of common educational training implies that the nature of the profession is "holistic" and "integrative". Bell states that this is because "no field is born fully mature" (2003: 67). He suggests that in the early stages of a profession, practitioners have to be educated in different disciplines. In 2002, Bell and Marien exchanged a captivating discussion in Futures journal to convey their stances on how to advance professionalization of futurists. Marien (2002) advocated that futurists should stop believing in classic professionalization myths and that futurists should do more work to advance their profession intellectually. Bell (2002) argued in return that he was much more optimistic about the actions that futurists were already taking to professionalize. Both authors agreed that "establishing courses and programs of futures studies in educational institutions worldwide" should have priority.
Images 5 \& 6. Pictures taken at the first Trendrede at Seats to Meet Utrecht, November 9, 2010 and the sixth Trendrede at Pakhuis de Zwijger in Amsterdam, January 12, 2016. 
Bell's and Marien's observations about diversity in education are confirmed by futurists during a group conversation at LaFutura in 2013:

\section{A futurist asks: \\ "What is our educational background?"}

\section{The group looks around and one of the attendees starts:}

\author{
"For me it is \\ philosophy \& theology" \\ "Economics" \\ "Sociology" \\ "Psychology" \\ "Also, economics" \\ "Economics as well" \\ "History"
}

16 An update to 2018 could unfortunately not be added since the overview has been deleted from the website www.accelerating.org
Educational diversity is common among futurists. In current literature and articles about professionalization, futurists often refer to educational diversity in a negative way: their lack of common background. According to Kuosa (2011: 332), anyone can become a futurist without prior education, since there exist "no formal education" or "defined qualifications". Starting in the eighties, first steps towards educational progress certainly are taken by several academically oriented futurists. According to the Acceleration Studies Foundation in 2017, 26 international masters and $\mathrm{PhD}$ programs are offered in foresight, strategic foresight, prospective studies, prognostics, futures studies, futurology, futuring and futuristics. The overview by this foundation shows that the number has doubled from 13 in 2014. ${ }^{16}$

Becoming a futurist generally means that first another subject is studied, for example, economics, philosophy or sociology, only to participate in a master program to become a futurist later. Most practicing futurists I encountered at conferences told me that they have only decided to become a futurist in a later phase of their careers. Some decided to pursue a masters, some did not.

Gary and von der Gracht (2015) have carried out an insightful Delphi study amongst futurists. The scholars asked 143 futurists what they expect and desire for the future of their profession. The study showed that most futurists share the view that a desired future is one of academization (expectations that his would happen are around 60\%). Futurists have a strong desire to expand their academic presence, they wish for more faculties and departments that specialize in the future. Gary and von der Gracht envision the scenario of academization in 2030 as a time in which futurists have a stronger academic basis, able to outline their shared theories and methodologies. But the authors also imagine that futurists still have problems to generate impact with their work. The scenario describes how the title of futurists is still not preferred above professionals with a degree in economics or engineering. Although this Delphi mirrors how futurists wish for academization, it also demonstrates their awareness that academization does not directly correspond with growth of their authority.

During a pre-meeting of the LaFutura conference, the participants articulated that there is no particular tradition in educating (fieldnotes 25 September 2013). During the conference, the attending futurists explained they do not believe in a 'traditional' 4 or 5 years of specific training in one area. Rather, students should be able to pick courses that are interesting to them (fieldnotes 4 November 2013). Marien argued in 2002 that if he was to choose a priority in becoming a profession, he would "urge a careful, ongoing assessment of all courses and programs in 'futures studies' worldwide with (..) individual or group making some distinction as to which ones are exemplary models to follow, which are acceptable, and which are marginal or unacceptable." However, in my conversations with futurists, the content of a curriculum was never a point of discussion.

With the absence of a common education, futurist do raise questions on how to safeguard standards for the quality of their work. Wheelwright (2000: 915) claims that if futurists want to pursue becoming professionals, "a code of ethics will probably be required, if only because the existence of a code of ethics would help inspire public confidence in futurists." Moreover, inspired by sociology of professions 
scholar Moore (1970), Gary and von der Grach (2015: 133) created a list of traits for futurists. Implicitly this list is presented as an exemplary benchmark how to reach the hallmark of a profession. First on that list is futurists commit to a full-time activity that earns a living, second, futurists share a calling, third, setting up formalized organizations, fourth, possess valid knowledge based on specialized education, fifth, demonstrate a service orientation to clients and the community, and sixth, enjoy autonomy of work, re strained by responsibility. The authors do not explicitly argue for or against any of the mentioned traits, but the mere notion that they reference this list gives the impression it would be advisable for futurists to adhere to it.

In the discussions on education, futurists' expectations and their reality seem to drift apart. Most futurists (Bell, 2002; Marien; 2002; and the participant in the Delphi of Gary and von der Gracht) are persistent in their argument that if futurists do not adhere to some aspects of the classic professionalization model, they will not be taken seriously. This stance resonates with some of Marien's early statements in 1987 on this matter, when he doubted whether professionalization is possible without a solid educational program. And, this stance is also in line with the exchange between Bell and Marien in 2002, in which they disagreed on many things, except on the importance of education.

In the next paragraph, I examine how futurists set up organizations and how his contrasts with thei written accounts on the role of organizations in their professionalization. I first elaborate on the growth of the future industry and then study how futurists negotiate their common ground through organizations.
When did the futurist industry start to flourish? In his elaborate history of Western futurists, Hyeonju Son (2015) describes that from the 80s onwards, there was a fast growth in the number of futurists. He labels this the industrialization of the futures. De Wilde (2000) has used this notion in his critical account on futurists, reflecting on the implications of the widespread fascination for the future.

Along with growth, specialties flourish. For example, futurist Slaughter claims that futurists have developed "an exceptionally wide range of specialties in many different fields" (2008: 913) during recent decades. Futurists research various topics, use distinctive methods and find imaginative ways to communicate their findings.

To give direction and make sense of the range of specialties, futurists have tried to identify 'schools' of practitioners in their journals. For instance, Kapoor states that there is a 'pop variety', which reaches the wider world, is one-sided and poor in terms of alternative and critical perspectives (2001: 919). Others, for example Van der Duin (2009: 195), name this group 'trendwatchers'. He argues that trendwatchers "neither enhanced the reputation" nor "made a contribution to the scientific nature" of the futurists" work. However, van der Duin agrees with Kapoor that "whether we like it or not, they [trendwatchers] often have a major impact on decision-makers and policy-makers" (2009: 195). Bell (2003: 5) states that particular futurists "rigorously test the plausibility of their logic in open discussion and intellectual debate". However, "they also use creativity and intuition. Although some futurists occasionally abuse these values, they remain the ideals that most futur- ists strive to fulfil". In identifying the schools, some take the opportunity to critically express their view on particular schools.

There have also been several attempts to visually categorize futurists. Figure 2 is an example in which the futurists have been categorized in certain skills. The vertical axis shows the distinction between quantitative and intuitive type of work, while the horizontal axis shows the network-oriented versus individual approach. The details of how futurists were categorized are not important here, but the fact that the futurists have actively categorized the type of practices they carry out, is relevant.

Delia Dumitrescu has made a similar effort (Figure 3 ). The axes present methods, tools and approaches by showing their communality (2011: 229). Dumitrescu describes on her website ${ }^{17}$ (accessed September 2016):

It is time to explore overlaps and LaFutura is a great place to do so. All those innovation methodologies and companies out there didn't fully understand yet that they are no competitors. They are complementary and aim for the same targets. They should star talking, mingling and exploring their overlaps to create holistic innovation approaches and courageous collaborations, to break boundaries and create the future together.

With this quotation, Dumitresco makes a plea for more interaction between various kinds of futurists. Instead of problematizing the supposed diversity, Dumitresco creates an overview. In Figure 3, Dumitrescu has plotted the activities of futurists in categories 'think', 'interpret', 'act' and 'watch'. 


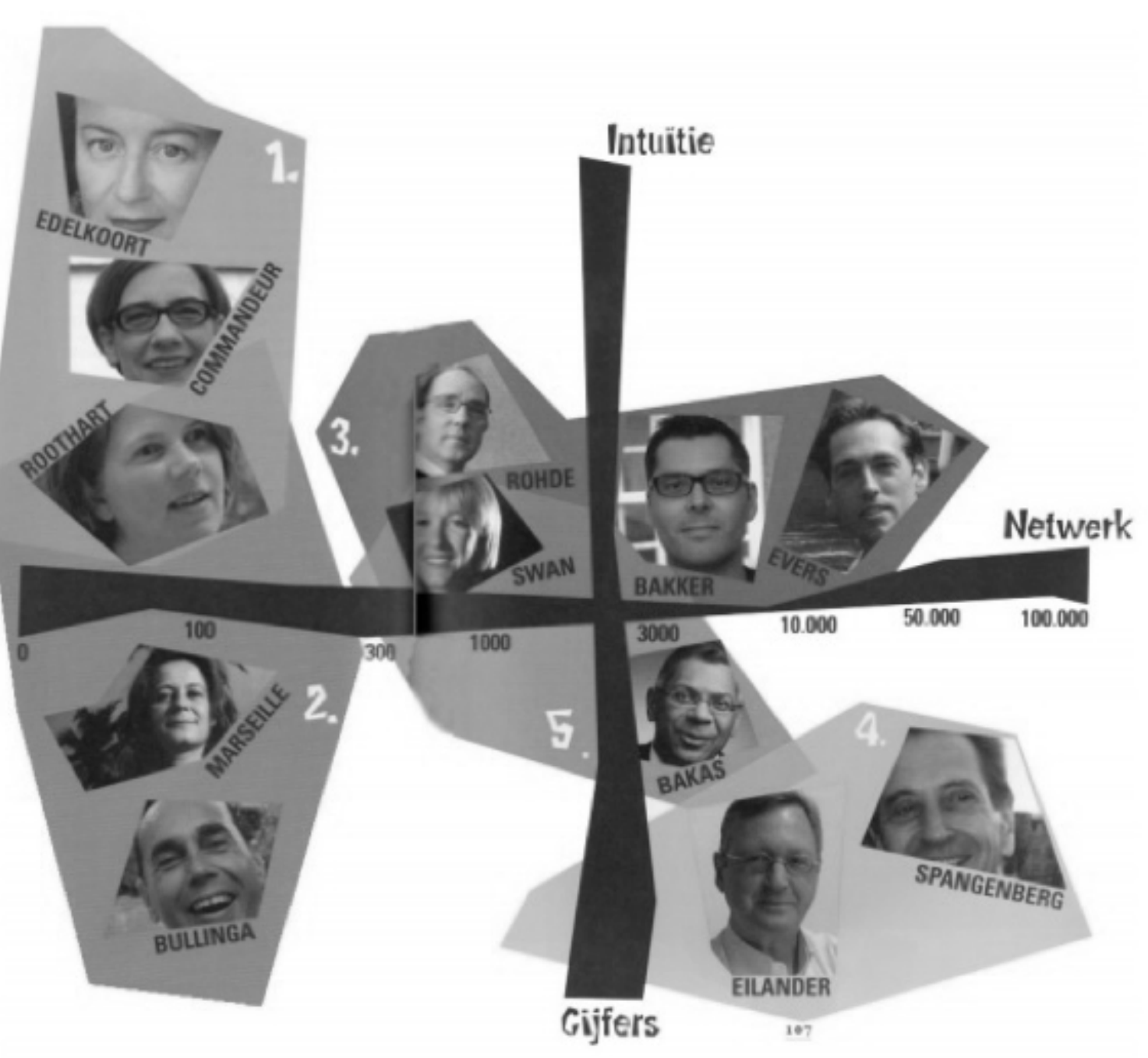

Figure 2. Visualization of suggested categorization of Dutch community of futurists.

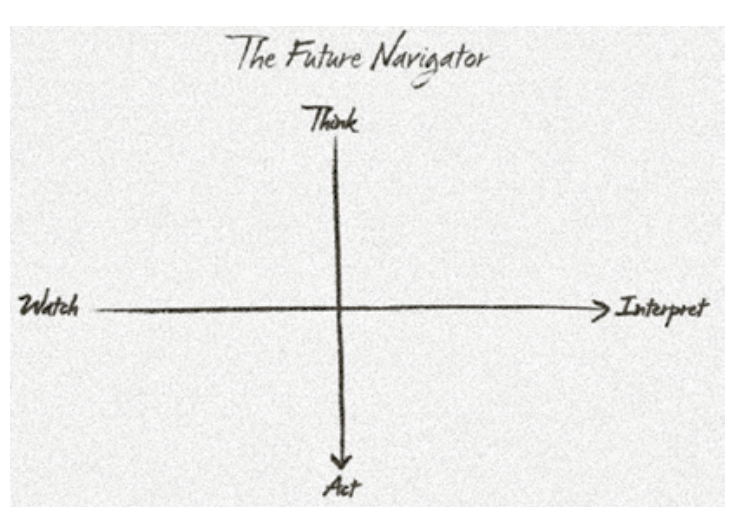

Figure 3. Overview of methods and tools.

These overviews give an impression of how futurists construct the parameters to demarcate practices. They do so by separating activities, like thinking, watching, acting or interpreting. This is a similar approach to Figure 2, in which the futurists are also organized based on their professional activities. These attempt to demarcate are not new. Toffler spoke in 1972 about a growing school of "social critics", "scientists" and "philosophers and planners" that are concerned with the future. In the eighties, Markley (1983: 47) observed "different schools of thought" in the domain of the futurists, which supposedly disagreed on many things. They disagreed on what to call their profession, how to define it and what to call practitioners. Years later, Bell (2003: 70) proposed an array of names, from futures analysis, futuristics and forecasting to futurology, prognostics and futurics.

To make sense of the diversity, Kuosa (2011: 327) argues that futures methods and theories are in "different stages of evolution" and a "mosaic of approaches, objectives and methods". Therefore, it is arguably hard for futurists to agree upon a name for the field. Its name has evolved from "futuristics" to "futurology" to "futures studies" and now, in some circles, to "foresight". To date, futurists have not been able to agree on one satisfying title for all practices. Notwithstanding the pending discussion, Ramos (2013: 155) argues that it is important to come up with one name: "We need to draw on the wealth of past knowledge, and have a place to contribute our knowledge, and something that connects us." Yet, it is telling that futurists have not decided on one name. Ramos (2013: 155) argues: "it is not a field that is just about understanding, analysis, it is about change, transformation, and evolution, cultural evolution." In addition, futurists produce knowledge in "interdisciplinary, transdisciplinary and integrative projects that work across a number of fields, locales, spaces, cultures, problems, issues, visions." This could explain the absence of one common name.

The problem to demarcate futurists causes a similar struggle as in education. Moreover, futurists have different responses to the professionalization struggle. One group of futurists argues that if futurists do not formulate standards in any way, they will never be a serious profession. Another group, however, is searching other ways to respond to the demarcation (and broader professionalization) problem. They are not interested in the doomsday scenarios that peers tend to lean on. In the next paragraph, I continue this exploration and examine the two tentative sides that futurists sketch in this discussion. According to Bell (1993) futurists have yet to formulate a code of ethics. Formulating this type of code requires effort and is often taken up by a specific organization (Slaughter, 1999). Various authors (Bell, 


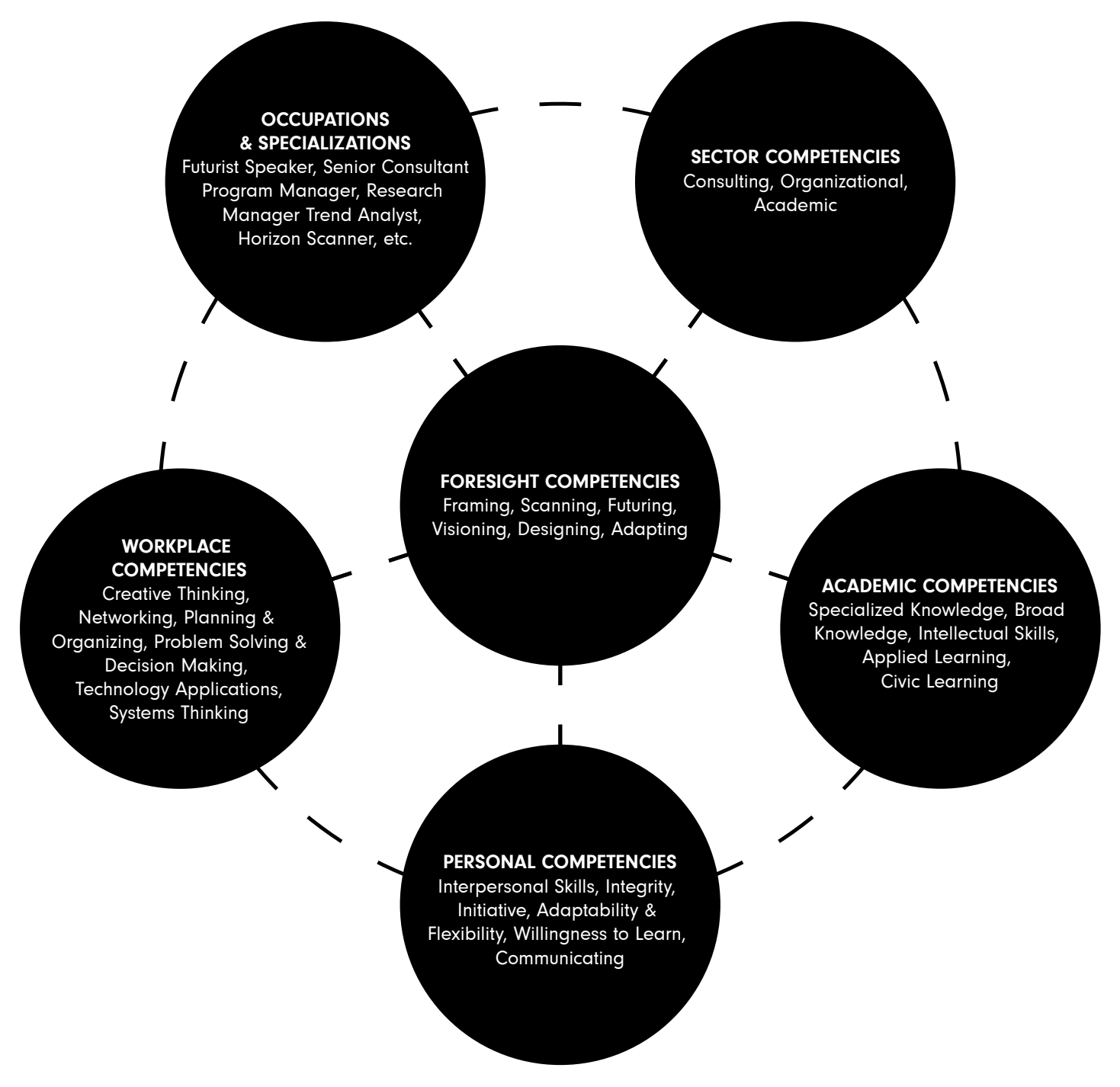

Figure 4. The Foresight Competency Model created by the Association of Professional Futurists members.
1993; Slaughter, 1999; Coates, 2001) contemplate about the value of a code of ethics and propose to give the associations of futurists a role in this discussion. In the 90s, Wendell Bell (1993) and Richard Slaughter (1999) proposed that associations like World Future Society and World Futures Studies Federation should take up the task to define good practices with quality standards of professional futurists. Both scholars independently suggested that leadership was necessary to draw up quality standards.

Various associations and organizations have played a role in trying to formulate a code of ethics. The Association of Professional Futurists launched three separate taskforces, respectively in 2005, 2007 and 2014, to examine futurists' professionalization. In a subreport of 2014, the involved futurists recommended that instead of making a code of ethics that nobody uses, it would be better to develop a set of practice expectations collaboratively with members. At a minimum and as a starting point for discussion only, they suggested that it should cover an 'overarching statement' about the role of futurists, integrity issues like honesty and professional respect and the expectation that members keep on learning and improving their competencies. As a result of these efforts, the Association of Professional Futurists published the Foresight Competency Model in the summer of 2016 (Figure 4). The competency gives an impression of what the involved futurists deemed relevant for futurists and their professionalization. For example, the core of the model is centered around the methodological process. The circles around this core depict the possible choices a futurist can make as a specialization. The shape of the Foresight Competency Model gives the impression of a 'flexible' model in which a practitioner can choose in which aspects they specialize.
The absence of a joint code of ethics continued to elicit debate. Stevenson (2008: 916) asserts that futurists are not a profession because they do not have an "explicit code of conduct and standards", nor do they have a "qualifying body". According to Stevenson, this lack of uniformity has a consequence: futurists do "not enjoy the real hallmark of professionalization, as do accountants, lawyers and medical practitioners". In Stevenson's view, a profession should draw up an explicit code of conduct. This contrasts with the results of the Delphi study (Gary and von der Gracht, 2015), in which futurists supported the claim that "a single over-arching framework is less likely, given the diversity of possible approaches, paradigms, and cultural assumptions". The Delphi respondents were not keen to formulate a single over-arching framework.

The futurists who were part of the professionalization taskforce initiated by the Association of Professional Futurists, have described several levels that can be achieved by practitioners. In September 2016, the chair Andy Hines presented the findings of the taskforce in a digital APF meeting. The PowerPoint slide below (Figure 5) has been shared with the APF community via their mailing list. The PowerPoint distinguished between entry, associate and senior levels.

Entry is the minimum activities a futurist should carry out. This level is focused on the first phase of the research futurists generally carry out, which is often referred to as 'scanning' (Bishop, Hines: 2012). The associate level is concentrated on helping clients understand how to work with futures and is focused on carrying out the whole research project independently. The futurist is often in charge of a project and manages the involved stakeholders. The senior level is the most strategically oriented. It fo- 
cuses on the results of the research projects and how to communicate them to clients and the public. On this level, the futurists oversee the research process as a whole and make strategic decisions. Figure 5 provides an example of the kinds of activities that are carried out at the three levels.

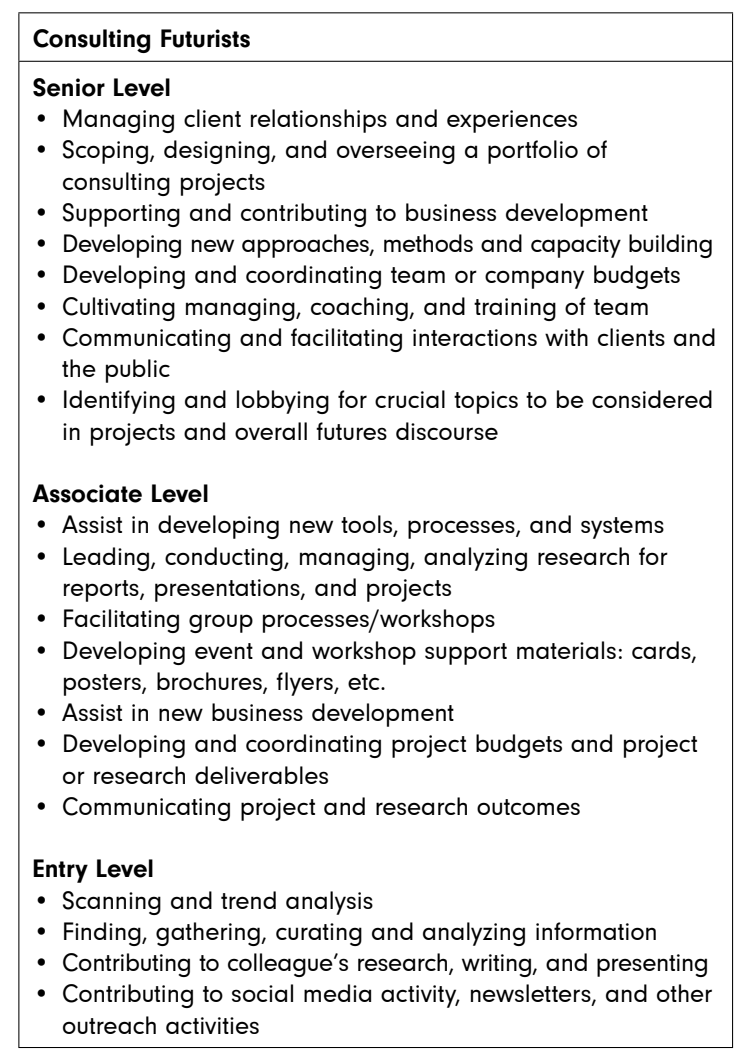

Figure 5. This overview was derived from a PowerPoint slide from Andy Hines for the APF Virtual Gathering September 2016.
The overview in Figure 5 demonstrates that the activities that futurists carry out cover many roles. Each of these roles requires a certain set of skills. Based on this overview, I conclude that a futurist should at least be a researcher, collecting the necessary information. In the associate level, additional roles are expected, like facilitating group processes and communicating the outcomes. On senior level, the futurists also manage the strategic aspects of constructing futures. This example of the taskforce can be seen as the intended 'overarching statement' that futurists wanted to create. Moreover, it is the result of their explicit wish to develop a set of practice expectations collaboratively instead of a code of ethics that nobody uses. The overview demonstrates how futurists are searching for ways to collectively give meaning to the activities of their day to day practice, without having to descend into strict, formalized boundaries.

Futurists are struggling to align their views on how to professionalize. Some futurists are explicit in their wish to professionalize, e.g. by formulating a code of ethics. Other futurists share the same wish, but do not find assurance in formal agreements. Those futurists take other actions, for example by collaborating on a taskforce to find their common ground in other ways. The first group of futurists, which wants to explicit professionalization agreement, support the existing notions of a profession. The other futurists explicitly break with the same, classic notions.

In their discussions on professionalization, futurists discuss topics like education, quality control, diversity and ways in which they are organized. They actively search for how to become a profession and in this search, several concerns emerged. What does this indicate about how futurists identify with the existing notions of a profession? The futurists are divided in how their professionalization is best advanced. Some futurists rely on classic notions of professionalization and others prefer a contemporary 'translation' of these notions that better suit their reality.

Between 2012 and 2017, I participated in several meetings that started with the implicit or explicit intention to outline quality standards. Looking back at the fieldnotes of those meetings, it proved to be challenging to make sense of them, especially in their mutual relation. Looking back, the discussions were more unstructure than I had anticipated and rarely built on previous insights. In the notes I took there was no one question that all futurists asked or one topic they all wanted to discuss or research. There was also little reference to other futurists, let alone to other conferences or discussion with a focus on professionalization. The discussions stayed within the boundaries of the specific group of futurists involved in that particular conversation. At the conferences I attended (see Chapter 2 for an overview), it became clear that the conversation on professionalization was quite problematic for futurists. This could have led me to conclude that the professionalization question is not an urgent matter for futurists. But I also noticed something interesting was happening. The discussion was ambiguous; futurists did express eagerness to professionalize, but at the same time were reluctant to do so. 


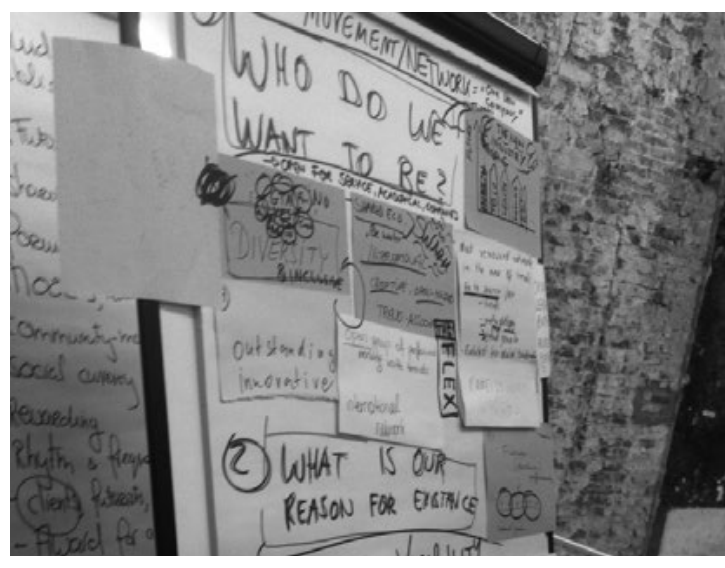

Image 7. Picture taken 6 November 2014 at the pre-meeting of the LaFutura conference 2014 in Brussels.

Regardless of the lack of structure in the discussions, futurists hardly make any references to scholars or experts with a specialty in professionalization. There is one important exception-the taskforce of the Association of Professional Futurists created a competency model. Their report published in 2014 shows that the taskforce used expertise of experts on professions. As stated in the final report of the taskforce members: "the team conducted a literature search with each member tasked with identifying, summarizing and sharing a piece(s) relevant to the question "what is professionalization?". For example, in the overview in Figure 6 references are made to an article by Hines and Gold (2013) (see criterion 2). ${ }^{18}$ This article contained several references to scholars who specialize in the sociology of professions, including Abbott (1988) and Friedson (2001). Although the taskforce did not refer to these sources in the final report, the members clearly used their content. For example, the futurists used words like 'jurisdiction' which is classic vocabulary of sociology of professions scholars.
18 Hines role was dual, he was author of the article

Professionalizing Foresight and involved in the Association of

Professional Futurists taskforce.

\section{Criteria of Professions}

\begin{tabular}{|c|c|}
\hline 1. Traditional, build-a-wall professionalization & $\begin{array}{l}\text { Task force identified no support for this and recommends not pursuing } \\
\text { this path }\end{array}$ \\
\hline $\begin{array}{l}\text { 2. "Traditional" professional criteria, but } \\
\text { aiming toward an ecosystem rather than } \\
\text { walls (Hines/Gold "Professionalizing } \\
\text { Foresight) }\end{array}$ & $\begin{array}{l}\text { 1. Specialized work grounded in a body of theoretically based, } \\
\text { discretionary knowledge and skills (think we have this, but not } \\
\text { characterized) } \\
\text { 2. Exclusive jurisdiction created and controlled by occupational } \\
\text { negotiation } \\
\text { 3. A sheltered position with labour markets based on qualifying } \\
\text { credentials of the occupation } \\
\text { 4. An ideology that asserts a commitment to doing good and quality } \\
\text { 5. A formal training program to provide qualifying credentials } \\
\text { 6. Sense of community and commitment (think we have this) } \\
\text { 7. A code of ethics } \\
\text { 8. Professional standards } \\
\text { 9. Professional association (have this) } \\
\text { 10. A new name }\end{array}$ \\
\hline $\begin{array}{l}\text { 3. Streamlined professional criteria (Jay } \\
\text { Gary's "Hell on Wheels") }\end{array}$ & $\begin{array}{l}\text { 1. A foresight competency model } \\
\text { APF should carefully study how professions have set standards through } \\
\text { competency maps that include personal, academic and workplace } \\
\text { competencies, set within a wider context of industry-sector, across } \\
\text { management and occupational competencies. } \\
\text { 2. A professional development pathway } \\
\text { APF qualifies its members, based on their portfolio review. It has created } \\
\text { a steady stream of face to face and virtual salons, seminars and } \\
\text { gatherings. But we should also focus on informal and formal pathways of } \\
\text { career development. } \\
\text { 3. A system of incentives } \\
\text { A foresight professional ecosystem needs clear incentives for } \\
\text { practitioners to travel along its pathway, for training programs to offer } \\
\text { quality, and for employers to hire qualified workers, all in keeping with } \\
\text { evolving industry standards. }\end{array}$ \\
\hline 4. New professionalism & Reinvent how to think about professions; obviously, a much larger scope. \\
\hline
\end{tabular}

Figure 6. Overview derived from the final APF Professionalization Task Force Report published in 2014 
Apart from this single effort to learn from the professionalization literature, futurists found their way intuitively. For example, LaFutura 2013 and 2014 conferences, respectively in Amsterdam and Brussels, were specifically set up by futurists to question how to professionalize. The 2013 conference was introduced with the identification of two possibilities; 1 . "stick our heads into the sand like ostriches" or 2. "take action". The organizer of the conference, futurist Erica Bol, said in her opening speech that the second option asks for ordering, organizing and structuring who futurists are-making clear what they do so others can find them and appreciate their value. This makes it possible to move from the current 'fuzzy situation' to creating and organizing road which helps others to find futurists (derived from fieldnotes 4 November 2013). The discussion that followed was structured with the help of tools well known to futurists, such as road mapping and strategic thinking.

Although futurists hardly refer to theory about professionalization, the issues raised by futurists are extensively addressed in literature, particularly in the earlier work of the sociology of professions. As such futurists identify with the existing notions of a profession, but are finding ways to stretch those notions a bit, the Foresight Competency Model is an example of how futurists carefully outline a professionalization framework.

\subsection{The traits perspective on professions} The interest in research on professions increased from early the 20th century onwards. Durkheim was the main influencer behind the idea that a profession had a moral basis in society. Elites received prestige with learning and working in other jobs besides in factories. Durkheim saw professional groups as 'organs of society', partly autonomous systems of relations, which cannot, however, exist except in contact with the other organs in society (cited in Hughes, 1960: 55). Scholars like Flexner (1915), Carr-Saunders and Wilson (1934) and Millerson (1964) categorized which traits and characteristics a profession should have. Both Flexner and Millerson tried to understand what made a profession a profession in contrast to an occupation, which was seen by scholars as a mere starting point of eventually becoming a morally superior profession. From the beginning of the 20th century onwards, scholars searched for a structure and overlapping characteristics to grasp what professionals had in common. They wanted to understand what was necessary for an occupation to grow into a profession.

In this early work, traits were the main focus of scholars. According to Brante (2011), numerous lists of traits have been formulated since the 1930s. These include shared theoretical knowledge, similar education, licensing, a specific association and organization, types of control, collegiality, ethics, work for the common good, autonomy, discretion and sometimes class position.

Futurists bring up similar themes to the ones that sociology of professions scholars have identified as traits. They discussed what the content of educational programs should be, whether it is necessary to create a code of conduct, think about ethics, how they should organize their community of practitioners and if they are an autonomous profession, and if so, how to claim autonomy. Other themes on Brante's list, like theoretical knowledge, types of control, collegiality, work for the common good and discretion have been part of futurists' discussion, albeit more implicit than the themes highlighted in this chapter.

Central to the traits perspective are uniformity, structure and overview. And futurists are searching for this uniformity, structure and overview. One of their deepest worries is whether they can overcome their differences. In the response to this worry, I observe two stances: on the one side there are futurists that focus on the dangers of not formalizing the practice. On the other side are futurists who try to find others ways to understand their common ground. These two stances only so often meet in the literature or during conferences.

Especially in journals and books, futurists articulate their doubts regarding the state of professionalization of futurists. For example, Stevenson (2008) wrote that futurists are not a profession. And Wheelwright (2000: 915) argued that if futurists want to pursue becoming professionals, a code of ethics is necessary to inspire public confidence in futurists. Kuosa (2011: 332) expressed his concern about the absence of common education: anyone can become a futurist.

A futurist that has argued for both stances is Hines, director of a master's program of futures in Texas, he writes: "I admit, even in my most sanguine moments, I feel as if FS (futures studies) is on a teetering on a precipice, ready to crash" (Hines, 2002: 346). This is not a comment to take light-heartedly and this doubt is shared by (some) other futurists. Hines did not take this feeling light-heartedly either and has since attempted to find common ground. In his role as member of the Association of Professions taskforce, he had a fruitful part in advancing the discussion. 
Many futurists that I have observed during conferences had a productive attitude towards professionalization. An example is how APF members decided to that it would be best to collaboratively develop a set of practice expectations instead of formulating a code of ethics that nobody uses (see Figure 6). In my observations, several futurists wanted to take action and did so. Several futurists (Inayatullah, 2008; Slaughter, 2008; Sardar, 2010) described how futurists flourish in a wide range of specialties instead of searching fo uniformity. A telling example of how futurists tried to find common ground in their professionalization, becomes more tangible in the overview created by the APF taskforce in 2014 (this is an excerpt of the same overview as Figure 6). Right above the overview, futurists decided to add a scale, from traditional to new.

\section{Criteria of Professions}

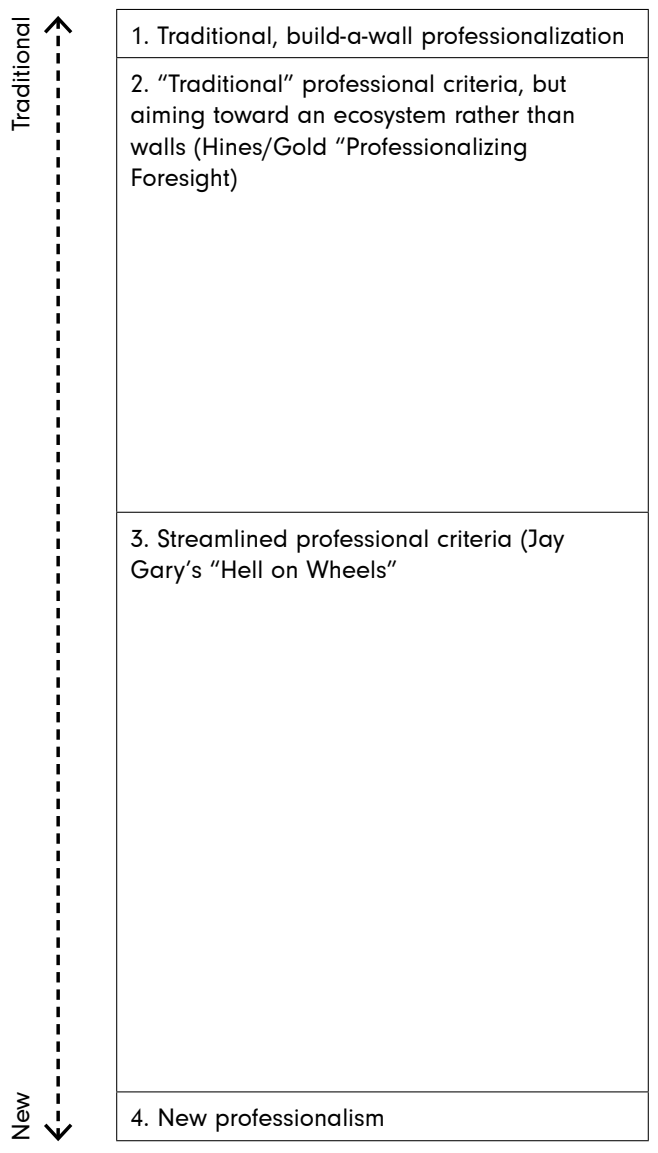

Figure 7. Excerpt of overview derived from the final APF Professionalization Task Force Report published in 2014
In their accompanying text, the futurists write that they "did not agree with column \#1, noting in particular that we do not recommend attempting to build walls or fences". Colum \#1 is the perspective on professionalization identified as 'traditional'. The authors describe that it can be relevant "to look at how professions are changing, as suggested in Column 4" (APF taskforce report, 2014: 3). Futurists describe a tension between traditional and new perspectives. They do not formulate a specific pathway to explore the new perspectives. Rather, they argue that new perspectives in professionalization are possible that are relevant to understand their own practice.

The opposing stances of futurists may give the impression that futurists do not 'believe' in their professionalization. But this disqualifies their efforts to find common ground. Futurists intuitively lean towards the promises of 'new professionalism'. They recognize that their work is inherently interdisciplinary and practiced across a number of disciplines, spaces, cultures, wicked problems, questions and visions (Ramos, 2013). However, at the same time futurists tend to lean towards the traits perspective in advancing their professionalization.

Futurists struggle to align their traits assumptions on how to be a profession, with their diverse, contextualized realities. Based on the analysis of my observations, traits are not an adequate perspective for futurists to decide on their professionalization. The traits perspective is too narrow to use as a framework to examine how futurists are professionalizing. It causes weighty tension and a lot of incomprehension among futurists which resulted in futurists questioning the maturity of their profession for years. Whilst at the same time, that does not stop futurists from discussing, negotiating, organizing, and taking several actions to make their profession. 
This chapter started with the question: how do futurists identify with the existing notions of a profession? Futurists have been discussing their professionalization since the 80 s, for example by publishing article in journals and allocating timeslots at conferences. When looking at the debate over time very little has changed in tone or topics. The futurists seem to have gotten stuck in circular reasoning; they keep returning to similar conversations without finding fulfilling answers, paths forward or agreements on their common future.

In examining their debates, the struggle futurists experience in their efforts of finding consensus on what futurist ought to be and how to be a profession, is evident. In the introduction of this chapter, severa questions were raised: how should a futurist behave? What is a proper futurist? What are the norms in producing knowledge about the future? Those questions still remain, the literature and observations did not provide a straightforward answer.

For futurists, the prevailing notions of what a profession is and should be, still leans strongly on the classic traits perspective. Whilst, the practice and constructivist reality of futurists make adhering to this type of professionalization improbable and unlikely. In this chapter I argue that traits are not adequate to decide on professionalization of futurists.

Adhering to the traits perspective demonstrated how persisting and dominant societal view on profession are also among practitioners such as futurists.

Even futurists, who plea for out of the box thinking, have difficulties separating their expectations from this classic promise. It demonstrates how little the public opinion on what a profession ought to be, has changed since the 1960s. In this chapter, I observed how futurists were struggling to articulate how they envision their own professionalization. By taking a closer look at this struggle I noticed how many conferences futurists have organized, how many articles have been written, how many books have been published, how many interviews have been given, how many organizations have already been set up and how many attempts have been done to find a name for the profession. The sum of these source materials revealed that the struggle I signaled can best be defined as futurists' reluctance, hesitating to adhere to the classic model of professionalization.

In this chapter, the ambivalence in professionalization ambitions transpired. On the one hand there is a strong sense of community that was voiced by futurists through all those professionalization activities. And on the other hand, there is an undisputed diversity amongst futurists. Futurists take for granted that there is difference in how they work, in the methods they choose, and in their professionalization ambitions. They either do not strive for, or even do not believe in, uniformity as the way forward. In this chapter, I examined the futurists' ongoing conversation on professionalization. I observed that they are not succeeding in finding a common ground in ways forward. Some futurists wish to professionalize according to the traits perspective, others long for an alternative pathway.

Notwithstanding the ambivalence towards classic notions of professionalization, futurists did take numerous actions to 'make' their profession. By acknowledging these efforts, it is possible to start looking at futurists' professionalization from different viewpoints. Hereafter, I expect it is worthwhile to further study the actions that futurists are taking in their efforts to professionalize. In the next chapter, I examine how futurists nourish, shape and develop their common identity. 


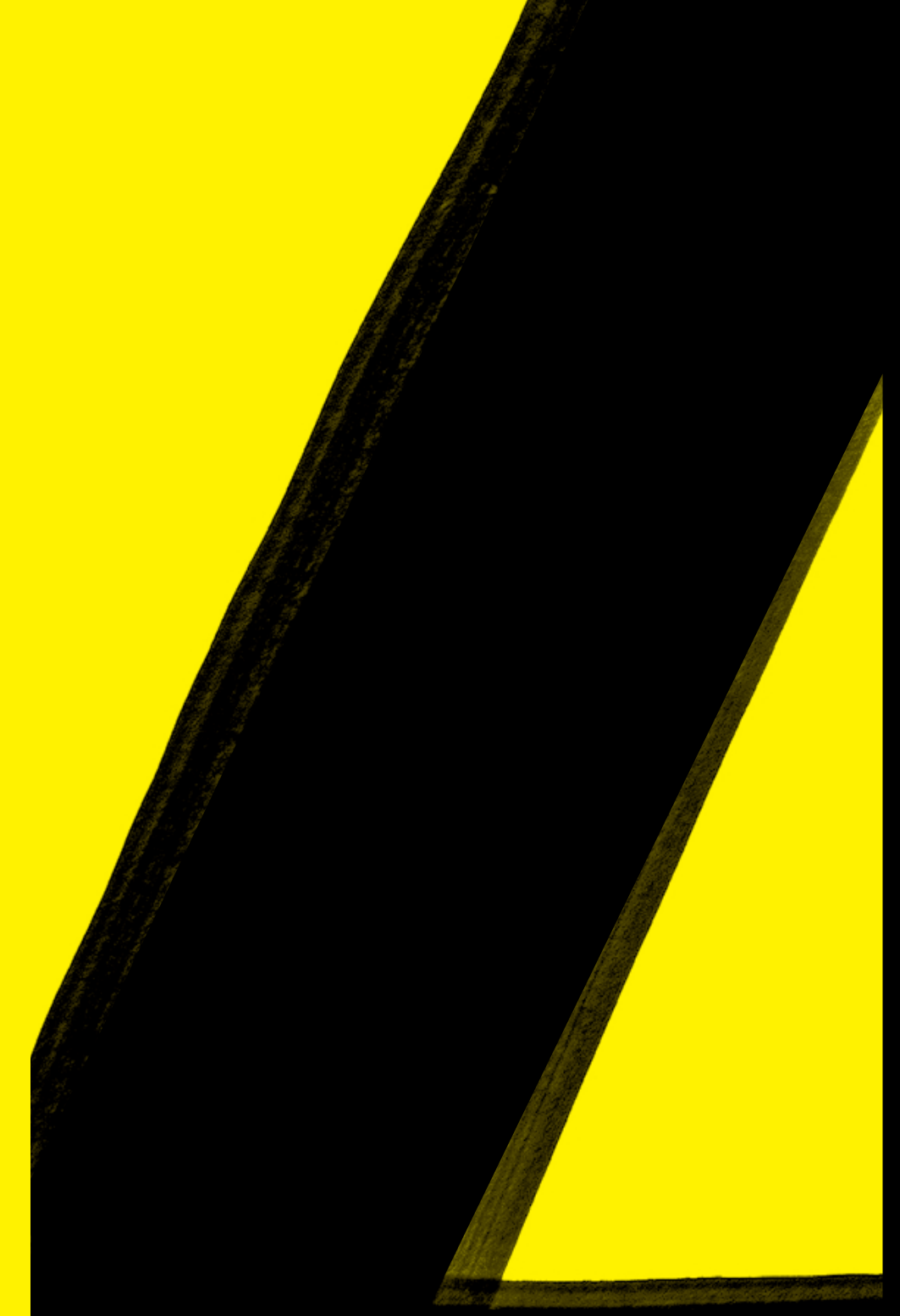




\section{Identity | the art of being} a futurist

4.1
4.2
4.3
4.4
4.5
4.6
4.7

\author{
Introduction \\ Traditions of becoming a profession \\ Claiming jurisdictions \\ Skills of a futurist \\ Image-making of futurists \\ The paradox of (not) fitting in \\ Conclusions: the making of the futurist
}

19 Abbott (1988) considered the group of scholars like

Freidson (1970), Hughes (1958), and Johnson (1972), to be pa of the 'monopoly perspective' as they focus on the desire for dominance and authority in becoming a profession. Howeve noth 'monopoly' and 'autonomy' may be notions that are too 70s onwards. Accordingly, instead I use the more clinical and neutral word 'process' to unite the perspectives of these particuld scholars.
4.1

Introduction

In Chapter 3, I examined how futurists struggle to align the traits perspective with their own professionalization. The analysis of their written and verba discussions demonstrated that futurists strive for further professionalization of their practice but do not agree on how to achieve this. As concluded in Chapter 3 , in their idea of professionalization, the futurists relied on a classic traits image of the profession which aims at uniformity and standardization, whilst at th same time acknowledging that diversity is an important feature of their profession.

There are scholars who, as a consequence of practitioners struggling with classic images of professionalization, have dissociated from the sociology of professions as a whole (for example, de Sonnaville, 2005). Any scholar expecting theory derived from sociology of professions to be an explanatory, universal model will be disappointed. Grasping the activities of professionalization through one theoretical lens, would presuppose a rather one-dimensional image of a profession as an objective entity. In this chapter appreciate the other perspectives that have been de veloped within sociology of professions.

More recent literature on professions has adopted broad view on professionalization. Within sociolo gy of professions, the so-called 'process perspective' shifted the focus of research from an orientation towards form (traits of a profession) to an orientation towards functions (process of being a profession). Scholars such as Larson (1977), Abbott (1988) and MacDonald (1995) started to research the ambiguous process of the making of a profession.

One of the leading authors of the process perspec tive is Abbott (1988). According to him, scholars that conduct research within the traits perspective have a surprisingly consistent view of what professions are and what about them must be explained. Abbott acknowledges that a profession certainly is an occupational group with specific skills, but also makes an effort to broaden the perspective by stressing the continuous, evolutionary character of a profession. In line with this process-oriented perspective, researchers began to study particular cases to grasp the complexity of professionalization (Freidson, 1970; Hughes, 1958; Johnson, 1972).

This chapter will focus on how to understand what futurists actually do in order to constitute a profession, informed by the process-oriented perspective. The central question of this chapter is: what actions do futurists take to professionalize? I will unravel the complexity of futurists becoming a profession. I will construct my analysis based on empirical data sources: the interview series with international futurists. Moreover, I draw from the notes of the observations I made during my attendance at a mix of 50 (in) formal conferences. Furthermore, I include relevant outcomes of several group discussions with Dutch futurists (for further details, see Chapter 2). To help structure the empirical analysis, I will further elaborate on the work of the sociologists Abbott and Larson. This chapter concludes with a reflection on the professionalization activities of futurists.

\subsection{Traditions of becoming a profession} The history of the process perspective goes back to the 1960s. It was the eminent sociology of professions scholar, Everett Hughes, who argued in 1960 that the orthodox traits perspective in the sociology of professions posed the wrong question. In his view there was too much focus on whether an occupation could be elevated into a profession. He argued that the core of the studies should focus on action not on structures. Hughes suggested that it is more relevant to focus on the circumstances in which people in an occupation attempt to turn it into a profession and themselves into professional people. MacDonald (1995) stated that several sociologists took note of Hughes' insight but were not able to put it into practice. However, with hindsight it is apparent that Hughes' view precipitated a radical change of thinking concerning professions. Hughes' argument that the starting question was wrong, presented scholars with the opportunity to head in a new direction.

The traits perspective continued to dominate the sociology of professions until the early '70s. Hughes' conceptualization of professions gained traction in the 1970s when numerous scholars inspired by Hughes' view began to develop symbolic interactionist alternatives for the functionalist nature of the traits perspective. This symbolic interactionist tradition took as its subject matter the actions and interactions of individuals and groups, how they constituted their social worlds as participants and how they constructed their careers (MacDonald, 1995: 4). The themes addressed by these scholars were diverse and elaborated in many different ways. One of the common denominators seems to be their process-oriented perspective towards professions. The underlying assumption of the process perspective is that professions want to become powerful and claim work that others cannot do. ${ }^{19}$

The process perspective is noticeably a collection of several views on professionalization. In the broad theoretical scope that has been developed in re- 
sponse to the traits perspective, two scholars stand out: Larson (1977) and Abbott (1988). Larson has situated her analysis of professions in the everyday reality of modern societies in which scientific knowledge and existence of free markets are determining elements. Abbotts' contribution is to identify a system to study professions. As Evetts point out (2012: 3), the ideas developed by Abbott and Larson are still useful in analyzing the becoming of professions.

In her work Larson emphasizes the economic and social order and explores market control of a profession and the social mobility of its practitioners. Larson studies what professions actually do in everyday life to negotiate and maintain their special position. Her intention is "to examine how the occupations that are called professions organized themselves to attain market power" (1977: xvii). Larson suggest that when a profession gains the control over a market (for example because the practitioners possess expert knowledge for which they are being rewarded) this could lead to the monopoly of a profession. According to Larson, "professionalization is thus an attempt to translate one order of scarce resources special knowledge and skills - into another - social and economic rewards" and "the focus on collective social mobility accentuates the relations that professions form with different systems of social stratification; in particular, it accentuates the role that educational systems play in different structures of social inequality" (Larson, 1977: xvii). Larson sees socia mobility as a collective project. Joint organizationa efforts bring desired status for the individuals. Professions are formed by a group of individuals seeking prestige. Larson calls this the professional project that practitioners set up to work towards social closur with the objective to establish a monopoly in their specific field of knowledge.

Larson's concept of the professional project is based on two main features of Weber's thinking (1976/1904-1905). Firstly, professions and the professionals strive for abstract knowledge which makes it part of the class system. Either capital or labor power provides professional significance. Secondly, Weber's emphasis on the actions of collective groups can be conceptualized as a strategy to realize social closure. The social order of the professional project is determined by trust in the professional and how they build their status and respectability. In addition, MacDonald (1995: 31) argues that the development of the economic order by professionals is notable in two areas, the first is "legal closure and monopolization of the market and occupation" and the second, "the exclusive acquisition of the knowledge and education on which the profession is based."

An additional question posed by Abbott (1988) is: when do we use experts? Furthermore, he asks how do we structure and control expertise in society? One of Abbott's key concepts is the claim of jurisdiction, which addresses the social control of a profession. The definition of jurisdiction is a claim a practitioner makes in a particular area of expertise. For practitioners, it is essential to make clear what they do. In this way, it is possible to claim exclusive rights to their area of expertise. These rights could lead to control over the work and ultimately to a monopoly. Once a profession has claimed its jurisdiction, the work does not cease. Practitioners continuously have to pay attention to the overlap with other jurisdictions. These claims of jurisdiction are constantly re-negotiated and, in this sense, it is a continuous process. This process is also driven by on-going societal innovation. Both social and technological change destructs and creates new jurisdictions.

Abbott describes jurisdiction as the central phenomenon of professional life, being the link between work and its profession. He points out: "to analyze professional development is to analyze how this link is created in work, how it is anchored by formal and informal social structure, and how the interplay of jurisdictional links between professions determines the history of the individual professions themselves" (Abbott, 1988: 20). Claiming a jurisdiction is a dynamic process that depends on several dimensions, such as competition and interaction with other practitioners. Jurisdictions are related to those of other practitioners, which are also constantly shifting.

Claims for jurisdiction can be made at different levels depending on the professions' own desires (Abbott, 1988: 59). Abbott describes that there are different arenas in which the claims are made: the legal system, public opinion and the workplace. Each of these arenas has a function in the process as a whole.

Abbott describes the legal arena to be the most durable of the three arenas. He argues that when professions claim this type of jurisdiction, it usually lasts for dozens or even hundreds of years. By claiming jurisdiction in the legal arena, the profession has gained a monopoly over certain tasks. In obtaining legal jurisdiction the practitioners must rigidly define their vocabulary. Moreover, their tasks must be concisely demarcated. Consequently, this type of jurisdiction does not offer space for altering practice; practitioners must all stick to the defined vocabulary and tasks. Thus, the practitioners are legally the same and their practice must 
be uniform. When they obtain legal jurisdiction, their profession has reached 'the heartland'. The heartlan is, according to Abbott, the ultimate goal for (almost) every profession.

According to Abbott the public opinion arena is the most familiar arena for practitioners and usually the first one they are able to shape. This is the place where they establish power and the legitimacy to control a certain type of work. The public opinion gives th practitioners the right to perform. A successful public jurisdiction leads to social and cultural authority. Claiming this type of jurisdiction is a pervasive activity, Abbott argues. It is the way to explain what the outsider, the layman, needs to know. The crux is the image-making of the profession. When a professional image is socially accepted, it can endure for a long time. It is important to note that discourse about practitioners is significantly constrained by the fact that there is limited space for nuance. To build th image of a profession the public needs a clear archetype that does not allow for too much differentiation.

The last and most informal type of jurisdiction is the workplace arena where the actual work is done. The claim of jurisdiction at the workplace focuses on control over certain kinds of work. According to Abbott the basic questions are who can control and supervis the work and who is qualified to do the work? In this type of jurisdiction, the complexity and diversity of its practitioners are recognized. While the legal and public opinion arenas constrain the images of the practitioners and the vocabulary that is used, the workplace arena can do more justice to the actual practice of a practitioner. Then questions arise such as: who carries out the actual tasks? In the case of workplace jurisdiction, it is the real output of an individual not its credentials that matter. According to Abbott, talent for the job is equally as important as education. Practitioners actively pursue this type of jurisdiction because this is part of their everyday routine.

According to MacDonald (1995) there is no real difference between Larsons' 'professional project' and Abbotts' 'jurisdiction'. He considers the work of Abbott, particularly the concept of jurisdiction, as a continuation of the thesis that Larson formulated with the professional project. Both authors underline the idea that professions need to legitimize and fight for their reason for existence every day (MacDonald, 1995: 33). The practitioners need to take actions to safeguard quality and gain respectability. The underlying quest in both Abbott's and Larson's work is to gain trust from outsiders in different arenas to be able to reach the heartland.

4.3

Claiming jurisdictions

Abbott's three types of jurisdiction served as inspiration to structure the empirical analysis. At first glance, futurists seem to take most actions to professionalize in their day-to-day life, which can be understood as the workplace arena. Abbott directly links workplace jurisdiction to everyday practice. Therefore, I commence the analysis with this arena. In this first part of the analysis I concentrate on which skills are necessary to be a respected futurist in the workplace. Many futurists were articulate about this topic, suggesting it was important to them.

The second part of the analysis focuses on their professional identity through image-making, a process which relates to the public arena. Futurists are mindful of the perceptions that outsiders have of their practice. The analysis will focus on the social dynam- ics between futurists and their clients. I do this by reying upon the professionalization stories of futurists. Abbott's perspective on the public opinion helped to structure my observations. In addition, the work of Larson is useful in this part of the analysis and will be used as source of inspiration to reveal the actions undertaken by futurists in order to gain trust.

Finally, the third part centers on legal jurisdiction. The conception of Abbott's legal arena helps to raise questions about the standards and norms that govern professions. In the previous chapter, I observed the struggle experienced by futurists with this forma aspect of their professionalization. In this chapter, will further elaborate on why futurists are reluctant to professionalize.

In brief, in the following paragraphs I will further unravel the efforts associated with professionalization by elaborating on the following three aspects:

a. Skills of a futurist, related to the workplace arena;

b. Image-making of futurists, related to the public opinion arena;

c. The paradox of (not) fitting in, related to the legal arena. 


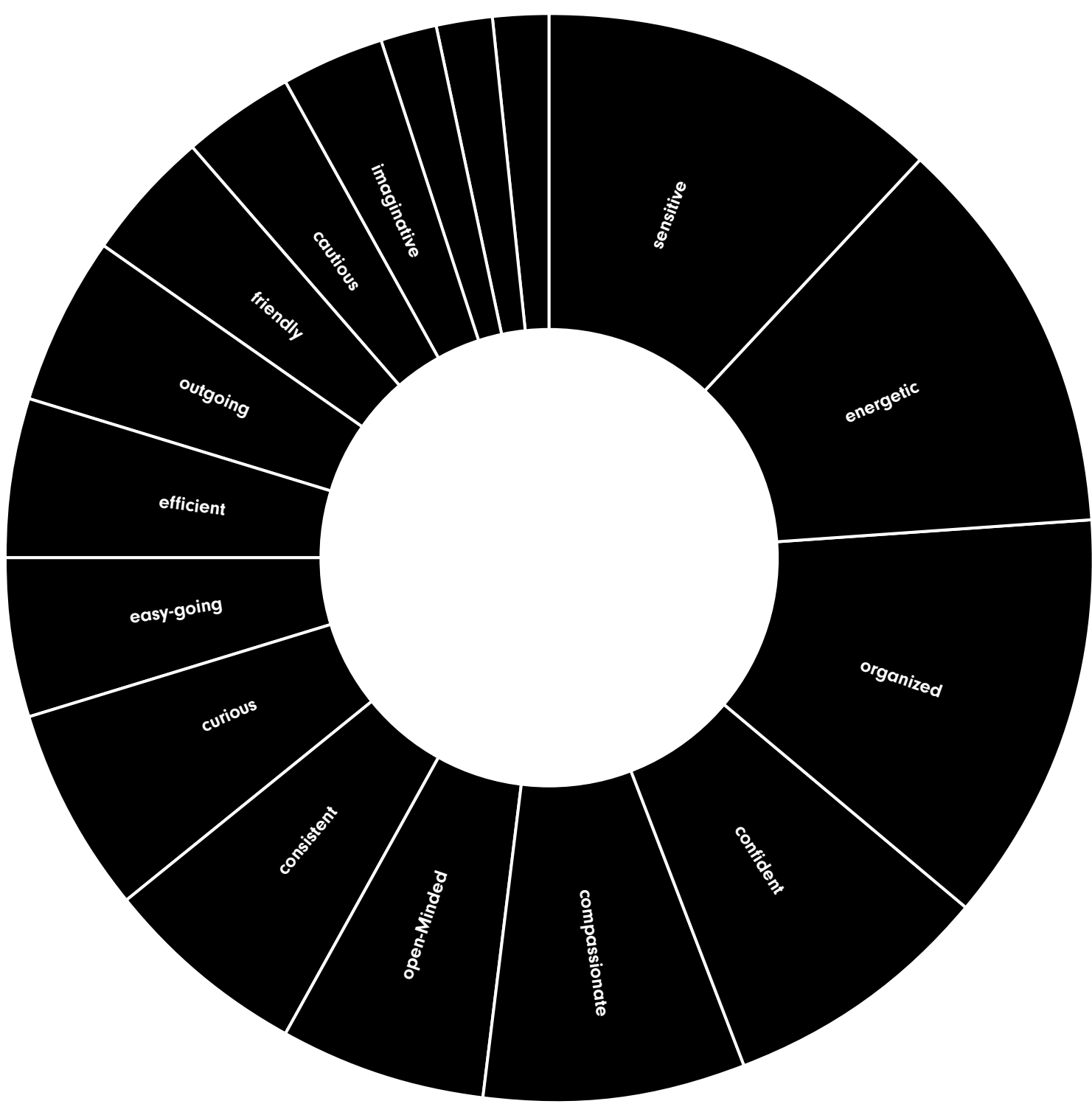

Figure 8. Skills of futurists.
The workplace arena has the most informal character; it focuses on the actual work that is assigned to the ones delivering output. According to Abbott it is the real output of an individual, not the "credentialed or noncredentialed status", that matters (1988: 66). In the conceptualization of the workplace arena, Abbott recognized that it is necessary to acknowledge the diversity of practitioners. Abbott argued that workplace arena is especially blurred because in this arena actual work needs to be completed and deadlines need to be met. Those tasks are far more urgent than any formal agreement on hierarchy or credentials. Abbott argues that in this arena the reputation of a practitioner first and foremost depends on professional attitude, not on credentials. Based on observations at conferences and interviews with international futurists, I obtained data about the necessary skills attributed to a futurist and their dynamics in the workplace arena. I will first elaborate on the views of futurists concerning which skills are significant to them.

During the series of interviews, I asked every futurist; "what skills are necessary to be a futurist?". The answers that the futurists provided are illustrated in Figure 8. In the next paragraph I will explain the skills that futurists have mentioned often and analyze their significance in relation to the workplace arena.

Conversations with futurists demonstrate that they are actively formulating which skills are necessary to do this type of work. After examining the first layer of the quotations provided by futurists on this topic, it emerged that futurists did not pause when answering this question and were articulate in why they think certain skills are necessary. The three skills that have been mentioned most often by futurists are sensitivity, energy and organization. The accompanied explanation discloses much about the implicit norms that govern the futurists' workplace arena. I will elaborate on each of these skills by citing what futurists explained about them during the interviews.

Futurists describe the importance of being in touch with what is happening around them, to be sensitive. According to futurists, being sensitive is to understand the dynamics of change. This requires different types of sensitivity, both internally as well as externally focused. Internally focused sensitivity is the skill to be curious in order to gain deeper understanding of trends in relation to the future. Externally focused sensitivity is the ability to understand the needs of clients and their context.

A term a senior futurist used was intellectual sensitivity'. This type of internally focused sensitivity can be understood in terms of curiosity that drives futurists' acquisition of a deeper understanding of new developments.

I mean with sensitivity that you have the power, the capacity of training yourself to see a lot of interesting things and give depth to it, depth sensitivity.

According to futurists, they need to be open to adopting new methods and tools to improve the quality of their work. Hence, they mention another aspect of internally focused sensitivity: to be sensitive in order to adapt to how knowledge is used. The same senior futurist elaborated on this some more:

Sensitive for new ways of thinking, new developments, new ways of doing foresight, because it is a profession in development and I need to be sensitive for things in movement and things that are important. 
The futurists also give examples of more externally focused sensitivity. Futurists describe the importance of being sensitive to the setting they are in. To be able to understand change a futurist needs to be open to new things. A newcomer futurist elaborated on this:

I see it as being aware of your environment. So, sensitive in the sense that I am curious, I'm looking a what is going on around me and I look for the why. So, I question; why is this happening? What does a particular sign mean? What kind of value does it have for people?

Sensitivity is also linked to the ability to connect with others. This is important because futurists are part of a change process and need others to be able to carry out the work. An established futurist lived by the following words:

A futurist needs to be able to basically form an ecosystem with other people that support the change process.

Next to this sensitivity futurists describe that because their role largely entails the radiation of energy to crowds they have to be energetic. They often take on the role of enhancer of a process and the leader into a new way of thinking. That requires an inspiring and positive mind-set. A futurist familiar with the community described:

Yes, you should be energetic because that's contagious, people are actually listening because of that.

Or, they must at least give the impression that they have the energy to be out there, a senior futurist trusted me with the following explanation:
It's more the radiation of energy, people always say 'oh wow you are in Shanghai?' or 'oh wow you are in Madrid' - that's so energetic. To be honest: I am not so energetic; it is more that I understand that I radiate energy. I love to sit on the sofa, reading a book. When I am on stage, I radiate.

The futurists describe that in their work sensitivity for newness is required but that this can also be overwhelming. It raises the question of how to distinguish the relevant ideas from the mediocre ones. This is the phase in which organizational skills are important. Organization is not just a matter of being efficient; it is a necessity to be able to tell a coherent story about the future. By being organized the futurists can separate the wheat from the chaff in the information they encounter. A respective mid-level policy-oriented futurist, a creative newcomer, and a futurist from a strategy firm familiar with the community, found the following words to describe this phenomenon.

\section{It will be chaos if you are not organized.}

You have to filter things because you have to filter what is most important to see connections and see directions and this you can't see if you aren't able to organize your findings.

Most things are hidden in a pool of information. So, if for example I'm reading about 5000 blog posts a day. (..) You have to be able to differentiate between the things that are just interesting and the things that are really game changing.

Futurists describe their skills in terms of being able to organize the overload of available information.
They translate and guide others towards what is necessary to know and away from what is not. A newcomer told me:

There is so much information, so much data, (..) so people who are more organized can look at a lot of different sources and pull different things out of them; that is what you need as good futurist.

Futurists strongly identify with the skill of being organized (they mention it relatively often), but at the same time they do not find the skill unique. According to futurists this skill does not necessarily set a futurist apart as any practitioner could benefit from it. Below is another example of how an established futurist described the generic skill of efficiency.

I think efficiency is important. So, I think that in order to provide value for people a certain amount of efficiency is required and organization as well. But I think these are pretty generic. They apply to many, many fields.

Remarkably, not all futurists were willing to sum up their skills. Some futurists were critical of having to identify similar skills. A futurist familiar with the community formulated this as follows:

I think there's none that you need to have as a futurist. I mean, you might think energetic. But then again there are some futurists who are pure thinkers. They sit down, gather thoughts and communicate them effectively. So, they can just as well be energetic. And I think you know you could be any of these or the opposite of any of these. Really, it means again there's a different style to how a futurist engages. 
Some futurists could not imagine that there are skills specific to futurists. According to these futurists the skills of every futurist are unique, there is no general commonality. The quotation above is an example of this stance. These futurists dismissed the usefulnes of establishing common skills as to them the common skills noted by other futurists are generic across many professions.

In Chapter 3, diversity among futurists was a topic of discussion and caused dispute. The importance of diversity was confirmed during interviews, futurists told me that their strength is originality and the ability to be autonomous. This corresponds with the observation made in Chapter 3, that most practicing futurists have interdisciplinary backgrounds and only decide to become a futurist in a later phase of their lives. Frequently, futurists shared there was no specific intention to grow the skills of futurists but rather the practitioners became futurists by accident. For example, after practitioners noticing a pattern that they were working on several forward-thinking questions, they may have identified as a futurist.

As Figure 8 illustrates, futurists claim to have many varying skills. However, in spite of that diversity, Figure 8 also draws attention to some generalities. Futurists represent their skills in the following way; the futurist can quickly adapt to people and situation and is sensitive to the worlds in which they move. A futurist knows how to make others enthusiastic by energizing and engaging their audiences. Futurist are also researchers that are used to managing a lot of data; they describe how important it is to be able to cope with that by being organized and by being able to determine relevance. Futurists also described the importance of balancing what appears, at first glance, to be contradictory skills, sensitivity and confidence. They describe that being confident is necessary to bring ideas to an audience, whilst sensitivity is necessary to communicate change to an audience.

At first glance it became clear: skills help futurists explore their professional unity. I observed how some skills were articulated as universally necessary for every futurist. At the same time, I noticed how futurists articulated different nuances in how they actually specified their individual skill set. For one futurist, sensitivity meant something else then for the other futurist. Moreover, next to some general skills that were voiced, futurists also mentioned many additional skills necessary for their individual practice. Those additional skills were distinctive, depending on the context of the futurists and his or her professional aspirations. 
During the interviews I started to notice that not only skills connected the futurists. In the conversations, it emerged that growing as a futurist is as much about developing a mindset as it is about working on a skill set. It became apparent that futurists share a specific way of looking at the world. Moreover, several futurists have described that there was no deliberate choice in developing a futurist mindset, it had just grown over the years.

How do futurists describe their mindset? One of the main features that they have articulated is the futurists' natural combination of rational scientific thought with intuition. They often referred to the importance of uniting both the analytical and the imaginative side in their work. Futurists are keen to validate their research to demonstrate they are solid researchers. Furthermore, at the same time, they need to be able to charm a crowd by using storytelling, images, sounds and video to effectively bring across a deeper understanding of futures. Futurists like to bring imagination, but emphasize they make sure that there is a solid foundation too in order to convince their audiences.

The futurist mindset is open-minded and growth oriented, as they aim to think

differently about topics that may in the eyes of others be confronting. Futurists like to ask unexpected questions about the world and are curious to know: could it be otherwise? As such, futurists describe their wish to transcend difficult or uncomfortable topics and help others navigate them.
For example, although the word uncertainty in itself has negative connotations and is often avoided, futurists try to embrace it. To them, the uncomfortable space of uncertainty is a valuable source to yield new questions. Moreover, futurists describe that their antidisciplinary mindset enables them to identify the topics and places that are tedious but productive. Especially since futurists naturally cross multiple worlds and think across disciplines that help them generate new ideas.
During conversations on skills of futurists, practitioners also frequently referred to the dynamics of their workplace. According to futurists, the people with whom they work are likeminded practitioners with similar drive, but also 'rebels' and 'out of the box thinkers'. However, futurists hardly ever refer to other futurists in terms of 'we'. They describe having small circles of trusted practitioners around them that they perceive as their closest allies. Despite this, the futurists in the conversations did not refer to those other practitioners as futurists. In fact, there are hardly any projects that futurists undertake together. During interviews and group discussions other futurists are described as 'others' and 'they'. Instead of aligning with other futurists, they tend to reach out to other likeminded practitioners who are capable of doing different things, other types of experts. For a futurist it is self-evident to work with others on projects. In the workplace arena, tasks are often completed in an interdisciplinary team. Futurists consider their teams to be broader than futurists alone. A futurist familiar with the community used the following words during a group discussion to describe his relation with other futurists:

The work of a trendwatcher consists of collaboration with likeminded practitioners, designers, researchers and clients. But not with other trendwatchers. This could be possible in a larger assignment, but with a simple lecture it is best to work alone.

During conversations futurists emphasize that they would actually like to work more with other futurists but they admit that in practice, they rarely do. They find partners that have similar expertise but who also offer additional skills. When asking futurists: "Who would you hire as a futurist if you had carte blanche?" they respond, almost without exception, that this is difficult to answer and that it differs. They suggested that it depends on the project and what is necessary to achieve. An example response from a futurist familiar with the community:

Yeah that's hard. I would say it always depends on the segment or the category. Because, but at least that's what we do. We always work with experts from the field we are trying to approach.

The team of practitioners that futurists involve depends on the project. The futurists describe that in picking the right practitioners to cooperate with they are sensitive to the clients' wishes. In picking their team, other futurists are usually not considered. Their explanation for this choice is that the projects need practitioners with different skills.

According to Abbott the basic question of the workplace arena is who can control and supervise the work and who is qualified to do the work. Futurists did not show any interest in the first question (control and supervision) but did refer to who is qualified by addressing the necessary skills. Conversations with futurists illustrated that the necessary skills are, although often tacit, very clear to futurists. Yet, the futurists have not formulated a list of skills that every practitioner should have, nor have they followed a common curriculum. In spite of this, futurists do clearly articulate what type of practitioner is fit to do the work. Addressing skills was for futurists a much-appreciated exploration of their common ground. where practitioners establish power and legitimacy. 
20 In his extensive overview Son (2015) provides an insightiful

framework of the many traditions in futures thinking.

21 The Dutch title is: Toekomst van de toekomstindustrie,
manifest voor oneindigheid. Translated as: future of the future

manifest voor oneindigheid.
industry, manifest for infinity.

Here the practitioners establish their right to do certain kind of task, which eventually leads to socia and cultural authority. For the public, explanation is necessary. Additionally, in her work on the professional project Larson points out how important it is to generate trust among clients and outsiders. In this arena a common effort is made by practitioners to influence and instill the public identity of the profession.

How do futurists construct their image for outsiders? Futurists have described during interviews that outsiders have a somewhat skewed idea of what a futurist is. The source of a dominant image of futurists as 'prophets' dates to Antiquity. In ancient times, an oracle was seen as the intermediary between ordinary people and higher powers. In the legend of King Croesus, he asked the Oracle of Delphi in 500 B.C. if he should go to war. The oracle answered that if he started a war, a kingdom would be lost. This answer convinced the king to go to war, as he did not realize that the oracle referred to his own kingdom, which would be defeated. The future has had this mystical aura since the beginning of mankind. The idea of human ability to influence the future only arose in modern times (Adam and Groves, 2007; Nowotny, 2008). ${ }^{20}$

Despite of the different character of the futurists' work today, old images of crystal balls and fortune-tellers prevail. Futurists share that they are very aware of the cliché of crystal balls and that this image is still held in the minds of many of their audience members. Futurists told me that one of the first questions futurists often get asked when they describe their work is: do you predict the future? What will the future be like in a few years?
Dutch futurist Hilde Roothart describes this in a manifesto:

Did you know that futures thinking is as old as the Oracle of Delphi and known like the road to Rome? Probably because of these (unconscious) associations, the rising future industry has not been able to get rid of the cliche of fortune-tellers with crystal balls (translated from Dutch) ${ }^{21}$

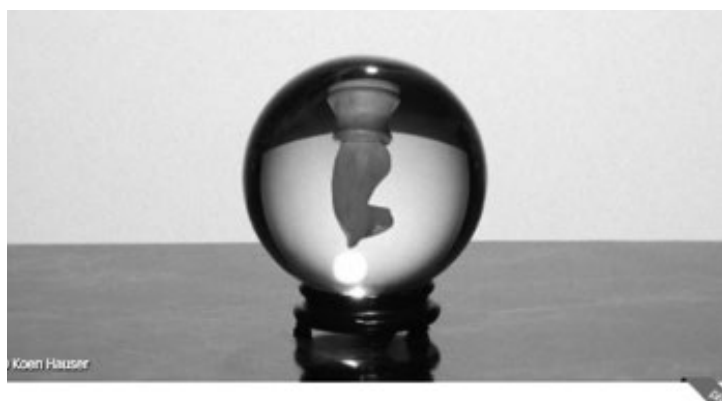

'Een goede voorspelling maakt iets los' Interview toekomstverkenner Freija van Dujne

NTERvEw Of voorspellingen uitkomen? Eigenlijk gaat het daar niet om, zegt Frej van Duljne, toekomst verkenner en president van de Dutch Future Society.

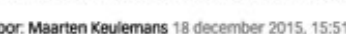

(4) (8) (8)

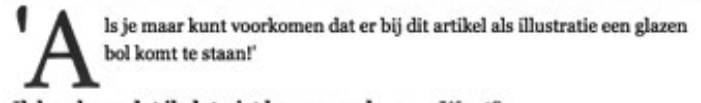

Ikben bang dat ik dan niet hang garanderen.... Want?

Dat zet het vak weg als: het draitit hier on voorspellingen. Maar voorspellingen zijfragmentarisch, je kunt ter vaak weining mee. Bij toekomstverkenningen gaat het juist je hier in ming thegglas dat we in de toekomst geen voedsel meer eten, maar een

Figure 9. Newspaper article depicting a crystal ball.
The futurists described their frustration with this crystal ball imagery. They often started lecturing on what they actually do and that it has nothing to do with crystal balls. When a newspaper article is published on a futurist, crystal balls are often illustrated in the accompanying images. The chair of the Dutch Future Society, Freija van Duijne, once expressed her amazement during a board meeting (fieldnotes 18 December 2015) about an article that was published that morning, in which she was interviewed about her profession. After concluding the interview, van Duijne asked the interviewer 'please do not use a crystal ball as the accompanying illustration'. The journalist could not promise this because the illustrator had already embarked on the project of finding an original take on the crystal ball. It transpired that the illustrator had already rented a studio and was set to take the picture. It could not be cancelled at that stage and a crystal ball was presented at the top of the article, see Figure 9 .

As Abbott argued, the public opinion is slow to adopt images made or promoted by a profession. In the case of futurists, images of crystal balls proved to be common. The attempt to dispel myth and cliché has led to an urge among futurists to explain their work. Futurists are conscious that they did not choose a straightforward job. An instance in which this becomes especially clear is when first meeting a futurist and the usual ritual of introduction takes place. Futurists consider this moment of introduction as the first instance in which they can share their professional story. Futurists describe that they take time to explain their job title. More often than not, their audience has no clear idea of what a futurist does. Futurists do not perceive this as negative, as having to explain their work generates new understanding. 


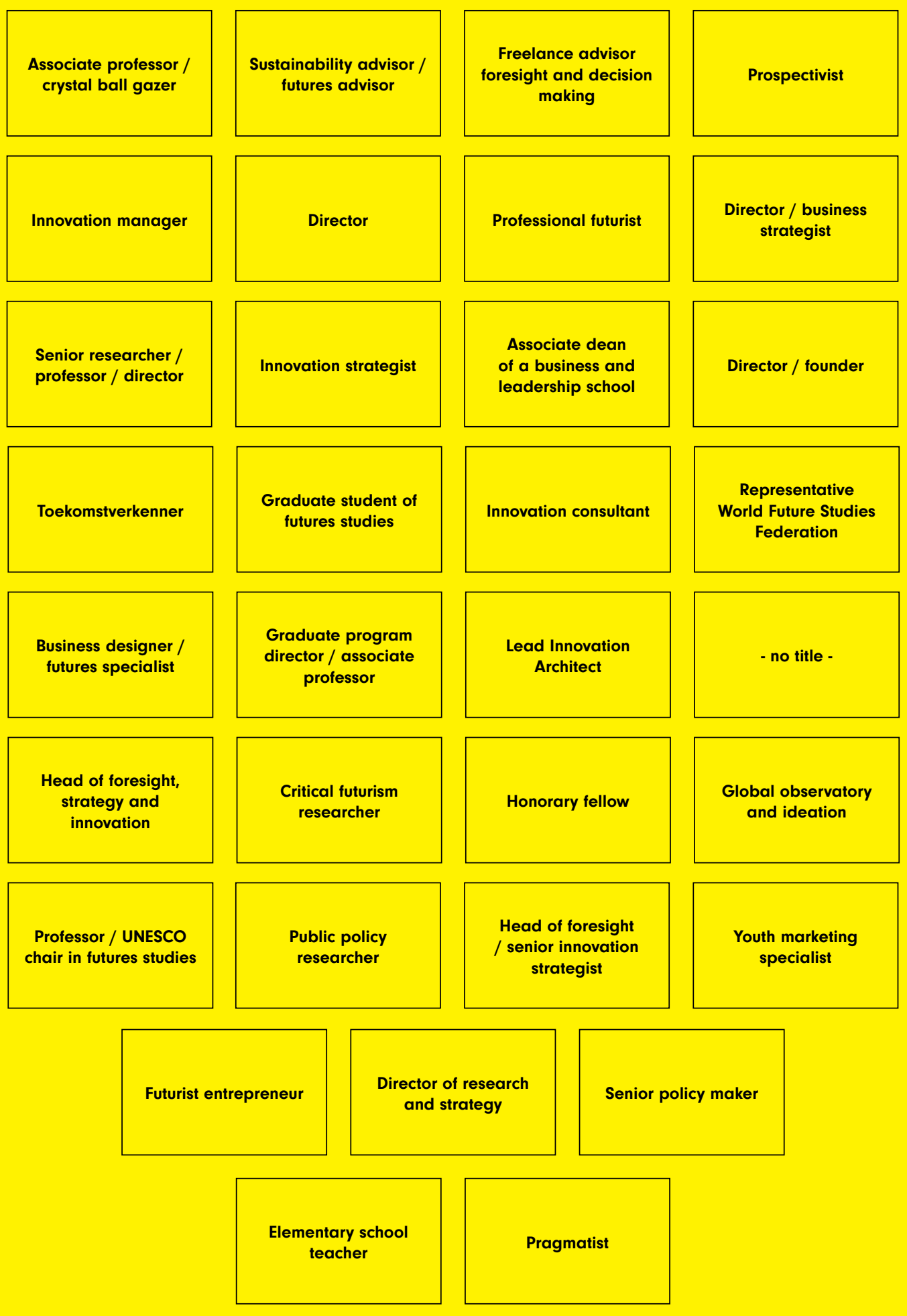

Figure 10. Business cards of interviewed futurists

Of all the futurists I interviewed, none of them mentioned the same title. All of the titles that were cited are shown in Figure 10. In Chapter 3, this lack of a common name for futurists was articulated. Some futurists did not find it necessary to pinpoint such a thing, while others remarked that it illustrates how fragmented futurist practices really are. It is thus difficult for futurists to articulate job titles. Futurists would like more communality but at the same time articulate that they appreciate the artistic freedom that they have to come up with their own unique titles.

It is remarkable that whatever choice the futurists make regarding their title, they are very conscious of the importance of the decision they make. For example, some futurists decide to focus on skills and the type of job. They mention that they are professors, researchers or strategists. They consciously decide not to mention the word futurist or future. Futurists told me they do this for several reasons; some would never think of referring to themselves as a futurist while others express that they do not feel comfortable with using such a title. The latter reason suggests that for some, the title futurist does not hold positive connotations. These futurists articulate their desire to keep it simple and not refer to futures at all. A futurist familiar with the community said:

I say strategy-advisor because people understand that better, while I am in fact a strategy facilitator.

Another group of futurists do the opposite; they choose to focus on their futuristic appeal and call themselves a futurist of any sort. They believe that this title helps them to provoke conversation. Futurists explain that people are not immediately aware of what they do and so they take the time to explain, which they do not mind. Others explain that their job title helps them pitch their value. Those futurists describe that in the process of explaining their title, at least they stand out of the crowd. For example, one futurist playfully addresses himself as a 'crystal ball gazer'. This futurist explains that this term is not suitable for every audience but he notices that it does spark imagination.

The international character of practitioners also has implications for the choices futurists make in their job title. Geography determines which words form part of the vocabulary. For example, in the Netherlands, the word trend is commonly used, whilst in the UK or the USA this word is hardly mentioned.

Moreover, futurists often describe using several titles at once, depending on the audience they face. For example, if they meet an expert audience they are inclined to turn to titles that will resonate with that group of people. If the audience is broader then they tend to use the word futurist. Futurists often come up with their own job titles, often consisting of several words. For example, the Dutch Future Society launched a website on which futurists could subscribe and make a profile of their work. One of the questions asked by a futurist before filling in the form was: "is it possible to insert my own titles instead of standardized titles?"

Job titles also have another function: they are part of a form of social control. Futurists pay attention to the titles of other futurists. They make remarks and use typologies to address certain (lesser-) qualified groups. These qualifications are again culturally oriented. For example, in the Netherlands, futurists describe that a word like trendwatcher is supposedly used by 'superficial entertainers' (fieldnotes, April 2015) 
Some futurists prefer not to associate themselves with this word. Outside the Netherlands, the word futurist has a similar connotation of an entertainer, although it is still widely used by many.

When strictly adhering to the definitions of workplace and public opinion arenas, futurists' efforts would not count as claiming jurisdictions, but their activities tell me otherwise. The aspiration of futurists to professionalize is visible in both the workplace and public opinion arena. Futurists discuss, examine and negotiate about what unites and separates them from each other and from other occupations. In this case, it does not matter if futurists are successful in achieving both jurisdictions, but rather that and how they take actions in the arenas.

The paradox of (not) fitting in In Paragraph 4.2, I described that Abbott claimed the legal arena to be the most durable, usually lasting for decades or even hundreds of years. A claim in this arena means that a profession has gained a monopoly position over certain tasks. In obtaining a lega jurisdiction the practitioners must therefore rigidly define and demarcate their tasks. There is no possibility for altering practice; practitioners are legally the same and their practice must be uniform. When practitioners obtain legal jurisdiction, in hierarchy the last of three arenas, the profession has reache 'the heartland'. The assumption is that this uniformity is the ultimate goal for (almost) every profession.

With the aim to professionally grow, futurists have looked for ways to organize themselves, for example by stating that a union is needed. ${ }^{22}$ Other futurist have looked for ways to find more formal common ground, for example, in journals, as well as at con- ferences. However, during those particular group conversations, futurists never fully took the idea to search for formal common ground seriously or made concrete plans to pursue it. On the contrary, if there is one aspect on which all futurists agree, it is their ambiguous relationship with rules, regulations and standards. They describe how efforts are being made to create these rules, regulations and standards and yet they simultaneously articulate that their practice is still very autonomous. A well-known futurist explained:

The futurist practices are scattered. People are working on standardizing them. For example, in journals like Futures.

In addition, a futurist working at a large commercial firm described:

It is still very individual, we don't have standardized products and to me that's a sign of a new industry.

The two citations articulate a comparable observation. Both futurists expressed that their practices are individual and therefore "scattered". The futurists described how they are part of a new industry. They also referred to efforts being made by people to standardize the practices of futurists. The reference to the word 'people' creates a certain distance, as if this is happening behind the scenes. In the second quotation, there is also a reference to standardization and the assumption that this ought to happen to enable transformation into a mature industry.

The quotations from the futurists above are not just reflective of the current situation but also communicate futurists' doubt on how to advance their collective professionalization. Hardly any of the futurists expressed the wish to professionalize in any formal way. Rather, futurists expressed that they did not have the intention to claim jurisdiction of thei practice in such formal way. This observation is supported by results of the Delphi study (Gary and von der Gracht, 2015) that I referred to in Chapter 3. The 143 participating futurists were articulate about their least desirable projection for their future: a recognized council for standards (expectations that this could happen was just over 20\%, the lowest ranking). The participating futurists voiced reluctance towards the possibility of a council for standards.

Futurists that work in more institutionalized domains, like a university, mention the struggle of fitting into the existing structures. Most futurists are familiar with institutionalized professions that have rich traditions as they have been educated in a traditional academic setting or have hands-on experience within an institutionalized practice. Thus, the futurists understand what is necessary to conform to the legal arena. A scholarly oriented futurist articulated this as follows:

The same rules apply. Though we are not (..) positivists like traditional scientists are.

Futurists with academic ambitions described that they strive to be taken seriously and be considered as credible academics. The work of futurists is regarded as something out of the ordinary. The futurists ex pressed that it takes time to explain the value of their work to other academics. They also described the necessity of having patience as they seek to gain acceptance of their work. Other futurists describe their reservations regarding university training. 
Futurists explain that a cross-functional mindset is required, but that this is a type of mindset that can not just be trained through academia. A newcomer told me:

I don't see how it is ever going to be possible very effectively train a professional futurist through a university system or through academia. You need the cross-functional mindset. You need a cross-functional mind and cross-functional thinking and you need a little bit of life experience.

Many futurists at least have an academic orientation as most of them were academically trained. Futur ists described the struggle between longing for academic recognition and the uneasiness of trying to fit into a system that does not fit with their practice.

The struggle with the academic system is symbolic of the broader reluctance that futurists have voiced. Full jurisdiction of a profession (claiming jurisdictions in all three arenas) assumes that at some point the practitioners will reach agreement on their (legal) common ground: the heartland. After reaching the heartland, there is the implication of a certain degree of stability and uniformity. Of course, professions are assumed to evolve and change (for example because of new technological developments), but are less likely to be challenging basic agreements continuously.

The accounts of futurists illustrate the opposite of any stability and uniformity: they honor the continuous renewal of the questions asked as well as the foundational knowledge and topics. Futurists have even described that they are never done learning. Besides the particular skills that are considered nec essary, the futurists describe that they need to have a specific mind-set to be able to do the work. A newcomer futurist described this as follows:

I have deep interest in how society functions and evolves. A little bit of anthropology and social science here and there, a little bit of politics. When you put all of that together then you have a cross-functional mind.

Futurists often referred to learning as a vital part of their practice. The quotation above gives a good impression of how futurists have articulated this. I observed how futurists are eager to think across disciplines, like anthropology and social science, to collect the knowledge they need. During interviews and informal conversations at conferences, futurists articulated that it was challenging for them to draw boundaries. Moreover, they did not express any urgency to explicitly demarcate their practice from other related practices. Especially because it could strip them from a source of knowledge that futurists deem necessary to grow professionally. A well-known futurist claimed:

\section{The field needs soft boundaries.}

This call for soft boundaries fits into a broader understanding that rigid boundaries may not necessarily beneficial for the involved practitioners. In Chapter 1, I referred to Bauman's Liquid Modernity (2000), in which he addresses the changing context of professions, arguing we find ourselves in a time in which old systems are no longer sustained, but that new systems are yet to be designed. Intuitively, futurists strive for boundaries that are 'soft', or 'fluid' as Bauman would suggest. Futurists also use other words than 'soft' to refer to the boundaries they wish to draw, for example by suggesting that it is their ambition to be frameless. A futurist familiar with the community described:

Most people need a frame they can operate in, and, as a futurist you need to be frameless in terms of, you do not judge and you do not have an opinion but you just see things coming and research them

How may one understand this 'frameless' mindset? Futurists describe that the (academic, commercial or artistic) worlds in which they operate are the reason why this is important. The same futurist continued:

That (to be frameless) is what the business has in it self as well: that it's always without strict boundaries, without a frame.

The broader interpretation boundaries also become visible the other way around, when futurists describe, as detailed in Chapter 3, that they do not own the future alone. There are other practitioners that use futurist knowledge in their work too. Varying motives attract practitioners to pursue their own interest in the future, for example, to stay ahead of competition or to understand strategic risks that might not be visible yet. A newcomer told me:

In general futurists can be from various backgrounds, like from the creative industries, designers, marketers, innovation strategists but also of cours people from humanities, psychologists, sociologists. It's really a broad spectrum. I think that is what makes this industry special and not like any oth er industry because it's quite open in a way. It also makes it quite difficult. 
Futurists honor diversity of practitioners and practices and the accompanying soft, frameless boundaries. Any formal attempt to standardize practice or knowledge evokes suspicion among futurists. The reluctance of futurists towards claiming jurisdiction in the legal arena, is unmistakable. A key component of practitioners becoming a profession is the objective to professionalize legally. In Chapter 3, I demonstrated that in the professionalization discourse, some futurists focus on the need for common education, codes of conduct and ethics. But in their practice, majority of the futurists expressed their reluctance to set rigid boundaries, let alone legal rules, because they do not feel it suits their practice.

Futurists carry out several activities in the workplace and the public opinion arena. But not in the legal arena. What does that mean? Abbott sees the professionalization process as a natural evolutionary force, leading to presupposed utopia of all occupational groups becoming true professions: the heartland (1988: 71). In addition, he argues that, "every profession aims not only to possess such a heartland but to defend and to expand it."

As the previous paragraphs have illustrated, futurists do not confirm to all arenas of the jurisdictional perspective. The way in which jurisdictions are presented theoretically, does not strictly align with the activitie of futurists in either of the arenas. Jurisdictions have been designed to advance a fixed, singular notion of the professional, that may or may not be recognized by colleagues, clients and the public. This perspective assumes that professionals are doing similar work in uniform contexts, otherwise the jurisdictions cannot be claimed. Abbott described in the eighties that, "the few who are content with limited jurisdictions - actuaries, veterinarians - are quite atypical." n Chapter 3, I identified how futurists struggle with the promise of professionalization. The futurists' struggle is a consequence of how they have been trying to adhere to a traits model of professionalization. In order to understand the actions futurists to become a profession, I examined how futurists carry out professionalization activities. Several scholars, like Larson (1977) and Abbott (1988), have made relevant contributions to advance understanding of the practitioner's actions to grow their profession.

In this chapter, Abbott's concept of jurisdictions offered a fruitful, yet not all-encompassing, perspective to structure the empirical data. Abbott distinguished three types of arenas in which claims are made: the workplace, the public opinion area and the legal arena.

a. Skills of a futurist, related to the workplace arena: Concerning the first jurisdiction, the workplace arena, I demonstrated how futurists think about necessary skills to be able to do the work of a futurist. It is noteworthy that futurists have a clear image of the necessary skills of a futurist. A futurist is sensitive, can adapt to different situations, brings energy and is able to organize and structure large quantities of data. Futurists also acknowledge a broader interpretation of those skills and recognize that they need to have a creative as well as an analytical mindset. Futurists take professionalization actions that could be translated as activity in the workplace arena, however, they are not strictly claiming jurisdiction.

b. Image-making of futurists, related to the public opinion arena: In the second jurisdiction, the public opinion arena, futurists consciously try to influence their public image and are articulate about how much time this costs them. As Abbott argued, the public is slow to adopt images made by a profession. Futurists commonly fight the clichéd image of crystal-ball gazing, for example by taking the time to introduce their job title and explain what they actually do. Each futurist feels the responsibility to explain what a futurist actually is and does. However, they do so in their own unique ways, with their own unique titles. As such, futurists carry out numerous activities in the public opinion arena, although they are not strictly claiming jurisdiction in this arena either.

c. The paradox of (not) fitting in, related to the legal arena: Lastly, considering the third jurisdiction in the legal arena, futurists have expressed reluctance to professionalize. The lack of formal structures demonstrates that futurists are not professionalizing along these lines and I observed that they are not keen to do so in the future. Whereas futurists are taking action in the workplace and public opinion arenas, in terms of the legal arena they are not active as a community at all, not even the most vocal futurists, which unmistakably manifests their reluctance.

Within the sociology of professions, the process perspective has departed from the traits perspective by focusing on the actions that are taken to claim jurisdiction. However, the underlying assumption that professions want to strive for a heartland is maintained. This underlying assumption actually unite the traits perspective with the process perspective.

Intriguingly, whereas traits represent a fixed mode of professionalization and the process perspective has a more dynamic character, both perspectives encourage the development of a 'true' profession and the 
ambition to reach the classic utopia of a heartland. The way in which the traits and process perspective scholars have conceptualized the pathway towards professionalization is different, both emphasizing different aspects, but the underlying assumption that all professions are striving for a heartland, remain unchallenged.

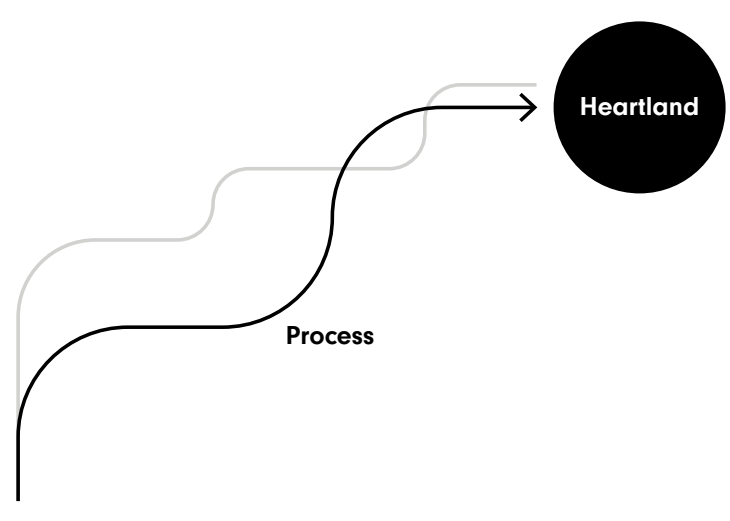

Traits

Figure 11. Visualization of shared assumption in traits and process perspectives that professions strive for a heartland.

Futurists oppose reaching the professional heartland. When strictly following the model of jurisdictions as Abbott envisioned, the actions of futurists would not suffice as professionalization. However, when using Abbott's concept of jurisdiction as a perspective to understand on which actions are taken, it is clear that futurists challenge the status quo in claiming jurisdiction. Futurists negotiate, re-negotiate and construct their professionalization, eventually finding common ground in the diverse possibilities of what it means to be a futurist.
An important feature of the professionalization of futurists is their diversity. In Chapter 3, I demonstrated how much futurists value their diversity, they regard it as a key quality of their identities. Against that background, it is questionable whether the notion of claiming jurisdiction can provide an adequate account of the activities of futurists in both the workplace and public opinion arena, beyond the analysis put forward in this chapter. Since futurists do not aim to possess, defend or expand a heartland, the question is; how do futurists advance their profession?

In the next chapter I introduce additional perspectives to further examine professionalization activities of futurists. The conception of claiming jurisdictions can be paralleled with reputations structures and boundary theory. Especially in the context of the legal arena, boundaries already emerged in the vocabulary of futurists. As such, it may be fruitful to direct the focus of the next chapter to how futurists are building reputations as it may reveal if, and how, futurists negotiate and compete to draw the boundaries of their profession. This is not a paved pathway, because when there are no formal or legal structures, how do futurists actually build their reputations? In the next chapter, pursue this line of enquiry and direct the focus towards how futurists construct their reputations. 


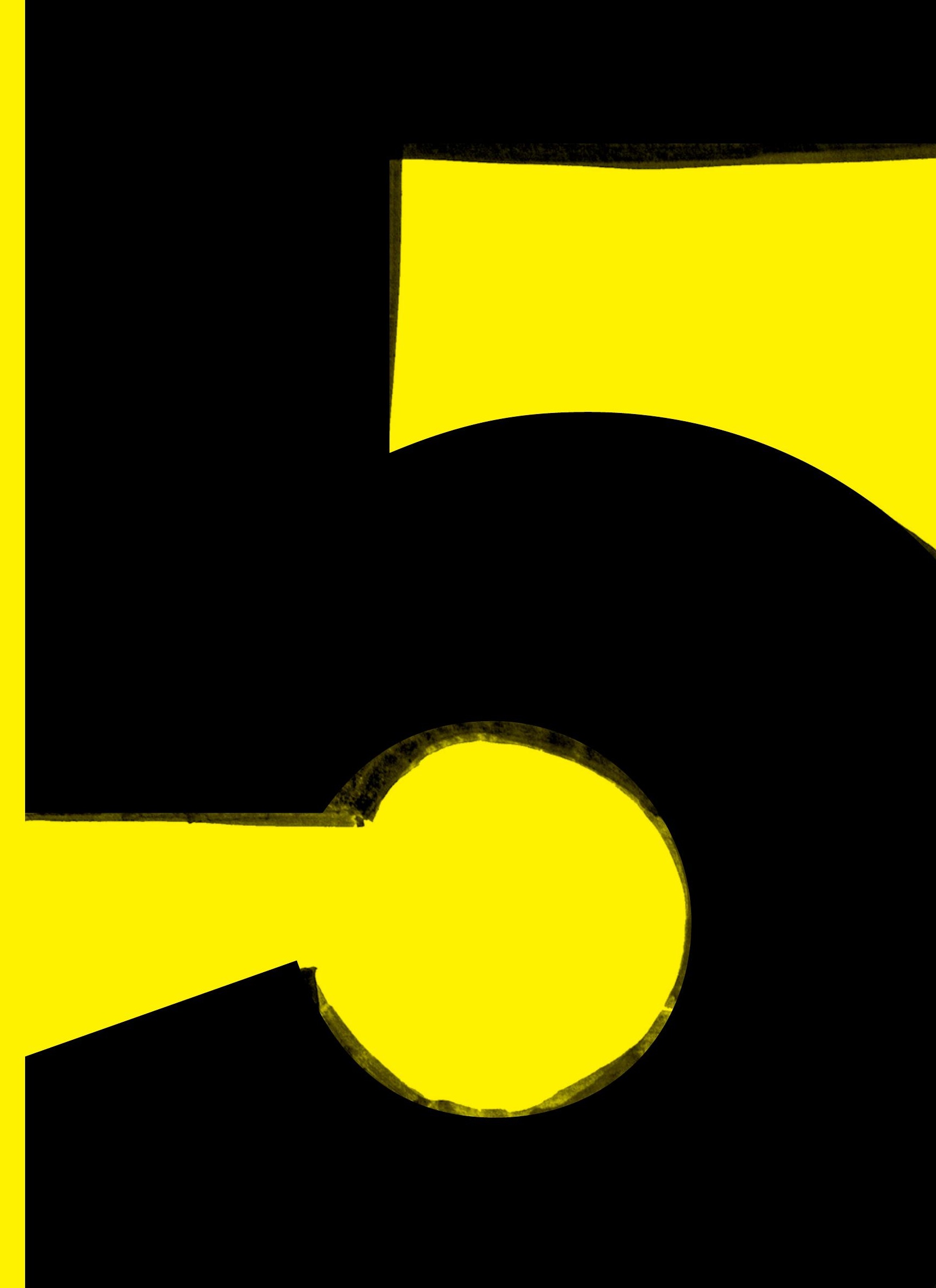




\section{Reputations | a heartland-} free profession
Introduction

Redefining the heartland ambition: the making of a reputation

Scholarly world

Commercial world

Artistic world

Cross-boundary reputations

Conclusions: a heartland-free
5.1

Introduction

In Chapter 4, I concluded that futurists are reluctant to strive for a heartland. The futurists' reluctance challenges the assumption of both traits and process perspective scholars that all professions follow a similar pathway of professionalization. Abbott (1988) argued that there are different arenas in which claims of professionalization can be made: in the workplace arena the public opinion arena and the legal arena. When professionals obtain the latter, a state that Abbott refers to as legal jurisdiction, they reach the heartland of a profession. Abbott (1988) presents this heartland as the ultimate goal to achieve professionalization.

In the literature of the sociology of professions, 'the heartland' is seldomly directly addressed. Abbott used the concept in the System of Professions (1988), although the index did not mention the word separately. Searching ScienceDirect or Google Scholar does not provide links to other scholars that use the word in this context, except for articles authored by $\mathrm{Ab}$ bott (1981) and Freeman (1997) that it is reasonable to assume that every profession aspires to reach for a heartland. This scarcity of references might sugges that scholars within the sociology of professions do not regard the concept as relevant. However, the scarcity can also be attributed to the idea that the notion of a heartland remains unchallenged. Rather scholars maintain the assumption that a profession is professionalized when a certain stage of professionalization has been reached. Unlike many other concepts (such as traits or jurisdiction) this assumption has been, and remains, largely unchallenged by professionalization scholars.

However, in Chapter 4, I have demonstrated that futurists do not strive for a heartland, notwithstanding their activities in the workplace and public opinion arena. This inspired me to pose another question: which notions of professionalization become apparent in futurists' efforts to professionalize? In Chapter 3, I concluded that futurists do not adhere to the classic traits model of professionalization. In the previous chapter, I illustrated that futurists are taking actions to professionalize. Although futurists are in the midst of becoming a profession, they are not professionalizing in a classic way. In the previous chapter, futurists demonstrated which skills are necessary within their profession and how they explain their work to outsiders. Futurists were active in two of the three jurisdictional arenas. The activities in the workplace and public opinion arena are closely related to how futurists build reputations. In this chapter, I further examine how futurists are building reputations and the worlds in which they do this.

In this chapter I first examine the literature on reputations and identify the three different worlds in which futurists are active: academic, commercially as well as artistically. The chapter ends with a reflection on how futurists build reputations individually but with a common feature they all value: cross-boundary reputation building. The foundation of this analysis consists of the interview series with international futurists, the observations at conferences and the group discussions with Dutch futurists. The methodology of this fieldwork is described at length in Chapter 2. the making of a reputation

Reputations exist and grow through the interaction with colleagues, co-workers and clients. My question "who are your colleagues?" proved to provoke confusion. Futurists found it difficult to answer this ques- tion immediately. Almost without exception, clarifying questions were asked in return, especially with regards to the interpretation of the word 'colleague'. This also happened during one of the group discussions, in April 2015. After a preliminary clarification, I transcribed the futurists' responses in my fieldnotes as follows:

The futurists consider their colleagues as broader than merely other futurists. A distinction is made between futurists, like-minded people, colleagues who work from the same DNA (like designers) and also, specialists on a particular topic. It is project dependent, colleagues do not necessarily have the same skill set but help improve the quality and/or relevance of the work. In general, colleagues add something extra.

It transpired that futurists interpret the word colleague in different ways. Futurists mention differen types of professionals as colleagues, including startups and anyone that influences their thinking. According to the participants of the group discussion the definition of a colleague is highly dependent on the settings in which they operate. One of the futurists suggested that colleagues could be distributed in 'circles'. Those circles are described as fluid and different for every futurist. Image 8 depicts the subsequent effort to explore and visualize social circles. 
23 Publish or perish implies that the production of persuasive publications leads to the acceptance of colleague peers (Hyland, 1999). Acceptance increases the amount of citations by other scholars. The quantity of 'accepted' work that has been produced affects the scholar's reputalion. The criteria tor high reputation publications (Dewett and Denisi, 2004). Moreover, scientific quality, productivity, and even tenure is primarily judged through citation counts (Snyder and Bonzi, 1990).

24 Whitley (1984) states that systems of scholars' reputations are the core organizing mechanisms of science (Simpson, 1985: 658). In the scientific community etiquettes exist about how work is execuled and evaluated. This set of behavioral codes is of the foremost importance. According to Whitley (1984), reputations

ists' reputations depend on clients outside of the futurist community. According to futurists, validation of one's quality is done via the market. An established futurist argued:

If the professionals do the best job possible then the marketplace will recognize that

Each futurist I interviewed was quite clear that they focus on the judgement of their clients. If their work does not meet the requirements of the client, neg ative referrals can be expected. These referrals are vital in building a reputation. Futurists describe that they expect to be judged on their quality every time they complete an assignment. However, in practice, the assumption that only clients judge quality does not hold. During conferences I observed that futurists long to exchange about how to judge quality as there are no official criteria or credentialed guidelines. How do futurists construct reputations in such a context?

There is a rich body of knowledge on how reputations are built. This interdisciplinary body of knowledge has roots in the sociology of professions as well as in science and technology studies. Distinction between experts, in terms of their reputation, are relevant as they reveal desirable attitudes, social norm and a perception what of a 'good' colleague is. As Fombrun and Shanley (1990) and Fombrun (1996) suggest: reputation is a general impression, which represents how a collective perceives an organization or an individual. Futurists describe that maintaining their reputation is vital to their professional success. This is not just relevant on an individual level. Frankel (1989: 110) argues that overlapping aspirations, values and training connect practitioners. are won by persuading the relevant audience of the importance of one's work and in this manner affecting their own priorities and procedures. Gaining a reputation in the scientific comm definitely has a competitive element. Scholars compete for claims for future funding (Simpson, 1985: 658). With extra funds scholars are able to further develop their reputation. Pichard Whitley's view on reputation structures originates from the conceptualization of bureaucratization by Max Weber. The German sociologist Weber tried to understand the impact of bureaucratization on society. Weber (1971: 270/1920) coined the term "disenchantment" to describe the way in which scientific thinking in the modern world has 'swept away sentimentality' (cited from Giddens, 2009: 20). Moreover, bureaucratic

A review of included literature on reputation structures resulted in the overview in Table 2. Table 2 demonstrates that reputation structures have been generally perceived as limited to one world. Simonton $(1983,1992)$ was the exception and crossed the boundaries of two separate reputation structures. The table also demonstrates that scientific reputations have been explored at length. Whitley (1984) has written extensively about scholarly reputations, Rao (1994) and Evetts (2011) have focused on reputations in commercial worlds, and a few others have explored artistic worlds.

\begin{tabular}{|c|c|}
\hline Academic world & $\begin{array}{l}\text { R. Whitley (1984) T. Dewett, A. Denisi } \\
\text { (2004) D. Simonton (1983), Hyland } \\
\text { (1999, 2011), S. Bonzi, H. Snyder (1990), } \\
\text { S. Akkerman, W. Admiraal, R. Simons } \\
\text { (2005), B. Keith, N. Babchuk (1998), } \\
\text { C. Camic (1992), K. Merton (1972), C. } \\
\text { Goldman, S. Gates, Brewer, D. (2001) }\end{array}$ \\
\hline Commercial world & $\begin{array}{l}\text { P. Montagna (1972), W. Goode (1957), } \\
\text { V. Rindova, I Williamson, A. Petkova } \\
\text { (2005), M. Frankel (1989) H. Rao (1994), } \\
\text { M. Larson (2003), J. Evetts (2011), E. } \\
\text { Hughes (1960) }\end{array}$ \\
\hline Artistic wc & $\begin{array}{l}\text { G. Lang and K. Lang (1988), D. Simon- } \\
\text { ton (1992) }\end{array}$ \\
\hline
\end{tabular}

Table 2. Overview of literature review on reputation structures.

The literature on reputations presupposes that reputations are made in one world. There is explicit attention for scholarly reputations and commercial reputations and somewhat for artistic reputations. Taking into account the diversity of futurists, which has become visible throughout the previous chapters, I would not do justice to futurists if I choose a par- rationalization also affected the world of science, whilst reputational systems became solidified in university disciplines (Simpson, 1985). Consequently, this can be identified as an
indication of the 'bureaucratization of science' (Simpson, 1985: 658).

ticular reputation structure a priori. In each of these worlds it is to be expected that a different set of rules applies. In the following Paragraphs, 5.4, 5.5 and 5.6 respectively, the three reputation structures will be elaborated on and connected to what futurists have shared about each of them

Scholarly world

According to Dewett and Denisi (2004) reputation in the scientific community is based on the judgment of peers and not that of outsiders (Goode, 1969). The scholar's reputation is evaluated on the basis of the quality of his research and its impact on the development of the scientific field. For scholars it is necessary to publish: it is 'publish or perish'. ${ }^{23}$ Through publishing in journals and presenting papers at conferences, scholars gain acceptance in the scientific community (Hyland, 1999). Attaining reputation is vital in order to become an influential scholar. ${ }^{24}$ According to Dewett and Denisi (2004), three qualitative criteria influence reputation: publications in the best specialist scientific journals, the number of journal editorships and the number of research related awards. However, understanding scientific reputation requires more than simply focusing on quantity of citations and publications (Dewett and Denisi, 2004). Simonton (2000) describes that a scholar needs to produce a significant amount of quantity before quality is reached. Scientific reputation is more complex than just counting publications and citations.

For a futurist, this type of building a reputation is common. Many of the practitioners have been trained in academia. Futurists describe that this helps them to be taken seriously. Futurists described that it is vital to have the mind-set of an academic. They should be able to adopt the scientific mode of critical analysis. 


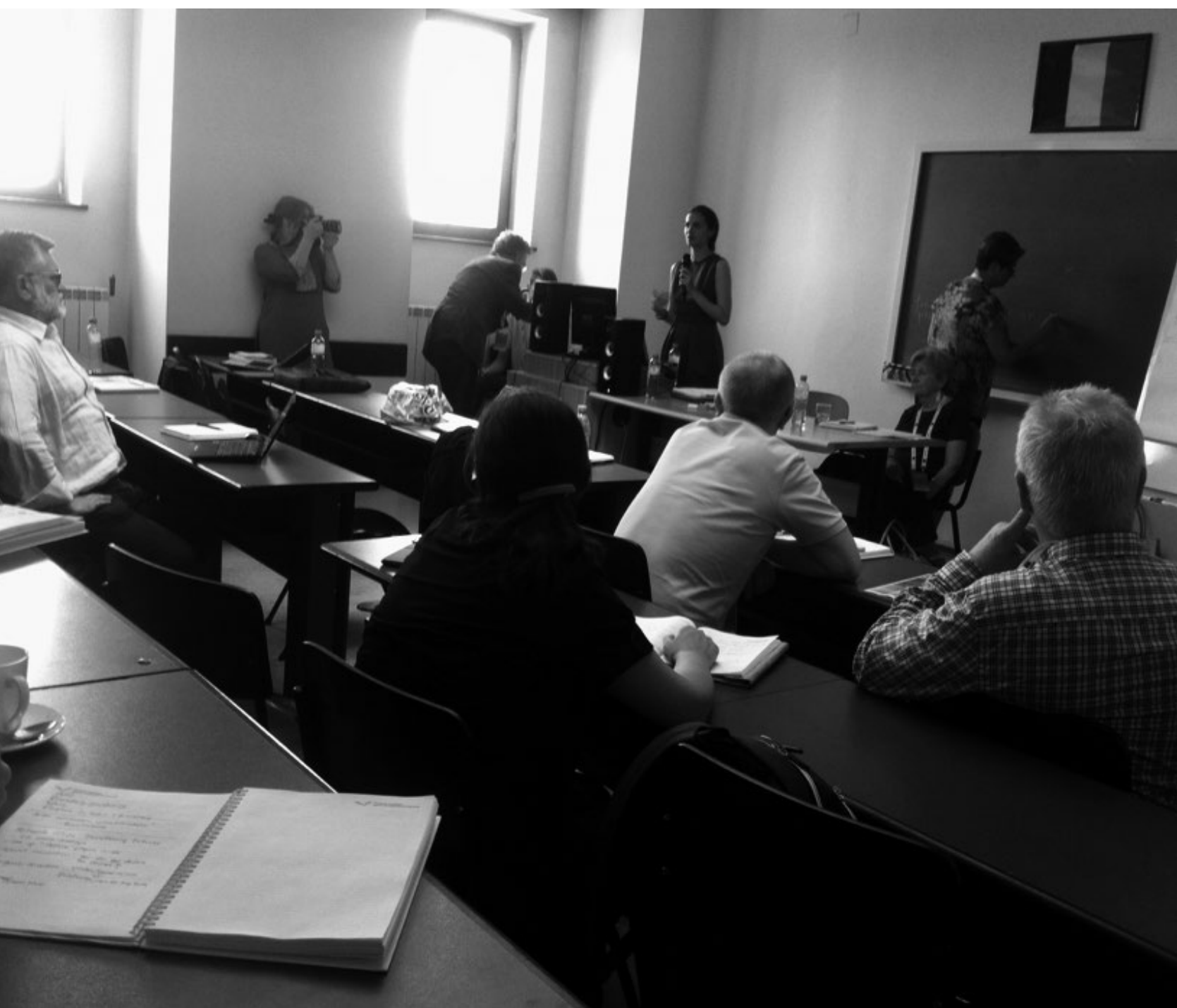

Image 9 Meeting of WFSF members after the conference in Bucharest, 28 June 2013.

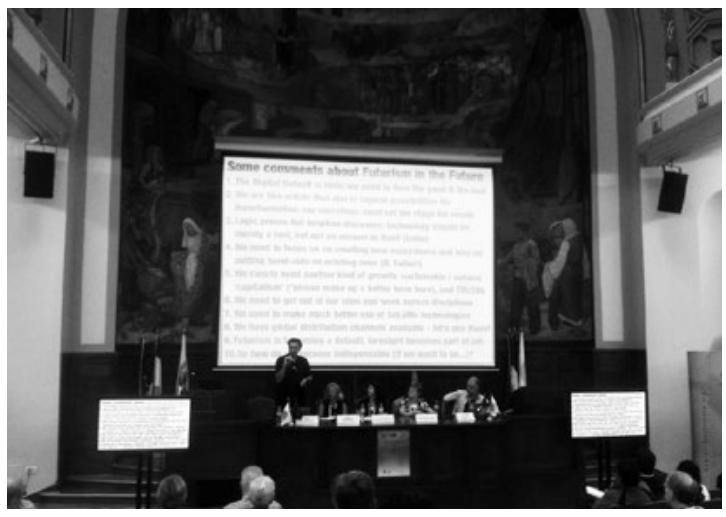

Image 10. Keynote speech of futurist Gerd Leonhard at the WFSF conference in Bucharest, 27 June 2013.

Of the 50 conferences I have attended, the WFSF conferences had the strongest academic orientation. Both conferences I attended (in Bucharest, Romania in 2013 and in Turku, Finland in 2015) were set up as academic conferences, including a call for abstracts and papers. The format of the conferences was aligned with how academics would organize a conference; the programs consisted of a few key note speeches (by relevant futurist scholars) and separate sessions in which four or five academically oriented speakers had the time to present their futures research to a smaller audience.

In the fieldnotes for both conferences, I described the formal character of the conferences. The conferences took place in university settings, in lecture halls and classrooms. The main lectures took place in the largest halls in the venue. The scheduled speakers were lined up behind a long lectern and took turns to present their studies. My notes point out that the attending futurists had trouble with the little time allocated to answer any questions about the keynote speeches. There was hardly any space for improvisation. Moreover, as well as the notes, I also took pictures of the conferences. At both WFSF conferences, most pictures I took consisted of PowerPoint slides with references to academic (futures) research. Image 9, taken at the WFSF conference in Bucharest in 2013 is an example. It depicts one of the slides keynote speaker Gerd Leonard showed the audience.

Image 10 depicts a members-only meeting (I was a member at the time) organized by the WFSF board. The location was a classroom in the University of Bucharest. During these sessions, futurists were inclined to talk about organizational topics and ways in which to spread the word concerning the value of scholarly futurists. A scholarly oriented futurist also articulated a similar inclination during a group discussion in April 2015:

I have to explain my practice and defend myself as a futurist. Futures research is science but it is still difficult to convince people of this. Therefore, it is important to make explicit how I carry out the work, to amplify the methods. Demonstrate what I do, that there are methods and that it is not just playing around.

This reputation building by focusing on methodology is a broader phenomenon. This was highly visible in the conference programs of the WFSF conferences. The attending futurists predominantly emphasized the research conducted on the methodological aspects of their practice. The excerpt of the program depicted in Figure 12 is illustrative of this. 
Futures Studies Tackling Wicked Problems:

Where Futures Research, Education and Action Meet

11-12 June 2015, Turku, Finland

\section{Session Programme}

\section{Thursday 11 June}

\begin{tabular}{|c|c|c|c|c|c|c|c|}
\hline $\begin{array}{l}12: 30- \\
14: 00\end{array}$ & $\begin{array}{l}\text { SESSION 1: } \\
\text { Methodology I: } \\
\text { Introduction } \\
\text { (Osuuskauppa) }\end{array}$ & $\begin{array}{l}\text { SESSION 2: } \\
\text { Studies on Fu- } \\
\text { tures Research } \\
\text { I: Technology } \\
\text { and foresight } \\
\text { (LS 01) }\end{array}$ & $\begin{array}{l}\text { SESSION 3: } \\
\text { Futures Educa- } \\
\text { tion and } \\
\text { Learning I } \\
\text { (LS 16) }\end{array}$ & $\begin{array}{l}\text { SESSION 4: } \\
\text { Research Tools } \\
\text { I: Backcasting } \\
\text { (LS 07) }\end{array}$ & $\begin{array}{l}\text { SESSION 5: } \\
\text { Education and } \\
\text { Learning I: } \\
\text { Future orien- } \\
\text { tation } \\
\text { (LS 09) }\end{array}$ & $\begin{array}{l}\text { SESSION 6: } \\
\text { Philosophy of } \\
\text { Futures Studies } \\
\text { (LS 18) }\end{array}$ & $\begin{array}{l}\text { SESSION 7: } \\
\text { Arts as Means } \\
\text { to Shape } \\
\text { the Futures } \\
\text { I: Scenario } \\
\text { gaming } \\
\text { (OP-Pohjola) }\end{array}$ \\
\hline $\begin{array}{l}15: 00- \\
16: 30\end{array}$ & $\begin{array}{l}\text { SESSION 1: } \\
\text { Methodology } \\
\text { II: Critical } \\
\text { as-sessments } \\
\text { of the futures } \\
\text { research } \\
\text { methodology } \\
\text { (Osuuskauppa) }\end{array}$ & $\begin{array}{l}\text { SESSION 2: } \\
\text { Studies on Fu- } \\
\text { tures Research } \\
\text { II: Cases on } \\
\text { energy sys- } \\
\text { tems } \\
\text { (LS 01) }\end{array}$ & $\begin{array}{c}\text { SESSION 8: } \\
\text { Information } \\
\text { Technology } \\
\text { and Disruptive } \\
\text { Innovations: } \\
\text { A wicked yet } \\
\text { empowering } \\
\text { combination } \\
\text { Innovation I } \\
\text { (LS 16) }\end{array}$ & $\begin{array}{l}\text { SESSION 4: } \\
\text { Research Tools } \\
\text { II: Causal Lay- } \\
\text { ered Analysis } \\
\text { (CLA) } \\
\text { (LS 07) }\end{array}$ & $\begin{array}{l}\text { SESSION 5: } \\
\text { Education and } \\
\text { Learning II: } \\
\text { Developing vi- } \\
\text { sionaries and } \\
\text { future thinkers } \\
\text { (LS 09) }\end{array}$ & $\begin{array}{l}\text { SESSION 9: } \\
\text { The Impact } \\
\text { of Foresight } \\
\text { Studies: The } \\
\text { Role of Dark } \\
\text { Scenarios } \\
\text { (LS 18) }\end{array}$ & $\begin{array}{l}\text { SESSION 7: } \\
\text { Arts as Means } \\
\text { to Shape the } \\
\text { Futures II } \\
\text { (OP-Pohjola) }\end{array}$ \\
\hline $\begin{array}{l}16: 30- \\
18: 00\end{array}$ & $\begin{array}{l}\text { SESSION 1: } \\
\text { Methodology } \\
\text { III: Methodo- } \\
\text { logical } \\
\text { chal-lenges of } \\
\text { par-ticipatory } \\
\text { fu-tures } \\
\text { research } \\
\text { (Osuuskauppa) }\end{array}$ & $\begin{array}{l}\text { SESSION 2: } \\
\text { Studies on Fu- } \\
\text { tures Research } \\
\text { III: Scenarios } \\
\text { and horizon } \\
\text { scanning } \\
\text { (LS 01) }\end{array}$ & $\begin{array}{c}\text { SESSION 8: } \\
\text { Information } \\
\text { Technology } \\
\text { and Disruptive } \\
\text { Innovations: } \\
\text { A wicked yet } \\
\text { empowering } \\
\text { combination } \\
\text { Innovation II } \\
\text { (LS 16) }\end{array}$ & $\begin{array}{l}\text { SESSION 4: } \\
\text { Research Tools } \\
\text { III: Causal Lay- } \\
\text { ered Analysis } \\
\text { (CLA) } \\
\text { (LS 07) }\end{array}$ & $\begin{array}{l}\text { SESSION 5: } \\
\text { Education and } \\
\text { Learning III: } \\
\text { Developing vi- } \\
\text { sionaries and } \\
\text { future thinkers } \\
\text { (LS 09) }\end{array}$ & & $\begin{array}{l}\text { SESSION 7: } \\
\text { Arts as Means } \\
\text { to Shape the } \\
\text { Futures III } \\
\text { (OP-Pohjola) }\end{array}$ \\
\hline
\end{tabular}

Figure 12. Overview of the 2015 World Futures Studies Federation conference in Turku, Finland.
Both conferences were a moment for futurists to exchange and discuss methodological issues. More often than not, futurists discussed methodological perspectives. This was also visible in the broader community of futurists; they describe methods as useful to translate their work to outsiders. Moreover, futurists also described to lean on methods to give outsiders an impression of a sound body of knowledge.

However, only a relatively small component of the futurist profession relies solidly on a scholarly approach to building a reputation. In the quotation below, an established futurist described the tension between thorough (academic) research and the reality of working with clients.

Scholars work on incredible methods to build the future. These are beautiful - intellectually speaking. And they are really interesting to study from a scholarly perspective. But if you are a practical person, if you have to work for a client, you need an answer to real questions. In that case you have to be efficient with resources, you do not have a huge amount of money to do a study. We all know this.

The last sentence of this quotation is telling. The phrasing "we all know this" insinuates that amongst futurists it is apparently common knowledge that they have to be efficient with resources to be able to answer 'real' questions. This also conveys that just obtaining scientific prestige is not all that matters for futurists.

Futurists who are building reputations in the scholarly world have articulated that they experience a sense of community. They interact, discuss and negotiate about how to best research futures. These scholars take academic rigor seriously and articulate its value. At the same time, it was difficult to identify futurists that solely build their reputation as a scholar. Futurists described that academic rigor is important, but they preferably did not dwell on it, because futurists feel the responsibility to answer real, practical questions.

\section{4}

Commercial world The reputations in the commercial world do not merely rely upon the judgment of colleagues or peers. For futurists pursuing a reputation in the commercial world, it is equally important to deliver good work to clients. The client will give professional reviews and directly influence the reputation of a professional. Expanding business can be done by collecting professional referrals and references (Goode, 1957; Podolny, 1993; Rao, 1994). All of these activities are based on what professionals need to do, and areas in which they need to excel, before achieving a solid reputation. One of the conventions in professional reputation is 'the more experience, the more status. ${ }^{25}$

Futurists have often mentioned that maintaining a warm relation with the client is important to them. They explained how they work towards building a relationship of mutual trust. Earning this trust takes a lot of futurists' time and is a delicate process; one bad review and the trust can disappear in an instant. An established futurist described the importance of building trust:

We have to earn, not money wise, but the trust of our clients. And that is really difficult, I can never say that I love science fiction because if I say so to $m y$ clients, I am not considered someone they can trust. 
A lot of futurists described themselves as (partly) active in this commercially oriented world. They are tasked with assignments to inspire companies or to help with formulating a vision and strategy. These futurists are often quite visible as they give public lectures and interviews on their latest insights. This helps them to become a well-known voice for the public. Some futurists shared that they often reference their academic skills in order to convince clients of their capabilities. One futurist described, during an informal conversation at a conference, how he always starts his presentation with a lot of numbers and data, to convince the client that he did his homework and knows what is going on.

Of the 50 conferences I have attended, the LaFutura conferences had the most explicitly commercially oriented character. The aim of the LaFutura conferences was to share the latest insights for a broade audience and specifically larger companies working with trends and futures. LaFutura also organized pre-meetings for futurists to discuss professionalization issues. Those pre-meetings provided me with insights on how commercially oriented futurists interact. In my notes I wrote down that the attending futurists had a 'hands-on' mentality and were concise in their goals. The agenda (Figure 13) illustrates the effort the futurists made to professionalize. They started of the day with state-of-the-art updates on the professionalization of futurists (amongst others from me), but also on crowdsourcing and best practices of future-oriented organizations. After gathering relevant information, the futurists organized three parallel sessions with the aim to create a roadmap, develop a vision and a strategy. Image 11 captured the futurists at work during one of the parallel sessions.

\section{LaFutura 2014}

Agenda

10:00

11:00

Arrival \& breakfast by Nils Müller. Why are we here? What is the aim? How can we work together?

$11: 15$ Deep dive into the trend industry by
Franziska Krauskopf, TrendONE.

- Industry analysis and future outlook

- Key players in the industry

- Key influences

- Recent developments

- Future of the industry

12:00 - Professionalization of futures studies by Tessa Cramer
(PhD student)

12:45 (PhD student)

14:00 - Academical perspective, dr. Heiko von der Gracht

14:30 Etienne Verbist, Crowdsourcing

15:00 Coffee

$15: 30$ Current activities in networks and associations:

GLOBAL: ISPIM, PDMA, WFS World Future Society, dr. Stefan Kohn APF Association of Professional Futurists, Erica Bol

GERMANY: Netzwerk Zukunftsforschung,

dr. Heiko von der Gracht

FINLAND: Future Specialists Helsinki, Pauli Komonen

SWITZERLAND: SwissFuture

NETHERLANDS: Dutch Future Society,

Tessa Cramer Trendnetwerk, Hilde Roothart

16:30 Parallel Sessions: (all in one room =

Teams can work together and exchange results)

TEAM JUST DO IT

Ideas, projects \& roadmap for the next 3 years - Hilde Roothart

VISIONEERS TEAM

Vision development - Nils Müller

\section{STRATEGIC TEAM}

SWOT analysis and strategy development - Franziska \& dr. Michael Herbst

$\begin{array}{ll}\text { 17:30 } & \text { Presentation of results } \\ \text { 18:00 } & \text { Discussion \& Decisions } \\ 19: 00-\text { Closing } \\ \text { 20:00 }\end{array}$




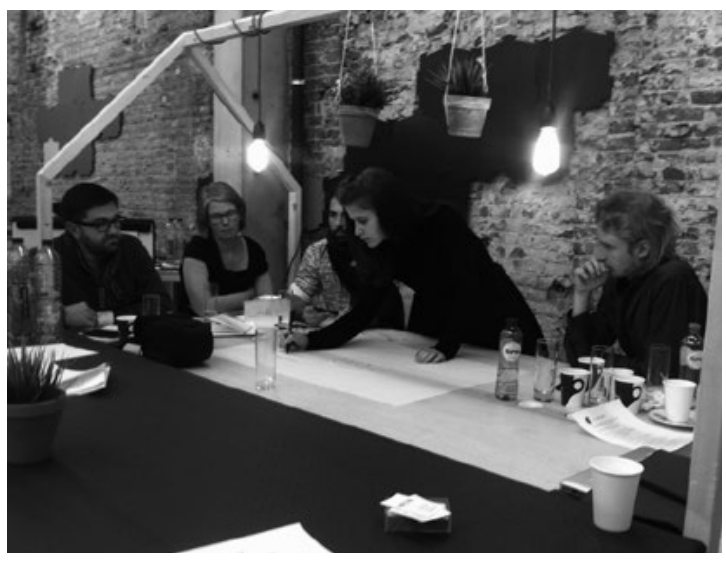

Image 11. Discussing professionalization at the LaFutura pre-meeting November 6, 2014.

After the presentations it was time for parallel sessions to make a roadmap, and formulate a vision and strategy. During these parallel sessions no time was wasted to develop a step-by-step plan to professionally reach common ground. The attending futurists all arrived prepared and my fieldnotes describe how futurists were ready to discuss and eager for connection with their fellow futurists. I noticed that the attending futurists had a longing for concrete answers to their professionalization questions. The futurists asked: who do we want to be? What is our reason for existence? Furthermore, the futurists wished to formulate a strategy, based on the strengths that they identified. Tellingly, the third working session was focused on formulating concrete 'tasks' to set up a common futurist organization.

The agenda of the pre-meeting was based on the most actionable approach I had encountered thus far. In the morning there were a few short lectures.
26 It is interesting to find out when and why an artist becomes successful. What are the conditions of a successful artist? Lang and Lang (1988: 79) questioned: why is it that the names of some persons, and the accomplishments on which their reputations res acclaimed? The researchers notice in historical lits once simil while some artists stick in collective memory (Lang, Lang, 1988. 79), others do not. Becker (1982) recognized that it is not only about the artist but also about the context of the artist. The works have to be exceptional, schools should have a certain reputation, genres of work are 'en vogue' or not and media have a ranking. Becker means with 'media' having a ranking that, for instance, an oil painting on an easel has a 'better' reputation than weaving or glassblowing. Moreover, art worlds may vary in size. It is not likely hat the same kind of reputation exists in such distinct organizations (Becker, 1982).

My fieldnotes describe that the futurists were actually just really looking forward to getting to work and to starting the working sessions that were planned for the afternoon. The futurists got to work and delivered a concrete action plan, including a list of divided tasks.

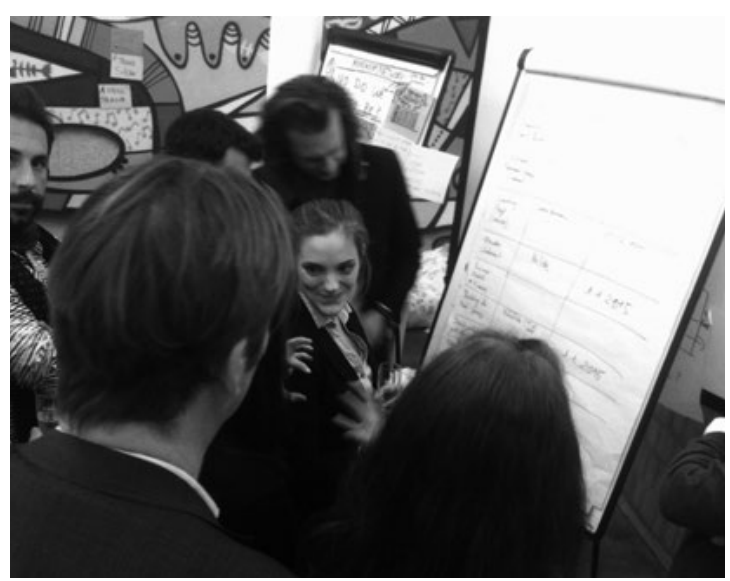

Image 12. Dividing tasks at the LaFutura pre-meeting on November 6, 2014.

Where the scholarly oriented futurists could rely on academic formats to inform their discussions, commercially futurists had another strategy, they gathered as much relevant information as possible (by inviting experts) before embarking on discussions. This resulted in informal conferences with very varying formats, from meetups to workshops, to more classic conference presentations. A joint characteristic of these conferences was that in each setting, time for interaction among the futurists was allocated. During these conferences, the tension between allocating time for either professionalization discussions
27 Lang and Lang recognize four directions in which to seek clues to the durability of the reputation. Firstly, the artist's own efforts. Secondly, others that, after the artist has died, prese

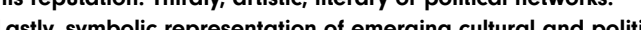
identities.

and content exchange was apparent. Some futurists just wanted to discuss new research ideas, whilst others where more worried about the future of their professionalization.

The observations mirrored that the reputations of these futurists are not just based on referrals of clients but also on the judgement of colleagues and peers. The futurists were eager to discuss and compare their professional experiences and common outlook. However, in contrary to the scholarly futurists, I observed that there was not a single, set community. The attending futurists varied greatly, sometimes making an effort to contribute to the discussion, and simultaneously pursuing their own individual goals.

5.5

Artistic world

The literature on artistic reputation is less extensive than that of the two reputation structures mentioned before. "An artist is someone who is gifted in some way that enables him to do something more or less well which can only be done badly or not at all by someone who is not thus gifted" (Stoppard, 1975 38). People with special gifts can manipulate the existing conventions, perhaps change them or invent new ones, and thus produce works which are not just "soso or ho-hum but, rather, are extraordinary" (Becker, 1982: 355). ${ }^{26}$ Visibility is important in the construction of an artistic reputation. Once an artist has visibility, "greatness begins to feed on itself" (Lang and Lang, 1988: 85). ${ }^{27}$ However, this visibility does not happen overnight. Lang and Lang (1988) and Becker (1982) argue that an artist needs to produce a large amount of work to reach quality. According to them it is also important for an artist to create a broad network, to go to a prestigious school, to use the 'media' that is in fashion and to be in the genre that is in demand. 
Futurists are not artists per se, and do not often mention this reputation. Futurists do describe that intuition and imagination are vital to increase understanding of the future. Futurists explain that imagination is key to be able to talk about possible futures Raymond (2010) argues in a handbook on trend research that intuition is a core element of being a futurist. In addition, an established futurist described:

A futurist needs the skill of being able to talk on different levels: not just the action-oriented idea generation, also the artistic way of thinking.

The futurists that build their reputation structure along the lines of artistic reputation consists of futurists that are not as mutually connected as in the academical and commercial worlds.

Amongst the more artistically inclined futurists there was little interaction. These futurists did organiz events, but did not refer to any professionalization issues. Moreover, artistically inclined futurists have not articulated their wish to organize their practice. However, some showed up at professionalization events organized by their commercially oriented counterparts, such as at the group discussions organized by Hilde Roothart. The futurists that have artistic ambitions have an autonomous practice. In my fieldnotes, I observed that these futurists connect to other futurists occasionally but only when they feel that this has added value for their work.

The events that artistically oriented futurists organized, strictly focused on conveying the content of their research. A prime example of these futurists is Lidewij Edelkoort, a Dutch futurist who advises several design and fashion clients on color trends.
During her presentation that I attended in 2016, Edelkoort shared her insights with an audience that clearly was comprised of commercial clients. It was a large venue, with space for at least 500 people. In this presentation all the senses were included; there was a lot of music and many images accompanied by an explanation from Edelkoort. At the end of the presentation, the audience was allowed to ask a few questions. The time allocated for questions was short (15 minutes) and all questions raised by the audience focused on how to apply and translate her relatively abstract insights to a specific industry.

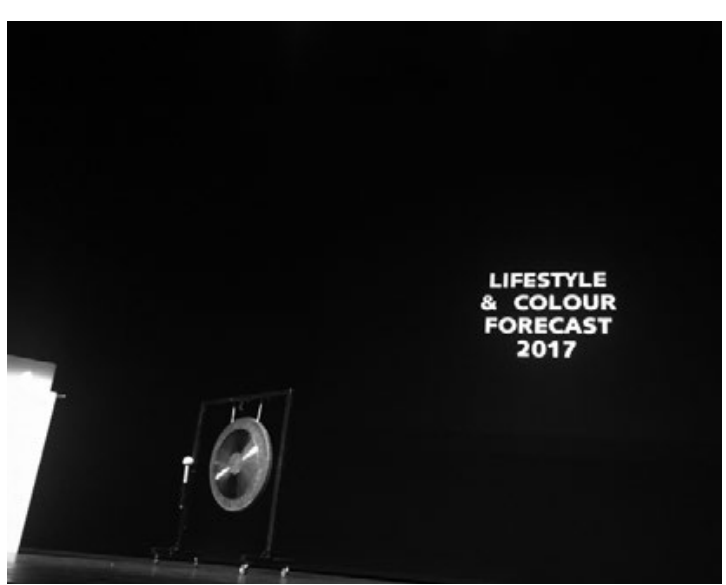

Image 14. Picture taken at introduction of Picturing the Future, September 25, 2014

In 2014, futurists with artistic reputations organized a conference together. It was called Picturing the Future and was conducted under guidance of two experienced futurists, Brugmans and Soeters. The conference consisted of presentations by several students of their trend academy. Futurists Brugmans and Soeters are active members of the commercially oriented futurist community (they were present at virtually every commercially oriented professionalization conference). However, in their work, they make use of what visual culture has to offer. The futurists also teach their students to do the same. Their presentations are distinctive; they are very visual and have a lot of emphasis on the images that represent the story they are telling. During this conference, there was no reference made to the larger community of futurists or to any type of professionalization issues. Although the founders do consider this an important Image 13. Picture taken before the start of Lidewij topic, they tend to discuss the issues associated with Edelkoort's Lifestyle \& Colour Forecast 2017. 
In this type of reputation building, futurists strongly emphasize the individual endeavor. These artistically inclined futurists work like artists, preferably in seclusion, advancing an autonomous practice. The artistically inclined futurists develop their ideas, and do this in solitude or with a carefully selected team around them. The conversations and discussion around professionalization hardly find traction in this world, not necessarily because they do not want to but because these futurists hardly seek out likeminded futurists. And, if artistically oriented futurists do want to have these conversations, they cross-over to conferences of academic and/or commercially oriented futurists.

5.6

\section{Cross-boundary reputations}

\section{Whilst examining each of the three reputation struc-}

tures it proved to be challenging to demarcate futurists. In hindsight, I had assumed too swiftly that if some futurists made a distinction between the academic and commercial worlds, then probably all futurists would do the same. And that futurists could be identified as being either academic, commercial or artistic. However, on several occasions' futurists articulated the opposite: their reputations are simultaneously built in several worlds at once. In the previous paragraphs, I observed how futurists described to navigate academic, commercial as well as artistic worlds and build their reputations simultaneously. For example, a newcomer acknowledged that futurists need to be active in several worlds:

As a futurist, you have to be trained across functions. When you are someone who has just studied medicine all their life and not done anything else, then all you know is medicine. And don't know anything outside of that field. Professionally, or, in the amateur sense, do not foresee it being logically and objectively possible for such a person to effectively study the future.

Futurists articulate the need to be able to look outside of the walls of universities, businesses and governmental organizations. Gary and von der Grach (2015: 135) have argued that, "futurists work in widely different contexts. Many serve as academics (..), others create bottom-up participatory social processes (..). Still others serve the needs of top-down decision makers in business or government". There are hardly any futurists that limit their work to one professional world. Futurists consciously combine their knowledge of several worlds in building their profession.

Although I have examined the three reputation structures separately, in hindsight, the accounts can be merged. The futurists' reputations should rather be understood in a spectrum of the worlds that are considered to be connected. In similar vein, an established futurist described:

There are a lot of similarities. If I would make a distinction between futurists: those who are business foresight oriented and those who are on the university future studies side. But their link is also very clear.

To date, scholars have viewed reputations as existing in one reputation structure at a time (see Table 2 for all references). The way in which futurists build reputations diverges from the pathway that emerged from the literature review in Paragraph 5.2. Remarkably, futurists not only make reputations in different professional worlds, they also interchange them. Futurists have described that they do not wish to limit their professional activities to just one of the three professional worlds. Futurists actually praise other futurists for their ability to cross the boundaries of separate worlds. Below is an example of an established futurist praising a well-known futurist:

He (referring to a well-known futurist) has taken futures studies in the academic side over to the business side. And he has combined the two. In my opinion he is successful in doing that.

These actions vary depending on the focus of the individual futurist. For example, a futurist that mostly consults businesses may also have scholarly goals Meanwhile a futurist with a scholarly focus may also have a creative ambition to be able to transfer knowledge. Futurists carefully construct reputations in a dynamic blend of worlds.

How to understand this alternative way of building reputations? Abbott (1988), Larson (1977) and other thinkers within the sociology of professions acknowledge that professions are not homogeneous entities. However, they did not dwell on differences between professionals within a profession. For example, Abbott's concept of jurisdiction addresses internal fights among practitioners but regards them as of minor importance in the process of becoming a profession. Larson and Abbott focus on groups of professionals that might be diverse but both assume that the practitioners carry out similar work in similar professional worlds. From this perspective, differences between reputational worlds are problematic. Except, the futurists do not give the impression that they encounter problems in their way of building reputations. Diversity is a bit of an obstacle for $\mathrm{Ab}$ bott and Larson, while specifically those differences can lead to new perspectives on reputation building. 
28 Work on boundaries originated from science and technology studies. I am aware that this is not yet a generally accepted term but I agree with van ' $t$ Klooster (2007) that now is the time is now to start referring to this body of knowledge as such.

29 In this paragraph, I refer to legal arena but do not dwell on any jurisdiction in that areno.
A perspective that could be helpful to understand futurists' reputation building is boundary theory. ${ }^{28} \mathrm{It}$ offers "a new fine-grained appreciation of diversity" (Akkerman et al., 2011: 135) as this body of knowledge emphasizes how differences between practitioners an practices is created, sustained and challenged. Boundary theory, also known as boundary work, was developed by Gieryn (1983) and subsequently studied by many other scholars (Jasanoff, 1990; Star, 1989; Hilgartner, 2000; Dunsby, 2004; Schmid, 2004; Jasanoff, 2005 Bijker et al., 2009). These scholars have explored how professionals, and especially scientists, build reputation by acquiring authority. In early work on boundaries, scholars focused on the scientists carving out boundarie and distinguishing their activities from other, nonscientific, activities. Gieryn argued that "boundaries are drawn and redrawn in flexible, historically changing and sometimes ambiguous ways" (1983: 782). Gieryn defined boundary work as "the attribution of selected characteristics to the institution of science (i.e. to its practitioners, methods, stock of knowledge, values and work organization) for purposes of constructing a social boundary that distinguishes some intellectual activity as non-science" (1983: 782). These boundarie were intended to demarcate science from non-science. How does boundary theory yield alternative notions that help to interpret the activities of the futurists in the workplace and public opinion arenas? ? $^{29}$

The connection between boundary theory, a prevalent topic in science and technology studies, and jurisdictions, a well-known topic within the sociology of professions, is not necessarily obvious. But in hi work, Gieryn has accredited the sociology of professions as the theoretical nourishment for his theory on carving out boundaries. Gieryn described how Abbott has created a "model for understanding the constructed boundaries of science" (1995: 409) which he regarded useful to interpret the scientists' "pursuit of professional goals" such as intellectual authority (1983: 781). As such, the connection between jurisdictions and boundaries has been made, albeit not abundantly. To theoretically contextualize his work, Gieryn has initially described the overlapping aspects of both jurisdictions and boundaries. Abbott argued that professions develop in the context of others and focus on the inter-professional arenas to claim jurisdictions. Boundary theory focuses on the negotiations between practitioners, accordingly revealing their patterns, struggles and settlements. It would, as Gieryn argues, "no doubt be profitable to compare representations of science" (1995: 409) in the three separate arenas that Abbott has identified. But, to be able to connect jurisdictions and boundary theory, more conceptual attention is required.

Although Gieryn has convincingly demonstrated that boundaries and jurisdictions have some overlap, there are also notable differences, especially in materialization. Jurisdictions are claimed by practitioners with the implicit aim to reach a heartland. A heartland implies a successful pathway in obtaining agreements on the jurisdictions of the profession in either workplace, public opinion and legal arenas. The claim of jurisdictions may be an ambiguous process, while the activities do have the joint aim of reaching this valued end goal. Whereas boundary work, from Gieryn's perspective, is an ongoing process of negotiating with competitors without striving for a particular end goal such as a heartland. It is a continual activity carried out by practitioners and does not assume any particular heartland. Gieryn (1983: 792) described boundaries of science as "ambiguous, flexible, historically changing, contextually variable, internal- ly inconsistent, and sometimes disputed." Sources of this continual activity of carving out boundaries are ascribed to, for example, obstacles that scientists encounter in their aim to claim authority, as well as conflicting professional ambitions and goals.

Gieryn argued that comparing representations of science to jurisdictional arenas referring to them in terms of the court (legal arena), the mass media (public opinion arena) and the laboratories (workplace arena) would be profitable. At first glance the parallels between jurisdictions and boundaries can be drawn. However, when examined more closely, the court, mass media and laboratories cannot straightforwardly be translated to each of the three jurisdictional arenas. The act of carving out boundaries is an inherently informal activity that implies movement, negotiation and fluidity. Abbott (1988) described the public opinion arena as the place where practitioners establish power, legitimacy and the right to do a certain kind of task, which eventually leads to social and cultural authority. In boundary theory there are also references made to ways of claiming authority, but with a specific aim: to unveil the ambiguous process that precedes the actual claim. For example, the public opinion arena is the arena in which archetypes are created. But the actual work of sorting out that exemplary archetype has already been done before a jurisdictional claim can be made. The character of boundary work is inherently informal and consists of ambiguous activities and therefore cannot simply be aligned with the public opinion arena. The workplace arena has an informal character in which the output of practitioners matters more than their hierarchy. As such, the workplace arena and activities to carve out boundaries can be characterized in a similar way. In spite of the limitation that boundary theory can 
only really be paralleled with the workplace arena, does it yield alternative notions to interpret the activities of the futurists? In the workplace arena, practitioners examine who can control and supervise the work and who is qualified. Boundaries are carved out as a result of, amongst others, competition with other practitioners. This competition helps practitioners understand how they compare and connect with peers, and also how they differ from other practitioners.

How does boundary theory provide an additional perspective in the way futurists are building reputations? Futurists value the search for boundaries, and undertake activities to do so. For example, futurists mention that they often involve relevan experts from varying disciplines to inform their research. However, those futurists' activities are not clear-cut boundary work either. Futurists do carve out boundaries in their process of building reputations, but do so on their own terms. A characteristic aspect of how futurists are building reputations is that futurists are not concerned with drawing, negotiating and maintaining 'static' boundaries with outsiders. Futurists do not care to demarcate from others. They do sometimes make a distinction between science and art, but preferably to transform it into a hybrid form. As such, futurists describe they prefer 'soft' boundaries. In Chapter 4, I observed how futurists are eager to think across disciplines to be of value for others. Moreover, futurists articulated that it was challenging for them to even draw boundaries, and they expressed no urgency at all to demarcate their practice. Especially because it could separate them from a source that futurists have in high regard: their diversity.

The diversity that futurists embrace on an individua level enables them to cultivate a common ground too. Futurists described they have the tendency to think across disciplines and wish to be of service. With this mindset, they are able to unite ideas and worlds. In their diversity, futurists find communality in the way they build their reputations. The search of futurists to connect and transcend professional worlds can be regarded as the futurists' pursuit for common ground. The futurists' striving for soft boundaries provides fertile ground for the growth of a communality that was not visible at first glance.

Scholars in boundary theory have been concerned with notion of common ground too. To be able to connect expertise, separate disciplines need "common ground" (van 't Klooster, 2007: 103). This is the place of interaction between separate disciplines (for example scientists and designers) to be able produce knowledge together. Boundary theory scholars have also referred to common ground as 'overlapping territory' (Klein, 1996), 'trading zone' (Galison, 1999) and 'translation terrain' (Brosveet, 2004). Regardless of the varying descriptions, common ground is widely conceptualized as the meeting ground for professionals from different disciplines. The notion boundary crossing captures the professionals that "enter onto territory in which we are unfamiliar and, to some significant extent therefore unqualified" (Suchman, 1994: 25) and "face the challenge of negotiating and combining ingredients from different contexts to achieve hybrid situations" (Engeström et al., 1995: 319). Boundary crossing usually refers to a professional's transitions and interactions across different worlds (Suchman, 1994, Hoppe 2002). However, this perspective assumes that professionals do not intend to keep crossing boundaries, and will soon go back to their own respective territories. Yet, futurists did not express any intention to stop crossing boundaries to go back to their 'own' territories. Instead they preferred to remain at the intersection where the activities of boundary-crossing take place. For futurists, boundary crossing makes way for the type of skills that futurists have described to value, such a sensitivity and creativity. Other scholars have also recognized boundary crossing as a competence. For example, boundary theorists Fortuin and Bush (2010) have made the effort to identify several boundary skills, such as awareness and appreciation of disciplinary and cultural boundaries, dealing with uncertainty and overcoming barriers that are originated because of interdisciplinarity. In addition, boundary theorists Walker and Nocon described boundary crossing as the "ability to manage and integrate multiple, divergent discourses and practices across socia boundaries" (2007: 181). This is in accordance with my observations on how futurists value a frameless mindset in Chapter 4.

According to boundary theorists Akkerman et al. (2011: 140) a cross boundary professional can be "easily seen as being at the periphery, with the risk of never fully belonging to or being acknowledged as a participant in any one practice." The phrasing of the 'risk that practitioners may never fully belong to a world, affirms an assumption that this may be a potentially problematic situation. However, futurists have articulated that they appreciate their outsider's role. Some futurists even go as far as looking for the periphery. They do not see this role as problematic; it helps them to maintain an outsider's position and see things with fresh eyes, which allows them to be of value for others. This indicates that in boundary theory there is also a tendency to acknowledge the appreciation of professional activity in one world at a time. 
In conclusion, boundary theory yields alternative notions to interpret futurists' professionalization activities. It provides a supplementary perspective by giving a starting point in examining how to challenge the persisting singular view on reputations. ${ }^{30}$ Usually, professions build reputations in either commercial, artistic or academic worlds, by learning about and adhering to the established norm. Futurists, however, naturally take on an outsider's position and prefer to remain at the intersection where the activitie of boundary-crossing take place. This durable interes in movement has led to a great diversity in individua reputations, but futurists do find common ground in how worlds are crossed. Actually, diversity in reputations is not only acceptable, it is eminent. Professionalization of futurists is not dedicated to advancing a homogeneous, singular notion of what a futuris should be. Instead, futurists choose to follow an alternative pathway of professionalization, in which main taining the intersection of separate worlds with their cross-boundary reputation building is a key feature.

\subsection{Conclusions: a heartland-free profession} In Chapter 4, I argued that futurists do not formally claim any type of legal jurisdiction. For critics (often futurists are their own harshest critics) this fuels the argument that futurists are not a profession. However, I also argued that it would be too easy to dismis futurists as a profession because they do not fit the classic model of professionalization. With this chapter I demonstrated one of the key features of futurists' alternative pathway towards professionalization their cross-boundary reputation building.

In this chapter I further examined the reluctance to professionalize that emerged in the former chapters and question: which notions of professionalization become apparent in futurists' efforts to professionalize? The analysis demonstrated that futurists are reluctant to professionalize when it concerns claiming jurisdiction in the legal arena. Futurists did not articulate any ambition to reach a common endpoint, referred to by Abbott as the heartland. The activities futurists carry out to build reputations are neither strictly claiming jurisdictions nor carving out boundaries. As such, futurists do not fit into the heartland model. In their professionalization, futurists are only active in two of the three jurisdictional arenas. And, futurists carve out soft boundaries in the workplace arena. This chapter demonstrated how futurists reach beyond a heartland. It is important to formulate this well: reaching beyond does not imply that they reach the heartland and then proceed. Rather, it means that they choose an alternative pathway.

What does this chapter teach us about that pathway? Literature on reputation structures offered a worthwhile perspective to understand how futurists go about and build reputations. Based on the literature review it was possible to identify three types of reputation structures: academic, commercial and artistic assuming that practitioners build reputations in one world at a time. However, futurists carry out professional activities in each of these separate worlds. But it goes deeper than that. Futurists even simultaneously navigate several worlds at once. As a consequence, futurists challenge the assumption that professional reputations are built in one world at a time. Based on the data derived from interviews, group discussions and observations, I argued that futurists do not aim for one heartland but rather build, both individually and collectively, cross-boundary reputations in academic, commercial and artistic worlds.
This alternative route has a consequence. Futurists have expressed their frustration that their field is fragmented and scattered among a lot of differen practitioners (see Chapter 3). In this chapter, I argued that futurists' individual trajectories to obtain reputations differ as they can be built in several worlds. Indeed, they are a combination of the three worlds. Futurists aspire cross-boundary reputations as it yields space for their individual trajectories as well as unity in the pathway of this profession-in-the-making. As pointed out earlier, overlapping aspirations and values connect practitioners, even if that connection is not obvious at first glance. 


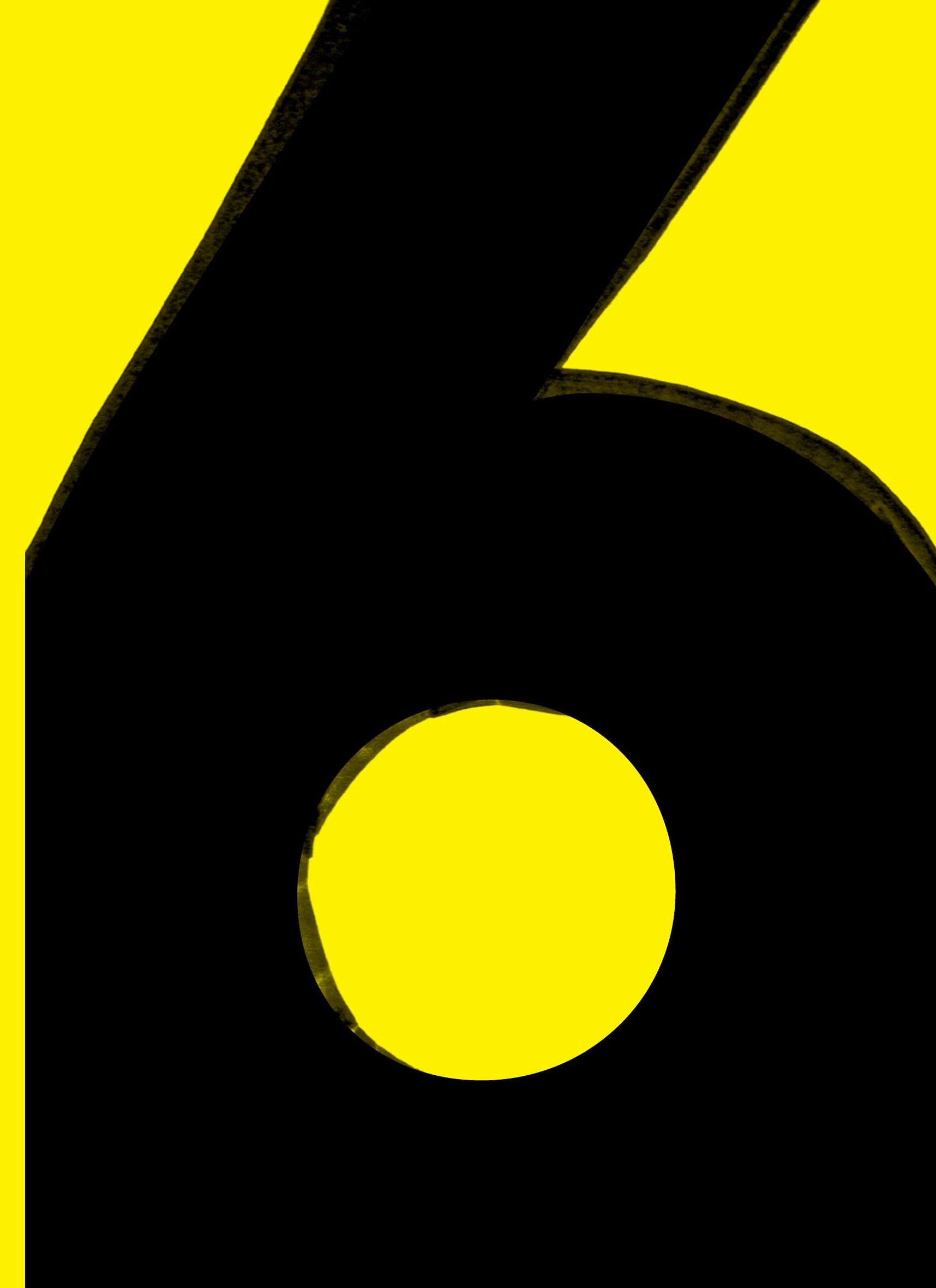


Service | a knowledge-

\section{producing profession} land-free' profession and build 'cross-boundary' reputations. The heartland model of professionalization assumes that professions are knowledge-based, or more precisely, it assumes that each profession recognizes a core body of knowledge that professionals have to master in order to qualify as a professional. In a professional heartland this knowledge is certified in different ways, for example in the form of obligatory educational programs, requirements and certificates. In the previous chapter, I concluded that futurists are reluctant to organize their profession in this way Notwithstanding their wish to professionalize, they do not solely aim to set up obligatory educational programs nor do they specify educational requirements. Yet, futurists often refer to their knowledge, it apparently has a vital role in their professionalization. Can I better understand this reluctance, if I appreciate the role of knowledge in the futurist profession?

I am not the first to examine the knowledge claims that futurists produce. Several scholars have reflected on practices through, and in which, futures are produced by questioning how futurists produce 'knowledge' about the future (Brown et al., 2000; van 't Klooster, 2007; van Notten, 2005; van Asselt et al., 2010ab). The questions originally asked about futurists, were concerned with how futurists produce knowledge. For example, it was questioned how futurists construct stories and future claims. And, more particular how futurists construct stories and future claims while dealing with uncertainty, complexity and discontinuity.

Futurists and how they produce knowledge are in herently connected to the difficulties to professionalize. Especially because futurists, and everybody else for that matter, know(s) that the future is not here yet. Hence, the future can be seen as a 'social construct' (van der Duin et al., 2016: 43), which is an image or a projection of possible futures. Fuller and Loogma (2009: 71-72) argue in a similar manner: "a common feature of the way that knowledge about futures is created is the centrality of symbols. (..) Symbols such as trend lines, images, models, equations and of course the ubiquitous scenario are the stockin-trade of foresight activities." They describe that producing knowledge about the future "is a social process" of which the "purpose is to construct meaning" (2009: 73). Working within the realm of intangible processes, events and actions creates a reality for futurists that is difficult to align with a functionalist, or positivistic, way of viewing the world. Regarding the nature of the knowledge they produce, futurists suggest that it is in flux and changes on a daily basis. One cannot know what the future might hold. As mentioned by van Asselt et al. (2010a: 137), "futurists produce statements about prospective conditions, actions and events that have not yet happened, processes in flux, states not yet in existence and policies not yet in force." Futurists construct futures that are relevant and might have impact (Gidley, 2017). As such, futurists carry out a conceptual practice. They create, imagine, and construct images of the future. In doing so, they make knowledge claims about the future in tangible products. Making claims about the future is an activity that futurists carry out on a daily basis; it is their service to clients. Futurists see themselves and are characterized as producers of knowledge claims. In this chapter, I examine the meaning of futurists knowledge in relation to their professionalization. In doing so, I build on the existing work on knowledge production of futurists (Brown et al., 2000; van Asselt et al., 2010ab).
The question initially posed in Chapter 5 is just as relevant for this chapter: which notions of professionalization become apparent in futurists' efforts to professionalize? This chapter will give an account of futurists as a knowledge-producing profession, based on interviews, group discussions and fieldnotes from observations at conferences. As an introduction, describe the products that futurists produce. This gives an impression of what futurists actually create. Subsequently, I examine how their knowledge production can be characterized. Next, I will relate this empirical account to the role of knowledge within the sociology of professions. In doing so, the underlying assumptions of a knowledge-based profession will be contrasted with the role of knowledge in the professionalization of futurists. Every profession provides service to society that represents the identity of the profession. Service can, for example, be portrayed as a lawyer who defends clients and a doctor who takes care of patients. To understand the reluctance of futurists to professionalize, it is necessary to appreciate the service that futurists aim to provide to society. In this section I will share my observations pertaining to futurists' service to society.

To give their clients an idea of what to expect of their profession, several futurists have come up with ways to share the knowledge they produce. They make newsletters, books that people can download and occasional updates on specific topics. For example, Trendwatching.com sends out mailings on the latest trends every month. Dutch planning agencies such as the Netherlands Environmental Assessment Agency, publish their scenario studies in reports and online. 
Dutch forecaster Lidewij Edelkoort has a blog with updates on current design trends. And, scholarly oriented futurists publish articles in academic journals.

I attended meetings in which futurists explicitly reflected on their service. They discussed about what kinds of knowledge they produce, what means they introduce and to what end. The various sources enable me to outline the services that they aim to deliver. The description below is a stylized report, based on the observational report of a group discussion attended in September 2015.

The attending futurists are discussing what type of service they deliver. They are writing down a list of all their activities on a large sheet of paper. They talk about what they often produce (reports) and the other knowledge that is more creative (exhibits). The list of products turn out to be surprisingly diverse. The futurists describe that they build websites, give lectures, publish (trend) books,

facilitate brainstorm sessions, hold workshops, work in education, teach courses and organize events and congresses. They also create blogs, design online platforms and build prototypes.

This particular discussion can be considered a summation of the kind of products futurists aspire to produce. In my interviews the provision of similar products to clients and society were reported. Key products are reports, workshops and keynotes. Below I will illustrate the products of futurists in more detail.

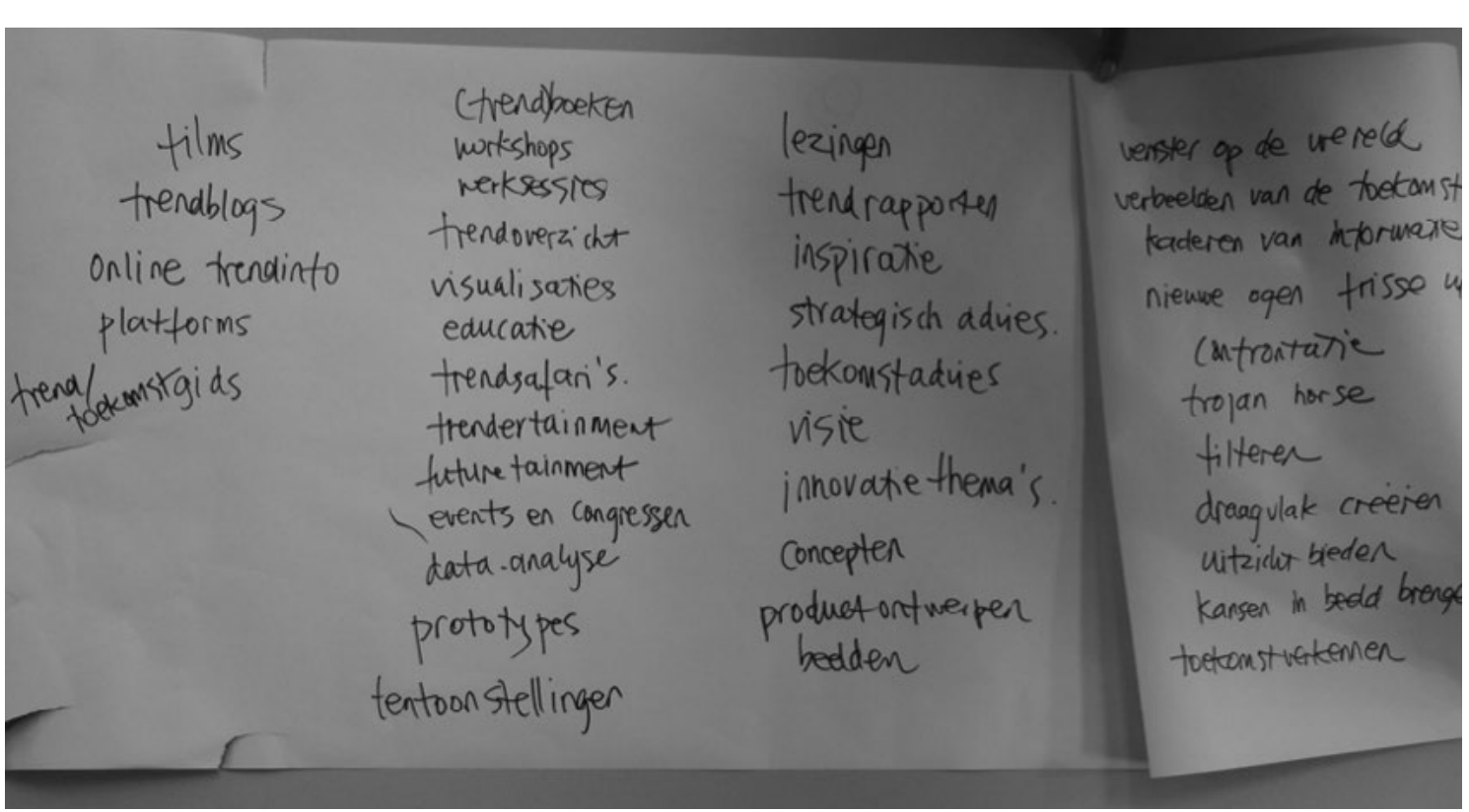




\section{Our Trend Framework}

\author{
16 mega-trends that define the future \\ of business and consumerism.
}

These 16 mega-trends form the foundation of TrendWatching's research and analysis process. They are big, slow-moving currents that remain broadly stable year-on-year, and they can be applied across regions, industries and demographics.

Understanding and innovating around these megatrends is the first step for consumer-facing organizations that want to address changing customer expectations.

This Trend Report is structured around these megatrends and their evolution. Each chapter picks out an exciting new trend that offers a potent innovation opportunity for 2018.

\section{Hoe is de WLO tot stand gekomen?}

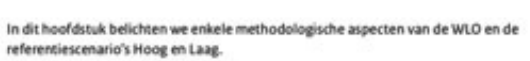

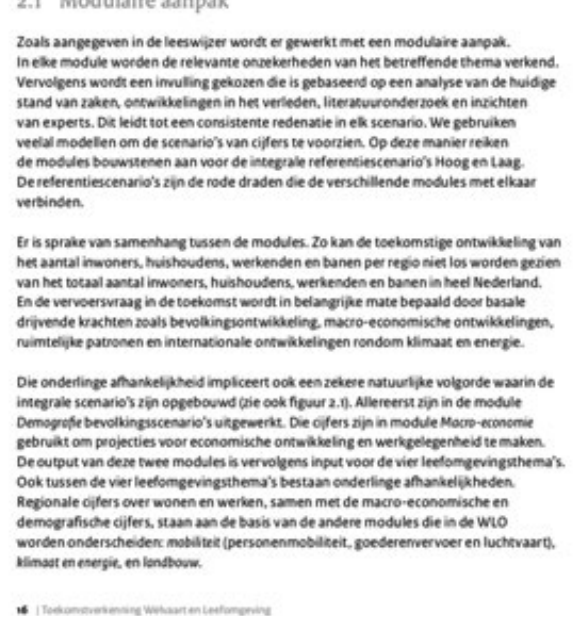

Figure 15. Excerpt from the first pages of the methodology of a Dutch report by PBL Netherlands Environment Assessment Agency and the Central Agency for Statistics (CPB).

Reports

Reports are usually a mix of images and text, with the goal to inspire the reader. In general, a report starts with an explanation of methods, followed by textual and visual visions of possible futures. This explanation of methods is important for futurists to justify their perspective. They explain the methodology,
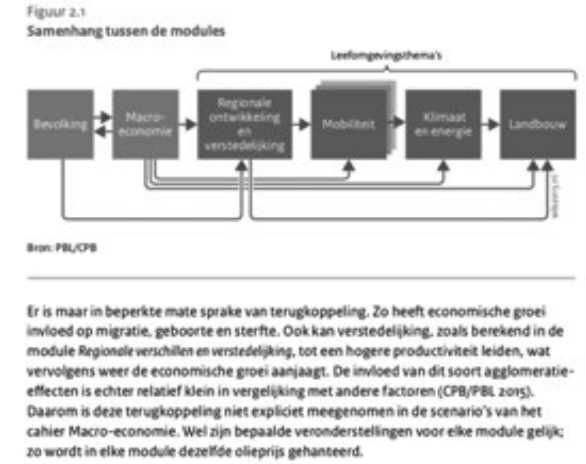

2.2 Beleidsarme scenario's

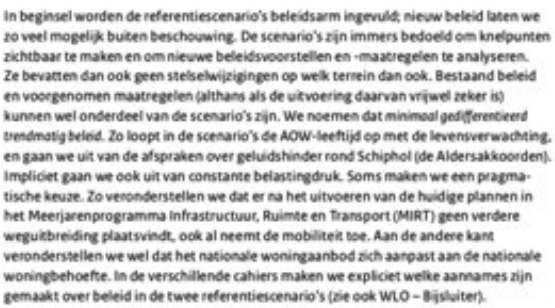

the sources to which they refer and how to value the results of the methods. For futurists it is crucial to balance this part of the report. They will need to convince the reader that the report is relevant for them and should also be engaging at the same time. An example of this can be found in the 2018 annual report of Trendwatching.com. They make use of trend levels as a framework but do not use too many words to explain these levels. Content-wise, it is comprehensible for any reader. As for reports that have a more particular expert audience, such as planning agencies, the explanation is much more elaborate. Excerpts of both examples can be found in Figure 14 and 15. 

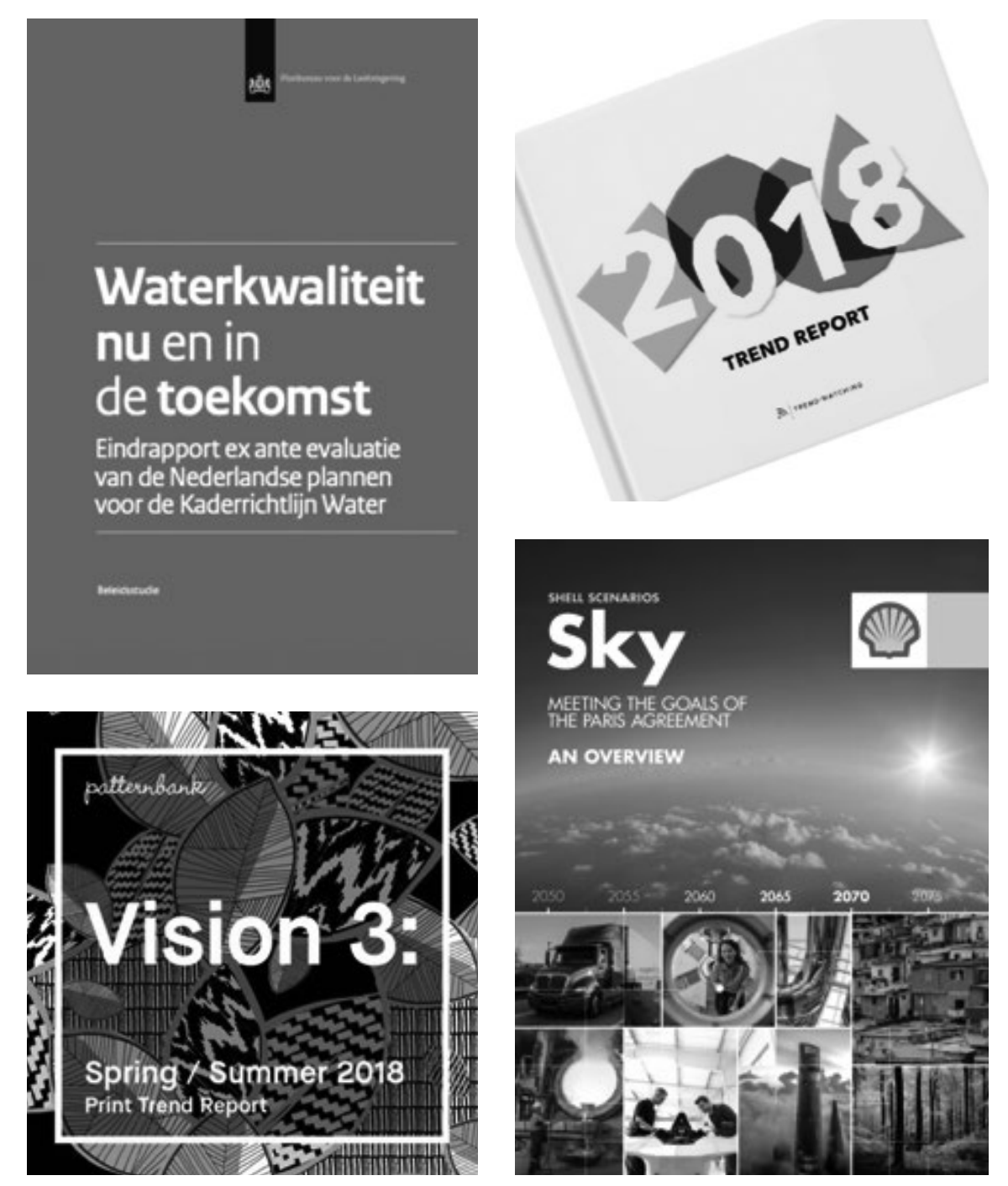

Figures 16, 17, 18 \& 19. Reports by Trendwatching.com PBL Netherlands Environment Assessment Agency, Patternbank and Shell.
After explaining the basics of their research approach, futurists start with imagining the future. This is done in many different ways but is strongly dependent on their audience. Most futurists choose to use storytelling (such as narrating possible futures with stories), interviews, poetry, visuals and photos. The forms of expression that futurists choose vary greatly, by way of illustration I added a cross section of some report covers, see Figures 16, 17, 18 \& 19.

To create their reports, futurists draw from existing information but pride themselves on only using it as a basis to create personalized knowledge. Futurists described that their clients often have difficulties formulating relevant questions regarding the future. They also shared that they do not carry out the wishes of the clients right away and instead force themselves to dig deeper. This can be seen as the futurist' quest to find the question behind the question. They articulate to find this important to be able to be of service for their clients. In addition, when the futurists arrive to the point to communicate their findings in the report, they need a specific vocabulary. A futurist familiar with the community argued:

For years we have been trying to find unique but consistent language on how to talk to clients. We really want to strengthen the profession overall, but it's very difficult because everybody obviously sells their own work. In that sense, we really need the differentiation. But at the same time, it's quite difficult to align diversity.

In the reports the language needs to be accessible, understandable and relatable for all kinds of readers. This results in a balancing act between the general accessibility of futurists' work and their individual approach (like methods and vocabulary).

Reports are a common medium for futurists to convey their work. It is a tangible product that a client can keep for future reference. Futurists create an array of different types of reports, which have in common that it is a mix of rational and intuitive elements. They all introduce validating methodology as a foundation and make use of images and visuals to convey the story. Futurists have described their wish to create a report that is applicable for their clients by asking the questions that are relevant in their context.

\section{Workshops}

Today, clients do not solely want to be lectured on what the future will bring. They want to learn how to use the tools so they can do and think about the future themselves. Workshops are organized when a client wants (to learn how) to assess the future. A workshop is often organized with different stakeholders that represent different perspectives on, for example, a theme. Futurists describe to find this approach useful when a client wants to immerse in how to think about the future. During a workshop, practical tools are shared in order to teach and practice with the participants how to do the work themselves. Futurists observed that this method has become increasingly popular among clients over the last years. 


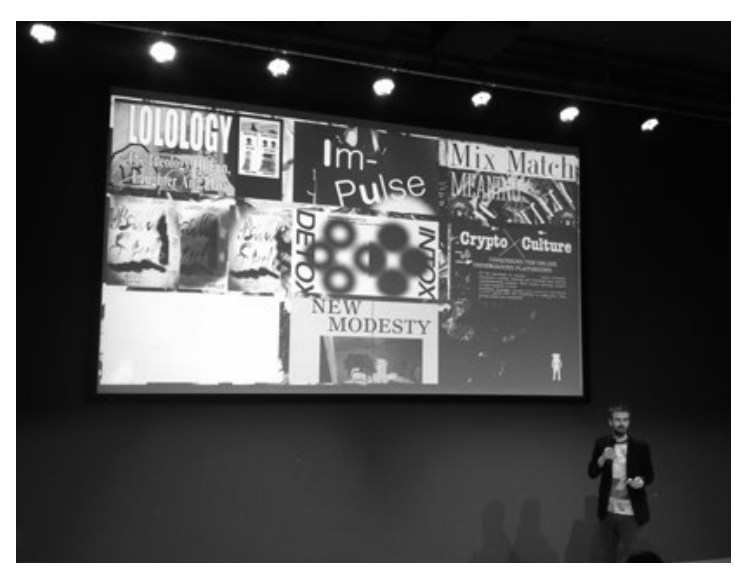

Image 17. Picture taken during keynote speech of Belgian futurist Tom Palmaerts at Dutch SecondSight event in Amsterdam, November 28, 2014.

There are several approaches to how a client can learn to deal with the future. Many futurists regard the keynote as an insightful start for a client. For example, during a group discussion, an established presenter described how he introduces his ideas to the client through a combination of products, including keynotes and subsequent workshops:

We invest in knowledge. We support (..) companies methodologically in their choices. We are not going to sit on their seats. There is no ready-made solution and it is an exploratory process. But we prefer not to stick with just learning, something must also happen (fieldnotes 26 June 2015).

Futurists suggest that the delivered knowledge claims used to be one size fits all. In the nineties several futurists earned their salaries by telling different audiences the same catchy story about the future.
31 Jasanoff coined the term 'serviceable truth' - but using the word truth in this context would be difficult to defend since I argue that futurists are an example of a constructivist practice. Hence, I 'serviceability'.
Due to the availability of information, futurists suggest that keynotes are currently not as popular as they used to be. Senior futurists describe that in their early years, clients never asked to learn the methods because it was not something, they could imagine to be doing themselves. Some futurists were able to captivate the crowds quickly by sharing large amounts of information. It seemed as if the knowledge of a futurist was based on quick, intuitive connections instead of the thorough work that, as I was told, precedes these presentations.

Serviceability for sensemaking The three products depict the most prevalent activities that futurists carry out to share their knowledge of the future with clients and the public. The activities of futurists often consist of reports, workshops and keynotes. The description of the products suggested that futurists did not just aim to deliver a product to their clients, but wished to do more. In this paragraph, I continue by further examining this observation.

In their discussions, futurists often referred to products as a resource that enabled them to offer their service. For example, many futurists articulated how they strived to create learning environments during their workshops. In addition, futurists have described how much they value the inquiry with clients whether the raised questions about the future make sense. Moreover, the futurists described how the purpose of giving keynotes has changed over the years, from one standard presentation advanced to more interactive formats. Regardless which products were deemed appropriate, futurists articulated the wish to contribute to broader sensemaking. Their service can be described as sensemaking of and for the future. This implicates that products are seen as a resource to realize that goal. For example, futurists help clients to develop their long-term strategy or give direction to a government in their decision-making processes. This aspiration was something that Bell (2005) also observed, arguing that futurists have the responsibility not to lead people astray in their choices that concern the future.

With each of these products, futurists prioritize that their service should be useful for their audiences. In the words of Jasanoff (1998), futurists' products are 'serviceable'. ${ }^{31}$ Jasanoff coined this term in the Fifth Branch as a "state of knowledge that satisfies tests of scientific acceptability and supports reasoned decision making, but also assures those exposed to risk that their interests have not been sacrificed on the altar of an impossible scientific certainty" (supra note 5, at 250.8). In transferring their knowledge, futurists aspire to help others better understand how to deal with the future. As such, the serviceability can in this study be understood as futurist knowledge that is made applicable in the context of the given situation.

In order to be serviceable as a profession, it is helpful if the produced knowledge is accessible to others Practitioners usually translate their insights into generic knowledge to enable circulation. However, the knowledge that futurists produce is often described to be interconnected with its context. For example, to the particular situation of a client, the question raised, to the topic and/or the particular futurist doing the work. In other words, futurists derive their knowledge not just from credentialed sources like handbooks, but keep developing their knowledge over years, and regard it as a form of applied wisdom. Futurists deliver a broad range of products, that 
enable them to offer their service, depending on the context. The contours of those products may be alike (like the form of a report, workshop or keynote), but the content is not, according to a futurist familiar with the community:

So, we don't have a commodity product, we rather tend to utilize the knowledge, and do this from all useful perspectives, with the aim to make it tangible for organizations.

The quotation illustrates that the knowledge produced by the futurists expresses their serviceability as well as individual creativity. For example, futurists have described (fieldnotes, September 2015) that the manifestation of final results typically depends on the vision of the individual futurist. That particular futurist decides which connections to make, based on a distinctive combination of experience, interest and specialties. In the way futurists produce knowledge, they utilize their cross-boundary mindset to make 'unexpected' connections. A commercially oriented futurist explained:

We are making new connections in knowledge to create value and we are also breaking existing connections, in so doing creativity is highly desirable.

Futurists refer to creativity and the use of intuition as vital aspects of their knowledge production to create meaningful service, sensemaking for and with clients. That service involves doing new things, and if necessary, break with old patterns. As discussed in previous chapters, the art of becoming futurist is not just a matter of obtaining a set of required skills, it is also the growth of a futurist mindset which, amongst other things, includes the ability to think differently.
With their services futurists provide their clients with sensemaking. The word sensemaking stems from a tradition of scholars instigated by Weick $(1995,2001)$ who examined organizational sensemaking: "In real-world practice, problems do not present themselves to the practitioners as givens. They must be constructed from the materials of problematic situations that are puzzling, troubling and uncertain. In order to convert a problematic situation into a problem, a practitioner must do a certain kind of work. He must make sense of an uncertain situation that initially makes no sense" (Weick, 1995: 9). ${ }^{32}$ From this perspective, futurists can be regarded as sense makers as they introduce alternative views (of the future). Futurists have described to be acting as guides to help make sense of a changing world. In their role as guides, futurists wish to inspire, broaden worldviews, help envision the future, provide innovation themes, create images of the future, offer hope and a vision, create a space to reflect and have a thoughtful conversation (fieldnotes, September 2015). Driven by a common ambition for sensemaking, futurists help their clients to act on the future. An established policyoriented futurist described:

I help find a new role for the government. Not via traditional routes of jurisdiction and enforcement but by building networks, and using co-creation and facilitation methods. As such, I am not advising - I am acting.

Introducing others to thinking about the future evokes a common sense of responsibility amongst futurists. And they do not take this task lightly. Futurists articulate how they feel the necessity to bring across knowledge about how to act upon the future. Most futurists describe that they aspire to influence audiences with their knowledge. They wish to do more than just delivering products. To them, those products are just one of the resources to be of service for their clients. In general, futurists help others make sense of situations, problems or interactions that they face.

At first glance, futurists' work has a thoroughly individual character, in their practice futurists rely on personal skills and knowledge. This especially became visible in how futurists take pride in creating unique work. Futurists described to produce knowledge that embodies their practice, which leads to great diversity in the products that they offer. However, this type of knowledge production is not only an individual undertaking, it is also a collective pursuit, in which futurists regard knowledge as a resource to enable them to offer services.

I examined how futurists use their knowledge (e.g. in products and activities) in becoming a professional and how consciously knowledge is part of the service futurists aspire to provide. In the next part of this chapter I study how knowledge is usually connected to professionalization according to the sociology of professions. In Paragraph 6.4, I first examine how sociologists have characterized the role of knowledge in professionalization and use this as backdrop to compare this with the role knowledge has in the professionalization of futurists. Furthermore, in Paragraph 6.5, I further examine the role knowledge has in the broader professionalization of futurists.

The knowledge-based profession assumption The heartland model of professionalization assume that professions are knowledge-based in order to be 
able to provide a service to society. To better understand the reluctance of futurists to adhere to the traditional model of professionalization, it is relevant to return to how scholars in the sociology of professions describe the role of knowledge in the making of a profession.

In the sociological accounts of professionalization, knowledge follows a model of rational, formalized scientific knowledge. This model was formulated when a new spectrum of work arose after the en lightenment and the industrial revolutions. ${ }^{33,34} \mathrm{~A}$ class of professionals had gathered enough knowledge to be experts and a mandate to use their expertise. Regarding professionals, Weber (1978/1922) argued that their knowledge should be certified and credentialed. These types of credentials can be obtained by a degree from a licensed institution. Weber (1978/1922) regarded this type of knowledge as the ground on which an occupation can establish social closure and advance its social status. And as a consequence, the professional status moves from occupation to profession. The sociology of professions has continuously assumed that the role of knowledge is a resource in gaining power and establishing a monopoly.

Although knowledge is an aspect that many sociology of professions scholars touch upon, often the matte is not emphasized to great extent. For example, $\mathrm{Ab}$ bott mentions knowledge on multiple occasions in Systems of Professions; in his index there are 31 references to the word 'knowledge'. Abbott uses the word to refer to abstract, academic knowledge. As for Freidson's use of the word in Third Logic, while the index is clearly less elaborate than Abbott's, 'knowledge' is still mentioned 15 times. Freidson makes
33 The development of theory on professions is obviously interwoven with shifts in modern history (Münte, Scheid, 2017). 34 Between the lines, the rational formalized scientific view is not as firm as the title would suggest. For example, indetermin
is taken into account to do justice to the inevitable fuzzy
aspects of a profession. However, it is not considered to be a aspects of a profession. However, it is not considered to be a good thing if there is a high level of indeterminacy. Moreover, MacDonald argues that images of a profession reside in peop
organizations and commodities. Which gives a glimpse of the idea that knowledge is not only produced in academic settings, as words like 'rational', 'formalized' and 'scientific', would suggest. In the description of how futurists produce knowled an alternative image of knowledge becomes visible. The professionals actually embrace indeterminacy and know

that can be produced in settings outside of academia.
35 All considerations can be found in MacDonald (1995: 157).

distinction between professional knowledge (and its effects) and knowledge types ranging from 'everyday', to 'tacit' to 'formal'. A sociologist that has tried to combine these views is MacDonald (1995), who has written an extensive, historical overview of how scholars have treated knowledge as part of becoming a profession.

In this overview, MacDonald (1995) argues that sociologists of professions generally reason from the viewpoint that knowledge is rational, formalized and scientific. For example, MacDonald (1995) describes how professions ought to use knowledge to set professionals apart from laymen. MacDonald has made an effort to summarize a number of considerations. ${ }^{35} \mathrm{He}$ mentions several topics such as the nature of knowledge and how credentials are relevant. I only elaborate on those three, as they are valuable in order to understand the role of knowledge in the classic model of professionalization and in the professionalization of futurists.

According to MacDonald, professions are so called 'knowledge-based' occupations (MacDonald, 1995: 160). According to MacDonald, knowledge can be seen as abstract, generalizing and self-expanding, and should be applicable to issues that are relevant at any time or place. He cites Murphy's (1988: 246-247) definition of 'modern knowledge':

Knowledge of how to calculate market profitability, to organize and plan in bureaucracies, and to develop, apply and predict the abstract codified laws of the legal system have all been developed under the process of formal rationalization. This formally, rational abstract utilitarian knowledge has resulted in new means of control (over nature and over other groups).
MacDonald quotes Halliday (1987:29) to explain that knowledge is regarded as "a core generating trait" of a profession. This is, according to MacDonald (1995), to be found in all sociological treatments of the professions and is certainly endorsed by Larson (1977: 40), Abbott (1988: 9) and others. Knowledge is regarded as a means to gain control as a profession and as a means to become a professional.

The words that are used to refer to the actual function of the knowledge are valuable to understand sociologists' perspectives on knowledge in becoming a profession. Words like 'means of production' (1995: 162) and 'resource' (1995: 163) are mentioned. For many of the scholars mentioned by MacDonald, knowledge is a resource to obtain power or a monopoly in their preferred domain. Abbott's views on jurisdiction had a similar understanding of the use of knowledge.

In other words, professionals "carry the means of production for their line of business in their heads" (MacDonald, 1995: 162). In a knowledge-based profession, practitioners treat knowledge as a resource to become a professional and to establish a monopoly as a profession. As a consequence, credentials ought to be obtained from an educational institution to show that a knowledge base is mastered in order to be accepted as a professional within and outside of the profession. In this perspective, knowledge is treated as fixed, relying on a shared knowledge base and regarded as one of the resources to claim jurisdiction in the legal arena.

A reservoir of knowledge In a knowledge-based profession, it is assumed that knowledge is advanced in certified learning environments and ought to be obtained before practitioners 
are eligible to carry out the work. This type of knowledge is usually acquired through formal education. This is anticipated as a typical route to obtain the necessary knowledge to professionalize. For futurists this is not the route to professionalization. In which way does knowledge play a role in futurists' effort to professionalize? Which notions become apparent? Futurists are searching for ways to advance their knowledge. I summarized a conversation of futurists about this topic.

We want to advance our knowledge base. How can we do that better? What is the content of a typical futures course? Being a futurist is lifelong learning but ther are no courses to update knowledge. We have to initiate innovation within the profession ourselves. We have to take the initiative to teach each other; for example, knowledge about experiences with clients, th way of working, metaphors, instruments and methods. There is currently little exchange about this. We can make a commitment to each other (summary of fieldnotes 10 September 2015).

During the session of which the above fieldnotes were derived the attendees were specifically discussing how to advance their knowledge, implying that there is no overarching knowledge base. The futurists came up with initiatives like courses as a way to fill the void of this resource.

Although futurists are referring to a knowledge base in this conversation, it is disputable if they actually have one. Futurists' knowledge is personalized to such extent, that it becomes problematic to speak of a 'knowledge base' in the first place. For example as described in Chapter 1, futurists have published handbooks, which can be regarded as a framework of their knowledge. But these handbooks cannot simply be applied by other futurists as most of them have set up their own individual routine of doing the work. Moreover, although futurists appreciate their existence, handbooks are not recognized by futurists as formal, credentialed learning materials or education. As such, futurists approach handbooks in a very particular way, not with the aim obtain a framework for knowledge, but only to obtain a possible framework for action. Futurists described to focus on advancing their individual applied wisdom, which is based on their specific skills and methodological and theoretical knowledge.

Instead of relying on forms of credentialed knowledge, futurists search for new knowledge for each separate assignment. For example, by reaching out to a dynamic circle of experts as a way to gather knowledge. Futurists may also make use of the process information in handbooks to guide them how to carry out methods like trend analysis, backcasting or scenario planning. Moreover, their research may also be informed by scholarly, theoretical perspectives and journalistic articles or industry specific knowledge packaged in reports of planning agencies or consultancies. It did not matter whether the futurists were senior or junior, each of them articulated a willingness to learn about new topics or methods. An established futurist sharing during a group discussion:

This sector must continually update the knowledge and organize this kind of sessions. It is about learning and growing (fieldnotes 26 June 2015).

This continuous act of gathering knowledge from different sources is an activity that futurists have in com- mon. The ongoing quest for relevant information is at the heart of how futurists tend to treat knowledge in their professionalization. These activities of harvesting knowledge contribute to the development of becoming a futurist. As such, knowledge has a vital role for futurists in becoming a professional, but for them it does not have a certifying purpose.

To enable these gathering activities, futurists access a 'reservoir' of knowledge when necessary. This reservoir can be characterized as a flexible, lively poo of possibly useful knowledge. The reservoir is intangible but can be seen as the collection of all possible resources. For example, books, articles, online data, visuals, video, audio, and anything that may be of relevance. This knowledge grows organically and is produced by commercial, scientific as well artistic futurists.

During conferences I attended, futurists called for a greater, more expansive reservoir of knowledge, albeit articulated in other words. In the fieldnotes shared earlier in this paragraph, it became clear that futurists wish to advance their knowledge and question how they can best approach this. This is not the first time I encountered this wish, in Chapter 2, I observed the discussion that was evoked among futurists about my claim that there was little awareness of the history of futurists. By setting up a library, the stunned futurists wanted to make sure that if another scholar was ever to ask fellow futurists about a common history again, they would have a sense of their predecessors. This example echoed how futurists value a common understanding of knowledge as it supports them in their aim to professionalize, but they do not regard it as an obligatory resource in becoming a profession. 
Futurists have mentioned that they sometimes feet alien in their way of approaching knowledge. And in a way, they are, considering the role knowledge has in their professionalization. Rather than continuing the tradition of treating knowledge as a resource in professionalization, futurists have an inherently different relation with knowledge as a professional and can be depicted as 'knowledge-producing' profession. To futurists, knowledge is important in their practice, but they do not apply knowledge-based principles in their professionalization. I observed that futurists did not just aim to deliver a product to their clients, but wished to deliver serviceable products with the aim to help clients make sense of the future (world). Moreover, in advancing their profession, futurists cultivate a knowledge reservoir which they continuously expand.

\subsection{Conclusions: a knowledge-producing} profession

This chapter started with the question: which notion of professionalization become apparent in futurists' ef forts to professionalize? Notwithstanding their diverse products in terms of topics, focus areas and specializations - futurists all make knowledge claims about the future. This is visible in the knowledge they produce, ranging from presentations to research reports and business concepts. However, futurists do not just create reports, workshops and keynotes, they also articulate the wish to do more; producing serviceable knowledge. Products that are useful, valuable and of service for their audience.

Diversity is a persistent theme that reappears in each of the empirical chapters. In this chapter it has come to the fore that futurists produce a diversity of products. Unmistakably, futurists have found many differen ways to make their knowledge claims about the future tangible in products. Again, at first glance this could give the impression that there is no common ground in this professionalization issue either. But that would be jumping to a hasty conclusion. In this chapter, I observed common ground in how futurists value the serviceability of their products and share the urge to contribute to broader sensemaking. Futurists articulate that they feel a particular responsibility and wish to help others make sense of the world, but, they all do this in their own way. Futurists are strongly connected to the knowledge they produce; it reflects their professional identity. Their tangible products may be worlds apart, but overlapping aspirations and values about knowledge connect the futurists.

In this chapter I directed my attention to the meaning of futurists' knowledge in relation to their professionalization. To that end, I examined if the knowledge-based assumption of knowledge as a resource for professionalization also applied to futurists. It quickly became clear that futurists challenge this assumption. In Paragraph 6.5, I observed how futurists appreciate the actual search for knowledge as a professionalizing activity and how they continuously tailor, adjust and organize their search in new ways. I described how highly futurists think of the ability to search for relevant data, to do that in the relevant context, and to ask relevant questions. To supplement these information searching activities, futurists cultivate a reservoir of joint knowledge. This reservoir is not tangible, but it is an accessible structure of useful knowledge (e.g. methods and theories) that can be used to produce new knowledge. Futurists have expressed their hope in expanding this reservoir as it represents the core of their dynamic knowledge to which each professional should have access and should be able to contribute to.
While in the traditional model of knowledge is considered to be a key resource for professionalization of practitioners, it has a different role for futurists. Knowledge functions as a resource to advance their service, not to advance their profession. Futurists search for knowledge is not about mastering a fixed knowledge base to rely on during the rest of their career. Instead, futurists value that acquiring knowledge is a dynamic and continuous learning process. This way of viewing knowledge differs from the widely applied knowledge-based perspective. In the latter case, the practitioner is professional when he or she has acquired sufficient knowledge. Futurists do not aim for this type of certified knowledge, which ought to be obtained before a practitioner is deemed eligible to carry out the work. To the contrary, futurists' aim is to develop serviceable, personalized knowledge to help others make sense of the world. Therefore, the flexibility to constantly acquire and apply knowledge, is a key feature of their work. Futurist' specific type of knowledge production is an intrinsic quality of their individual as well as collective professionalization activities. In sum, with their alternative pathway futurists have not only challenged basic assumption regarding traits, jurisdictions, the heartland, boundaries and reputations but also the knowledge-based model of professionalization. 


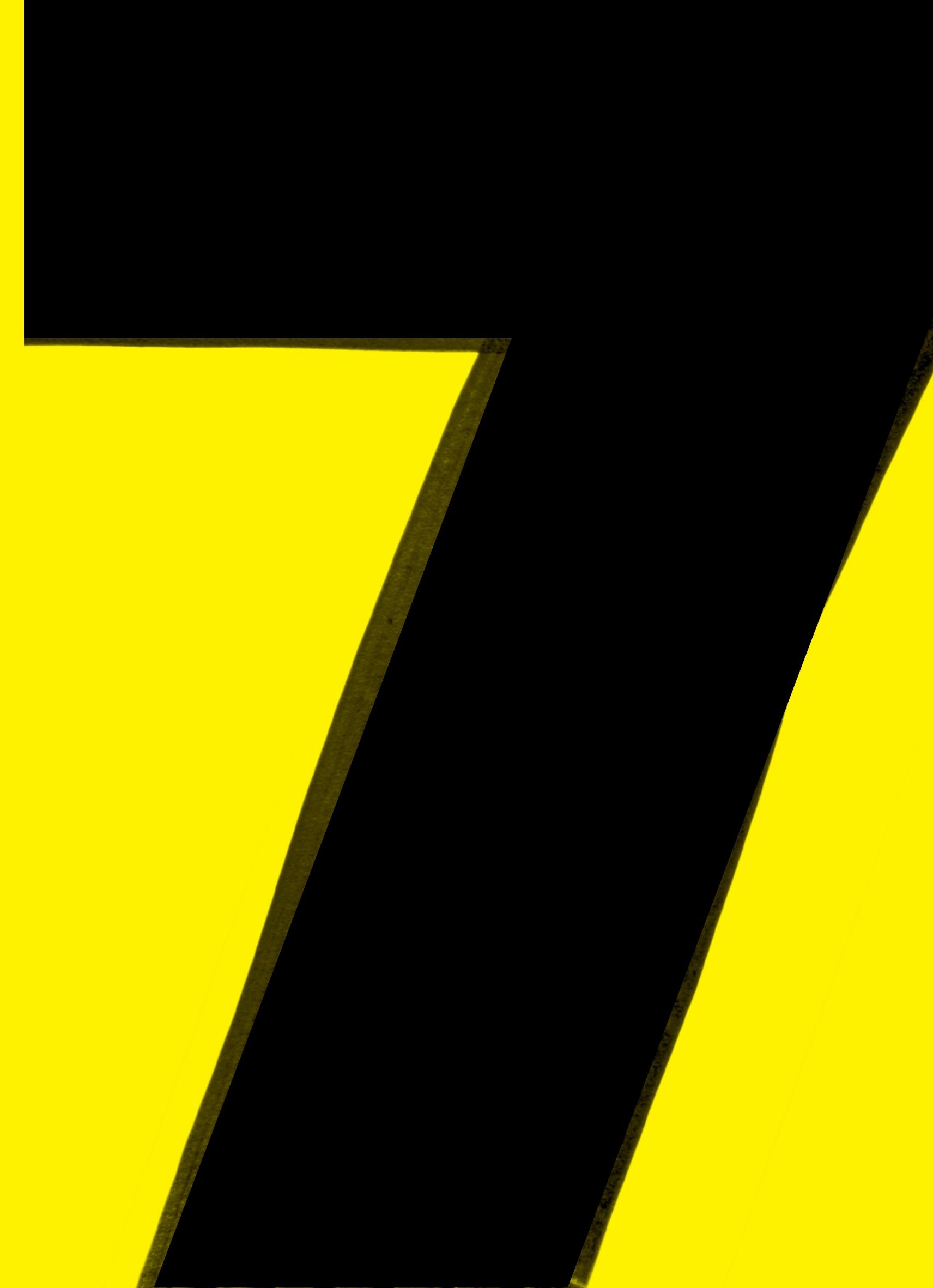




\section{Futurists and \\ their promise of professionalization}

Introduction

\section{Reluctance and the making of futurists}

Professionalization themes: identity,

reputations and service

An alternative pathway towards

professionalization
of Type 2 professions
7.1

Introduction

How to understand the making of the futurists' profession? In this thesis, I analyzed futurists and their reluctance to professionalize. I investigated their debates on professionalization and the (implicit) assumptions about professionalization that they incorporate in their thinking. I witnessed how futurists negotiated the state of their professionalization within their community and compared their development with other professions. The central research question brough me to conferences and meetings. Many futurists mentioned that they are trying to professionalize, and at the same time I observed how they struggle to become a profession. I examined their struggle and reluctance to adhere to traditional notions of professionalization. The key insight is that the reluctance points to an alternative pathway of professionalization that goes beyond traits and jurisdictions and transcends the heartland and knowledge-based assumptions. I thus claim that futurists' professionalization should be seen as a skill-based, heartland-free, boundary crossing and knowledge-producing profession.

In this final chapter, I summarize and discuss the empirical findings to clarify how futurists make their profession. Hence, I return to the research questions posed in Chapter 1:

1. How do futurists identify with the existing notions of a profession?

2. Which actions do futurists take to professionalize?

3. Which notions of professionalization become apparent in futurists' efforts to professionalize?

The answers to these questions matured in the course of the thesis. In Section 7.2, I synthesize my findings. In the following sections I proceed to delineate the alternative pathway futurists have chosen to follow in their professionalization. To close this chapter, and this thesis, I discuss what these findings imply for the scholarly knowledge on professionalization, in particular for the sociology of professions and for science and technology studies.

\subsection{Reluctance and the making of futurists} In the first empirical chapter (Chapter 3), I raised the question whether and how futurists identify with existing notions of a profession. I concluded that implicitly and without reflection, futurists took the traits model, derived from the sociology of professions, as their reference. These traits are a list of preconditions a profession should adhere to, such as education, organization of the community and a code of conduct. Usually, professions are portrayed as occupations with recognizable traits and well-established jurisdictions. Despite their awareness of their own professional particularity, futurists' expectations of how to become a profession are still shaped by a classic ideal of professionalization. Futurists mentioned, and complained, that there was hardly any common education and they have not organized themselves in a structured manner. Some futurists expressed their disappointment that they could not come up with a shared title that refers to their profession.

At first glance, these observations could lead to the conclusion that futurists do not 'believe' in their professionalization or cannot be considered as a profession. Some futurists indeed talked about their profession in those terms. This, however, disqualifies their practice and dismisses their efforts to professionalize. On several occasions, futurists informally exchanged experience and knowledge to find common ground. Moreover, futurists also made efforts in terms of traits. Over the years, for instance, more and more educational programs have been set up, and organizations like the Association of Professional Futurists and LaFutura have advanced different communities in the profession.

At the same time, futurists struggle with the traits model itself and are uncomfortable with the imposed norms of how to become a profession. Although futurists long to be recognized as a respectable profession, they find communality in their reluctance to adhere to a notion of professionalization that denies their self-understanding. Futurists, for example, share a broad recognition that there are different kinds of practitioners within their community. They do not necessarily know how to view this diversity in connection to their professionalization, but no one proposes to reduce diversity or calls for one archetypical practitioner. The futurists' struggle shows that they aspire to professionalize but at the same time are reserved to do so, as it may threaten their diversity. Although futurists long to be recognized as a respectable profession and a homogenous community adhering specific traits, they unite in their reluctance.

To date, this struggle has not been resolved, an paralyzes futurists. Some get frustrated by the perceived incapability to professionalize resulting in disqualifying their practice; others are entangled in repetitive or even uninformed conversations about professional communalities without follow-up. Although futurists consider creative thinking a crucia skill for their profession, they ironically tend to get stuck in their efforts to professionalize according to the classic professionalization model. Arguably an out-of-the-box perspective on professionalization is necessary to understand futurists as a profession. 
In Chapter 4, this struggle was further unraveled by questioning which actions futurists actually take to professionalize. I first followed Abbott's (1988) perspective, who coined 'jurisdiction' as a professional claim that is made in a particular area of expertise in three arenas, i.e. the workplace, public opinion and legal arenas.

With regards to claiming the workplace jurisdiction, futurists had, contrary to many of their written accounts, no difficulty describing what skills a futuris should have. They explained that futurists should have sensitivity for novelty as well as for people. They ought to have sensitivity for change and are able to translate its organizational consequences. In their view, being a futurist means being able to think across disciplines and beyond boundaries. The futurists mindset is anti-disciplinary, imaginative, growth oriented and open-minded. The workplace arena demonstrated how futurists have a shared image of the skills a futurist ought to obtain and the mindset that they share. These images are informally formulated, circulate as tacit knowledge, and are not imposed via any official credentialed route. With regards to the public opinion, futurists have described they are actually actively using the caricature I mentioned in Chapter 1: the image of futurists as prophets. Futurists use this sticky, yet flawed, image to star conversations about how they view their identity as futurists. Futurists use the opportunity of explaining their job title, by clarifying the value they attach to adopting a future-minded perspective.

Futurists are not reluctant to claim jurisdictions in both the workplace and public opinion criteria. The activities in both arenas demonstrate how futurists are willing to advance their professionalization by taking actions, both individually and collectively. Futurists have explained these actions as a way to shape their professional identity. Claiming jurisdiction in the legal arena, however, did cause noteworthy reluctance among futurists. This reluctance was expressed whenever standardization of practice was brought forward by futurists. Futurists all stood together in their unwillingness to standardize, and therefore did not express any interest in harmonizing their individual (work) routines.

The classic legal jurisdiction is obtained with the prospect of reaching the promise of professionalization. Abbott refers to this promise as the heartland - the assumed end-point of professionalization. Futurists deviate from the usual path of seeking professional status through reaching the treasured heartland: the presupposed utopia of all occupational groups becoming true professions. This heartland is to be reached after carrying out professionalizing activities in the workplace arena, in the public opinion arena and the legal arena. The assumption is that most aspiring professions aim to finally claim jurisdictions in each separate arena. Both Schön (1983) and Abbott (1988) expect that only a few professions do not adhere to this heartland model. This has been considered as an incongruity to which no further attention is paid. Futurists, too, deviate from the classic model by challenging the heartland in their professionalization efforts. Instead of viewing the deviation as an incongruity, I have further analyzed and expanded the idea of what I coined as a 'heartland-free' profession.

Regarding the third question, alternative notions of professionalization became apparent in Chapter 5 and 6 when I examined futurists' reluctance to standardize their professionalization. In the reluctance of futurists, there was a lot to learn about the implicit assumptions that govern the professionalization of any type of profession. In these two chapters I examined two themes that repeatedly were mentioned by futurists: the way in which they build their reputations and the service that they offer.

In Chapter 5, I have built on recent studies in the sociology of professions that abstained from a traits perspective, but still believe in the idea of a common heartland. Based on the insights in how futurists claim jurisdictions in Chapter 4, I concluded that futurists did not try to reach the heartland but strive for a heartland-free profession. With this observation I had to leave the jurisdictions as a theoretical perspective. Instead I turned to the perspective of reputation structures, which is rooted in the sociology of professions and can be regarded as a separate theoretical perspective. This perspective was promising for this $\mathrm{PhD}$ thesis because the previous chapters made clear that futurists are a diverse community of practitioners with a variety of audiences. Hence, they need to build their reputation in different contexts: the academic, commercial and artistic world in a combination thereof

In the literature on reputation structures, I learned that while for instance scholars tend to lean on reputation building in one world at a time, futurists break with this by engaging in multiple worlds, and that in each of these worlds, futurists are (implicitly) negotiating boundaries. Comparable to jurisdictions, futurists are not concerned with carving out boundaries in the strict sense as they are not prioritizing competition with other practitioners to draw boundaries. On the contrary, aware of their diversity, futurists are seeking a 'common ground' with other practitioners. 
This notion has been formulated in boundary theory by referring to the place where different practitioners meet and find mutual understanding.

The common ground of futurists is not found in thei aim to claim jurisdictions or to carve out boundarie in order to separate themselves from others, but rather in how they appreciate the crossing of boundaries. The futurists' individual reputations are distinctive the particular emphasis between the different world and how boundaries are crossed substantially differ among futurists. Yet, futurists do find communality in their appreciation for the sole activity of crossing boundaries. Building a reputation in just one world is not sufficient in the futurist profession. These cross-boundary reputations honor the diversity that is so often mentioned as a given feature of futurists.

In Chapter 6, I further analyzed the futurists reluctance by appreciating the role of knowledge in their professionalization, because futurists often referred to their service in relation to their professionalization. Therefore, this chapter focused on the knowledge futurists produce, resulting in tangible products like reports, workshops and keynotes. The products mean more to futurists than just output they are seen as a valuable resource to present their service to society. The knowledge claims futurist produce cannot, and should not, be separated from their professional identity. Futurists take pride in creating their own unique work. Futurists strongly identify with what they produce. Ask two differen futurists to produce a report, and they will come up with entirely different work-a phenomenon they are proud of. It proves, according to futurists that their knowledge is not just derived from handbooks but matures in practice.
In the sociology of professions, the assumption that a profession is based on knowledge remains unchallenged. Sociology of professions scholars consider knowledge as a resource to gain power. Practitioners use knowledge to acquire legitimatization from outsiders, often by obtaining credentialed knowledge, requiring practitioners to demonstrate that they master the knowledge base. Amongst futurists, knowledge is significant for their professionalization as well, but in another way. Futurists produce knowledge that has an ever-changing character. Futurists professionalize in their continuing search for knowledge. As such, futurists organically build on a dynamic knowledge reservoir, which can be seen as an intangible archive of relevant books, articles, video, audio, images and so forth. This archive does not contain credentialed knowledge, but does offer futurists a common resource. Instead of demarcating a knowledge base and setting up credentialed institutions, futurists develop a growing knowledge reservoir that every futurist can use and contribute to.

With regard to the third question, Chapter 5 and Chapter 6 demonstrated how futurists 'break' with two implicit assumptions that have governed classic professions. In Chapter 5, I studied why futurists do not aspire for a heartland, and how they follow their alternative pathway by advancing cross-boundary reputations in the academic, commercial and artistic worlds. Individual futurists decide which worlds are emphasized to a greater or a lesser extent, and as a collective they find common ground in their aspiration to constantly cross boundaries. And, in Chapter 6 , I demonstrated how futurists value to contribute to broader sensemaking by offering serviceable knowledge claims packaged in products. For futurists, the actual search for relevant knowledge contributes to becoming a futurist and their broader professionalization. For a concluding overview of the topics, questions and findings, see Table 3 .

My choice to follow the futurists' reluctance has indeed been fruitful. Futurists have publicly been struggling with their professionalization, which resulted in stories of their identity, reputations and service. After studying those professionalization stories, I interpreted the struggle as reluctance. This reluctance was an opportunity to further examine how futurists are becoming a profession. The study made visible that futurists take actions to build a community of likeminded practitioners. But while doing all that work, futurists have not been able to solve their reluctance. They recognized their reluctance, articulated it, but did not dwell on it. To them it is a given feature of their professionalization. As a consequence, futurists did not scrutinize their reluctance, where it arises, how it feels and why it is present. 


\section{Chapter 3}

Topic

Futurists and the struggle of professionalization.

Research question

How do futurists identify with the existing

notions of a profession?

\section{Findings}

Futurists struggle with their professionalization.

Traits are not an adequate perspective to

decide on professionalization of futurists.

Futurists are taking action to find common

ground in professionalization.

\section{Chapter 4}

Topic

Futurists and their reluctance.

Research question

Which actions do futurists take to

professionalize?

Findings

Defined efforts of professionalization are made by futurists. Futurists are active in the workplace and to influence the public opinion.

However, legal jurisdiction causes shared reluctance among futurists.

\section{Chapter 6}

Topic

\section{Chapter 5}

Topic

A heartland-free profession.

Research question

Which notions of professionalization become apparent in futurists efforts to professionalize?

Findings

Challenging the heartland: finding an alternative pathway to professionalize. Futurists build, construct, negotiate and nourish their reputations in different, overlapping commercial, academic and artistic worlds. Futurists appreciate the lasting effort of the crossing of the boundaries of any world.
A knowledge-producing profession.

Research question

Which notions of professionalization become apparent in futurists efforts to professionalize?

Findings

Futurists do not aspire to be a knowledgebased profession, instead they are a

knowledge-producing profession. Futurists produce individual knowledge claims about

the future, packaged and retailed as tangible products, which is their service to their clients. Futurists become professional by continuously searching for new knowledge and growing an intangible knowledge reservoir that they can access when necessary. 
7.3 Professionalization themes: identity, reputations and service

The professionalization literature (traits, arenas, claiming jurisdictions, heartland, reputations, services) and science and technology studies (boundary work) provided useful notions to analyze the reluctance of futurists to professionalize. I am now in a position to formulate what my study can add to the studies of professionalization. To do so, I identified three empirically informed themes that reoccurred in the observations, interviews and group discussions. I detailed the quest for a professional identity. I mirrored the ways in which futurists build reputations and examined the service that futurists offer to society.

\section{Identity}

Early on in this research, I observed futurists' diversity in every possible professionalization aspect. Futurists' methods, objectives, theories and approaches were different. From the outset, diversity took center stage in the professionalization discussions. I observed contrasting ways in which futurists interpreted their diversity. For some futurists, diversity did not fit the dominant notions of what a professional should be. For others, their diversity symbolized the value of futurists and functioned as a defining feature of the profession. As such, the discussion on diversity lifts the veil of the shared identity of futurists.

Diversity was a persistent theme that reemerged in each of the empirical chapters. The workplace and public opinion arenas offered a space in which complexity and diversity of its practitioners was recognized whereas the legal was constraining in vocabulary and imagery of what a professional is ought to be. I observed that their products differ in every way, but overlapping aspirations and values inherently seem to connect the futurists. In no way, shape, or form, a plea was made to outline an archetypical futurist. Futurists expressed no urgency to reduce professional diversity which makes it a core feature of their common identity and consequently of their profession.

\section{Reputations}

Professionalization of futurists is not dedicated to advancing a homogeneous, singular notion of what a futurist should be. For example, futurists are not only making knowledge claims, but also getting commercial acquisition to mobilize necessary funds. They described that academic rigor is important, but preferably did not dwell on it, because futurists feel the responsibility that practical questions need to be answered. Moreover, commercial reputations of futurists are not just based on referrals of clients but also on the judgment of colleagues and peers. Artistically inclined futurists work like artists, preferably in seclusion, advancing an autonomous practice. However, if they do want to have professionalization conversations, they cross-over to conferences of academic and/or commercially oriented futurists. As such, there is not a clear-cut, singular pathway of building a solid reputation. Instead, futurists find common ground in their shared activity of crossing boundaries, it allows for their diversity to develop. Futurists are united by honoring their collective cross-boundary reputation building.

\section{Service}

In the introduction I detailed that professionals are offering their services to society, with the commitment to, for example, build houses, write stories, design clothes or cure diseases (Schön, 1983; Noordegraaf, 2007). I also observed how the demand for services is changing. New professions come into existence to offer additional services that are claimed to be of societal value. Futurists deliver a broad range of products, that enable them to offer their service to their clients. Those products may be alike (like the form of a report, workshop or keynote), but the content is not. Futurists refer to creativity as a vital aspect of their knowledge production to create meaningful service. That service consists of doing new things, and if necessary, break with old patterns. While knowledge is considered to be a key resource for professionalization of practitioners, it has a different role for futurists. Knowledge functions as a resource to advance their service. Futurists' search for knowledge is not about acquiring a credentialed knowledge base to rely on during the rest of their career. Instead, futurists value that acquiring knowledge is a dynamic and continuous learning process. For futurists, this implies that they use guidebooks in a very particular way, not with the aim obtain a framework for knowledge, but only to contribute to their futurist mindset.

This study thus yielded three central professionalization themes that became a central part of the search to observe professionalization activities of futurists. Along the lines of the three themes it was possible to demonstrate that futurists efforts can be regarded as professionalization too. I have observed futurists struggling, negotiating, discussing their professionalization And based on these professionalization stories/actions, I was able to demarcate an alternative to the dominant typology that exist in professionalization.

How can these findings be connected to the current state of professionalization theory? The current theoretical conversation in the sociology of professions is fragmented: communality is absent and the per- 
36 Brante already referred to this word in 2011 in his aim to harmonize professions by analytically separating different "types of professional knowledge" (2011: 19). Although Brante's scholarly aim may have been different, it does articulate the significance of creating
of professionalization.

37 The notion of 'wired in' was derived
(2014) from the work of Gray (1971: 778). spectives, topics and methods are scattered (Saks, 2012). Sociology of professions scholars do not seem to agree on which methods to use and which perspective could be most valuable to grasp modern-day professionalization (Brante, 2011; Evetts, 2011; Saks, 2012). In those approaches, the themes of identity, reputations and service are articulated as relevant, although not dwelled upon and often mentioned indirectly. In sum, there is potential that the three themes are a starting point for sociology of professions scholars to progress the theoretical conversation from a new perspective.

\section{4}

An alternative pathway towards professionalization

There already exists a scholarly awareness of the need to reconfigure the understanding of professions. For example, Suddaby and Greenwood (2001); Evetts (2003); Kirkpatrick and Muzio (2011); and Noordegraaf (2007 and 2011) refer to the changing notions of professionalization. At the same time, they continue to remain within the classic framework, leaving the fundamental assumptions of the professionalization model unchallenged. Based on my analysis of the professionalization struggle of futurists, I agree that more profound theoretical innovation is needed.

How, then, to characterize the alternative professionalization pathway of futurists? I conclude that it is needed to consider the classic model as a particular type of professionalization and that we have to accept that other types of professionalization exist. With this $\mathrm{PhD}$ thesis, I documented another 'type' of professionalization. ${ }^{36}$ The classic pathway of professionalization obviously was the first typology that was identified and can therefore best be referred to as 'Type 1'. Type 1 is the classic promise of profession- alization as presented in the literature of sociology of professions. 'Type 2' is an alternative promise of professionalization that can be derived from my analysis of a particular profession, i.e. futurists.

In Table 4, I illustrate the key differences between Type 1 and Type 2 professions by detailing general, contrasting themes of professionalization that I have identified in the previous, empirical chapters. The comprehensive list of Type 2 attributes summarizes how futurists are entering new grounds of professionalization.

The demarcation of two separate typologies of professionalization clarifies why futurists struggled to identify with existing role models of professionalization. Nonetheless, the overview is not intended to represent two poles. Noordegraaf et al. (2014) convincingly argued for shifting focus from binary dimensions to focus on relational dimensions of professionalization. Their perspective makes it possible to observe professionalization for what it is today and helps to articulate specific contextual particularities. In the same way I would argue that Type 1 and Type 2 are not dualistic professionalization paths, instead they evolve alongside each other.

The alternative characterization of a Type 2 profession resonates with other studies of practitioners professionalizing in a particular manner. For example, Noordegraaf et al. (2014) identified and studied professionalization of strategists. There are some striking resemblances between the Type 2 professionalization I identified and Noordegraaf et al.'s (2014) observations of Dutch strategists who also consider their professionalization to be unconventional. Their study concludes that strategists, just like futurists, refer to their practice with a wide-ranging choice of formal names and titles. Moreover, Noordegraaf et al. also describe how strategists need practical skills that enable them to gain access and get 'wired in' the relevant groups and communities to be trusted with strategic work. ${ }^{37}$ In this $\mathrm{PhD}$ thesis, I refer to boundary crossing and serviceable sensemaking in a similar manner: futurist need connection to be trusted with their contributions. Whether strategists are also professionalizing in a Type 2 manner is an open question, but both studies at least point in a similar direction, problematizing conceived notions of professionalization.

What are the implications of this alternative typology of professionalization? It is difficult, almost impossible, to speculate about the possible consequences of my observation. I have given words to this phenomenon, but it will be up to the futurist to shape the future of their professionalization process. Until now, futurists have been 'doing' professionalization first. With these observations, I aim to provide futurists - and other professionals - with tools to reflect, advance, and maybe even consolidate, their professionalization. It is very well possible that futurists' growing awareness of their unique Type 2 professionalization pathway, enables them to give new meaning to their becoming of a profession. And if futurists start to articulate what it means to be a futurist, outsiders may recognize that and respond accordingly, filling the label 'futurist' with substance (van Lente and Rip, 1998). The depiction of Type 2 may help futurists reflect on, and value, their professionalization actions. And, the notion can also stimulate futurists to explicitly decide on how they wish to shape the future of their pathway. Accordingly, the promise of Type 2 has the potential to become the professional futurists' social reality. 


\section{Type 1 Professions}

\section{Identity}

Traits

Colleagues and peers

Standardization

\section{Reputations}

Heartland

Activities in at least three jurisdictional arenas

Reputations in one world at a time

Carving out boundaries to claim authority
Type 2 Professions

\section{Identity}

Skills

Circles of other, relevant experts

Diversity

\section{Reputations}

Heartland-free

Activities in one or two jurisdictional arenas

Reputations in multiple worlds

Crossing boundaries to connect worlds

\section{Service}

Knowledge-producing

Aim for serviceable sensemaking

Knowledge reservoir 

38 This is based on a scan I performed of the empirical cases in
journals like Current Sociology, Professions and Professionalism and Organization Studies. Scan via Google Scholar and ScienceDirect on May 23th 2018.

\subsection{The promise of Type 2 profession}

With this $\mathrm{PhD}$ thesis, I challenge explicit and im-

plicit assumptions in the sociology of professions. Notwithstanding the arguable fragmentation of perspectives on professionalization, the salience of traits, jurisdictions, heartland and knowledge-base is not fundamentally questioned. The reluctance that futurists voiced enabled me to unveil existing assumption of professionals referring to reaching the heartland and following knowledge-based principles. When futurists articulate their reluctance, it mostly concerned with these two assumptions.

The study of professions is not the sole domain of sociology of professions scholars anymore. Othe scholars have also directed their attention to professions. Several scholars, from interdisciplinary backgrounds, have argued that professional practices are hybrid, mixed and connected (Brock et al., 1999; Noordegraaf, 2007, 2011, 2014, 2015, 2016) and operate in novel occupational contexts (Evetts, 2011). Especially the work of Noordegraaf has served as an exponent of the apprehension amongst scholars to study present-day professions. Noordegraaf point out that there is more to learn about how identitie and reputations are constructed and how that in fluences services that professions may provide. He emphasized that professions need renewed consideration, in notions and overall reframing. With my $\mathrm{PhD}$ thesis I have examined futurists with this renewed consideration. By following their reluctance, I was able to characterize their alternative pathway to becoming a profession.

It is increasingly vital to alter the traditional empirical cases that are currently being presented by scholars. Even today, in the midst of changing notions of professionalization, there is a discrepancy between the forward-looking theory on the character of professions and the conservative empirical cases. The traditional cases continue to dominate the study of professions. Most journal articles may have considered changing professionalization but still evolve around professions that have already institutionalized to a certain extent. Examples include teachers, journalists and architects. Up-and-coming professions are still hardly addressed in articles in journals on professions. ${ }^{38}$

A new generation of interdisciplinary scholars has also struggled with the classic model of professionalization, leading to small steps towards new notions of professionalization. For example, by Waring (2014) who argued for the growth of hybrid professions and the blurring of professional boundaries. He analyzed changing notions of professionalization in the context of 'classic' bureaucratic and marketized workplaces. This can be connected to Noordegraaf's (2011) thought-provoking argument on reconfiguration of professions, which he supported with an empirical account of medicine. The third example is the work of Evetts (2011), in which she examined new kinds of professionalism in public sector service work such as health, welfare and education. Although the theoretical aspiration to broaden the perspective on professionalization is promising, it has not equally been cemented in the empirical cases. As a consequence, sociology of professions scholars did not yet fundamentally challenge the dominant Type 1 standards and ideals.

To that end, the fundamental implication of the repeated observation that many professions do not fit in the classic professionalization model (associated with lawyers and doctors) is yet to be drawn. With this $\mathrm{PhD}$ thesis I demonstrated that professions are excluded, and even exclude their own practice from the classic model of professionalization. To this day, no alternative pathway has been recognized that could equally count as professionalization. With the case of futurists, I documented the contours of an alternative type of professionalization that thus far has not received the scholarly attention or appreciation it deserves. Furthermore, if the possibility of multiple types of professionalization is not recognized in the first place, it is not likely that the existence of alternative types of professionals, professions and professionalization will be acknowledged.

The futurists have served as guiding example to show the relevance of studying professions that are still in the midst of their professionalization. Futurists of fered a look in a machine yet to be oiled. Observing how those new professionals are evolving their practice provides the opportunity to theoretically and empirically appreciate the process of how professions come into existence.

This $\mathrm{PhD}$ thesis has illustrated that sociology of professions scholars would benefit from an interdisciplinary scholarly perspective. For example, by finding support in the perspective of science and technology studies, which has a keen eye for novelty in science and society. Science and technology studies scholars focus on the interaction between the development of science and technology and societal change, and study both practices and controversial topics that emerge from that interaction. The result is a forward-looking perspective, which contributes to a better understanding of how boundaries are carved out by professionals and the role of knowledge in professionalization 
Harvest for science and technology studies scholars

In this thesis, while examining the professionalization of futurists from the sole perspective of the sociology of professions it was not all-encompassing to grasp the full extent of their process. The body of knowledge created in science and technology studies proved to be a useful additional perspective to examine my research questions. In response, science and technology studies scholars can learn from sociology of professions, too.

I contributed to the science and technology perspective by redirecting my attention from the notions, conceptions and methods that futurists use in their practice, to their professionalization. The perspective of 'professionalization' has not been related to the actual methods, theory and practice of futurists before. Futurists have been studied while carrying out their daily activities and the aforementioned authors have reflected on multiple significant aspects of futurists practice. For example, how futurists construct stories and future claims while dealing with uncertainty, complexity and discontinuity. The social processes have been described but were not part of the overal scope (Brown et al., 2000; van 't Klooster, 2007; van Asselt et al., 2010ab). Moreover, Fuller (2009: 73) a scholar who is familiar with the futurists' community, has argued that producing knowledge about the future "is a social process" of which the "purpose is to construct meaning". Examining this realm of intangible processes, events and actions somehow immediately generates focus on how meaning is constructed. Questions on who the producers are and how they relate professionally have not been intricately advanced yet. This inspired me to shift the focus to the practitioners by systematically examining the professionalization of futurists.
The questions originally asked about futurists, were concerned with how futurists produce knowledge, not by whom. Whereas science and technology studies scholars successfully identified emerging professions, often related to technological progress, and emerging interdisciplinary partnerships, like epistemic communities, they hardly connect to professionalization. I was not the first to value the connection between the how and the who. My perspective can be connected to how, for example, Haas (1992) has developed his work on epistemic communities. An epistemic community is regarded as a varied network of professionals that influence policy decisions with their common expertise. Epistemic communities consist of many different stakeholders with the same goal: influence national or international governmental policy with their insight. In this perspective, Haas and others examined a community of practitioners in the context of their policy influencing activities. In that study, the latter is stressed and not necessarily the professionalization efforts of those practitioners. However, it does observe a similar social aspect of communal knowledge production.

In addition, I was also fascinated by the question how futurists build their reputations to professionalize. Initially, I turned to the body of knowledge of reputation structures, which is related to sociology of professions. After learning about the inner conflict that futurists have with the underlying assumption that reputations are bound to a specific world, I concluded that I needed more perspectives to inform my search how futurists pave their pathway. Sociology of professions literature was useful as a starting point, but not exhaustive to answer my questions.

Over the years, boundary theory has developed a sound body of knowledge (for example, Jasanoff,
1990; Star, 1989; Hilgartner, 2000; Dunsby, 2004; Schmid, 2004; Jasanoff, 2005, Bijker et al., 2009). In this $\mathrm{PhD}$ thesis I mostly narrate Gieryn's $(1983,1995)$ perspective, who raised questions regarding carving out boundaries in relation to others. Those others can be other professions, practitioners, competitors, or the general public. Whereas his work emphasizes the boundaries of science and non-science, the notion was useful to reinterpret the materialization of boundaries that futurists tend to draw, negotiate and articulate. Moreover, Gieryn assumed that boundaries are carved out in each of the three arenas that $\mathrm{Ab}$ bott has defined. Shortly thereafter, I concluded that the concepts 'jurisdictions' and 'boundaries' are no interchangeable. At most, the concepts could be theoretically paralleled, although to be able to connect jurisdictions and boundary theory, more conceptual attention is required. Furthermore, I established that boundaries are mostly crossed, redefined and changed in the workplace arena. Only in that arena there was sufficient space for informal activities such as boundary crossing. Futurists emphasize that they did not strive for carving out strict boundaries. It is not an urgency, especially since soft boundaries serve futurists to shield their creative freedom.

Futurists are crossing boundaries and the act of connecting worlds provides a common ground in their search for professionalization. What does this insight yield for science and technology (STS) scholars? The crossing of reputational boundaries has been recognized by scholars as an occasional feature of professionalization, however: not in a durable state. The example of futurists demonstrates that it is fruitful to further examine how professionals may translate and connect different worlds by crossing from one into another (Wenger, 1998) and being comfort- 
able in staying in that in-between space. In studies on boundary work, scholars still assume that practitioners will want to move back to their own worlds to translate the knowledge that they have harvested. However, this assumption dismisses a possible type of boundary work that may be relevant for other aspiring professions too.

Boundary theory evolved around the notion that practitioners take those actions to be able to claim authority as a professional. As such, the characterization of professionalization directly relates to how professionals carve out their boundaries. However, the difference between Type 1 and Type 2 professions is also of relevance for present work on bound ary theory. As the link between boundary theory and professions has often been made, it will be relevant for science and technology scholars to consider the influence of the changing perspective on professions on their own body of knowledge.

\section{Harvest for societal understanding of professions}

Next to broadening the academic perspective, m study also aimed to broaden the societal understanding of professionalization. On a societal level, it is problematic that there is such a narrow conception of what a profession is. When people are introduced to others, their profession is assumed to detail their identity. And our education systems are still designed to channe children to a single discipline profession. Professions are everywhere. Still, most of our daily concerns are related to our commitment to a particular profession. The narrow conception mainly involves that many new, up-and-coming professions are not regarded as equally substantial. At the same time, change is at the horizon; some professions that were non-existent 20 years ago, are now a vital part of the knowledge society
(Drucker, 1993, Abramowitz and David, 1996, OECD, 2000). This also reflects Bauman's (2000) argument that we find ourselves in a time in which old systems are no longer sustained, but that new modes of life have not yet been designed, let alone set in operation. It would be a missed opportunity to overlook the practitioners that are bringing this change and new modes of life. Especially since societal questions are persistently altered and demand different mindsets from practitioners than in the beginning of the $20^{\text {th }}$ century.

Moreover, I learned that the futurists have a mindset that is not just worthwhile for their own professional purposes, but also for broader society. The futurist mindset is anti-disciplinary, imaginative, growth oriented and open-minded. Futurists honor the continuous search for new perspectives to tackle old issues. A futurists mindset may be beneficial for non-futurists too, by opening them up to new perspectives, evoking new connections between disciplines and people, and maybe most importantly, it could help to find solace in the change that unfolds every day.

Futurists as a profession-in-the-making are stretching our imagination and point to an alternative pathway to professionalization. Not bound to a discipline and not afraid to be misunderstood - futurists help to raise novel questions, in science and society. They will ask: could it be otherwise? With their professionalization pathway, they have answered their own question: yes, it can be otherwise. With this $\mathrm{PhD}$ thesis I hope to have contributed by raising pertinent questions about what professions are, what professionalization entails and what a good professional is. Such questions remain significant, especially since professions are a lasting, and ever-changing, cornerstone of our societies. 


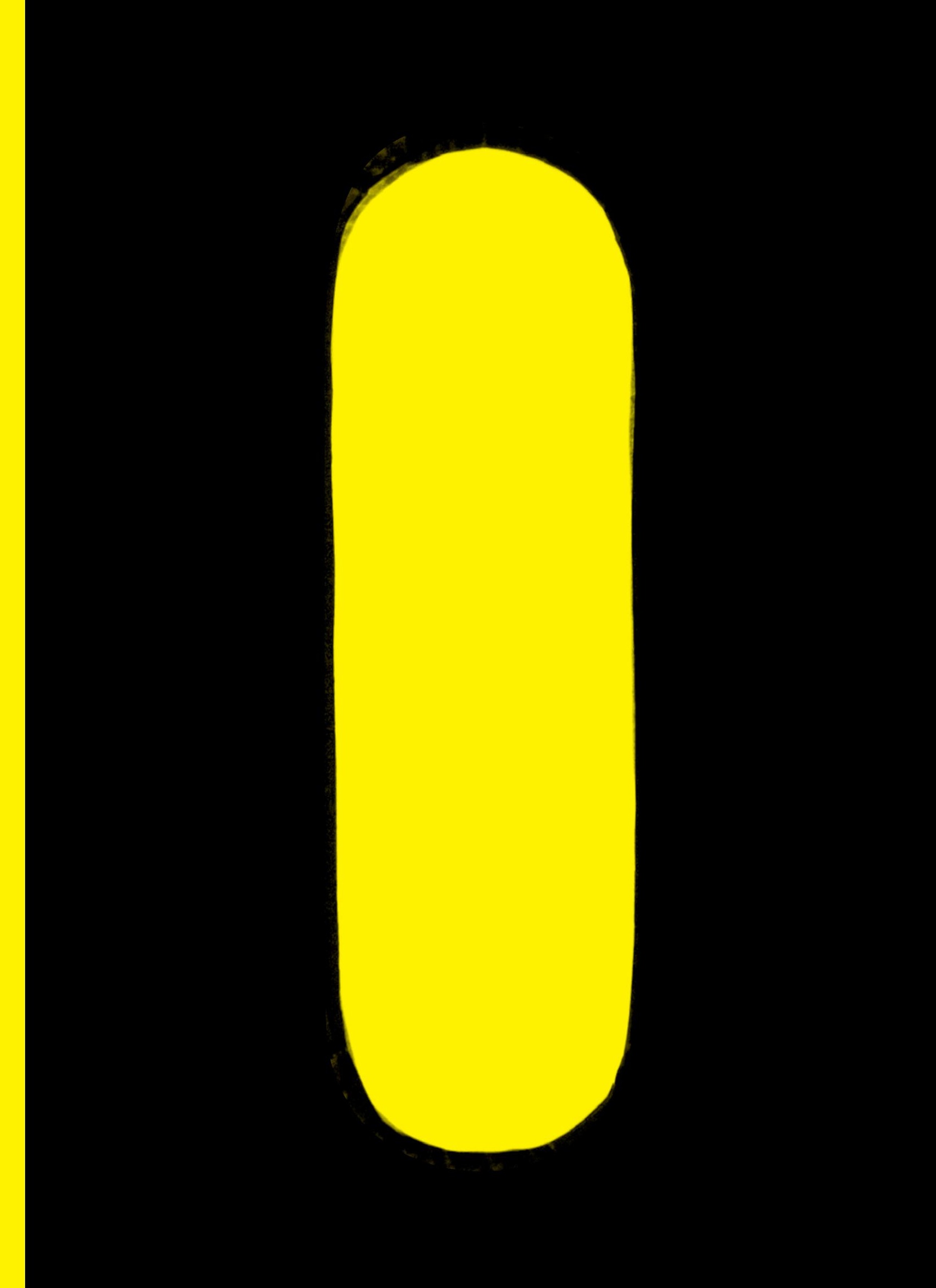


Abbott, A. (1988). The System of Professions: an essay on the division of expert labour. Chicago: University of Chicago Press.

Abir-Am, P. (1985). Themes, Genders and Orders of Legitimation in the Consolidation of New Scientific Disciplines: Deconstructing the Historiography of Molecular Biology. History of Science, Vol. 23, pp. 73-117.

Abramowitz, M. David, P. (1996). Technological change and the rise of intangible investments: The US economy's growth path in the Twentieth Century, in Foray, D. Lundvall B.A. (eds.),

Employment and growth in the knowledge-based economy, Paris, OECD.

Adam, B. and Groves, C. (2007). Future matters:

actions, knowledge, ethics. Leiden/Boston: Brill.

Akkerman, S. Admiraal, W. Simons, R. J. Niessen,

T. (2006). Considering Diversity: Multivoicedness in International Academic Collaboration. Culture \& Psychology, Vol. 12 (No. 4), pp. 461-485.

Akkerman, S. F. Bakker, A. (2011). Boundary Crossing and Boundary Objects. Review of Educational Research, Vol. 81 (No. 2), pp. 132-169.

van Asselt, M.B.A. van 't Klooster, S.A. van Notten, W.F. (2003). Verkennen in onderzekerheid. Beleid in Maatschappij, Vol. 30 (No. 4), pp. 230-241. van Asselt, M.B.A., van 't Klooster, S.A., van Notten, P.W.F., Smits, L.A., (2010a). Foresight in Action, developing policy-oriented scenarios. London: Earthscan.

van Asselt, M.B.A., Faas A., van der Mole F., Veenman S.A., (2010b). Uit zicht: toekomstverkennen met beleid. Amsterdam: Amsterdam University Press.

Barber, B. (1979). The Rise of Professionalism: Sociological Analysis. By M. S. Larson. Political
Science Quarterly, Vol. 94 (No. 1), pp. 155-156. Bauman, Z., (2000). Liquid Modernity. Polity, Cambridge.

Becker, H.S. (1963). Outsiders: Studies in the Sociology of Deviance. New York: Free Press. Becker, H.S. (1982). Art Worlds. University of California Press Ltd. London, England.

Beckwith, B. (1967). The next 500 years: Scientific predictions of major social trends. New York: Exposition Press.

Beerden, K. (2013). Worlds full of signs. Ancient Greek Divination in Context. Leiden: Brill.

Bell, W. (1993). Professional ethics for futurists: Preliminaries and proposals. Futures Research Quarterly, 9, 5-7.

Bell, W. (2002). A community of futurists and the state of the futures field. Futures, 34, 235-247. Bell, W. (2003). Foundations of Futures Studies: Human science for a new era (Vol.1). New Brunswick: Transaction Publishers.

Bell, W. (2005). Creativity, scepticism, and visioning the future. Futures, Vol. 37, pp. 429-432 Beuving, J. de Vries, G. (2015). Doing Qualitative Research: The Craft of Naturalistic Inquiry. Amsterdam: Amsterdam University Press

Bijker, W. Hughes, T. Pinch, T. (1987). The Socia Construction of Technological Systems: New Directions in the Sociology and the History of Technology. Cambridge: MIT Press.

Bijker, W. Bal, R. Hendriks, R. (2009). The Paradox of Scientific Authority: The Role of Scientific Advice in Democracies. Cambridge: MIT Press. Bishop, P. (2005). Futures studies as a profession? Proceedings of 19th World Conference of World Futures Studies Federation, WFSF

Bishop, P. Hines, A. (2012). Teaching about the Future. Palgrave McMillan.
Blumer, H. (1969). Symbolic Interactionism: Perspective and Method. Berkeley and Los Angeles, CA: University of California Press. Bonzi, S., Snyder, H.W., (1990). Motivations for citation: a comparison of self-citation and citation to others. Scientometrics, Vol. 21 (No. 2), pp. 245-254.

Boulding, K. E. (1965). The meaning of the

twentieth century: The great transition. New York: Harper Colophone.

Brante, T. (2011). Professions as Science-Based Occupations. Professions and Professionalism. Vol. 1 (No. 1), pp. 4-20.

Braun, V. Clarke, V. (2006). Using Thematic

Analysis in Psychology. Qualitative Research in Psychology. Vol. 3, (No. 2), pp. 77-101.

Brock, D. Powell, M. Hinings, C. R. (Eds.). (1999).

Restructuring the professional organization.

London: Routledge.

Brosveet, J. (2004). Translation terrain and pied piper detour: How experts eliminated a Norwegian digital city project. Science, Technology \& Human Values. Vol. 29 (No. 2), 213-241.

Brown, N., Rappert, B., Webster, A. (red.). (2000). Contested futures: A sociology of prospective techno-science, Ashgate: Aldershot.

Bruner, J. (1986). Actual minds, possible worlds. Cambridge, MA: Harvard University Press. Bryman, A. (2004). Social Research Methods, secon edition. Oxford, UK: Oxford University Press.

Brynjolfsson and McAfee (2014). The Second

Machine Age. Norton \& Company.

Camic, C. (1992). Reputation and Predecessor

Selection: Parsons and the Institutionalists. American Sociological Review, Vol. 57 (No. 4), pp. 421-445.

Cassidy, A. What next? How future gazing becam big business. (Last retrieved on September 4 2018). The Guardian. 
Carr-Saunders, A. and Wilson, P. (1933). The Professions. Oxford: Clarendon Press.

Chase, S. (1968). The most probable world.

Baltimore: Pelican Books.

Clarke, A. C. (1962). Profiles of the future: An enquiry into the limits of the possible. London: Gollancz.

Club of Rome (1972). The Limits to Growth. Potomac Associates.

Coates, J. F. (2001). Certifying futurists Technological Forecasting and Social Change, 66, 313-321.

Cörvers, F. Mommers, A. van der Ploeg, S. Sapulete, S. (2017). Status en imago van de leraar in de 21 ste eeuw. Researchcentrum voor Onderwijs en Arbeidsmarkt.

Craig-Lees, M. (2001). Sense making: Trojan Horse? Pandora's Box? Psychology \& Marketing. Vol. 18 (No. 5), pp. 513-526.

Crouch, M. McKenzie, H. (2006). The logic of small samples in interview based qualitative research. Social Science Information, Vol. 45, pp. 483-499. Dammers, E. (2000). Leren van de toekomst. Over de rol van scenario's bij strategische beleidsvorming. Delft: Eburon.

Dator, J. (2008). Futures, volume one and two: Then and now, Futures Vol. 40, pp. 903-906.

Denzin, N. K. (1970). The Research Act. Chicago, IL: Aldine.

Dewett, T. and Denisi, A.S., (2004). Exploring scholarly Reputation: It's more than just productivity. Scientometrics, Vol. 60 (No. 2), pp. 249-272.

Dick, B. (2004). Action research literature; Themes and trends, Action Research, Vol. 2 (No. 4), pp. 425-444.

van Duijne, F. de Wilde, S. (2016). The essence of scenarios, learning from the Shell experience. Las retrieved 13 may 2016.

Dragt, E. (2017). How to research trends?

Amsterdam: BIS publishers.

Drucker, P. (1993). The Post-Capitalist Society, Butter Worth Heinemann, Oxford.

van der Duin, P.A. (2009). On applied science, prediction and contingency. Futures. Vol. 41, pp. 194-196.

van der Duin, P.A. (ed.) (2016). Foresight in Organizations: Methods and Tools. New York Routledge.

Dumitresco, D. (2012). Roadtrip to Innovation. How I came to understand Future Thinking TrendOne.

Dunsby, J. (2004). Measuring environmental health risks: the negotiation of a public right-to-know law. Science, Technology and Human Values. Vol. 29 (no 3), pp. 269-290.

Durkheim, E. (2001). The Elementary Forms of Religious Life. Oxford University Press. (Original work published 1917).

Engeström, Y. Engeström, R. Kärkkäinen, M. (1995). Polycontextuality and boundary crossing in expert cognition: Learning and problem solving in complex work activities. Learning and Instruction. Vol. 5, pp. 319-336.

Ellul, J. (1964). The technological society. New York: Vintage.

Ester, P. Geurts, J. Vermeulen, M. (eds) (1997). De makers van de toekomst: Over nut en noodzaak van toekomstverkenningen voor beleidsonderzoek. Tilburg: Tilburg University Press.

Evetts, J. (2003). The sociological analysis of professionalism: occupational change in the modern world. International Sociology. Vol. 18 (No. 2), pp. 395-415.

Evetts, J. (2006). Introduction: Trust an professionalism: Challenges and occupational changes. Current Sociology, 54(4), 515.

Evetts, J. Gadea, C. Sánchez, M. Saez, J. (2009). Sociological theories of professions: Conflict, competition and cooperation. In Denis, A.B. Kalekin-Fishman, D. (eds), The ISA Handbook in Contemporary Sociology. Los Angeles: SAGE.

Evetts, J. (2011). A new professionalism? Challenges and opportunities. Current Sociology. Vol. 59 (No. 4), pp. 406-422.

Flexner, P. (1915). Is social work a profession? School and Society. Vol. 1, pp. 901-911.

Flick, U. (2011). Mixing Methods, Triangulation and Integrated Research: Challenges for Qualitative Research in a World of Crisis. pp. 132-152. In: Denzin, N.K., Giardina, M. (eds) Qualitative Inquiry and Global Crises. Walnut Creek, CA: Left Coast Press.

Flick, U. (2014). An introduction to qualitative research, edition 5. London: Sage.

Freidson, E. (1970). Medical Dominance. Chicago: Aldine-Atherton.

Freidson, E. (2001). Professionalism. The Third Logic. Polity Press.

Fombrun, C.J., Shanley, M. (1990). What's in a Name? Reputation Building and Corporate Strategy. Academy of Management Journal, 33 (No. 2), pp. $233-258$.

Fombrun, C.J. (1996). Reputation: Realizing Value from the Corporate Image. Harvard University Press.

Fortuin, I. Bush, S. (2010). Educating students to cross boundaries between disciplines and cultures and between theory and practice. International Journal of Sustainability in Higher Education. Vol. 11 (No. 1), pp. 19-35.

Frankel, M. S. (1989). Professional Codes: Why, 
How, and with What Impact? Journal of Business Ethics. Vol. 8, pp. 109-115.

Freeman, M. (1997). Is librarianship in the UK a true profession, a semi-profession or a mere occupation? New Library World, Vol. 98 (No. 2), pp. $65-69$.

Fuller, T. (2009). Re-examining and renewing theoretical underpinnings of the Futures field: A pressing and long-term challenge, Futures. Vol. 41, pp. 67-70.

Fuller, T. Loogma, K. (2009). Constructing futures: A social constructionist perspective on foresight methodology. Futures Vol. 41 (No. 2), pp. 71-79. Gabor, D. (1964). Inventing the future. New York: Knopf.

Galison, P. (1999). Trading Zone: Coordinating Action and Belief. In Biagioli, M. (ed) The Science Studies Reader. New York/London: Routledge. Gary, J. von der Gracht, H. (2015). The future of foresight professionals: Results from a global Delphi study. Futures. Vol. 71, pp 132-145.

Georghiou, L. Cassingena Harper, J. Keenan, M. Miles, I. Popper, R. (eds.) (2008). The handbook of technology foresight: concepts and practice. Cheltenham, UK, Edward Elgar Publishing.

Giddens, A. (2009). Sociology 6th Edition. Polity Press: Cambridge.

Gidley, J. (2017). The future: a very short introduction. Oxford University Press.

Gieryn, T. (1983). Boundary-Work and the Demarcation of Science from Non-Science:

Strains and Interests in Professional Ideologies of Scientists. American Sociological Review Vol. 48, pp. 781-795.

Gieryn (1995). Boundaries of Science. In Jasanoff, S Markle, G. Petersen, R. Pinch, T. (ed.) Handbook of Science and Technology Studies. London, UK: Sage.
Gilbert, G.N. Mulkay, M. (1984). Opening Pandora's Box. A sociological analysis of scientists' discourse. London: Cambridge University Press.

Goldman, C. Gates, S. Brewer, D. (2001). In Pursuit of Prestige: Strategy and Competition in U.S. Higher Education. New Brunswick, NJ: Transaction Publishers.

Goode, W.J. (1957). Community within a community: The Professions. American Sociological Review, Vol. 22 (No. 2), pp. 194-200. Goode, W. J. (1969). The Theoretical Limits of

Professionalization. In A. Etzioni (Ed.), The Semi Professions and Their Organization (pp. 266-313). Free Press, New York, NY.

Gibbons, M. Limoges, C. Nowotny, H.

Schwartzman, S. Scott, P. Trow, M. (1994). The new production of knowledge: The dynamics of science and research in contemporary societies. London: Sage.

Haas, P. (1992). Introduction: epistemic communities and international policy

coordination. International Organization, special issue: Knowledge, Power, and International Policy Coordination. Cambridge Journals. Vol. 46 (No. 1), pp. 1-35.

Halliday, T. (1987). Beyond Monopoly. London: University of Chicago.

van der Heijden, A. (2018). Sustainability embedding seen through a sensemaking lens. Understanding engagement strategies of change agents in companies and chain collaboration. Utrecht University: Copernicus Institute of Sustainable Development.

Helmer, O. (1983). Looking Forward: A Guide to Futures Research. Beverly Hills, CA Sage.

Hessels, L. van Lente, H. (2008). Re-thinking new knowledge production: a literature review and a research agenda. Research policy 37: 740-60. Hessels, L. (2010). Science and the Struggle for Relevance. BOXPress: Oisterwiik.

Hideg, E. (2002). Implications of two new paradigms for futures studies, Futures. Vol. 34, pp. 283-294. Hilgartner, S. (2000). Science on Stage. Expert Advice as Public Drama. Stanford: Stanford University Press.

Hilgartner, S. (2003). Expertise and the production of the unknowable. $4 \mathrm{~S}$ annual meeting, Atlanta, US Hines, A.G. (2013). Professionalizing foresight:

Why do it, where it stands, and what needs to be done, Journal of Futures Studies, Vol: 17 pp. 35-54. Hines, A. Gold, J. (2013). Professionalizing foresight: Why do it, where it stands, and what needs to be done. Journal of Futures Studies, 17, 35-54.

Hoppe, R., (2002). Van flipperkast naar grensverkeer. Veranderende visies op de relatie tussen wetenschap en beleid, AWT, Den Haag. Hughes, E. C. (1958). Men and Their Work. New York: the Free Press.

Hughes, E. C. (1960). The Professions in Society. The Canadian Journal of Economics and Political Science. Vol. 26 (No. 1), pp. 54-61

Hyland, K. (1999). Academic Attribution: Citation and the Construction of Disciplinary Knowledge. Applied Linguistics. Vol. 20 (No. 3), pp. 341-367. Hyland, K. (2011). The presentation of self in scholarly life: Identity and marginalization in academic homepages. English for Specific Purposes. Vol. 30, pp. 286-297.

Inayatullah, S. (2008). Futures as heterotopia. Futures. Vol. 40, pp. 924-926.

Intezari, A. Pauleen, D. J. (2014). Management Wisdom in Perspective: Are You Virtuous Enough to Succeed in Volatile Times? Journal of Business Ethics. Vol. 120 (No. 3), pp. 393-404. 
Jasanoff, S. (1990). The Fifth Branche: Science advisors as Policy Makers. Cambridge: Harvard University Press.

Jasanoff, S. (2005). Designs on nature: science and democracy in Europe and the United States. Princeton University Press.

Jordan, K. Lynch, M. (1992). The sociology of a genetic engineering technique: ritual and rationality in the performance of the "Plasmid Prep". In Clarke, A.E. Fujimura, J. H. (Eds.), The right tools for the job: At work in twentieth-century life science. New Jersey: Princeton University Press.

Johnson, T. (1972). Professions and Power. London: Macmillan.

Jungk, R. Galtung, J. (1969). Mankind 2000. Oslo: Universitetsforlaget.

Kahn, H. Wiener, A. J. (1967). The year 2000: A framework for speculation on the next thirtythree years. New York: Macmillan.

Kapoor, R. (2001). Future as fantasy: forgetting the flaws. Futures. Vol. 33, pp. 161-170.

Keith, B. Babchuck, N. (1998). The Quest for Institutional Recognition: A Longitudinal Analysis of Scholarly Productivity and Academic Prestige among Sociology Departments. Social Forces. Vol. 76 (No. 4), pp. 1495 - 1535.

Kirk, J.L. Miller, M. (1986). Reliability and Validity in Qualitative Research. Beverly Hills, CA: Sage. Klein, J. T. (1996). Crossing boundaries: Knowledge, Disciplinarities, and Interdisciplinarities. Charlottesvolle: University Press of Virginia.

Klooster, van 't, S.A., (2007). Toekomstverkenning; ambities en de praktijk; een etnografische studie van de productie van toekomstkennis bij het Ruimtelijk Planbureau (RPB). Delft: Eburon. Klostermann, J. (2003). The social construction of sustainability in Dutch water companies.
Wageningen: Alterra.

Knorr-Cetina, K. (1981). The Manufacture of

Knowledge: An Essay on the Constructivist and the Contextual Nature of Science. Pergamon Press, Oxford

Knorr-Cetina, K. (1999). Epistemic Cultures: How the Sciences Make Knowledge. Harvard University Press, Cambridge.

Knorr-Cetina, K. (2006). Knowledge in a knowledge society: Five transitions. Knowledge, Work and Society, 4(3), 23-41.

Kuosa, T. (2011). Evolution of Futures Studies. Futures. Vol. 43, pp. 327-336.

de Laat, B. (2000). Scripts for the future: Using innovation studies to design foresight tools. In Brown, N. Rappert, B. Webster, A. (Eds.), Contested futures: A sociology of prospective techno-science. Aldershot, UK: Ashgate. Kurzweil, R. (2005). The Singularity is Near. Penguin Books.

Lang, G. E., Lang, K. (1988). Recognition and Renown: The Survival of Artistic Reputation. American Journal of Sociology. Vol. 94 (No. 1), pp. 79-109.

Larson, M.S. (1977). The Rise of Professionalism. California: University of California Press

Larson, M. S. (2003). Professionalism: The Third Logic (review). Perspectives in Biology and Medicine. Vol. 46 (No. 3), pp. 248-462.

Latour, B. Woolgar, S. (1979). Laboratory Life: The social construction of scientific facts. Beverly Hills, USA: Sage.

Latour, B. (1987). Science in Action: How to Follow Scientists and Engineers Through Society. Milton Keynes: Open University Press.

Latour, B. (1999). Pandora's Hope: Essays on the Reality of Science Studies. Cambridge: Harvard
University Press.

Latour , B. (2005). Reassembling the social: An introduction to Actor-Network Theory, Oxford, UK: Oxford University Press.

Lave, J. Wenger, E. (1991). Situated Learning Legitimate Peripheral Participation, Cambridge University Press, Cambridge.

van Lente, H. (1993). Promising technology: The dynamics of expectations in technological developments. Twente University, Enschede, the Netherlands.

van Lente, H. Rip, A. (1998). The Rise of Membrane Technology: From Rhetorics to Social Reality. Socia Studies of Science. Vol. 28 (No. 2), pp. 221-254. van Lente, H. (2000). Forceful futures: From

promise to requirement. In Brown, N. Rappert, B. Webster, A. (eds.), Contested futures: A sociology of prespective techno-science. Aldershot, UK: Ashgate. Lincoln, Y.S. Guba, E.G. (1985). Naturalistic Inquiry. London: Sage.

Lynch, M. (1985). Art and Artifact in Laboratory Science. A study of shop work and shop talk in a research laboratory. Taylor \& Francis.

Markley, O.W. (1983). Preparing for the

professional futures field: observations from the UHCL futures program. Futures. Vol. 15, pp. 46-64 MacDonald, K. (1995). The Sociology of the professions. London: Sage.

Marien, M. (1987). What is the nature of our embryonic enterprise? An open letter to Wendell Bell, Futures, 4, pp. 71-79.

Marien, M. (2002). Futures studies in the 21s Century: a reality-based view. Futures. Vol. 34 (No. 2), pp. 261- 281.

Masini, E. B. (1993). Why Futures Studies? Grey Seal Books.

Masini, E. B. (2001). New challenges for futures 
studies. Futures. Vol. 33, 637-647.

Maxwell, J.A. (1992). Understanding Validity in

Qualitative Research. Harvard Educational

Review. Vol. 62, pp. 279-300.

McHale, J. (1969). The future of the future. New York: G Braziller.

McHale, J. (1976). An assessment of futures studies worldwide. Futures. Vol. 8 (No. 2), pp. 135-145.

Merton, R.K. (1972). Insiders and Outsiders: A Chapter in the Sociology of Knowledge. American Journal of Sociology. Vol. 78 (No. 1), pp. 9-47.

van der Meulen, B. (2002). Methodiek

toekomstverkenningen: naar een

ontwerpbenadering voor het opzetten van

verkenningen. Amsterdam: KNAW/Universiteit

Twente.

Millerson, G.L. (1964). The Qualifying Association.

London: Routledge \& Kegan Paul.

Mishler, E.G. (1990). Validation in Inquiry-Guided Research: the Role of Exemplars in Narrative

Studies. Harvard Educational Review. Vol. 60, pp. 415-442.

Montagna, P. (1972). Sociology of Occupations and Professions by Ronald M. Pavalko, Contemporary Sociology, Vol 1 (No. 6), pp. 532-533.

Moore, W.E. (1970). Professions, The Roles and Rules. Russell Sage Foundation.

Moss, M. (2001). Sensemaking, complexity and organizational knowledge. Knowledge and

Process Management. Vol. 8(No. 4), pp. 217-233.

Münte, P. Scheid, C. (2017). Coping with Crises: A

Neo-Classical View on Professions. Professionals

\& Professionalism. Vol. 7 (No 1), pp. 1-14.

Murphy, R. (1988). Social Closure. Oxford: the Clarendon Press.

Muzio, D. Kirkpatrick, I. (2011). Introduction:

Professions and Organizations - a conceptual framework. Current Sociology. Vol. 59 (No. 4), pp. 389-405.

Noordegraaf, M. (2007). From 'Pure' to 'Hybrid' Professionalism: Present-Day Professionalism in Ambiguous Public Domains. Administration \& Society. Vol. 39 (No. 6), pp. 761-85.

Noordegraaf, M. (2011). Remaking professionals? How associations and professional education connect professionalism and organizations. Current Sociology. Vol. 59 (No. 4), pp. 465-488.

Noordegraaf, M. van der Steen, M. van Twist, M. (2014). Fragmented or connective

professionalism? Strategies for professionalizing the work of strategists and other (organizational) professionals. Public Administration. Vol. 92 (No. 1), pp. 21-38.

Noordegraaf, M. (2015). Hybrid Professionalism and Beyond: (new) Forms of Public Professionalism in Changing Organizational and Societal Contexts. Journal of Professions and Organization 2: 187-206.

Noordegraaf, M. (2016). Reconfiguring Professional Work: Changing Forms of Professionalism in Public Services. Administration \& Society. Vol. 48 (No. 7), pp. 783-810.

van Notten, P. W. F. (2005). Writing on the wall: scenario development in times of discontinuity. Amsterdam: Thela Thesis \& Dissertation.com. Nowotny, H. Scott, P. Gibbons, M. (2001). Rethinking science: Knowledge and the public in an age of uncertainty. Cambridge: Polity Pr.

Nowotny, H. (2008). Insatiable Curiosity, Innovation in a Fragile Future. Cambridge: MIT Press.

OECD (2000). Knowledge management in the learning society. Paris, OECD.

Ogilvy, J. (1992). Future Studies and the Human Sciences: The Case for Normative Scenarios. Futures
Research Quarterly. Vol. 8 (No. 2), pp. 5-65. Paul, E. (1968). The population bomb. New York: Ballantine Books.

Phillips, N. Hardy, C. (2002). Discourse Analysis: Investigating Processes of Social Construction. Thousand Oaks, CA: Sage Publications.

Podolny, J. (1993). A Status-based Model of Market Competition. American Journal of Sociology. Vol. 98 (No. 4), pp. 829-872.

Polak, F. (1961). The image of the future: The promise land, source of living culture. New York and Leiden: Sythoff.

Pollock, F. (1955). Gruppenexperiment:

Ein Studienbericht. Frankfurt: Europäische Verlagsanstalt.

Popcorn. F. (1992). The Popcorn Report: Faith Popcorn on the Future of Your Company, Your World, Your Life. New York: HarperCollins. Rao, H. (1994). The Social Construction of Reputation: Certification Contests, Legitimation, and the Survival of Organizations in the American Automobile Industry: 1895-1912. Strategic Management Journal, Vol 15, pp. 29-44. Ramos, J. (2013). Mutant Futurists in the 21st Century, Journal of Futures Studies. Vol. 17, pp. $151-158$.

Raymond, M. (2010). The Trend Forecasters Handbook. London: Laurence King Publishing. Rindova, V. P. Petkova, A. P. Sever, J. M. (2005). Being good or being known: an empirical examination of the dimensions, antecedents, and consequences of organizational reputation. Academy of Management Journal. Vol. 48 (No. 6), pp. 1033-1049.

Rip, A. Schot, J. Misa, T. J. (1995). Managing technology in society: the approach of constructive technology assessment. Londen/New 
York: Pinter Publishers.

Saks, M. (2012). Defining a Profession, the Role of Knowledge and Expertise. Professions and Professionalism. Vol. 2 (No. 1), pp. 1-10.

Sardar, Z. (2008). Futures at forty, Futures, Vol. 40, pp. 893.

Sardar, Z. (2010). The Namesake: futures; futures studies; futurology; futuristic; foresight - what's in a name? Futures. Vol. 42, pp. 177-184.

Schmid, S. (2004). Transformation discourse: Nuclear risk as a strategic tool in late Sovjet politics of expertise. Science, Technology and Human Values. Vol. 29 (No. 3), pp. 353-376.

Schoemaker, P. Day, G. (2009). How to make sense of weak signals. MIT Sloan Management Review. Last retrieved April 1, 2019.

Schot, J. Rip, A. (1997). Technological Forecasting and Social Change. Vol. 54, pp. 251-268.

Schön, D. (1983). The Reflective Practitioner, how professionals think in action. New York:

Routledge.

Schwandt, T. (1998). The Landscape of Qualitative Research: Theories and Issues, ed. Norman K. Denzin, Yvonna S. Lincoln. Thousand Oaks, Sage Publications.

Simonton, D. K. (1983). Scientific Eminence Historical and Contemporary: a Measurement Assessment. Scientometrics. Vol. 6 (No. 3), pp. 169-182.

Simonton, D. K. (1992). New Ideas in Psychology. Vol. 10 (No. 2), pp. 167-171.

Simonton. D.K. (2000). Creative development as acquired expertise: Theoretical issues and an empirical test. Developmental Review. Vol. 20, pp. 283-318.

Simpson, R. L. (1985). The Schema of Science.

Science, New Series. Vol. 230 (No. 4), pp. 658-659.
Slaughter, R. (1999). Professional standards in futures work. Futures. Vol. 31, pp. 835-851

Slaughter, R. (2002). From forecasting and scenario's to social construction: changing methodological paradigms in futures studies. Foresight. Vol. 4 (No. 3), pp. 26-31.

Slaughter, R. (2008). Reflections on 40 years of futures studies and Futures. Futures. Vol. 40, pp. 912-914.

Son, $\mathrm{H}$ (2015). The history of Western future studies: An exploration of the intellectual traditions and three-phase periodization. Futures. Vol. 60, pp 120-137.

De Sonnaville, H. (2005). Retorische aspecten van professionaliseren. Een zoektocht naar beroepsvorming bij organisatieadviseurs. Amsterdam: Amsterdam University Press.

van der Staal, P. M., van Vught, F. A. (1987). Vijftien jaar toekomstonderzoek door de WRR: de uitgestelde methodologische reflectie Deel 1. Beleidsanalyse. Vol. 87 (No. 4), pp. 16-25.

Star, S. L. (1989). The structure of ill-structured solutions: Boundary objects and heterogeneous distributed problem solving. In Gasser, L. Huhns, M. (eds.), Distributed artificial intelligence (pp. 37-54). San Mateo, CA: Morgan Kaufmann.

Star, S. L. (2010). This is not a boundary object: Reflections on the origin of a concept. Science, Technology \& Human Values. Vol. 35, pp. 601-617.

Stevenson, T. (2008). Imagining the future: Ideas for change, Futures. Vol. 40, pp. 915-918.

Stoppard, T. (1975). Travesties. London: Faber and Faber.

Suchman, L. (1994). Working relations oftechnology production and use. Computer Supported Cooperative Work. Vol. 2, pp. 21-39. Suddaby, R. Greenwood, R. (2001). Colonizing knowledge: Commodification as a dynamic of jurisdictional expansion in professional service firms. Human Relations. Vol. 54 (No. 7), pp. 933-953.

Tamir, E. Wilson, S.M. (2005). Who should guard the gates? Evidentary and Professional Warrant for Claiming Jurisdiction. Journal of Teacher

Education. Vol. 56 (No. 4), pp. 332-342.

Toffler, A. (1970). Future Shock. New York: Bantam Books.

Toffler, A. (1972). The Futurists. New York: Random House.

Walker, D. Nocon, H. (2007). Boundary-crossing competence: Theoretical considerations and educational design. Mind, Culture, and Activity. Vol. 14, pp. 178-195.

Wallace, R. Wolf, A. (2006). Contemporary

Sociological Theory: Expanding the Classical Tradition, 6th Edition. Pearson.

Waring, J. Currie, G. (2009). Managing expert knowledge: Organizational challenges and managerial futures for the UK medical profession. Organization Studies. Vol. 30 (No. 7), pp. 755-778 Waring, J. (2014). Re-stratification, hybridity and professional elites: questions of power, identity and relational contingency at the points of 'professional organisational intersection. Sociology Compass. Vol. 8, pp. 688-704. Weber, M. (1971). The Sociology of Religion. London: Methuen. (Original work published 1920).

Weber, M. (1976). The Protestant Ethic and the Spirit of Capitalism. London: George Allen \& Unwin. (Original work published 1904-1905) Weber, M. (1978). Economy and Society: An

Outline of Interpretative Sociology. Berkeley:

University of California Press. (Original work published 1922).

Wells, H.G. (1902). Discovery of the Future. Nature. 
Vol. 65, pp. 326-331.

Weick, K. (1995). Sensemaking in organizations.

Thousand Oaks, CA: Sage.

Weick, K. (ed.) (2001). Making sense of the

organization. Malden, CA: Blackwell Publishing.

Wenger, E. (1998). Communities of Practice

- Learning, Meaning and Identity, Cambridge

University Press, Cambridge.

Wenger, E. (2000). Communities of practice and

social learning systems. Organization. Vol. 7 (No.

2), pp. 225-46.

Wheelwright, V. (2000). A profession in the future?

Futures. Vol. 32, pp. 913-918.

Whitley, R. (1984). The Intellectual and Social

Organization of the Sciences. Oxford, UK: Oxford

University Press.

Whitley, R. (2000). The Intellectual and Social

Organization of the Sciences (second edition).

Oxford: Oxford University Press.

Wiener, N. (1961). Cybernetics: or the Control and

Communication in the Animal and the Machine. Cambridge: MIT Press.

de Wilde, R. (2000). De voorspellers: een kritiek op de toekomstindustrie. Amsterdam: Uitgeverij de Balie.

Wilensky, H.L. (1964). Professionalization of

everyone? American Journal of Sociology. Vol. 70 pp. 137-158.

WRR (2000). Terugblik op toekomstverkenningen.

WRR - Stuurgroep Toekomstonderzoek en

strategisch omgevingsbeleid. The Hague. 


\section{Appendix A / List of \\ attended conferences}

Full list of conferences, gatherings

and meetups.

World Futures Studies Federation Bucharest, June 2013 [including presentation];

LaFutura in Amsterdam (November 2013) and in Brussels (November 2014) [including

presentation at the pre-event];

Trendrede (literal translation: trend address) presentations between 2011 and 2017 (in September of each year):

Book launch of Angela Wilkinson 'the essence of scenario's: learning from the Shell experience' (Oxford university, Shell) (March 2014);

Second Sight and beyond 2015 in Amsterdam (November 2014)

The History and the Future of Fashion

Prediction in Rotterdam (October 2014)

Rozenbrood presentations of the class of 2014 (September 2014);

Conference with the aim to generate input for RIVM study on the future of public health (December 2014);

World Futures Studies Federation Turku, Finland, in June 2015 [including presentation];

Trendnetwork meetings every three months between 2014 and 2016 [including several presentations]

Dutch Future Society events, organized and occurred between 2013 and 2017 [including presentation];

Superforecasting method explanation by

Regina Joseph hosted by RIVM (March 2016);

Lecture by Lidewij Edelkoort in Amsterdam

(November 2016);

Book clubs by cultural sociologist and

trendwatcher Carl Rohde (between 2013

and 2017);

Netwerk Toekomst Verkenningen (literal

translation: Network Futures Outlook)

network events between 2013 and 2016

[including two presentations]

Female futurists events between 2012 and 2013;

Association of Professional Futurist events

during WFS conference in 2016:

World Future Society conference (July 2016)

[including presentation];

Pakhuis de Zwijger event on how to research

trends (May 2017) [including presentation]

Educational programs regarding the future,

including but not limited to events at

Nyenrode and the University of Amsterdam

(between 2014 and 2017);

Several presentations at study days of

Fontys Academy for Creative Industries in

the Netherlands (between 2013 and 2017). 


\section{Appendix B | List of interviewees}

\begin{tabular}{|c|c|c|c|c|}
\hline Name & $M / F$ & Affiliation & Job title & Location \\
\hline Peter Bishop & M & University of Houston & $\begin{array}{l}\text { Professor Emeritus of Foresight at the } \\
\text { University of Houston \& Founder and } \\
\text { Executive Director of Teach the Future. }\end{array}$ & United States \\
\hline Mei-Mei Song & $\mathbf{F}$ & Tamkang University & $\begin{array}{l}\text { Director at Center for Futures } \\
\text { Intelligence and Research (CFAR) \& } \\
\text { associate professor Graduate Institute } \\
\text { of Futures Studies }\end{array}$ & Taiwan \\
\hline Mihaela Ghișa & $\mathbf{F}$ & University of Bucharest & Researcher & Romania \\
\hline Huai-Yao, Chiv & $\mathbf{F}$ & Tamkang University & Student & Taiwan \\
\hline Tzuying & $\mathbf{F}$ & Taiwanese elementary school & Teacher, PhD candidate & Taiwan \\
\hline Freija van Duijne & $\mathbf{F}$ & $\begin{array}{l}\text { Ministry of Economic Affairs \& } \\
\text { Dutch Future Society }\end{array}$ & $\begin{array}{l}\text { President Dutch Future Society (2013-2018) } \\
\text { and in several strategic roles at the } \\
\text { Ministry of Economic Affairs until } 2016 .\end{array}$ & The Netherlands \\
\hline $\begin{array}{l}\text { Susan van 't } \\
\text { Klooster }\end{array}$ & $\mathbf{F}$ & SAVIA & $\begin{array}{l}\text { Senior advisor foresight and decision- } \\
\text { making under deep uncertainty. }\end{array}$ & The Netherlands \\
\hline Marcus Bussey & M & $\begin{array}{l}\text { The University of the Sunshine } \\
\text { Coast }\end{array}$ & $\begin{array}{l}\text { Deputy Head of School, School of Social } \\
\text { Sciences, Senior Lecturer, History and } \\
\text { Futures }\end{array}$ & Australia \\
\hline $\begin{array}{l}\text { Sohail } \\
\text { Inayatullah }\end{array}$ & M & $\begin{array}{l}\text { Tamkang University, Macquarie } \\
\text { University, University of the } \\
\text { Sunshine Coast }\end{array}$ & $\begin{array}{l}\text { Unesco Chair of Futures Studies at } \\
\text { Usim (Malaysia) Professor, Tamkang } \\
\text { University (Taiwan), Adjunct Professor, } \\
\text { the University of the Sunshine } \\
\text { Coast (Australia) }\end{array}$ & $\begin{array}{l}\text { Australia, Taiwan, } \\
\text { Malaysia }\end{array}$ \\
\hline Ivana Milojević & $\mathbf{F}$ & $\begin{array}{l}\text { University of Novi Sad, University } \\
\text { of the Sunshine Coast, }\end{array}$ & $\begin{array}{l}\text { Adjunct Professor University of the } \\
\text { Sunshine Coast, Visiting Professor } \\
\text { University of Novi Sad, Serbia. }\end{array}$ & Australia, Serbia \\
\hline John Sweeney & M & $\begin{array}{l}\text { Qazaq Research Institute for Futures } \\
\text { Studies, Interpol, Narxoz University }\end{array}$ & Advisor, director, assistant professor & $\begin{array}{l}\text { Kazakhstan, } \\
\text { Singapore }\end{array}$ \\
\hline Tuomo Kuosa & M & Futures Platform Oy & Co-Founder \& Content Director & Finland, Singapore \\
\hline $\begin{array}{l}\text { Fabienne Goux- } \\
\text { Baudiment }\end{array}$ & $\mathbf{F}$ & ProGective, Yonders & $\begin{array}{l}\text { Futurist, director of proGective and } \\
\text { associate of Yonders }\end{array}$ & France \\
\hline Martin Börjesson & M & $\begin{array}{l}\text { Chalmers University of Technology, } \\
\text { University of Göteborg, RI.SE } \\
\text { (Research Institutes of Sweden), } \\
\text { Futuramb }\end{array}$ & Teacher, advisor \& futurist & Sweden \\
\hline Jose Ramos & M & $\begin{array}{l}\text { Action Foresight, Journal of Futures } \\
\text { Studies }\end{array}$ & $\begin{array}{l}\text { Director Action Foresight, Senior } \\
\text { Consulting Editor Journal of Futures } \\
\text { Studies }\end{array}$ & Australia \\
\hline
\end{tabular}

\begin{tabular}{|c|c|c|c|c|}
\hline $\begin{array}{l}\text { Galina } \\
\text { Kääriäinen }\end{array}$ & $\mathbf{F}$ & Turku School of Economics, WFSF & $\begin{array}{l}\text { Master student, executive assistant } \\
\text { to President World Futures Studies } \\
\text { Federation. }\end{array}$ & Finland \\
\hline Alisha Bhagat & $\mathbf{F}$ & Forum for the Future & Futurist \& senior strategist & United States \\
\hline Ross Dawson & M & $\begin{array}{l}\text { Advanced Human Technologies } \\
\text { Group }\end{array}$ & Futurist, entrepreneur & Australia \\
\hline Delia Dumitrescu & $\mathbf{F}$ & Trendwatching.com & Lead Innovation Architect & Austria \\
\hline Carl Rohde & M & Science of the Time & $\begin{array}{l}\text { Cultural sociologist, academic } \\
\text { trendwatcher }\end{array}$ & The Netherlands \\
\hline Ian Yeoman & M & Victoria University Wellington & Head of Tourism Management Group & New Zealand \\
\hline Jay Gary & M & $\begin{array}{l}\text { Association of Professional } \\
\text { Futurists, Oral Roberts University }\end{array}$ & $\begin{array}{l}\text { Chair of Association of Professional } \\
\text { Futurists and Associate Professor of } \\
\text { Leadership }\end{array}$ & United States \\
\hline $\begin{array}{l}\text { Anna Luise } \\
\text { Sulimma }\end{array}$ & $\mathbf{F}$ & TrendSketcher & Founder & Germany \\
\hline $\begin{array}{l}\text { Karsten van der } \\
\text { Donk }\end{array}$ & M & $\begin{array}{l}\text { Cosight, The meaning } \\
\text { management company }\end{array}$ & Managing Partner & $\begin{array}{l}\text { The Netherlands, } \\
\text { France }\end{array}$ \\
\hline Minna Koskelo & $\mathbf{F}$ & $\begin{array}{l}\text { Futures Specialists Helsinki, } \\
\text { Futuresday, 11Helsinki Oy }\end{array}$ & $\begin{array}{l}\text { Futures Designer, Founder, Chairman } \\
\text { of Board }\end{array}$ & Finland \\
\hline Jan Kristof Arndt & M & $\begin{array}{l}\text { Trendinnovation \& } \\
\text { innovationsberatung }\end{array}$ & CEO, founder & Germany \\
\hline Michaela Büsse & $\mathbf{F}$ & FHNW Academy of Art and Design & PhD candidate at the Critical Media Lab & Switzerland \\
\hline Phil Sang Gu Yim & $\mathbf{M}$ & BBVA & Manager, Global Observatory & Spain \\
\hline Katharina Kiéck & $\mathbf{F}$ & Sturm und Drang & $\begin{array}{l}\text { Senior Innovation Strategist, Head of } \\
\text { Foresight }\end{array}$ & Germany \\
\hline Kirsten van Dam & $\mathbf{F}$ & $\begin{array}{l}\text { Out of Office, Service Design Lab } \\
\text { at Aalborg University Copenhagen }\end{array}$ & $\begin{array}{l}\text { Director Out of Office, Project \& } \\
\text { research at Service Design Lab }\end{array}$ & Denmark \\
\hline Scott Lachut & M & PSFK & $\begin{array}{l}\text { Partner/President of Research \& } \\
\text { Strategy at PSFK }\end{array}$ & United States \\
\hline Brian Tuying & M & La Futura Global Trend Network & $\begin{array}{l}\text { President Asia Pacific La Futura, } \\
\text { advisor Yup.gg and Yeah1 Group } \\
\text { (digital media space) }\end{array}$ & Singapore \\
\hline Harish Shah & M & Stratserv Consultancy & Futurist, speaker, consultant, strategist. & Singapore \\
\hline
\end{tabular}




\section{Appendix C Interview}

\section{INTRODUCTION}

My $\mathrm{PhD}$ study addresses the similarities and differences between the main practices in futures studies in order to shed light on possible learning opportunities. The interview mainly contributes to the study by focusing on the interviewee's construction of the professional history, their definition of a futurist, their membership of professional communities and the context of their knowledge.

\section{JOB TITLE}

What does your business card say?

\section{HISTORIES OF FUTURISTS}

Who do you regard as the founding father(s)

\& mother(s)?

\section{A FUTURIST}

Imagine you are going to lead a futures research project and you have carte blanche to hire someone. Who would you hire?

Which skills do you need in your practice as a futurist (see the picture below)?

Are there skills that define a futurist that are not pictured below?
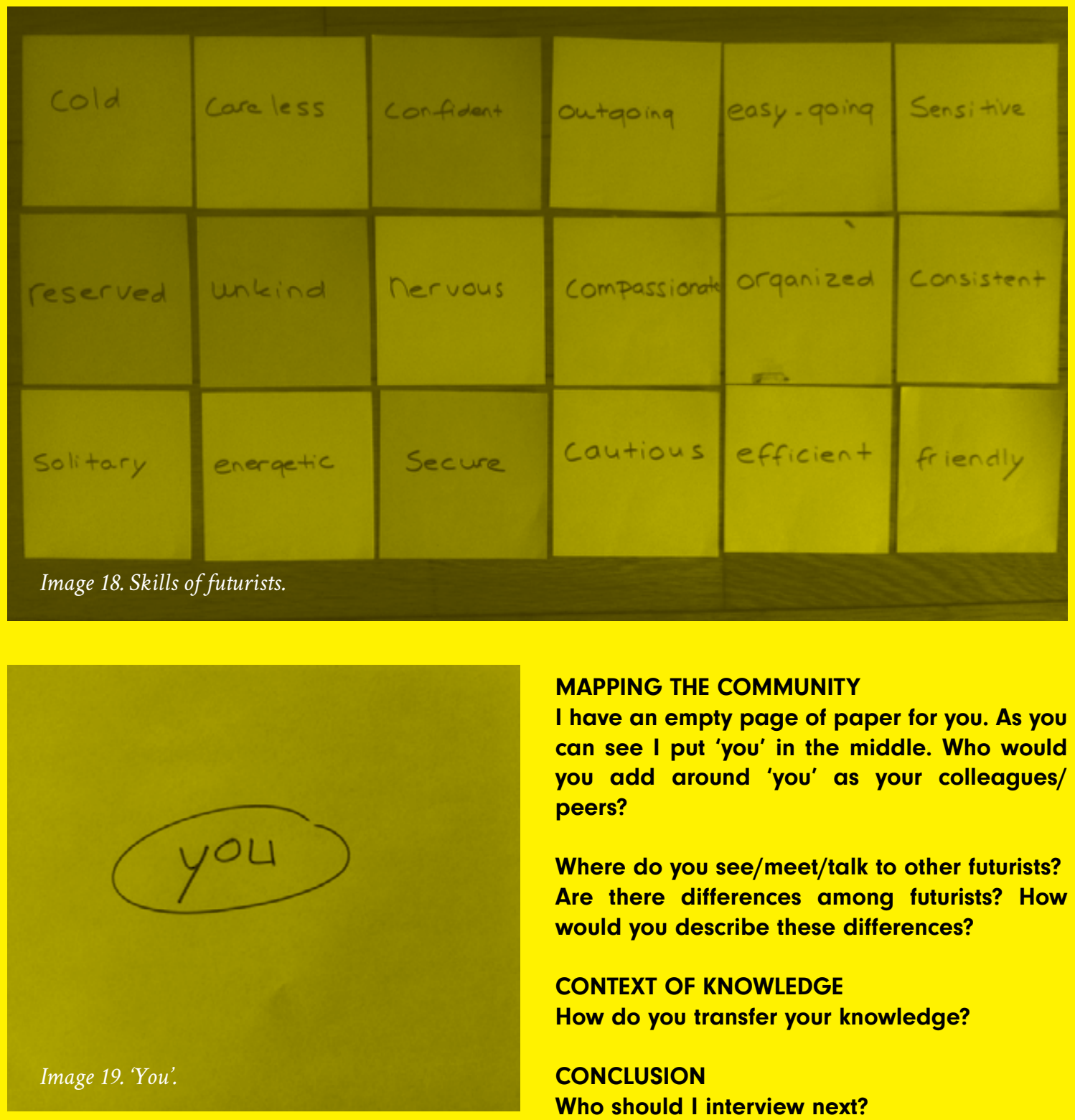

MAPPING THE COMMUNITY

I have an empty page of paper for you. As you can see I put 'you' in the middle. Who would you add around 'you' as your colleagues/ peers?

Where do you see/meet/talk to other futurists? Are there differences among futurists? How would you describe these differences?

\section{CONTEXT OF KNOWLEDGE}

How do you transfer your knowledge?

CONCLUSION

Who should I interview next? 


\section{Appendix D|Overview group discussions}

\section{First group discussion}

APRIL 9, 2015

Main question: how do you work as a

trend- or futures professional?

Hosting futurist: Hilde Roothart

\section{Presenting futurists:}

Patrick van der Duin (director STT),

Jacomine van Veen (Philips \& founder Likely).

\section{Second group discussion}

JUNE 4, 2015

Main question: why are you active in the trend

industry?

Hosting futurist: Hilde Roothart

Presenting futurists:

Ronald Beuk (founder Generous Minds);

Nanon Soeters \& Djenny Brugmans (founders

Rozenbrood);

Irene Koel (founder The Zooooo).

\section{Third group discussion}

\section{SEPTEMBER 10, 2015}

Main question: what service do you offer clients?

Hosting futurist: Hilde Roothart

Presenting futurists:

Freija van Duijne (president Dutch Future Society)

Caroline van Beekhoff (artist and marketing

strategist);

Leontine Wagenaar (founder Partners in Design).

\section{Fourth group discussion}

DECEMBER 10, 2015

Main question: How to give substance

and shape to concepts?

Hosting futurist: Hilde Roothart

Presenting futurists:

Peter Heshof (founder Bloom);

Angélique Heijligers (writer and journalist)

Siang-Lan Go (creator and owner de

Pizzabakkers).

\section{Fifth group discussion}

Main question: what is the future of the future professional?

Hosting futurist: Vincent Marchau

Presenting futurists:

Sietske Veenman (Radboud University);

Jan Nekkers (FutureConsult).

Jos Frijns (Kennisinstituut voor Wateronderzoek). 
The valorization addendum gives me the opportunity to share my thoughts on the societal merits of this thesis Becoming Futurists. In other words, I will discuss how I create value by making the study available for social usage (Van Drooge and Vandeburg et al., 2011). Writing Becoming Futurists was an academic as well as a personal journey to better understand the role of futurists in society. In the next pages, I detail the lessons that I have learned and how they are of societal value.

As a newcomer to the future industry, I observed the wealth of knowledge that the future brings, and the societal relevance that this knowledge carries. I am convinced that when people, including myself, become knowledgeable about possible futures, it provides them guidance in the rapidly changing world we live in. Changes happen at such a fast pace that people feel overwhelmed. Is it really possible that robots will replace people in the workforce? Will the Netherland one day be flooded with water? It takes courage to respond adequately to those changing circumstances and an effort to learn how to deal with such questions.

However, early in my career, I experienced that hardly anyone else shared my thoughts about the future because they were skeptical of the practitioners that translate the future: the futurists. Critics even questioned whether futurists were real professionals. For example, futurists were sometimes depicted as crystal ball gazers. This image is a relic from the past, as, until the Enlightenment, the future was the domain of prophets. The prophets were the connection between the divine and the human (Beerden, 2015). The prophets predicted the future as oracles and helped individuals make strategic choices. There was a certain amount of magic connected to foretelling the future. A crystal ball is a symbol of the same magic, but also of imagination and intuition.
The signal of skepticism was amplified when I became a teacher in 'futures studies' at the applied university Fontys. At open days of our institute, parents often asked me the implicit normative question: "what profession will be attainable for my child after completing this curriculum?" They wanted to know whether their child would be able to get a 'real' job after studying the future. As such, most parents seem to prefer a higher education degree that everyone understands right away and leads to a straightforward profession. This hesitance towards a training in becoming something as distinctive as a futurist, illustrates how dominant established professions are.

The aforementioned experiences motivated me to reflect upon my field of expertise: the future. My objective is to clarify what kind of professionals futurists actually are. With in-depth research into the translators of the future, I hope to contribute to the development of the future industry. And with that, I hope to contribute to a collective understanding of the importance of 'futures literacy'. Futures literacy means that we learn to speak the language of the future. The word 'literacy' is traditionally used to indicate that a language is mastered and fluently spoken. This term is also applied to all sorts of topics, for example to indicate whether someone knows the way digitally, i.e. whether this person is 'digitally literate'. In that spirit, I use the term literacy with respect to the future.

During my journey, I learned that not only outsiders but also experts in the sociology of professions had developed a view on the role of education (standardization is necessary) and what should be considered a profession. I realized how difficult it was - also for me - to let go of scholarly and societal views and think bigger. An example of such societal views is eloquent- ly illustrated by Ricardo Semler in an episode of the Dutch documentary show 'Tegenlicht'; we live in boxes (our houses), work in boxes (in the flowchart of our company), and move in boxes (our cars or trains). He describes how ever-present those systems actually are by using the metaphor of a box. At the same time, Semler explained, we are expected to be creative too, and think outside of the box. But our social context does not provide us with the tools to do so.

I realized that Semler's box metaphor can also be applied to the societal notion of professions. The curren representation of professions by scholars is 'boxed' in classic, yet for many unattainable, notions of prestige and status. Typically, prestige is achieved by theoretical knowledge, education, licensing and standardization. That raises the question: why focus on classic notion of professions when a large sum of young people today may not even practice anything like it? It is helpful to start formulating these kinds of new questions, as they may open new doors. Correspondingly, poet Mary Oliver demarcates between professions that make the world go round and professions that make the world go forward. She describes how we want a pilot to just follow the routine and let the flight be ordinary, preferably not extraordinary - just make the world go round. For creative work, Oliver (2016: 25 - 27) sees another task - make the world go forward:

In creative work - creative work of all kinds - thos who are the world's working artists are not trying to help the world go round, but forward. Which is something altogether different from the ordinary. Such work does not refute the ordinary. It is, simply, something else. Its labor requires a different outlook a different set of priorities. 
Semler's notion of boxes and Mary Oliver's distinction of the ordinary and the extraordinary are clearly applicable to the case of futurists. Even they, as forward-looking practitioners, experience struggles with fitting in and are, in that sense, also 'boxed'. Over the past years, I observed how challenging it was for futurists to rethink their professionalization. At first glance, futurists made it seem as if they were professional castaways, unable to answer the question "are we a profession?". This was especially striking because futurists often help others rethink and imagine their possible futures. It was remarkable to uncover that practitioners with such a forward-looking mindset were having so much difficulty consider ing the possibility that their own way of professionalizing may have unfolded, and needs to unfold, in a non-standard way. This was a clear indication that the notions of archetypical professions are still so authoritative that it was challenging for futurists in the forefront of the professionalization debate to even consider alternative professionalization pathways.

Indeed, futurists obviously are not pilots, instead they deliver, what Oliver refers to as, creative work. Com paring futurists to pilots would be like confusing apples with pears. What I hope to bring across is that we need both pilots and poets, lawyers and futurists These professionals do not replace each other. Thi also translates to the professionalization typologies: an alternative typology does not oppose the existing typology. They develop alongside each other. During the course of this study, I learned that advancing professionalization is not about overthrowing the old and introducing the new, it is about the willingness to see alternatives. Yet, recognizing alternatives can be a daunting task. Even futurists had a hard time appreciating their own alternative professionalization pathway. This observation relates to Ricardo Semler's argument that people are constantly tempted to think in the dominant system, which makes it hard for them to think otherwise or see the magic of an unpaved path. Becoming Futurists has illustrated that futurists' activities to professionalize can be understood as an alternative professionalization pathway. Futurists are an example of what I coined a 'Type 2' profession, an alternative to the dominant pathway of professionalization. In retrospect, going back to my conversations with parents of potential students, I could have shared with parents that becoming a futurist is simply something else than they know, but just as valuable.

During my fieldwork, I observed how futurists share a particular way of looking at the world. They do not only share skills, but also a mindset. How do futurists describe their collective mindset? Open-minded, antidisciplinary and growth-oriented, amongst other things. Futurists also appreciate their ability to unite analytical thought with intuition. Some futurists have described that their career as a futurist started with something as simple as 'wonder', by asking: "how could it be otherwise?" Journalist Krista Tippett eloquently wrote about wonder: "wondering is a useful way to begin to speak of a shared vocabulary of mystery we might embrace across our disciplines, our contrasting certainties, our doubts" (2016: 164). Wonder is a way to slow down, to distance ourselves from what we think we know, and to see the world for what it is today. Furthermore, wonder can help transcend disciplines, face complex issues and embrace uncertainty. Especially in combination with rational, analytical thought. Wonder implies no judgement, but a search for common ground.

The conversations among futurists about balancing intuition with analytical thought were not always positive. Futurists have struggled to balance the two. From the outset, I noticed that methods serve futurists to help them validate their work, as proof that the future can be systematically studied. However, validation is only one part of the futurists' job. Daring to openly use intuition is the second; wishing they could rely more on their intuition but afraid of the implications (such as how their audiences will respond). As a consequence, scientific methods and data grew as the principle underpinning of futurists' work. This phenomenon is not only specific to futurists but also a struggle in other fields. For example, renowned botanist Robin Wall Kimmerer recalled the moment she recognized that she had approached her teachings as solely from a technical perspective; "I was teaching the names of plants but was ignoring their songs" (2013: 43). From that perspective, the methods and data used by futurists serve as a mere vehicle to help others speak the language of the future.

This observation reminds me of the work of eminent scholar Max Weber (2004/1917-1919), who observed in the early 1900s that bureaucracy evolved at a fast pace. Weber described how the process of rationalization helped Western countries to organize their societies. As a result, a highly developed bureaucracy is in place, in which there is a tendency to rely on validation, figures and models - predominantly rational and intellectual means. According to Weber this development had a cost; he coined it 'disenchantment'. Weber argued that problems were solved with technology, not with magic or faith. As a consequence, the inexplicable hardly had a (pronounced) role in societies. I interpret disenchantment as an invitation for futurists to reflect on the value of wonder, especially in the rationalized, scientific world we created over the years. 
Someone who showed me how to wonder is the Dutch artist Thomas Trum. He creates artworks with paint as his muse. Trum paints with a super-sized felt pen, a machine for road line marking with brushes attached to a drill. In his work, I recognized Trum's ability to see alternatives. For example, Trum does not only see a machine that paints the familiar white traffic lines on the road, but also a giant paintbrush with endless possibilities. Trum reconfigured the meaning of a machine and presents us with an alternative outcome. The $\mathrm{PhD}$ thesis is wrapped in Thomas Trum's 'one yellow line 9' that he created in 2018 with gouache on paper. This artwork depicts my conviction that intuition and rationality go hand in hand. Trum uses the technology of the machine to create a very intuitive work. This can be compared to how futurists need their methods to imagine possible futures.

To conclude this valorization addendum, I come back to the initial question: what societal value does this study bring? With this PhD thesis, I acknowledge the value of questioning implicit societal beliefs. With 'implicit' I mean that it is considered common knowledge and that it is considered best to adapt what is deemed 'normal'. However, as Carl Jung once said: "to be normal is the ultimate aim of the unsuccessful" (1966: 161). The implicit belief - it is best to be nor mal - was challenged in two ways. The first involved futurists and their struggle to fit in. And the second questions how education is organized today.

From the outset, I observed the professionalization struggle of futurists and their wish to be taken seriously. As a consequence, futurists articulated the tendency to focus on validating their work. As an outsider observing their activities, I learned that their most powerful contribution resides in creating meaningful conversations about the future. With the simple act of aiding conversations about the unknown, futurists have the opportunity to bring imagination to our thoroughly rationalized world. With an insightful conversation, it is possible to ease the mind of others and facilitate genuine interactions. And if futurists find more clarity about their professional role and purpose, they will be able to contribute in a more meaningful way. Futurists may be capable to guide an increasing amount of people in becoming future literate.

On a deeper level, I observed how the educational system as a whole remains calmly intact. Many young children are still being taught in a $20^{\text {th }}$ century way. By rethinking the purpose of current education, it is possible to help new generations prepare for the pressing issues of this time, not of the past. Setting change in motion on a larger scale could be as simple as asking new questions. For example, by helping to rephrase the questions asked by parents. A fresh perspective can develop, just by formulating the initial question slightly different: "who can my child become?" Gently making parents aware of the norm of their original question ("what profession will be attainable for my child after completing this curriculum?"). The new questions may give more space for students to take ownership of their development and to advance skills to adapt to this rapidly changing world. They may be able to focus on their individual pathways, grow their problem-solving skills, demarcate important from urgent, and build courage to make difficult decisions. The new questions may also help students to see that they have all the time in the world to become wise, instead of hurrying into learning how to be smart.

To conclude this valorization, I return to a question that futurists like to ask: could it be otherwise?
With their professionalization pathway, they have answered their own question: yes, it can be otherwise. For futurists, their professionalization was an uncomfortable space of uncertainty; to me, it was a valuable source to yield new questions about professions. Futurists encouraged me to think outside of boxes. It helped me to see futurists for who they are: professionals that help the world move forward. As Ursula K. Le Guin timely wrote in 1997: "The dance of renewal, the dance that made the world, was always danced here at the edge of things, on the brink, on the foggy coast." 
addendum

Beerden, K. (2013). Worlds full of signs. Ancient Greek Divination in Context. Leiden: Brill.

Brouwer, K. (2013). De kapitale kracht van geluk. The Netherlands. Tegenlicht.

van Drooghe, L., Vandeberg, R., Zuijdam, F., Mostert, B., van der Meulen, B., Bruins, E. (2011).

Waardevol: Indicatoren voor Valorisatie. Den Haag: Rathenau Instituut.

le Guin, U. K. (1997). Dancing at the Edge of Things. St Martin's Press, New York.

Oliver, M. (2016). Upstream. Penguin Press, New York. Jung, C. G. (1966). Collected Works of C.G. Jung,

Volume 16: Practice of Psychotherapy. (Editors. G. Adler \& R.F.C. Hull). Bollingen Series XX. Princeton.

Kimmerer, R.W. (2013). Braiding Sweetgrass. Indig enous Wisdom, Scientific Knowledge and the Teachings of Plants. Milkweed Editions, Canada. Tippett, K. (2016). Becoming Wise. An inquiry into the Mystery and Art of Living. Corsair, London.

Weber, M (2004). The Vocation Lectures, science as a vocation. (Editors. Owen, D. \& Strong, T translation by Livingstone, R.). Hecket Publishing Company, Cambridge. (Original work published in 1917/1919). 
Gevestigde professies, zoals artsen, rechters, advocaten en notarissen, genieten maatschappelijk vertrouwen doordat ze met hun werk een gerespecteerde bijdrage leveren aan de samenleving. Het opbouwen van een professie ('professionaliseren') leidt tot maatschappelijk prestige en dat is veel waard. Daarom willen opkomende, nieuwe beroepen ook graag professionaliseren. Die opkomende beroepen ontstaan omdat zij in staat zijn om te voorzien in de continue veranderende maatschappelijke behoeften. Deze nieuwe groepen van beoefenaars passen alleen niet vanzelfspreken binnen het klassieke beeld van een professie (de medische stand, de advocatuur, het notariaat). Dat wringt. Tegelijkertijd ontstaan daardoor nieuwe, relevant vragen over wat professies nu precies zijn, wat professionalisering inhoudt en wat een goede beoefenaar is.

Het is niet eenvoudig om inzicht te verkrijgen in wat professionalisering betekent. Filosoof Bruno Latou (1999) benadrukt dat hoe succesvoller iets wordt (in zijn geval een artefact of een kennisclaim), hoe onduidelijker de constructie ervan wordt. Vertaald naar dit onderwerp zou dat betekenen dat wanneer een professie al is geconsolideerd, de daaraan voorafgaand constructie en de daarmee gepaard gaande worstelingen niet langer zichtbaar zijn voor buitenstaanders. Wanneer beoefenaren echter nog zoekende zijn naar wat hun professie is en de samenleving biedt, wat professionalisering inhoudt en wat een goede beoefenaa is, ontstaan er interacties waardoor de constructie en de worstelingen beter zichtbaar worden. Dit geldt met name wanneer mogelijke antwoorden op professionaliseringsvragen niet stroken met het klassieke beeld.

Futuristen vormen een beroepsgroep die zich bezighoudt met het systematisch verkennen van mogelijke toekomsten ten behoeve van besluitvorming.
Zo zijn er wetenschappelijk georiënteerde futuristen actief die toekomsten theoretisch en methodologisch proberen te doorgronden, maar ook commercieel georiënteerde futuristen die graag op podia staan met hun verhaal of onderzoekers werkzaam bij planbureaus die scenario's schetsen ten behoeve van beleid en creatieve futuristen die verbeelding centraal stellen. Futuristen zijn een voorbeeld van een gevarieerde beroepsgroep waarin vragen over professionalisering leven. Zij benadrukken publiekelijk dat zij de ambitie hebben om te professionaliseren. Omdat futuristen zo uitgesproken middenin een professionaliseringsproces zitten, zijn zij een interessant object van onderzoek om professionalisering beter te begrijpen. In dit proefschrift onderzoek ik de inspanningen die futuristen leveren om te professionaliseren. De centrale onderzoeksvraag van dit proefschrift luidt dan ook: hoe is de vorming van de professie van futuristen te begrijpen? Met het beantwoorden van deze vraag wil ik meer zicht krijgen op wat professionalisering is en vergt van beoefenaars.

De term 'futurist' betreft in dit proefschrift iedereen die systematisch de toekomst onderzoekt en dit onderzoek in de vorm van verschillende producten overbrengt om besluitvorming te informeren. Ik heb daarmee een brede definitie aangehouden waar futuristen in het bedrijfsleven, de overheid en kennisinstellingen onder vallen. Om de centrale onderzoeksvraag te kunnen beantwoorden ben ik vooral geïnteresseerd in degenen die de noodzaak, of zelfs urgentie, ervaren en uiten om te professionaliseren. Daarmee ligt de focus op de futuristen die actief willen bijdragen aan het debat over, en het proces van, hun professionalisering. Zij doen dat bijvoorbeeld door over professionalisering te spreken tijdens conferenties, door brancheorganisaties op te zetten en/of deel te nemen aan het debat. Als ik in dit proefschrift refereer aan futuristen dan doel ik op de futuristen die actief deelnemen aan het debat over hun professionalisering.

Theoretisch sluit bovengenoemde academische in teresse in professionalisering aan bij de sociologie van professies. Aanvankelijk was het belangrijkste doel van wetenschappers binnen dit onderzoeksgebied om te begrijpen wat een professie is. Deze wetenschappers probeerden de rol van professies te begrijpen door onderscheidende 'traits' (eigenschappen) toe te kennen. Deze omvatten doorgaan theoretische kennis, specifiek onderwijs, examens, licenties, specifieke verenigingen, organisaties, verschillende soorten controle, collegialiteit, ethiek, werk voor het algemeen belang en autonomie. Sinds de jaren zeventig van de vorige eeuw veranderde he perspectief op professies; de focus verschoof van de vorm (eigenschappen) naar de functies (proces). De sociale wetenschappers die zich bezighielden met professies gingen zich meer richten op de vraag hoe een groep beoefenaars zich ontwikkelden to een professie. Uit beide perspectieven ontstond een professionaliseringsmodel waarbij eigenschappen zoals een gecertificeerde kennisbasis centraal staan, maar ook het afbakenen van het professionele gebied ('jurisdicties'), en het vermeende eindpunt van professionalisering (het 'heartland'). Tegenwoordig zijn naast dit klassieke model, de theoretische perspectieven op professies meer gefragmenteerd. Een deel van de wetenschappers borduurt voort op voorgenoemde klassieke benaderingen (vorm en proces) maar er zijn ook wetenschappers die zoekende zijn hoe professies op nieuwe manieren te duiden. Daardoor ontbreekt het nu aan een gemeenschappelijk analytisch kader: er zijn nu verschillende perspectieven van waaruit professies worden bestudeerd. 
De eerste vraag impliceert dat onderzocht wordt hoe futuristen zich identificeren met de conceptualisering van het professionaliseringsmodel dat door de jaren heen is ontwikkeld door wetenschappers binnen de sociologie van professies. Met de tweede vraag wordt de aandacht gericht op de acties die futuristen ondernemen om te professionaliseren. Deze acties bieden inzicht in hoe futuristen een professie denken te kunnen worden. En ten slotte, de derde en laatste vraag biedt ruimte om te onderzoeken of futuristen mogelijk andere betekenis geven aan hun professionalisering dan gangbaar is volgens het professionaliseringsmodel.

In hoofdstuk 2 wordt het constructivistische perspectief van dit proefschrift inzichtelijk gemaakt. Dat houdt in dat het onderzoek zich concentreert op acties en interacties van futuristen die bezig zijn hun sociale wereld organiseren. Die wereld is continu in beweging en aan verandering onderhevig. Om recht te doen aan de complexiteit van het proces van professionalisering is daarom gekozen voor een kwalitatief ontwerp van het onderzoek. Dit proefschrift is gebaseerd op theoretisch geïnformeerde empirische verslagen, die bestaan uit observaties, interviews en groepsdiscussies. Het eerste deel van de empirische dataverzameling bestond uit observaties van 50 formele omgevingen zoals conferenties of vergaderingen waar futuristen gedachten en ideeën uitwisselden over professionalisering. Het tweede empirische deel bestond uit interviews met 33 futuristen. De selectie van futuristen was gebaseerd op hun bijdrage aan de discussies die betrekking hadden op professionalisering. Deze futuristen kwamen uit verschillende delen van de wereld. Daarnaast werden er futuristen geselecteerd op diversiteit in hun rollen met betrekking tot de discussie over professionalisering. Ik interviewde bijvoorbeeld gevestigde namen naar wie vaak werd verwezen maar ook futuristen in junior rollen die de discussie met een frisse blik benaderden. Het derde deel van de empirische data werd geïnitieerd door futuristen zelf: groepsdiscussies over professionalisering.

Tijdens het veldwerk zag ik een actieve voorhoede van futuristen die het debat voerde over professionalisering of er anderszins bij betrokken was. Het bleek geen sinecure om deze groep eenduidig te kunnen plaatsen. Elke conferentie waar ik observeerde werd bezocht door een diverse mix van futuristen. Er waren wel gradaties van betrokkenheid waarneembaar onder futuristen, van bezielde futuristen die organisaties hebben opgezet om de discussie over professionalisering te faciliteren, tot futuristen die naar conferenties gingen en meediscussieerden, maar geen interesse toonden in het verder uitdiepen van de uitwisseling. Tot slot waren er ook futuristen waarneembaar die geen affiniteit hadden met de professionaliseringsdiscussies. Gezien de focus van dit onderzoek zijn deze beoefenaars maar beperkt in beeld geweest. Met andere woorden, dit proefschrift pretendeert niet om een beeld te schetsen van de beroepsgroep in al zijn rijkheid en variatie, maar het beoogt zicht te krijgen op hoe leden van deze beroepsgroep individueel en in collectieven proberen te professionaliseren. Met als ambitie om een beter beeld te krijgen van professionalisering in de 21 ste eeuw.

In hoofdstuk 3 start de zoektocht naar professionalisering en staat de vraag centraal: hoe identificeren futuristen zich met bestaande noties van professionalisering? Futuristen beschreven desgevraagd dat er nauwelijks gemeenschappelijk onderwijs is in hun vakgebied en dat ze zich tot nu toe niet op een gestructureerde manier hebben georganiseerd. Sommige futuristen uitten hun teleurstelling dat ze niet kunnen komen tot een gezamenlijke titel voor hun professie. Hieruit lijkt het beeld naar voren te komen dat futuristen niet vertrouw-

\section{worden zichtbaar in de inspanning van futuristen om te professionaliseren?}


en in de voortgang van hun professionalisering of dat zi zelfs niet als een professie kunnen worden beschouwd. In de beelden die futuristen schetsen over hun professie en professionalisering klinkt een hang naar klassieke 'traits' door, waardoor zichtbaar wordt dat zij zich in hun professionalisering met noties uit het klassieke professionaliseringsmodel identificeren.

Ondanks de twijfel over de voortgang, of zelfs de mogelijkheid van professionalisering, leveren futuristen wel degelijk inspanningen om te professionaliseren. $\mathrm{Bij}$ verschillende gelegenheden wisselen futuristen informeel ervaring en kennis uit om een gemeenschappelijke basis te vinden. Bovendien hebben futuristen zich ingezet op het gebied van onderwijs. In de loop der jaren zijn bijvoorbeeld steeds mee educatieve programma's opgezet. En dan niet alleen door universiteiten en hogescholen maar ook door brancheorganisaties als de Association of Professional Futurists en LaFutura. Ook deze ontwikkeling om to gezamenlijk onderwijs te komen wijst erop dat futuristen zich met klassieke 'traits' identificeren.

In de worsteling van futuristen met hun ambitie om te professionaliseren valt een spanning op. Enerzijds identificeren zij zich met klassieke noties van professionalisering en anderzijds uiten zij ongemak rondom de normen waaraan ze moeten voldoen om als een professie te worden erkend. Futuristen vinden elkaar in hu weerstand tegen het klassieke professionaliseringsmodel; ze ervaren het als een keurslijf dat geen recht doet aan de diversiteit van hun beroepsgroep. Door futuristen wordt breed erkend dat er verschillende soorten beoefenaars binnen hun gemeenschap actief zijn. Maar geen enkele futurist stelt voor om de diversiteit binnen het vakgebied te verminderen of roept op tot het formuleren van één archetypische beoefenaar. Dit schuur met de klassieke noties van professionalisering die een zekere mate van standaardisering van het archetype professional veronderstellen. Het onbehagen van futuristen schuilt erin dat ze ernaar streven om te professionaliseren, maar tegelijkertijd reserves hebben om dit te doen omdat dit de gewaardeerde diversiteit kan ondermijnen. Tot op heden is het niet gelukt om het onbehagen te beslechten en dat verdeelt futuristen - er is sprake van een professionalisering dilemma. Sommige futuristen raken gefrustreerd door het vermeende onvermogen om te professionaliseren volgens klassieke lijnen, waardoor hun praktijk niet het maatschappelijk prestige krijgt dat het volgens hen verdient. Anderen raken verstrikt in semantische discussies.

In hoofdstuk 4 wordt voortgebouwd op het voorafgaande hoofdstuk met de vraag: welke acties ondernemen futuristen om te professionaliseren? Daarmee probeer ik meer zicht te krijgen op het professionalisering dilemma dat zich voor futuristen aandient. Dit hoofdstuk is gestructureerd aan de hand van activiteiten in drie arena's (Abbott, 1988): de werkvloer arena, de publieke opinie arena en de juridische arena. Op de werkvloer arena observeerde ik veel activiteit van futuristen die begrepen kan worden in termen van professionalisering. Er bestaan geen gemeenschappelijk vastgestelde regels over welke vaardigheden een futurist zou moeten hebben. Maar desgevraagd hebben futuristen er geen moeite mee om die vaardigheden te beschrijven en komen die beschrijvingen opvallend overeen. De capaciteit om grote hoeveelheden informatie te verwerken, sensitiviteit voor zowel mensen als de tijdgeest en creativiteit staan hoog in het vaandel. Futuristen beschrijven hun mentaliteit als anti-disciplinair, fantasierijk en ruimdenkend. Wat betreft de publieke opinie arena beschrijven meerdere futuristen dat zij het gegeneraliseerde beeld van futuristen als voorspellers gebruiken om zichzelf te introduc- eren. Niet omdat zij de wijsheid in pacht menen te hebben, maar omdat het vooroordeel een manier is om het gesprek te beginnen met buitenstaanders en hiermee een brug te slaan naar de bijdrage die ze juist wel kunnen leveren. Futuristen beschreven in relatie tot de juridische arena dat de contouren van het vakgebied informeel zijn geformuleerd en niet worden opgelegd via een officiële gecertificeerde route. In de interviews kwam weerstand om te professionaliseren met name tot uiting op momenten dat standaardisatie van de praktijk werd voorgesteld. Futuristen stonden zij aan zij in hun onwil om te standaardiseren en toonden geen interesse in het harmoniseren van hun individuele routines. Het gebrek aan activiteit van futuristen in de juridische arena moet opgevat worden als een uiting van die weerstand.

Om te professionaliseren, ondernemen beoefenaars idealiter activiteiten in de drie zojuist geïntroduceerde arena's. De veronderstelling van wetenschappers binnen de sociologie van professies is dat de meeste aspirant-professies erop gericht zijn om uiteindelijk het 'heartland', het vermeende eindpun van professionalisering, te bereiken. Dat houdt in dat ervan uit wordt gegaan dat een groep beroepsbeoefenaars ernaar streeft om op enig moment overeenstemming te bereiken over hun gemeenschappelijke doel. De implicatie van het bereiken van het 'heartland' is stabiliteit en uniformiteit. Natuurlijk worden beroepen verondersteld te evolueren en te veranderen (bijvoorbeeld vanwege nieuwe technologische ontwikkelingen), maar de professionals dagen nie doorlopend de basisovereenkomsten van het klassieke model uit. De verwachting van wetenschappers is dat slechts enkele professies zich niet conformeren aan het 'heartland'-model. Dergelijke professies worden beschouwd als een incongruentie waaraan verder geen aandacht hoeft te worden besteed. 
De vraag ontstaat of het geen gemiste kans is om de kandidaat-professies die niet naar een 'heartland' streven als incongruentie te betitelen. Futuristen spannen zich in met activiteiten in de werkvloer arena en de publieke opinie arena, maar blijven bewust weg van de juridische arena. In die zin werken zij niet toe naar een gezamenlijk eindpunt. De activiteiten van futuristen illustreren zelfs het tegenovergestelde, zij waarderen juist de voortdurende vernieuwing van hun kennis. Futuristen zien het als een uitdaging om continue nieuwe onderwerpen aan te snijden en beschrijven in die geest dat ze nooit klaar zijn met leren. Futuristen laten daarmee een benadering van professionaliseren zien die niet strookt met het klassieke beeld van een beoefenaar die toewerk naar een eindpunt (bijvoorbeeld door de beheersing van een kennisbasis). Vanuit dat uitgangspunt zijn futuristen een voorbeeld van een vakgebied waarin professionalisering anders verloopt dan het klassieke model beschrijft. De futuristen spannen zich wel degelijk in om te professionaliseren maar zij doen dat niet met een gezamenlijk einddoel. Futuristen zijn te beschouwen als een wat ik aanduid als een 'heartland-free' professie.

De weerstand van futuristen om te professionaliseren levert interessante inkijkjes op in het proces van professionalisering, ik identificeerde diverse impliciete veronderstellingen die een rol spelen in dat proces. Deze impliciete veronderstellingen zijn het waard om te discussie gesteld te worden, zo observeerde ik herhaaldelijk twee thema's in relatie tot de professionalisering van futuristen: de manier waarop ze hun reputatie opbouwen en de rol die kennis speelt in hun dienst aan de samenleving. Om een beeld te krijgen van deze twee thema's formuleerde ik de onderzoeksvraag die centraal staat in de laatste twee empirische hoofdstukken: welke noties van professionalisering worden zichtbaar in de inspanning van futuristen om te professionaliseren?
De gemeenschap van futuristen die deelnemen aan de professionaliseringsactiviteiten is divers, er bestaat een grote variatie aan beoefenaars. In hoofdstuk 5 onderzoek ik hoe futuristen hun reputaties opbouwen. De wijze waarop reputaties worden opgebouwd is een klassiek thema binnen de sociologie van professies en biedt mogelijk handvatten om de diversiteit van futuristen te kunnen plaatsen. Uit de literatuur over reputatiestructuren bleek dat sociale wetenschappers die gekeken hebben naar reputatie verschillende reputatiestructuren onderscheiden. Die reputatiestructuren zijn uniek voor de wereld waarin reputatie wordt opgebouwd. Zo werd er onderscheid gemaakt tussen academische, commerciële en een artistieke reputaties. Ik observeerde dat futuristen zich in hun praktijk niet houden aan het uitgangspunt van een reputatiestructuur in één wereld; zij bewegen zich consistent in meerdere werelden. Welke reputatie een individuele futurist opbouwt, hangt sterk af van zijn of haar individuele keuzes en capaciteiten. In welke mate zij participeren in de academische wereld, het commerciële of het artistieke domein verschilt per futurist. Toch is er een gemeenschappelijke waardering voor het opbouwen van een reputatie dat door veel futuristen wordt gewaardeerd: het vermogen om werelden te ontstijgen en te verbinden.

Futuristen bouwen aan, zoals ik dat noem, 'cross-boundary' reputaties. Zij opereren in verschillende werelden en bouwen gelijktijdig aan reputaties in elk van die werelden. De reputaties die futuristen bouwen versterken elkaar geleidelijk. De reputatie in de ene wereld is van waarde om reputatie in de andere wereld te verkrijgen, futuristen combineren daarmee diverse reputatiestructuren. Ik heb geprobeerd dit te duiden door gebruik te maken van wetenschappelijke literatuur over 'boundary work' (grensverkeer). De literatuur over 'boundary work' maakt inzichtelijk hoe interacties van professionals aan beide zijden van een grens te begrijpen zijn. Bijvoorbeeld op welke manieren er door beoefenaars gemeenschappelijke grond wordt gezocht om vervolgens met nieuw inzicht terug te keren naar zijn of haar oorspronkelijke wereld. Futuristen bleken zich zowel in de academische als de commerciële en artistieke werelden graag op te houden in en ron de grensgebieden. Zij uitten geen intentie om, n het opzoeken van grensverkeer, terug te keren naar een van de oorspronkelijke werelden. Sterker nog, futuristen creëren hun meerwaarde op het snijvlak van verschillende werelden. Zij gedijen in het tussengebied waar verschillende werelden elkaar overlappen, elkaar raken of overbrugd moeten worden 'cross-boundary' reputaties. Deze 'cross-boundary' reputaties stroken met de basisprincipes van 'boundary work' met uitzondering van de veronderstelling dat beoefenaars geen intentie hebben om te blijven in een tussengebied en het grensverkeer opzoeken om daarna terug te keren naar hun eigen respectievelijke territoria.

Tot slot is in hoofdstuk 6 de weerstand van futuristen om te standaardiseren geanalyseerd aan de hand van de rol die kennis speelt in hun service. Futuristen creëren een scala aan tastbare producten zoals rapporten, workshops en presentaties. Die producten bleken meer dan slechts output voor futuristen. $\mathrm{Ze}$ worden gezien als een waardevolle manier om hun bijdrage aan de samenleving te presenteren. Futuristen identificeren zich sterk met wat zij produceren. Vraag twee futuristen om een rapport te maken over één thema en ze zullen met heel ander werk komen - een fenomeen waar futuristen trots op zijn. Het bewijst volgens futuristen dat hun kennis niet alleen is afgeleid uit handboeken, maar juist in de praktijk rijpt. 
Echter, deze wijze van omgaan met kennis strook niet met de benadering van wetenschappers binnen de sociologie van professies. Wetenschappers binnen deze discipline beschrijven kennis als een middel voor beroepsbeoefenaars om professionele prestige te ver werven. Beoefenaars gebruiken kennis om zichzelf te legitimeren tegenover buitenstaanders, vaak door via gecertificeerde opleidingen kennis te verkrijgen Zo kunnen beoefenaars aantonen dat zij de specifieke professionele kennis machtig zijn. Dit is een dominan idee over de rol van kennis in professionalisering waa geen vraagtekens bij worden geplaatst.

De vraag is of de aanname dat kennis een middel is om prestige te verkrijgen, stand kan houden in de context van futuristen. Voor futuristen is kennis ook onverminderd belangrijk in hun proces van professionalisering, maar wel op een andere manier. De kennis die futuristen opbouwen verandert steeds van karakter, zij zijn voortdurend op zoek naar nieuw inzicht. Als zodanig bouwen futuristen organisch aan een dynamisch kennisreservoir, een archief van relevante boeken, artikelen, video, audio, afbeeldingen enzovoort. Dit archief bevat geen specifieke gecertificeerde kennis die alleen voorbehouden is aan futuristen, maar biedt hen een gemeenschappelijke bron. In plaats van het afbakenen van een kennisbasis en het opzetten van een erkende instellingen, ontwikkelen futuristen een groeiend reservoir waaraan elke futurist kan bijdragen en uit kan putten.

Een professionaliseringsactiviteit die past bij de klassieke aanname over de rol van kennis is het vaststellen van gecertificeerde kennis en het beheersen daarvan organiseren via onderwijs. Vanuit dat perspectief is kennis een middel om prestige op te bouwen, ook wel kern van een 'knowledge-based' perspectief op professionaliser ing. Maar futuristen zijn, zoals ik dat noem, een 'knowledge-producing' professie. Het produceren van kennis is hun bijdrage aan de samenleving. Dat betekent dat een futurist niet hoeft te bewiizen dat hij of zij de gecertificeerde kennis beheerst om de titel futurist te mogen dragen. Van professionele futuristen wordt verwacht dat zij bijdragen aan het zich continue ontwikkelende reservoir en daar op creatieve manieren uit putten.

$\mathrm{Na}$ het bestuderen van de drie deelvragen werd de worsteling van futuristen zichtbaar en begrijpelijk Deze was gelegen in het ongemak met een model van professionalisering die hen niet past. Dit proefschrift maakt inzichtelijk dat futuristen acties ondernemen om een gemeenschap van gelijkgestemde beoefenaars op te bouwen. Maar terwijl ze al dat werk doen, hebben futuristen hun weerstand niet kunnen oplossen. Ze erkenden hun ongemak, verwoordden het, maar hadden daar geen antwoord op.

In dit proefschrift wordt beargumenteerd dat er een nieuw perspectief op professionalisering nodig is om futuristen als professie te begrijpen. Er is al wetenschappelijk besef van de noodzaak om professies opnieuw te bezien. Tegelijkertijd worden fundamentele aannames nog niet betwist, omdat de neiging bestaat te blijven denken binnen het klassieke professionaliseringskader.

Professies zijn tot op heden benaderd vanuit één typologie. Het klassieke pad van professionalisering was de eerste typologie die werd geïdentificeerd en kan daarom het beste worden aangeduid als 'Type 1'. In deze typologie wordt onder andere waarde gehecht aan traits, gezamenlijke eigenschappen van de beoefenaar, de vorming van een gecertificeerde kennisbasis en de activiteiten om het professionele gebied af te bakenen en te standaardiseren in drie arena's. Het doel van de professionaliseringsinspanningen van beoefenaars in 'Type 1' is om te komen tot het 'heartland' vermeende eindpunt van professionalisering. Met dit proefschrift heb ik een ander type professionalisering geïdentificeerd. 'Type 2' is een alternatieve belofte van professionalisering die kan worden afgeleid uit mijn analyse van futuristen. Daarin staan met name vaardigheden centraal, diversiteit van beoefenaars, de 'heartland-free' benadering en het vermogen om 'cross-boundary' reputaties op te bouwen in verschillende werelden. En tot slot wordt er, in plaats van kennis als middel om prestige te verkrijgen, waarde gehecht aan de vorming van een fluïde kennisreservoir waaraan de professionals zowel kunnen bijdragen als eruit kunnen putten. 'Type 1' en 'Type 2' zijn geen dualistische professionaliseringspaden, zij evolueren naast elkaar.

Met dit proefschrift is 'Type 2' onder woorden gebracht, maar het is aan de futuristen om de toekoms van hun professionaliseringsproces vorm te geven Met deze studie bied ik futuristen (en andere professionals) handvatten om op hun professionalisering te reflecteren, deze vooruit te helpen en misschien zelfs te consolideren. Het is heel goed mogelijk dat het gezamenlijk bewustzijn onder futuristen van een mogelijk 'Type 2' professionaliseringstraject, hen in staat stelt nieuwe betekenis te geven aan hun professionalisering. De karakterisering van 'Type 2' kan futuristen helpen om hun professionaliseringsactiviteiten in ander licht te gaan bezien. Het begrip van hun professionaliseringsproces kan futuristen stimuleren om expliciet te beslissen hoe ze de toekomst van hun professie willen vormgeven. De belofte van een 'Type 2' professie heeft de potentie om de realiteit van professionele futuristen te worden. 


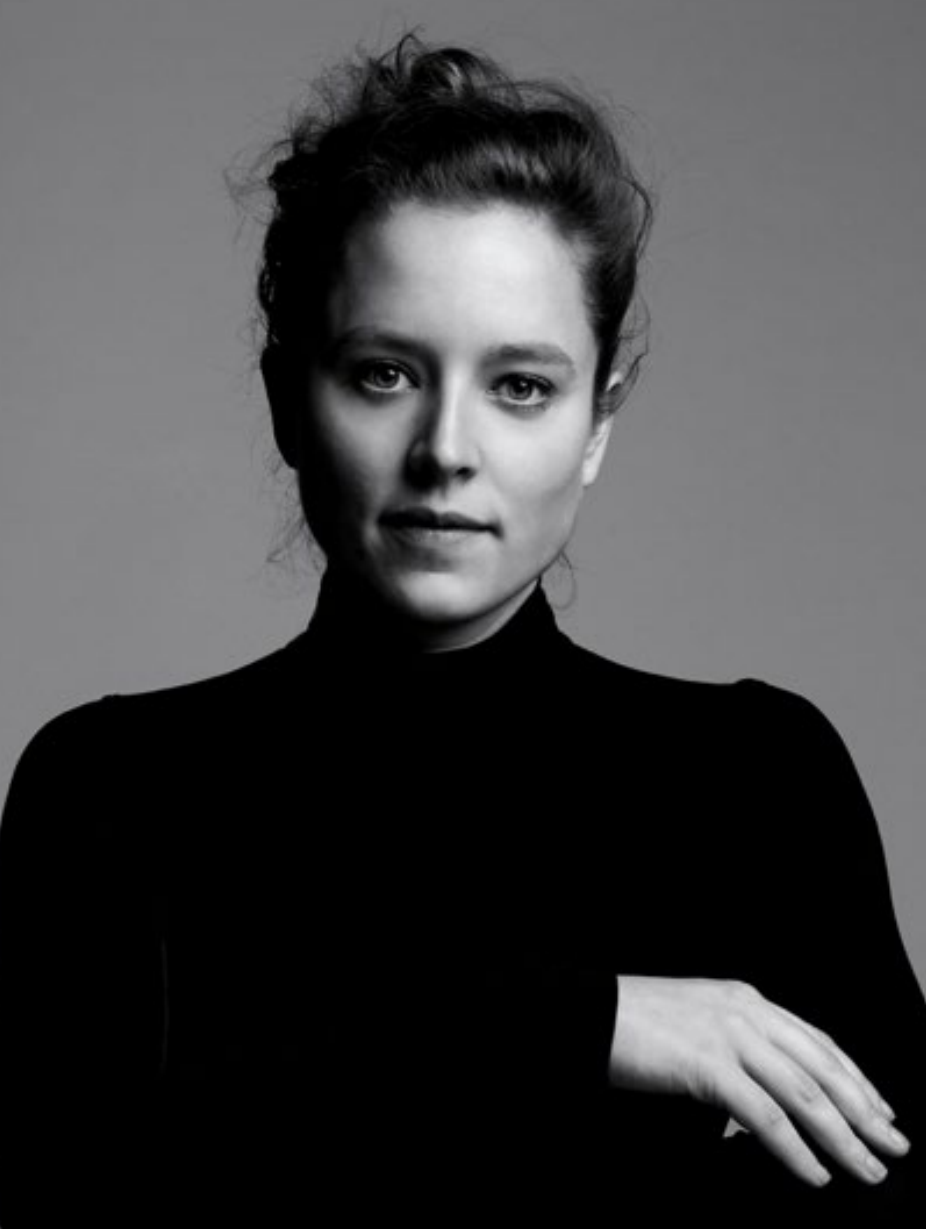

Tessa Cramer (1985, Amsterdam) is a futurist. As a newcomer to the future industry in her late teens, Cramer observed the wealth of knowledge that the future brings, and the societal relevance that this knowledge carries. She wanted to learn how to be a the Univesity of Amsterdam. Shorty after, became a teacher in 'futures studies' at Fontys Academy for Creative Industries. Next to her teaching duties, Cramer set up branch organization Dutch Future Society as well as an experimental laboratory, the Trend Research Lab. Cramer was also part of several advisory boards and trained various audiences on how to think like a futurist. Alongside those activities, Cramer completed her $\mathrm{PhD}$ thesis titled Becoming Futurists at Maastricht University. In hindsight, all of these activities connect in their underlying aim to help others learn to speak the language of the future, or in other words, to help people become futures literate.
Cramer's mission is to advance 'futures literacy' by connecting people and ideas.

Cramer is associate professor (lector) Designing the Future at Fontys Academy for Creative Industries. As part of a new generation of futurists who facilitate the in-depth discussion about the future with imagination and analytical skills, Cramer translates the futuris mindset for a broader public. She offers audiences tailored tools to get started with futures thinking. In her work, Cramer connects ancient wisdom with stateof-the-art knowledge. She draws inspiration from Japanese ikebana (flower art), the anti-disciplinary research at MIT Media Lab as well as thought leader like botanist Robin Wall Kimmerer and journalist Krista Tippett. This enables Cramer to look at the world with fresh eyes. In this spirit, Cramer helps others prepare for the pressing issues of this time. 